
Bülent Küçük

Die Türkei und das andere Europa 
Bülent Küçük (Dr. phil.) ist Soziologe und arbeitet im Forschungsprojekt »Eurosphere« an der Sabancı Universität in Istanbul. Seine Forschungsschwerpunkte sind Öffentlichkeits-, Diskurs- und Postkoloniale Theorien. 
BÜLENT KÜÇÜK

\section{Die Türkei und das andere Europa}

Phantasmen der Identität im Beitrittsdiskurs

[transcript $]$ 
Bei diesem Band handelt es sich um eine Dissertation an der Humboldt-Universität zu Berlin, Philosophische Fakultät III. Der Arbeitstitel lautet: »Die Türkei und das andere Europa. Identitäten, dialogischen Fantasien und Subjektivität des Anderen. Eine Diskursanalyse der deutschen und türkischen Printmedien«.

\section{(9) $(1 \Theta \Theta$}

Dieses Werk ist lizenziert unter der Creative Commons Attribution-NonCommercial-NoDerivs 4.0 Lizenz (BY-NC-ND). Diese Lizenz erlaubt die private Nutzung, gestattet aber keine Bearbeitung und keine kommerzielleNutzung. Weitere Informationen finden Sie unter https://creativecommons. org/licenses/by-nc-nd/4.o/deed.de/.

Um Genehmigungen für Adaptionen, Übersetzungen, Derivate oder Wiederverwendung zu kommerziellen Zwecken einzuholen, wenden Sie sich bitte an rights@transcript-verlag.de

\section{(C) 2008 transcript Verlag, Bielefeld}

\section{Bibliografische Information der Deutschen Nationalbibliothek}

Die Deutsche Nationalbibliothek verzeichnet diese Publikation in der Deutschen Nationalbibliografie; detaillierte bibliografische Daten sind im Internet über http://dnb.d-nb.de abrufbar.

Umschlaggestaltung: Miro Kaygalak, Berlin und Kordula Röckenhaus, Bielefeld

Lektorat: Sandra Pollex, Berlin

Korrektorat: Kerstin Ehlert, Detmold

Satz: Bülent Küçük, Berlin

Druck: Majuskel Medienproduktion GmbH, Wetzlar

Print-ISBN 978-3-8376-1012-3

PDF-ISBN 978-3-8394-1012-7

Gedruckt auf alterungsbeständigem Papier mit chlorfrei gebleichtem Zellstoff.

Besuchen Sie uns im Internet: http://www.transcript-verlag.de

Bitte fordern Sie unser Gesamtverzeichnis und andere Broschüren an unter:info@transcript-verlag.de 
INHALT

$\begin{array}{ll}\text { Danksagung } & 7\end{array}$

Abbildungen $\quad 8$

$\begin{array}{ll}\text { Tabellen } & 9\end{array}$

$\begin{array}{ll}\text { Abkürzungen } & 10\end{array}$

I. Einleitung 11

Die Suche nach der europäischen Identität 15

Europäische Identität und Andere 15

Europäische Identität und Öffentlichkeit 21

Europäische Identität und Europabegriff $\quad 27$

Europäische Identität und Orient $\quad 32$

Aufbau der Arbeit $\quad 34$

II. Diskurstheoretische Rahmen 39

Identifikation und politische Subjektivität $\quad 43$

Diskursive Knotenpunkte und politische Phantasie 46

Symptom und Dislokation $\quad 49$

Dialogische Diskursivität $\quad 51$

Fazit $\quad 53$

III. Orientalismus und Subjektivität des Anderen 57

Heterogenität des Orientalismus $\quad 59$

Okzidentalismus und Subjektivität des Anderen 67

Fazit $\quad 72$

IV. Türkische Identität und Bedeutung des Westens 75

Der osmanische Modernisierungsprozess $\quad 76$

Republik und Imitation von Oben $\quad 79$

Fazit: Türkischer Okzidentalismus $\quad 89$ 
V. Struktur des diskursiven Feldes $\quad 97$

Methodische Herangehensweise $\quad 97$

Auswahl des Untersuchungsmaterials $\quad 102$

Die Struktur des diskursiven Feldes $\quad 110$

Die diskursive Interdependenz $\quad 135$

$\begin{array}{ll}\text { Fazit } & 139\end{array}$

VI. Ost-West Repräsentationen im Beitrittsdiskurs 145

Die Türkei als Brücke $\quad 145$

Pragmatischer Okzidentalismus 145

Inklusiver Orientalismus $\quad 152$

Die Türkei als Grenze $\quad 158$

Exklusiver Orientalismus $\quad 158$

Das doppelgesichtige Europa $\quad 165$

Nationalistischer Okzidentalismus $\quad 166$

Minderheiten als interner Okzident $\quad 175$

Muslimische Migranten als interner Orient 186

$\begin{array}{ll}\text { VII. Schlussbetrachtung } & 197\end{array}$

$\begin{array}{ll}\text { Literatur } & 211\end{array}$ 


\section{DANKSAGUNG}

Viele liebe Freundinnen und Freunde haben mich in unterschiedlichen Etappen dieses Buches begleitet. Mein besonderer Dank gilt meinem Doktorvater Prof. Dr. Klaus Eder, für seine Offenheit und die sorgsame kritische Betreuung dieser Arbeit, sowie Prof. Dr. Werner Schiffauer für seine ermutigende und freundliche Unterstützung.

Für die Beratung in statistischen Fragen bin ich Özgür Arun zu tiefstem Dank verpflichtet. Ilker Ataç, Ulaş Şener und Meltem Ahıska haben sich mit mir in vielen Diskussionen über theoretische Aspekte den Kopf zerbrochen, mir wertvolle Anregungen gegeben und Gedanken mit mir ausgetauscht. Die Gespräche mit Biray Kırlı, Jara Kehl, Lena Ruthner, Laura Bruzzone, Marcus Engler, Nevim Çil, Nilgün Cön, Özlem Biner, Serhat Karakayalı und Zafer Yenal haben mich immer ein Stück weitergebracht. Miro Kaygalak hat mir in vielen langen Nächten mit seinen »erroristischen « Phantasien den Kopf frei gehalten und beim Layout unermüdlich beigestanden. Dem Transcript-Team danke ich für das Interesse, insbesondere Christine Jüchter für die freundliche Begleitung im Veröffentlichungsprozess und Kerstin Ehlert für das einfühlsame Korrektorat.

Diese Studie wurde durch ein Promotionsstipendium der HeinrichBöll-Stiftung ermöglicht. An dieser Stelle möchte ich mich insbesonders bei Juta Helm und Wilma Weber von der Promotionsfördung der Stiftung bedanken, die mich drei Jahren lang begleitet und unterstützt haben.

Von ganzem Herzen danke ich Sandra Pollex, die die Hauptlast des Korrektorats trug. Ohne ihre liebevolle Unterstützung wäre diese Arbeit nicht zustande gekommen. 


\section{AbBildungen}

Abb. 1. Artikelanzahl \& Jahr 104

Abb. 2. Jahr \& Themenfelder 116

Abb. 3. Jahr \& kulturelles Feld 117

Abb. 4. kulturelles Feld \& deutsche Akteure $\quad 118$

Abb. 5. kulturelles Feld \& türkische Akteure 118

Abb. 6. kulturelles Feld \& europäische Akteure 119

Abb. 7. Jahr \& Sicherheitsfeld 120

Abb. 8. Sicherheitsfeld \& deutsche Akteure 121

Abb. 9. Sicherheitsfeld \& türkische Akteure 122

Abb. 10. Sicherheitsfeld \& europäische Akteure 122

Abb. 11. Jahr \& politisches Feld 124

Abb. 12. politisches Feld \& deutsche Akteure $\quad 125$

Abb. 13. politisches Feld \& türkische Akteure $\quad 126$

Abb. 14. politisches Feld \& europäische Akteure 127

Abb. 15. moralisches Feld \& Jahr 129

Abb. 16. moralisches Feld \& deutsche Akteure 129

Abb. 17. moralisches Feld \& türkische Akteure $\quad 130$

Abb. 18. moralisches Feld \& europäische Akteure 131

Abb. 19. Jahr \& Zukunft Europas 132

Abb. 20. Zukunft Europas \& deutsche Akteure 133

Abb. 21. Zukunft Europas \& türkische Akteure 134

Abb. 22. Zukunft Europas \& europäische Akteure 134

Abb. 23. Akteure \& thematisches Feld 135

Abb. 24. Akteure \& kulturelles Feld 136

Abb. 25. Akteure \& Sicherheitsfeld 137

Abb. 26. Akteure \& politisches Feld 137

Abb. 27. Akteure \& moralisches Feld 138

Abb. 28. Akteure \& Zukunft Europas 139

Abb. 29. Mapping des diskursiven Feldes $1997 \quad 140$

Abb. 30. Mapping des diskursiven Feldes 1999-2004 141 


\section{TABELLEN}

Tab. 1. Artikelanzahl \& Zeitung 103

Tab. 2. Zeitung \& Jahr $\quad 105$

Tab. 3. Zeitung \& Genre 106

Tab. 4. Artikelanzahl \& Jahr $98 \quad 107$

Tab. 5. Zeitung \& deutsche Akteure $\quad 108$

Tab. 6. Zeitung \& türkische Akteure $\quad 108$

Tab. 7. Zeitung \& europäische Akteure $\quad 109$

Tab. 8. Themenfelder \& Akteure $\quad 114$

Tab. 9. kulturelles Feld \& Akteure $\quad 116$

Tab. 10. Sicherheitsfeld \& Akteure $\quad 119$

Tab. 11. politisches Feld \& Akteure $\quad 123$

Tab. 12. moralisches Feld \& Akteure $\quad 128$

Tab. 13. Zukunft Europas \& Akteure 131 


\section{ABKÜRZUNGEN}

AKP Adalet ve Kalkınma Partisi, Partei für Gerechtigkeit und Entwicklung

ANAP Anavatanpartisi, Mutterlandspartei

BBP Büyük Birlik Partisi, Große Einheitspartei

BRD Bundesrepublik Deutschland

CDU Christlich Demokratische Union Deutschlands

CHP Cumhuriyet Halk Partisi, Republikanische Volkspartei

CUM Cumhuriyet

DSP Demokratik Sol Parti, Demokratische Linkspartei

DYP Doğru Yol Partisi, Partei des Rechten Weges

EU Europäische Union

FAZ Frankfurter Allgemeine Zeitung

FDP Freie Demokratische Partei

FR Frankfurter Rundschau

GRÜNE Bündnis 90/Die Grünen

HÜR Hürriyet

IP Ișçi Partisi, Arbeiter Partei

ITC Ittihat ve Terraki Cemiyeti, Gesellschaft von Einheit und Fortschritt

MHP Milliyetçi Hareket Partisi, Nationalistische Bewegungs-partei

PDS Partei des Demokratischen Sozialismus

PKK Partiya Karkeran Kurdistan, Kurdische Arbeiterpartei

RP Refah Partisi, Wohlfahrtspartei, seit 1998 Fazilet Partisi (FT), Tugendpartei

SPD Sozialdemokratische Partei Deutschlands

SZ Süddeutsche Zeitung

TAZ Tageszeitung

TR Türkische Republik

ZAM Zaman 


\section{Einleitung}

Old Europe seems to have exhausted all the possibilities of discourse and counter-discourse about its own identification.

Derrida

Zur Frage der europäischen Identität herrschen im Bereich der Europastudien zwei dominante Strömungen vor. Es wird zum einen von einem sich selbst genügenden politischen Integrationsprozess Europas ausgegangen. Sich selbst genügend, weil er sich nicht in Abgrenzung zu anderen Regionen oder Gesellschaften, sondern durch interne Dynamiken und Mechanismen formiert, und der konstitutive Andere nicht außerhalb, sondern in der eigenen negativen Vergangenheit (Weltkriege und Holocaust) zu suchen ist (Ruggie 1993; Wendt 1999; Wæver 1998). Zum anderen wird argumentiert, dass es Europa an einer territorial bestimmbaren kollektiven Identität mangele, weil es an intermediären Strukturen und Mechanismen fehle, die in klassischen Demokratien des territorialen Nationalstaates die politische Herrschaft von unten zügelten (vgl. Grimm 1995; Jachtenfuchs 2000; Scharpf 1999; Kielmansegg 1996). Da kollektive Identitäten sich erst in der Öffentlichkeit formieren, so die theoretische Annahme, führt die empirische Feststellung eines Mangels an einer gesamteuropäischen Öffentlichkeit zu dem Schluss, dass eine kollektive Identität fehlt.

Die Debatte über den türkischen Beitritt zeigt uns hingegen die Formierung einer issuespezifischen und populären europäischen Öffentlichkeit, in der die gesuchten identifikatorischen Motive und Grenzen eines vorgestellten Europas sichtbar werden. Diese Debatte bringt unmittelbar die Frage mit sich, wo die Grenzen Europas im Osten aufhören oder an- 
fangen sollen, weil die Dichotomien zwischen Identität und Differenz, Innen und Außen, und »West und Ost « aufgrund der ungewissen Grenzen ins Wanken geraten. Während binäre Gegensätze klare Bedeutungen, Definitionen und Handlungen ermöglichen, verwirrt, lähmt und quält die Türkei als nicht eindeutig Bestimmbares (vgl. Bauman 1996: 77).

Die Ostgrenze nahm zwar immer schon eine ambivalente Funktion für die Formierung einer modernen westeuropäischen Identität ein: Ambivalent, weil sie einerseits primär für Europa eine Grenze der Exklusion ist, die die Identität Europas sicherstellt, andererseits weil sie jene imaginäre Grenze ist, die immer wieder überschritten und neu definiert werden muss. Jedes Mal, wenn das »Kern-Europa« sich transformiert und neu definiert, ist die Umdefinierung und Festlegung der Ostgrenze eine unmittelbare Folge, sowohl im Sinne einer Überschreitung der Grenze als auch der Ausschließung des Ostens. Sie ist eine Grenze, die verteidigt und überschritten werden muss, die gleichzeitig Furcht und Attraktion birgt. Eine Grenze, die sich in der Geschichte mehrfach neu definiert und verschoben hat, die aber nie verschwindet. Jede neue Grenzziehung schließt die alten Spuren ein. Maria Todorova (2007) weist darauf hin, dass Osteuropa mehr als eine räumlich-geographische Einheit ist und der »Balkan« mehr als ein Gebirge bezeichnet. Diese Begriffe sind mit eurozentristischen Deutungen gefüllt. Osteuropa erscheint als das Bindeglied zwischen Europa und Mittlerem Osten, als ambivalenter Raum, der beide geschlossenen und oppositionellen Entitäten zu verbinden verspricht (Todorova 2007: 7). Osteuropa fungiert als eine mythische Topographie, als die »Antithese der westeuropäischen Zivilisation innerhalb Europas, das `Heart of Darkness` im eigenen Fleisch « (Angelova 2007). Seit der Aufklärung bis zum Osterweiterungsdiskurs und darüber hinaus werden Ost- und Südosteuropa (Balkan) als das »quantitative « Andere Westeuropas, als ambivalent und unterlegen gedeutet, heute zwar nicht mehr als anti-europe, aber immer noch als less-europe (vgl. Kovacs \& Kabachnik 2001: 147ff).

Die Türkei ist hingegen für Westeuropa weder Osteuropa noch Mittelost, sondern eine Grauzone irgendwo dazwischen. Sie ist weder Freund noch Feind, sondern jene unentscheidbare Fremde, die nicht abschließend in binären Gegensätzen eingeschlossen werden kann, weil sie je nachdem, wie man sich ihr nähert, beides bedeuten kann. Die Türkei transportiert das europäische Außen nach innen und fordert die europäische symbolische Ordnung heraus. Sie intensiviert den symbolischen hegemonialen Kampf und teilt »Europäer« und Deutsche in zwei hegemoniale Blöcke. Sie zerreißt einerseits die europäische symbolische Ordnung, andererseits ermöglicht sie ihr diverse identitätsstiftende Mo- 
mente. Bestimmte orientalistische bzw. okzidentalistische Bedeutungen erfahren eine Renaissance, sie werden symbolische Ressourcen des Prozesses der Identitätsbildung in den deutschen bzw. europäischen und türkischen Öffentlichkeiten.

Betrachtet man wiederum die Bedeutung des Westens in der türkischen Nationalgeschichte, so begegnet man ihm als einem permanenten ambivalenten Signifikanten in der Sprache der türkischen politischen Öffentlichkeit und er übt eine effektive Macht in der Imagination der modernen türkischen Identität, sowohl als Bedeutung für Fortschritt und Wohlstand als auch als Figur der Entfremdung aus (vgl. Irzık/Güzeldere 2003: 285). Der Vertrag von Lausanne (1922), die modernistischen republikanischen Reformen nach der Gründung der Republik (1923-1935), das Ankara-Abkommen (1963), die Zollunion (1995), der HelsinkiGipfel (1999), alle diese Ereignisse werden als »historischer Wendepunkt« und »Schicksalskurve« markiert, als ein »Schritt in Richtung Europa«. ${ }^{1}$ Die Türkei erbringt zwar seit ca. 150 Jahren performative Leistungen, um ein Teil Europas zu werden. Das türkische Selbst kann sich jedoch seiner minderwertigen Position nicht entziehen, es stößt beständig an seine internen und externen Barrieren und sein »Zug« kommt in Europa nicht an. Je näher es dem Westen rückt, desto weiter verschiebt sich das Ziel, es kann die »Brücke zwischen West und Ost« nicht überqueren und die Freude des Ankommens nicht erleben. In dem Moment der Verschiebung der imaginären Endstation wird die Türkei enttäuscht, man fühlt sich betrogen, da die Bemühungen vom europäischen "großen Anderen« nicht gewürdigt werden. Wenn die EU als regulierende und disziplinierende Instanz auf den türkischen (politischen) Mangel hinweist, dann spricht der Diskurs von westlicher »Habgier«

1 Nicht nur türkische Politiker und Kolumnisten, sondern auch Vertreter der EG/EU betrachten die Beschlüsse des Ankara-Abkommens 1963 und den Beitritt der Türkei zur Zollunion 1995 als Bestätigung des Europäischseins der Türkei und als eine »Verwirklichung des historischen Traumes« (vgl. Ertuğrul 2000: 133ff). Dem damaligen Kommissionsvorsitzenden des gemeinsamen Marktes W. Hallstein zufolge war das Ankara-Abkommen »a walk in Atatürk's way« und zeigte, dass die Türkei »ein Teil Europas« sei. Dies sei dank der starken Persönlichkeit von Atatürk und seinen »progressiven Reformen « in allen gesellschaftlichen Feldern möglich geworden. Der damalige türkische Außenminister F.C. Erkin (CHP), der das Abkommen im Namen der türkischen Republik unterzeichnete, deutete es als den Beginn einer »neuen Epoche« für die Türkei. Das Abkommen bestätige, dass die Türkei mit ihrer »Identität und ihren Zielen« ein Teil Europas geworden sei. Die Unterzeichnung der Zollunion wurde als ein »turning point«, als Erreichen des westlichen Zivilisationsstandes und »vitaler Moment « in der türkischen nationalen Geschichte sowie als »Unterschrift für die Zukunft« dargestellt (vgl. Ertuğrul 2000: 135ff). 
und »Doppelmoral« und flüchtet in eine imaginierte »türkische Ehre«, über die mit »unehrlichen Fremden« nicht verhandelt werden dürfe.

Auch die politischen Reformen im Rahmen der EU-Beitrittsverhandlungen werden weniger als Lösung aktueller politischer und sozialer Probleme, sondern als Kodex und Symbol einer begehrten und gleichzeitig gefürchteten Verwestlichung wahrgenommen. Es wird weniger die praktische politische Bedeutung der Reformen diskutiert als vielmehr die Frage, »wie die Europäer uns sehen« (vgl. Ahıska 2003). Das türkische Selbst ist dabei stets auf den Blick des europäischen Anderen angewiesen. Reformen haben in erster Linie einen taktischen und pragmatischen Charakter in einem Spiel, dessen Regeln von Europa festgelegt und überprüft werden. Gerade durch diese wechselseitige Ambivalenz zwischen Europa und der Türkei entsteht ein Spielraum für den Kampf um die Deutungsmacht und macht den auf beiden Seiten vorhandenen strukturellen Identitätsmangel sichtbar.

Das Forschungsinteresse der vorliegenden Studie ist die Untersuchung genau dieses ambivalenten und dialogischen Zusammenspiels zwischen europäischen und türkischen Diskursen sowie der symbolschen Ausprägung der Europäisierungsdebatte für die interaktive Bildung europäischer und türkischer Identitäten bzw. des Markierens von Differenzen. Es geht hier um die zeitgleiche Analyse von diskursiven Praktiken, die im Rahmen der öffentlichen Debatten in Deutschland und in der Türkei in ausgewählten Printmedien über den ausgehandelten EUBeitritt der Türkei stattfinden. Die Arbeit hat insgesamt die Absicht zu zeigen, dass die türkische Differenz insofern ein formatives Moment für die Bildung einer europäischen Identität ist, als diverse Bedeutungen von »Westen« und »Osten«, »Europa« und »Islamischer Welt« in den deutschen bzw. europäischen Öffentlichkeiten kommuniziert und strukturiert werden. Dabei geht es im Wesentlichen um zwei Fragen, auf die die sich formierende(n) europäische(n) Öffentlichkeit(en) ihre Antworten gibt (geben): zum einen, ob die Türkei europäisch ist, und zum anderen, was dieses »Europäischsein« ausmacht. Es geht darum, zu definieren bzw. zu erfinden, was das gemeinsame Eigene und was das unerträgliche Andere ist. 


\section{Die Suche nach der europäischen Identität}

Seit den 1970er Jahren wird die Frage der europäischen Identität zunehmend thematisiert ${ }^{2}$. Eine europäische Union, zu der Zeit basierend auf neun Mitgliedern, sollte auf einer gemeinsamen Herkunft fußen, auf den Prinzipien der repräsentativen Demokratie, Rechtsstaatlichkeit, sozialen Gerechtigkeit und der Menschenrechte (vgl. Trunk 2001: 51). Mit dem Maastrichter Vertrag (1992) findet eine Verschiebung der Gewichtung von einer vorwiegend wirtschaftlich $\mathrm{zu}$ einer stärker politisch orientierten Gemeinschaft statt. Seitdem gewinnt die Frage der europäischen Identität auch immer mehr Raum in den europäischen Studien.

\section{Europäische Identität und Andere}

Die konstruktivistischen Perspektiven im Bereich der internationalen Beziehungen untersuchen die Identität von Nationalstaaten an der Schwelle des Selbst und des Anderen, sie positionieren sich als Kritik gegen die Realisten ${ }^{3}$ und heben die Rolle von Ideen, Bedeutungen und

2 Das erste europäische Dokument bezüglich europäischer Identität wurde 1973 in Kopenhagen als »Deklaration der europäischen Identität« verfasst. Diese Deklaration fasste die Beziehungen zu anderen Ländern in eine hierarchische Ordnung. Die Intensität und der Umfang von Beziehungen mit Anderen differierten je nach Nationen und Gebieten. Mit Ländern, mit denen die Europäische Gemeinschaft gemeinsame Werte und Aspirationen auf der Basis einer gemeinsamen Herkunft teilte, wie den USA, sollten enge Beziehungen hergestellt oder vorhandene Beziehungen intensiviert werden. Mit anderen, mit denen man diese historischen Bindungen und gemeinsamen Werte nicht teilte, sollte lediglich ein begrenzter Austausch stattfinden oder freundliche Beziehungen hergestellt werden, wie etwa mit den Ländern Osteuropas oder Asiens. Es gab also favorisierte Gebiete und weniger favorisierte, basierend auf kulturellen Gemeinsamkeiten und Differenzen (vgl. Passerini 2002: 193f).

3 Die realistischen funktionalistischen Theorien reden von objektiv gegebenen Faktoren und verstehen unter Macht lediglich materielle Fähigkeiten und Ressourcen, in denen Staaten als rational handelnde Akteure ihren Nutzen zu maximieren versuchen. Diskursiven Praktiken und der Bildung von kollektiven Identitäten wird dabei eine sekundäre Rolle zugesprochen. Die politisch-kulturellen Dissense werden lediglich als reaktionäre Systemgegnerschaft betrachtet (vgl. Keyman 1996; Neumann/Welsh 1991). Die Staaten werden als handelnde unitäre Entitäten konzipiert, staatsinterne Konflikte und Widersprüche und symbolische Prozesse, die Rolle von miteinander konkurrierenden politischen Diskursen um die Deutungsmacht werden marginalisiert (vgl. Diez 2001; Jachtenfuchs 2002). Auch die kulturell-historischen Kontexte, in denen sich Staaten formieren, werden übersehen, als würden Bildungsprozesse durch technische Professionen in einem kulturellen Vakuum funktionieren. Insbesondere im Bereich der Europastudien wird die Rolle der diskursiven Praktiken für den euro- 
Identitäten hervor (vgl. Jachtenfuchs 2002: 652; Smith 1999: 683). Konstruktivistischen Ansätzen zufolge sind nicht nur Interessen, sondern auch Identitäten in zwischenstaatlichen Beziehungen relevant (Adler 1997b: 322). Für die Formation von staatlichen Präferenzen sollten kollektive Identitäten von Akteuren betrachtet werden. Interessen und Präferenzen sind nicht exogen, sondern sind konstruiert durch die intersubjektiven kommunikativen Prozeduren und Verständnisse, eingebettet in den soziohistorischen Kontext (vgl. Wendt 1999: 393f). Die Diskurstheoretiker und die Rationalisten können Checkel (1998) zufolge jeweils lediglich eine Seite erläutern, Erstere beleuchteten die Strukturen und diskursiven Praktiken, Letztere fokussierten die Agenten und ihre materiellen Interessen (Smith 1999: 685ff). Checkel versucht die Beziehung zwischen Normen, Diskursen und materiellen Kapazitäten zu erfassen und an den Schnittstellen zwischen Strukturen und Akteuren zu operieren.

Wendt (1999) spricht von einer systemischen kulturellen Transformation und Diffusion und von der Entstehung von postnationalen Identitäten in den postmodernen Gesellschaften, die die Anderen einschließen. Er unterscheidet in internationalen Beziehungen zwischen negativer und positiver Identifikation. In der negativen Identifikation sehe das Selbst den Anderen als different, gefährlich und moralisch unterlegen, in der positiven Identifikation bezeichne es den Anderen als ähnlich und nicht bedrohlich. Es benenne in diesem Fall den Anderen als die Extension seines Selbst und als moralisch gleichwertig (vgl. Rumelili 2002: 7). Im Sinne von wechselseitiger Zugehörigkeit zu bestimmten Regionen sozialisierten sich Staaten in kollektiven Identitäten. Sie entwickelten durch diese Sozialisationen und Interaktionen gemeinsame Normen und Werte. Checkel (1989) zufolge haben Sozialisation und Lernprozesse einen bestimmten Einfluss auf die Interessen und Identitäten von Akteuren (vgl. Checkel 1998: 327; Smith 1999: 684). Die liberalen Konstruktivisten akzentuieren also die postnationalen Formierungsprozesse, in denen die europäischen Nationen sich gegenseitig als Erweiterung ihrer selbst betrachten.

Die deutschen und französischen Identitäten werden in dieser Hinsicht als Paradebeispiel gegeben. Risse (2001) und Spohn (2002) zufolge sind diese beiden Identitäten insbesondere seit dem Zweiten Weltkrieg pro-europäisch eingestellt. Beide Vorstellungen seien kompatibel mit europäischer Integration und Supranationalismus, während die briti-

päischen Bildungsprozess ignoriert. Die realistisch-funktionalistischen Theorien, die lediglich die Natur der europäischen Integration zu erklären versuchen, sind auch selbst am Konstruktionsprozess beteiligt (vgl. Diez 1999: 599). 
sche Identität zu Europa gegensätzlich konstruiert sei, wobei Europa als freundliches Andere verstanden wird. Die deutsche Identifikation mit Europa sei wahrscheinlich deswegen möglich geworden, weil sie eine Gelegenheit für die Deutschen biete, die Lasten ihrer Nazi-Vergangenheit auf der Basis dieses moralischen Fundamentes zu überwinden (vgl. Spohn 2002: 289; Risse 2001: 200). Es formierte sich für Risse zwischen SPD und CDU ein Konsens im Hinblick auf das europäische Projekt. Somit entstand ein deutscher Euro-Patriotismus - als Abgrenzung zum deutschen autoritären Militarismus und zum Nationalsozialismus (vgl. Risse 2001: 208). Dieser Konsens verwandelte laut Spohn »das deutsche Empire« in ein »europäisiertes Deutschland«, was wiederum »die deutsche Ostpolitik» und die Osterweiterung begünstigte (vgl. Spohn 2002).

Risse akzentuiert, dass der Zweite Weltkrieg und die Okkupation Frankreichs für die Franzosen eine traumatische Erfahrung waren. Deutschland war der »große Andere« der französischen nationalen Identität. Diejenigen, die für die europäische Integration waren, sorgten sich darum, mittels supranationaler Institutionen die »deutsche Gefahr» zu bändigen. Man sprach von einem »deutschen Problem». Die Bildung supranationaler Institutionen auf europäischer Ebene schien notwendig zu sein, um dieses Problem zu lösen. Frank (2002) weist darauf hin, dass die französische Vorstellung von Europa seit dem 18. Jahrhundert bis in die 1980er Jahre immer schon frankreichzentriert war. Demnach ist Europa das Zentrum der Welt und Frankreich das Zentrum Europas. Diese französische Idee basiert auf den Werten der Aufklärung, wobei Europa als Agent der Zivilisierung seiner Umgebung verstanden wird. Bis zur Regierungszeit unter Mitterrand dominierte diese Europavorstellung. Nach dem Scheitern des Programms von einem vereinigten sozialistischen Europa hat sich Frankreich in den 1980er Jahren »europäisiert«. Laut Frank (2002) hing es mit einem Machtverlust Frankreichs bzw. einem Machtgewinn der BRD zusammen, dass wir heute einem »europäisierten« Frankreich begegnen (Frank 2002: 311ff). Damit begann eine deutsch-französische Periode, in der sich eine föderative Vorstellung von Europa verfestigte: $» \mathrm{We}$ are at the moment where everybody unites, our fatherland, our Europe, Europe our fatherland, the ambition to support one by the other, the excitement of our land and of the people it produces, and the certainty of a new dimension is expecting them« (Mitterrand 1986, zit.n. Risse 2001: 212).

Ruggie (1993) akzentuiert die postmoderne und postnationale Natur der Europäischen Union als eine politische Kollektivität, die nicht auf der kollektiven Angst vor Anderen basiere, sondern auf der kollektiven Angst vor Uneinigkeit (vgl. Ruggie 1993: 172). Denn Identitäten von 
nationalen Staaten stützten sich auf der Konstruktion von eindeutigen Innen/Außen-und Selbst/Andere-Distinktionen. Die postnationalen Identitäten dagegen gingen über die Grenzen und die zentralisierte Souveränität des post-westfälischen Nationalstaates hinaus. Die Grenzen von postnationalen Entitäten wie der EU seien durchlässig und überlagert. Die internationale Politik der EU-Mitglieder unterscheide sich von der moderner Nationalstaaten. Mit ihren überlappenden Formen von Autorität und nichtexklusiven Formen von Territorialität ähnle die Politik der EU eher dem mittelalterlichen Herrschaftssystem.

Auch Wendt (1999) geht von einer sich selbst generierenden und sich selbst aufrechterhaltenden europäischen Gesellschaftsformierung aus, die keine »Anderen« zur Selbstverständigung benötigt: »If a process is self-organizing, then there is no particular other to which the self is related.« (Wendt 1999: 225) So könne kein Prozess sich selbst organisierend und selbst generierend sein, wenn er eine Grenzziehung beinhalte. Die westlichen demokratischen Staaten würden nicht über den konstituierenden Anderen aufgebaut und die EU sei ein gutes Beispiel für die Bildung einer solchen kollektiven Identität, wobei die Staaten einander als Erweiterung ihrer Selbst betrachteten, nicht als ihr konstitutives Anderes (vgl. Wendt 1999). Eder (2006a) geht davon aus, dass das dominante europäische Andere nicht im Außen, sondern in seiner eigenen (negativen) Vergangenheit zu suchen ist. Das Gute in Europa richte sich dann nicht mehr gegen das böse Andere draußen, sondern gegen das böse Andere in sich selbst (Eder 2006a: 155ff). Für Wæver (1998) sind die Länder, die vom Zentrum entfernt sind, nicht anti-europäisch, sondern wenig europäisch. Die EU gründet sich auch für ihn nicht auf einer gemeinsamen Angst vor dem Anderen. Sie habe keine klaren fixen Grenzen, sondern weite Gebiete diffuser Zonen. Es formiere sich eine politische Diskursgesellschaft, deren Identität auf universalisierbaren Normen basiere und die prinzipiell offen sei (vgl. Wæver 1998: 100ff). Unter seinen Mitgliedern ersetzt die EU die traditionelle westfälische Form des Nationalstaates, der auf einer Selbst/Andere-Distinktion basiert, durch gegenseitige überlappende Identitäten.

Doch damit wird die Differenz nicht aufgehoben, sondern jenseits der EU-Grenzen verschoben. Das europäische Selbst könnte demzufolge sich in Abwesenheit des Anderen verwirklichen und wäre selbstgenügsam, alles könnte somit von sich selbst abgeleitet werden (vgl. Bakhtin 2001). Die Geschichte der Modernisierung wird reduziert auf eine Geschichte der Diffusion, als ein Transfer von den europäischen Zentren in die Peripherie (vgl. Conrad/Randeria 2002: 13). Was die liberalen Konstruktivisten zu den Theorien der internationalen Beziehungen beitragen, sind die Identitätsformation und deren Transformation. Auch diese 
Theorie nimmt Staaten als Entitäten, die eine Identität besitzen. Denn die domestischen Konflikte und streitenden Diskurse wirken unmittelbar auf eine mögliche Transformation eines Staates und seine Politik. Betrachtet als Entität, können die hegemonialen und kontra-hegemonialen diskursiven Auseinandersetzungen und Brüche sowohl innerhalb eines Staates als auch im transnationalen Raum jedoch nicht erklärt werden (vgl. Bieler/Morton 2004; Diez 2001).

Jede Identitätsformation hat schon immer eine doppelte Konsequenz: Das Markieren von Gemeinsamkeiten in einer Gemeinschaft schließt notwendigerweise die Produktion von Differenzen zu Staaten oder Regionen außerhalb dieser Gemeinschaft mit ein. Die kollektive imaginäre Identität einer Gemeinschaft wird, wie alle Formen von Identität, performativ in Relation zur Differenz konstruiert, nach der Devise: »a thing is known by what it is not« (vgl. Campbell 1992: 85). Die eigene Identität mag in bestimmten Fällen das Andere als Erweiterung ihrer selbst ansehen. Doch hört die Konstruktion der Differenz damit nicht auf, sondern verschiebt sich vielmehr auf eine andere Ebene, indem sie sich z.B. vom wenig oder nicht demokratischen Anderen abgrenzt (vgl. Doty 1996: 136). Da Differenz in den Außenbeziehungen eines Staates stets präsent ist, reproduziert die Externalisierung die Distinktion zwischen Internen und Externen, sie vereinheitlicht das Innen und stellt das Außen als chaotisch dar (vgl. Campbell 1992: 69f).

»[...] the EU is much more than an economic market and political organisation. The EU is creating its own culture, which we see as sets of institutions, behaviours, and ideas which often coincide with, and often contradict, national and other forms of local culture, but which have, a one very important result, the shaping of identities throughout Europe, and identities of Europe outsides its boundaries.« (Bellier/Wilson 2000: 8)

Ebenso wie Nationalstaaten zieht also auch die Europäische Union symbolische Grenzen und bringt Grenzen schaffende politische Performanzen hervor. Im Gegensatz zu Nationalstaaten operiert die europäische Grenz- bzw. Migrationspolitik, Balibar zufolge, auf einem Regulationsfeld, auf dem die Souveränität deterritorialisiert und jenseits der Bürgerschaft hergestellt wird (vgl. Balibar 2003). Dabei würde die Migrationssteuerung jenseits des europäischen Territoriums (z.B. nach Marokko, Mauretanien oder Libyen) externalisiert. Diese Transformation von Souveränität selbst ist, Hess und Tsianos zufolge, als Effekt der globalen Migration zu denken, die die Grundlagen, auf denen Souveränität bislang funktionierte, tendenziell unterläuft. Sie konstituiere einen heterogenen und hierarchisierten Zirkulationsraum abgestufter Souveränitäts- 
zonen (vgl. Hess/ Tsianos 2007). Es macht in diesem Sinne keinen Sinn, nach dem Ende des Kalten Krieges über das Ende des Ost-WestUnterschiedes zu reden. Denn der Osten wird immer wieder neu beschrieben, um die europäische Identität zu rekonstruieren. Die Frage laute deshalb nicht, ob der Osten in dem diskursiven narrativen Prozess der neuen Identitätsformation der Europäischen Union benutzt wird, sondern wie das materialisiert wird (vgl. Neumann 1999: 207).

Die liberalen postmodernen Konstruktivisten bleiben in der Beziehung zwischen Selbst und Anderem der Subjektivität des Anderen gegenüber indifferent. Sie betrachten die Identitätsformation des Selbst einseitig und isoliert. Die Interaktion zwischen dem Selbst und dem Anderen wird nur im Kontext der Erweiterung bzw. Assimilation des Anderen, durch den Prozess der normativen Diffusion, Sozialisation und Imitation betrachtet. Durch die Diffusion transformiert und standardisiert das europäische Selbst seine Peripherie, das Andere bleibt dabei passiv, internalisiert das westliche Modell. Dieser Prozess funktioniert demzufolge reibungslos. Die diskursiven Performanzen des Anderen werden dabei außer Acht gelassen und seine komplexen und widersprüchlichen Aneignungspraktiken und Identifikationsprozesse werden ignoriert. Die Abhängigkeiten und Interferenzen, die Verflechtungen und Interdependenzen zwischen Selbst und Anderem geraten darüber hinaus kaum in den Blick.

"In the conceptualization of the self and other relationship poststructuralism also denies agency of the other in structuring the relationship. Poststructuralist theory focuses how identities are constructed and sustained by discourses of difference that create and maintain a moral hierarchy between self and other. It emphasizes that the relationship between self and other is not only one of difference but also power: hegemonic discourses structure self and other relationship in an asymmetrical fashion and deny the other effective agency." (Rumelili 2002: 60)

Doch die Formierungsprozesse des Diskurses und der symbolischen Grenzziehung sind dialogisch: Sowohl das Selbst als auch das Andere sind daran beteiligt. Man erzählt Geschichten über das Andere, gleichzeitig werden über das Selbst Geschichten erzählt. Die gegenseitigen dialogischen Erzählungen verbinden Vergangenheit, Gegenwart und Zukunft durch affektive Dimensionen und schaffen somit eine Kollektivität zu einer bestimmten Zeit an einem bestimmten Ort. Diese Dialogizität ist der konstitutive Part der Bildung von kollektiven Identifikationen und symbolischen Grenzen (vgl. Neumann 1999: 223). Die kollektiven Akteure handeln dabei nicht einfach nach bestimmten Subjektposi- 
tionen, die ihnen zugeschrieben sind, sondern gestalten mit, sie pervertieren oder verändern in bestimmten Fällen auch diese Zuschreibungen performativ. Jede Konstruktion von kollektiver Identität richtet sich an den Anderen und konstruiert Gegenidentitäten, wobei die diskursiven Performanzen des Anderen ein Faktor in der Beziehung zwischen Selbst und Anderem werden. In diesem interaktiven diskursiven Prozess findet sich ein komplexes Geflecht von »geteilten Geschichten«, eine ambivalente Geschichte des Austausches und der Interaktionen. Einerseits werden die Gemeinsamkeiten markiert, in denen verschiedene Gesellschaften eine Reihe zentraler Erfahrungen zu teilen glauben, andererseits werden Differenzen markiert, wobei der Anspruch auf Partikularität gestellt wird (vgl. Conrad/Randeria 2002: 17).

\section{Europäische Identität und Öffentlichkeit}

Die demokratietheoretischen Ansätze im Bereich der Europäischen Integration suchen nach bestimmten Mechanismen, die die politische Integration und die Formierung europäischer Identität beschleunigen. Sie stellen die Frage, inwieweit europäische Öffentlichkeit(en) auch eine europäische Identität hervorbringen. Es geht ihnen dabei weniger um bestimmte Inhalte, sondern vielmehr um die Prozesse und Prozeduren, in denen auch Kultur und Identität thematisiert werden.

»A lively political and academic debate has emerged about the normative viability and the empirical possibility of a collective European identity and how it relates to national identities. The debate is directly linked to the controversy about the democratic or legitimacy deficit of the European Union (EU). There is general agreement that modern democracies rely upon the diffuse support of their citizens in order to gain legitimacy which is necessary to ensure compliance with inconvenient and costly norms and rules. Collective identification with a polity provides one source of diffuse support for political systems.« (Risse 2003: 2)

Die Ausgangsposition des demokratietheoretischen Ansatzes ist Jachtenfuchs (1998) zufolge in der These Max Webers zu suchen, dass die politischen Systeme unstabil würden, wenn sie sich lediglich auf die Koinzidenz von sich verändernden individuellen Interessen stützten. Ein stabiles und effektives politisches System benötige Legitimität ${ }^{4}$, also die »diffuse Unterstützung« und "generalisierte Folgebereitschaft» seiner

4 Jachtenfuchs et al. (1998) unterscheiden zwischen drei Dimensionen der Legitimation: Legitimation durch Partizipation (Rechte, Demokratie), Output (Sicherheit, Wohlfahrt und Qualität des Lebens) und Identität (Werte, Geschichte und Zukunft). (Jachtenfuchs et al. 1998: 417). 
Mitglieder, welche neben input- und output-orientierter Legitimation des politischen Systems auch einen gewissen Grad von kollektiver Identität und Solidarität erfordere (vgl. Jachtenfuchs et al. 1998). Hier sind zwei einander entgegenstehende diskursive Positionen zu sehen. Die modernistischen Euroskeptiker sprechen von defizitären europäischen Strukturen. Demnach existiert eine Asymmetrie zwischen Macht und Legitimität auf der EU-Ebene, da es an intermediären Strukturen und Mechanismen fehle, die in klassischen territorialen Demokratien des Nationalstaates die politische Herrschaft von unten beobachteten und zügelten sowie mit dem Demos vermittelten (vgl. Grimm 1995; Jachtenfuchs 2000; Scharpf 1999; Kielmansegg 1996). Der Europäisierung der politischen Entscheidungen schließt sich demnach keine Europäisierung der Öffentlichkeit an. Dies führe wiederum dazu, dass die europäischen Bürger sich nicht repräsentiert fühlten, da sie die Willens- und Entscheidungsbildungsprozesse nicht beeinflussen und kontrollieren könnten. Da nun kollektive politische Identitäten sich erst in der Öffentlichkeit formieren, so die theoretische Annahme, führt die empirische Feststellung eines Öffentlichkeitsmangels zu der Schlussfolgerung einer fehlenden europäischen kollektiven Identität.

In den Kategorien von Gemeinschaft und Identität kann man Abélès (2000) zufolge den Europäisierungsprozess nicht verstehen. Der Begriff »Gemeinschaft« sei eher ein europäischer Traum oder eine Metapher als eine konkrete Realität. Es sei schwierig, eine homogene Vision von Europa zu kommunizieren und eine europäische Staatsbürgerschaft entstehen zu lassen. Es existiere ein Defizit an gemeinsamen Ritualen und Symbolen (vgl. Abélès 2000: 51). Abélès stellt fest, dass es auf der europäischen Arena permanente Konfrontationen zwischen unterschiedlichen kulturellen und politischen Identitäten gibt. Die Bedeutung des politischen Konzeptes variiere von einer Kultur zur anderen. Beispielsweise sei die Differenz zwischen der französischen universalistischen und der deutschen romantisch-föderalistischen Tradition sowie zwischen dem britischen liberalen Parlamentarismus und dem französischen Präsidentalimus sehr groß. Diese Unterschiede führten häufig zu Missverständnissen und Unstimmigkeiten auf der europäischen Ebene. Daher sei das zentrale Problem der europäischen Konstruktion kultureller Natur. Die EU verstehe sich als ein offener Raum und es sei daher unmöglich eine künftige Grenze zu ziehen (vgl. Abélès 2000: 39). Kielmansegg (1996) vertritt eine ähnliche Auffassung, die Integration könne über eine kollektive Identität nicht erreicht werden und deswegen könne auch keine Rede von einer gemeinsamen Politik sein, dieses Problem sei struktureller Natur (vgl. Kielmansegg 1996). 
Die EU als Ganzes ist für Balibar (2003) weniger mächtig und effektiv als ihre einzelnen Mitgliedstaaten. Ihre »politische Kapazität«, Konflikte zu lösen, sei sehr gering, sie könne nicht einmal Konflikte auf dem eigenen Territorium, wie den Bürgerkrieg in Jugoslawien, verhindern. Deswegen existiere Europa nicht, es sei kein politisches »Subjekt«. Europa habe keine starken kollektiven Symbole, die die internen Konflikte und Spaltungen zu neutralisieren in der Lage wären. Eine europäische Identität könne nicht in Opposition zu anderen Identitäten gestellt werden, weil Europa keine absoluten, klaren Grenzlinien zwischen einem eigenen historischen und kulturellen Territorium und seinen Nachbarn habe. Es gebe keine absolute Grenzlinie, weil Europa als solches eine Grenzlinie sei. Es sei die Superposition von heterogenen Beziehungen mit anderen Historien und Kulturen in der Welt, die in der eigenen Geschichte und Kultur reproduziert werde (vgl. Balibar 2003: 15f).

$»$ History seems to show that any political entity, in order to exist, needs an sidea or a universal project to unify its human and material forces. But Europe's project can no longer be to subjugate the world, as in the colonial era. Nor can it be a messianic project of announcing the birth of the snew man<. Europe can indeed try to exercise a >civilizing « influence in the world, as well as to build the moral conditions of its own construction, but in order to do so it has to be more active.« (Balibar 2003: 17)

Den Postnationalisten zufolge bleibt dieser Ansatz auf dem nationalstaatlichen Imaginären hängen, er suche die üblichen Mechanismen und Strukturen, die als Resultate der Nationsbildungsprozesse in Westeuropa entstanden seien, wie gemeinsame politische Parteien, Medien, Schule, Sprache, Militär und ein homogener Demos etc. Er könne demzufolge den Wandlungsprozess auf globaler und EU-Ebene nicht identifizieren (vgl. Habermas 2003: 96f). Er formuliert sozusagen einen Diskurs des strukturellen Mangels, der lediglich die europäischen Defizite identifizieren kann. Für die postnationalen Föderalisten ist ein zunehmender institutioneller post-parlamentarischer Integrationsprozess auf der EUEbene zu sehen: Der Transfer von politischen Kompetenzen auf die EU führe immer mehr auch zur politischen Europäisierung (Risse 2001: 202). Zwar fehle Europa ein gesamtheitlicher Kommunikationsraum, wohl aber finde ein Strukturwandel der Öffentlichkeit statt: die Emergenz sektorenbezogener und themenspezifischer elitärer Teilöffentlichkeiten (vgl. Eder et al. 1998; Eder 2000) und deliberativer kommunikativer Räume (Schmalz-Bruns 1999), die einen ausdifferenzierten horizontalen Vergemeinschaftungstypus und sektorale »Demoi« hervor- 
brächten (vgl. Abromeit 1998). Klaus Eder (2004) zufolge geht es hierbei um die Transnationalisierung politischer Kommunikation, in der sich funktions- und issuespezifische Öffentlichkeiten ausbilden, die sich nicht mehr an nationale Grenzen halten. Diese räumlich entgrenzten Öffentlichkeiten verlören sich jedoch nicht im globalen Raum, sondern würden als funktionsspezifische Kommunikationsräume organisiert: etwa als Elitenöffentlichkeiten, die selektiv inkludieren, oder als policybezogene Öffentlichkeiten (wie etwa die europäische Migrationspolitik). Sie erhielten also funktionsgruppen- oder politikfeldspezifische Grenzen, die wiederum mit besonderen institutionellen Regelungen variierten. In diesen funktionalen Teilöffentlichkeiten seien miteinander streitende transnationale europäische Akteure, soziale Bewegungen und Advokaten zu sehen, die in die institutionellen Entscheidungsprozesse eingebunden würden. Sie bildeten untereinander Netzwerke, die zur (sektoralen) Europäisierung führten (Eder et al. 1998: 331ff; Eder 2000: 169f). Die Öffentlichkeit übernimmt somit auch hier den zentralen Mechanismus des Europäisierungsprozesses auf der symbolischen politischen Ebene. Die Frage, ob die EU als eine intergovernmentale Organisation (Staatenbund) bei der internationalen Balancierung von nationalen Interessen bleibt oder ob sie als ein föderales System (Bundesstaat) aufgebaut werden solle, ist für Habermas (2003) von zentraler Bedeutung.

»The controversy between Euroskeptics and Eurofederalists is primarily focused on the question of whether the European Union [...] ever achieve the quality of an authentic state, or whether it will remain caught within the boundaries of a neocorporatist bargaining system. Eurofederalists want to strengthen the governing capacities of the Union in order to make possible the pan-European enforcement of policies and regulations that will compel member states to hew to a coordinated process if they want redistribution as a result. From this viewpoint, expanding the capacities for political action must go hand in hand with expanding the bases of legitimacy.« (Habermas 2003: 97)

Für Habermas kann nur ein föderaler Bundesstaat die politische Macht in die Lage versetzen, marktkorrigierende Entscheidungen zu treffen und re-distributive Effekte zu regulieren. Für die Verlagerung dieser Entscheidungskompetenzen von den Nationalstaaten auf die EU sei ein gewisser Grad von Legitimität und Solidarität vonnöten. Deswegen versuchen die Föderalisten eine europäische Verfassung einzuführen, die die internationalen Verträge zwischen den Mitgliedsländern in eine politische Verfassung umwandelt, um damit eine breite Legitimitätsbasis für die politischen Entscheidungen der EU-Institutionen (EU-Kommission und Ministerrat und Europäischer Gerichtshof) zu erlangen. Die kosmo- 
politische Position von Habermas unterscheidet sich von der der Föderalisten und der neoliberalen Intergovernmentalisten insofern, als sie den föderalen Staat als Ausgangsposition für die Entwicklung transnationaler Netzwerke von Regimen betrachtet, die eine Weltpolitik durchsetzen können, auch in Abwesenheit einer »Weltregierung«. Er hält es für möglich, einen solchen föderalen EU-Staat zu errichten, da auch die Nationalstaaten in ihrer Entstehungsperiode im 19. Jahrhundert unter oben erwähnten »Strukturdefiziten« (an Legitimität, nationalem Bewusstsein und ziviler Solidarität) litten, die jedoch im Konsolidierungsprozess »überwunden« worden seien. Deswegen falle die These vom »strukturellen Defizit« aus. Das nationale Bewusstsein und die zivile Solidarität für die politische Legitimität des Nationalstaates waren nicht a priori da, sondern sind Folgen dieses Nationsbildungsprozesses (vgl. Habermas 2003: 97f).

Wie die Modernisten stellen auch die Postmodernisten (bzw. Postnationalisten) ebenfalls den Mangel einer territorial bestimmten (gesamt-) europäischen Identität fest. Es fehle den Europäern ein gemeinsamer Nenner. Eder (2004) zufolge entsteht im Zuge der Europäisierung Europas einerseits eine ökonomische und rechtliche Gemeinschaft mit den entsprechenden Institutionen. Damit bilde sich ein Typus von moderner Staatlichkeit jenseits des Nationalstaates. Im gleichen Zug sei die Emergenz einer transnationalen europäischen Gesellschaft zu beobachten, die aus verschiedenen Völkern, Nomaden und sonstigen ethnischen Minderheiten jenseits des Nationalstaates bestehe. Eder stellt die Frage, ob solche hergestellten Interessengemeinschaften und sektoralen Teilöffentlichkeiten ausreichend für die Zusammengehörigkeit von so heterogenen Völkern und miteinander streitenden gesellschaftlichen Gruppen sein können oder ob die Bürger Europas eine besondere kollektive Identität bzw. einen kollektiven Gegner bräuchten, die/der den Zusammenhalt sicherstellte (vgl. Eder 2006a). Eine europäische postnationale Gesellschaft existiere zwar »an sich« aber sie sei »(noch) nicht für sich«, da ihr eine kollektive Identität fehle (vgl. Eder 2004).

Wenn nun eine europäische imaginäre Identität bzw. das » für sich da sein« lediglich im aus sich selbst also in den internen institutionellen Praktiken und strukturellen Dynamiken des Formierungsprozesses ${ }^{5}$ im

5 Die europäischen Strategien und internen Mechanismen zur Bildung einer Identität können unter drei Gesichtpunkten zusammengefasst werden. Erstens: Ähnlich wie im Nationsbildungsprozess geht es um die Konstruktion eines kollektiven kulturellen Ethos über historische Mythen, eine gemeinsame christliche Herkunft, eine humanistische Tradition sowie eine kollektive politische und legale Geschichte, die bis auf Rom zurückgeht. Zweitens finden sich europäische Rituale, wie Wahlen und die Benutzung von gemeinsamen Eurosymbolen (Flagge, Pass, Geld), Austauschpro- 
»Kern Europa« isoliert gesucht wird, wird sie auch kaum gefunden. Wie Ringmar (1996) feststellt: »[...] We can never come up with a conclusive answer to the question of what we [...] >really are, but this does not for a moment stop us talking about what we or others are like« (Ringmar 1996, zit.n. Neumann 1999: 222). Eine europäische Identität soll da gesucht werden, wo sie am deutlichsten zu sehen ist, nämlich in den ambivalenten Momenten und in den »Grauzonen«, in denen das europäische Selbst seinem konstitutiven internen und externen Anderen, seiner Externität begegnet bzw. wo das europäische Selbst dieses konstruiert, indem es anfängt, Geschichten über sich und über das Andere zu erzählen, wobei Repräsentationen vergangener Erfahrungen dialogisch rekonstruiert werden (vgl. Hall 1994).

»It is astonishing that in the United States one totally forgets the European national differences, which in Europe seem to be such important demarcation lines [...] The unity of Europe became evident and made us feel as Europeans sharing a common culture and a common language [....] The term `European`, which I never used in France: here I use it. When I finished a discussion with Americans, then Italians, Spanish, French, German Jews all seemed to me be children of the same >patrie<, which is also my >patrie<. They all had a sense for the same values.« (Beauvoir 1998, zit.n. Kaelble 2002: 173)

Wie im empirischen Teil ausführlicher gezeigt wird, bricht im türkischen Fall der deutsche und europäische Konsens über der Repräsentation der Osterweiterung als »Rückkehr zu Europa« und »Wiedervereinigung Europas« zusammen. Die Figur des türkischen Anderen übernimmt bei der Formation der europäischen kollektiven Identität eine zentrale Rolle dadurch, dass ihre Präsenz die Frage hervorbringt, wer das Selbst und wer das Andere ist. Die Türkei bzw. die »Islamische Welt« wird somit zur Projektionsfläche, mit deren Hilfe der Inhalt des Europäischseins festgelegt wird. Es ist dabei nicht die Rede von kontextdurchquerenden essentiellen Möglichkeiten, das transzendentale europäische Selbst und das türkische Andere zu bewahren. Vielmehr sind alle Identitäten narrative Identitäten und sind immer kontextgebunden. Es sind die Narrative, die bestimmte Identifikationen sichern, über Perioden von Jahren hinweg sich ausdehnen und es mangelt nie an Texten, die diese Repräsentationen bewahren. Das gegenseitige Erzählen von Geschichten zwischen Selbst und Anderem wird hiermit sowohl die Voraussetzung als auch der Effekt von identifikatorischen Handlungen. Wie im folgenden diskurstheoretischen Teil näher dargelegt wird, be-

gramme und kooperative Programme. Und drittens gibt es den freien Personenverkehr innerhalb der EU-Länder. 
steht die Funktion der diskursiven Praktiken darin, zu versuchen die Unmöglichkeit des kontextdurchquerenden essentiellen Selbst zu maskieren (vgl. Neumann 1999: 216ff). Das Selbst formiert sich entlang dialogischer narrativer Prozesse, in denen eine Mehrzahl von Identifikationen in einem spezifischen Kontext mit Anderen verhandelt wird.

Anders formuliert: Statt das europäische Selbst lediglich von seinem Inneren her verstehen zu wollen, so meine Ausgangsposition, sollte es in seinen ambivalenten und antagonistischen Verhältnissen analysiert werden. ${ }^{6}$ Keine Identität trägt von sich aus eine Bedeutung, sondern wird in Abgrenzung zu anderen Identitäten, durch den negativen Bezug auf das, was eine Identität nicht ist erzeugt (vgl. Stäheli 2001: 197). Wie Bellier und Wilson feststellen, »Identities are never better perceived than in places and times of encounter with their >others« within real and metaphorical frontiers« (Bellier/Wilson 2000: 9). Ich werde dabei die konstitutive Rolle des Orients bzw. des Orientalismus in der Identitätsformation Europas hervorheben und argumentieren, dass eine europäische Identität sich nicht nur durch europäische interne Dynamiken und Mechanismen konstruiert, sie nicht selbst-generierend ist, sondern sich unmittelbar in Relation zur Differenz formiert, in der Abgrenzung zu Anderen, dort, wo das europäische Selbst seinen internen und externen »orientalen « Anderen begegnet, bzw. sie konstruiert. Die daraus abgeleitete empirische Frage lautet deshalb nicht, $o b$ Orient- und Okzidentfiguren in dem diskursiven narrativen Prozess der Identitätsformation Europas benutzt werden, sondern wie dies geschieht (vgl. Neumann 1999: 207).

\section{Europäische Identität und Europabegriff}

Auf der Ebene der Bedeutung Europas sind zwei miteinander konkurrierende Positionen $\mathrm{zu}$ sehen. Als die normative Basis der europäischen Identität werden entweder Inhalte der Kultur oder das Projekt der Modernität gekennzeichnet. Im ersten Fall wird eine essentielle Kulturdefinition, die sich linear entwickelt, markiert, und im zweiten werden die positiven Seiten der Modernität wahrgenommen und für eine kritische Reflexion plädiert. Beide sind ein Versuch, den Inhalt der europäischen Identität zu fixieren, indem Geschichte selektiv rekonstruiert wird. Doch

6 Foucault (1987) schlägt diese Herangehensweise zur Analyse von Machtverhältnissen vor. Demnach sollen diese nicht von ihrer inneren Rationalität her, sondern von den gegensätzlichen Momenten der Strategien, von einer Reihe von Oppositionen und Widerstandsformen her analysiert werden (vgl. Foucault 1987: 245f). 
beide haben eine Idee von einem Europa, das sich historisch isoliert vom Rest der Welt formierte.

Der kulturalistische Diskurs spricht von der gemeinsamen christlichen Herkunft, von Humanismus und der liberalen Demokratietradition Europas und sucht identifikatorische Motive für eine europäische Identität in einer erfundenen mythischen Geschichte, in der Antike und in der christlichen Tradition, wobei eine traditionell-primordiale europäische kollektive Identität auf der Basis der Idee Europas für die europäische Zukunft beliebig rekonstruiert wird (vgl. Delanty 1995: 2). Huber zufolge ist die Religion zwar allein nicht maßgeblich, aber eine europäische Identität solle auch ohne Quellen der Religion nicht auskommen (vgl. Huber 2002: 57ff). Wintle (1996) stellt zum einen in Frage, dass eine triumphale europäische Identität existiert, zum anderen redet er von einer linearen "positiven« europäischen Entwicklung bzw. von einer europäischen Idee und einem Erbe, das sich insbesondere seit dem Römischen Reich über die christliche Religion, Renaissance, Aufklärung und industrielle Revolution vollzogen habe. Diese Erbe »has not touched all parts of Europe or all Europeans equally [...] but which is felt and experienced in varying ways and degrees by those whose home is Europe, and which is recognised [...] by many from outside« (Wintle 1996: 13).

Europa unterscheidet sich für Pagden (2002) von Asien und Afrika dadurch, dass es seit der Antike eine kollektive Identität konstruiert habe, die auf einer kollektiven Kultur basiere, während den anderen Kontinenten eine solche politische und kulturelle Kohäsion nicht gegeben sei. Europa »has long possessed an identity as a cultural space where there have been and continue to be frequent political unions « (Pagden 2002: 53f). Für Bartlett (1993) waren es westliche europäische Aristokraten des Karolingischen Reiches zwischen dem 10. und 12. Jahrhundert, die den kulturellen Rahmen Europas gestalteten. Die fränkischen Aristokraten hätten Europa »europäisiert«, indem sie durch Eroberungen und ihren Einfluss ihre partikuläre fränkische Kultur verbreitet hätten (vgl. Bartlett 1993: 101ff). Demnach seien diese Länder das originale Europa (die ersten sechs EU-Staaten: Deutschland, Frankreich, Italien, Belgien, Holland, Luxemburg) und die Menschen aus diesem Gebieten originale Europäer. Laut Ertuğrul (2000) kritisiert Davies (1996) eine solche Geschichtsschreibung, die sich über Erfolgsereignisse konstruiere und weist auf vernachlässigte »externe« kulturelle Einflüsse auf Europa hin. Er macht darauf aufmerksam, dass auch ägyptische, phönizische und islamische Zivilisationen auf die europäische Kultur eingewirkt hätten (vgl. Ertuğrul 2000: 49f). Da Davies, wie auch Talal Asad feststellt, diesen Einfluss a priori als Einfluss von außen bezeichnet, als »carrier civi- 
lisation that helped to bring important elements into Europe from outside [...] (Asad 2002: 216), reproduziert er somit den eurozentristischen kulturgeschichtlichen Metanarrativ.

Auf der Suche nach den Ursprüngen der europäischen Identität begegnet Remie Brague (1993) den beiden zentralen »Fundamenten« der europäischen Identität: zum einen der griechische Antikkultur mit dem Zentrum Athen und zum anderen der jüdisch-christlichen Tradition mit dem Zentrum Jerusalem. Brague identifiziert dabei eine doppelte Zweitrangigkeit der Europäer: den Griechen gegenüber in kultureller und den Juden gegenüber in religiöser Hinsicht. Europa habe sich in seiner Unterlegenheit die beiden fremden Elemente zu Eigen gemacht. Die Europäer haben also sich angeeignet, was nicht das Eigene war. Aus diesem Grund sei die europäische Kultur exzentrisch, Kultur sei für den Europäer weder ein Besitz, noch begründe sie seine Identität. Sie sei im Gegenteil etwas grundsätzlich Fremdes, dessen Aneignung Aufwand erfordere. Nur auf dem Umweg über das Vorgegebene und das Fremde hätten die Europäer Zugang zum Eigenen (vgl. Brague 1993: 106ff).

Brague zufolge hat man versucht, den Inhalt eines jeden der beiden Elemente zu isolieren: Athen: Religion der Schönheit, Ästhetik und Vernunft, und Jerusalem: Religion des Gehorsams, der Ethik und des Glaubens. Es seien diese beiden Elemente, die Europa durch ihre spannungsgeladene Dynamik zum Leben erweckten. Laut Brague ist das dritte höhere Große das Römische: Europa sei weder nur griechisch noch ausschließlich hebräisch noch griechisch-hebräisch, sondern entschieden römisch: Athen, Jerusalem und Rom seien sozusagen die drei Zentren Europas (vgl. Brague 1993: 28). Europa wird demnach der Nachfolger des Römischen Reiches, dessen Kultur zwar aus seiner Peripherie stammt, jedoch die vorherigen in sich integriert hat. Die eigentliche Gefahr für Europa bestehe darin, aufzuhören, sich auf jenes Fremde (Athen und Antike) zu beziehen, dem es sich unterlegen wisse (vgl. Brague 1993: 150).

Mit dem Hinweis auf diese Gefahr ruft Brague zur Bekenntnis und Reflexion auf. Er sucht dabei einen sinnvollen Anfang, einen Ursprung einer heroischen europäischen kulturellen Identität in der mythischen Geschichte und kombiniert einzelne »gute Fakten« miteinander, wobei Europäisches Subjekt und Europäischsein eine kumulative Einheit werden und einen transhistorischen Charakter, eine mythische Dimension erhalten, auf die man stolz sein kann. Brague konstruiert eine romantische europäische Identität mittels eines erfundenen kollektiven Gedächtnisses und entdeckt dabei die »Wunder« von Antike, Rom und Europa, die in einer linearen Reihenfolge zum gegenwärtigen Telos geführt hätten (vgl. Amin 2001: 1674ff). Mit anderen Worten, entlang 
einer systematischen Verzerrung von Narrativen wird eine Kollektivität rekonstruiert, wobei jene Aspekte »vergessen« werden, die zum triumphalen Narrativ nicht passen (vgl. Eder 2005: 210ff).

Delanty (1995) macht darauf aufmerksam, dass weder die Athener noch die Römer sich als Europäer verstanden. Es entstand weder in der Antike noch im Mittelalter ein kultureller Raum für die Formierung eines Europäischseins. Europa als Signifikant war unprivilegiert. Er symbolisierte nicht den westlichen Kontinent, sondern war ein Teil von Nord- und Kleinasien. Die Welt der Antike war »oriental«, nicht »westlich« (vgl. Delanty 1995). Das Mittelmeer wurde nicht als Grenze der heutigen landbestimmten Europavorstellung, sondern maritim verstanden, "wobei das Mittelmehr als Medium des Austausches, der Durchdringung und Vermischung fungierte« (Münkler 1996: 121). Der mediterrane Ozean verband also Menschen miteinander, anstatt sie auszugrenzen, es waren die Alpen, die die »natürlichen« Grenzen kennzeichneten. Bis zum 15. Jahrhundert hatte der Begriff Europa also eine geographische Expression und war als Signifikant dem Christentum untergeordnet (vgl. Stråth 2000: 29). Der Andere für die Griechen waren diejenigen, die nicht griechisch waren. Nicht der Begriff Europa, sondern die Begriffe »Okzident« und »Orient« besaßen eine politisch-kulturelle Bedeutung, welche wiederum anders war als in den kolonialen Zeiten.

Auch das Römische Reich war nicht europäisch im heutigen Verständnis, sondern ein mediterranes »orientales« Reich. Ebenso wenig Bedeutung wie für Athen hatte Europa für das Römische Reich. Ein erheblicher Teil des Römischen Reiches umfasste schließlich nicht heutiges europäisches Territorium. Entscheidend war nicht der Eurozentrismus, sondern der Rom-Zentrismus, nicht die Idee von Europa, sondern der Mythos, dass Rom das Zentrum der Welt war. Nicht der West-OstNexus, sondern der Nord-Süd-Nexus war entscheidend. Nach der Spaltung des Römischen Reiches hatten Okzident und Orient eine kulturellreligiöse Bedeutung gewonnen. Dies kennzeichnete die beiden Hälften des Römischen Reiches, das westliche Rom, der Okzident, das östliche Rom, der Orient, später Byzanz (vgl. Hentsch 1996; Polaschegg 2005). Die Erfindung der Antike als der Ursprung Westeuropas ist eine autonome und originelle kulturelle Formation der Eliten zur Zeit von Renaissance und Aufklärung, während derer sich die europäischen Interessen von Ägypten nach Indien verlagerten. Die afroasiatische Orientierung wurde somit ersetzt durch den Mythos der Antike (vgl. Amin 2001: 1676). Brague unterlässt vor allem, das Zusammenspiel zwischen Modernität und Kolonialität zu behandeln, und ignoriert somit die »dunkle Seite« und die Ambivalenz der westlichen Modernität, die Terror und Emanzipation einschließt (vgl. Passerini 2002: 196). Das europäische 
Imaginäre entsteht nämlich nicht aus sich heraus, ist weniger von sich selbst abgeleitet, weder von der Sprache und Religion noch von einer gemeinsamen Geschichte, sondern vielmehr von der Formierung einer Reihe von asymmetrischen Begegnungen, in der Abgrenzung gegen Andere (vgl. Delanty 1995: 84).

Die politisch-kulturelle Bedeutung Europas kann Delanty (1995) zufolge auf das Zeitalter der »Entdeckungen« und des Humanismus zurückverfolgt werden. Die religiöse Bedeutung des Begriffes Europa verschwand damit zwar nicht ganz, trat aber in den Hintergrund. Die Kirche hatte sich in mehrere Machtzentren fragmentiert und die Rolle des universalen christlichen assimilatorischen Projektes ist vom Diskurs von »Zivilisation« und »Fortschritt« übernommen worden. Dies war eine elitäre politische Phantasie in den europäischen Ländern, in denen der Humanismus sich mehr oder weniger etablierte. Diese elitäre Phantasie grenzte sich gegen alle Völkerschaften ab, die noch unter dem »Mangel« dieser humanistischen Bildung litten (vgl. Münkler 1996: 121f). Es gab eine signifikante Zunahme in den Frequenzen der Benutzung des Wortes »Europa« in Zusammenhang mit der Expansion des Osmanischen Reiches im 16. Jahrhundert (vgl. Podraza 1998: 49). Hier zeigte sich eine adversiale europäische Identität, die sich über die Stilisierung der osmanischen Bedrohung konstruierte. Papst Pius II., Burke, Luther und Erasmus, die alle unterschiedliche religiöse und politische Positionen vertraten, sprachen von einer osmanischen Gefahr und forderten eine kollektive europäische Positionierung dem Feind gegenüber. Die kulturelle und religiöse Diversität in Europa sollte durch diese diskursive Konstruktion eines gemeinsamen bedrohlichen Feindes vereinheitlicht werden (vgl. Heine 2000: 259ff; Fröhlich et al. 2000: 274ff). Ab dem 19. Jahrhundert wurde dieser Feind nicht mehr als bedrohlich, sondern als »kranker Mann am Bosporus« (bzw. als »Ostfrage«) benannt, der nur aufgrund der Streitigkeiten bzw. der Machtbalance zwischen den europäischen Großmächten und Russland überlebte (vgl. Todorova 2007). Die Frage der Bildung einer »europäischen Föderation« auf der Basis der Idee Europas wurde immer mehr thematisiert, als der Kontinent gespaltener war als zuvor (vgl. Delanty 1995: 37f). ${ }^{7}$

7 Die Bildung einer europäischen Föderation wurde besonders von französischen Eliten diskutiert: Europa als das Zentrum der Welt und Frankreich als das Zentrum Europas (vgl. Pocock 2002: 62ff). »[N]o one wrote more authoritatively about Russia than Voltaire, who never travelled east of Berlin, and no one was engaged more passionately and creatively on behalf of Poland than Rousseau, who never went to east of Switzerland." (Wollf 1994, zit.n. Kovác/Kabachnik 2001: 150). 
$»[\ldots]$ Europe is not a natural geo-political framework but is composed of core and number of borderlands [...]. To a very significant extent, much of the sunity< of Europe has been formed in relation to the eastern frontier and it has been possible only by violent homogenization. Unlike the western frontier, which has been a frontier of expansion, the eastern one has been a frontier of defence and has played a central role in the formation of European identity.« (Delanty 1995: 7)

Es war vor allem die Begegnung mit nicht-europäischen Gesellschaften im Westen und Osten, die die Konstruktion einer spezifischen europäischen Identität begünstigten. Die »Entdeckung« des »wilden« Amerikas und die Kolonisierung Afrikas sind in dieser Hinsicht beide historische Dimensionen der Entdeckung des »zivilen« Europas und des westlichen Selbst auf Kosten des Anderen (vgl. Coronil 2002; Mitchell 2002). Im 16. Jahrhundert war Mignolo (2000) zufolge die »koloniale Differenz« im geographischen Raum platziert, wobei gegen Ende des 18. Jahrhunderts die Geschichte Maßstab geworden ist: »Menschen mit Geschichte« konnten gegen Ende des 18. Jahrhunderts die Geschichte der »Menschen ohne Geschichte« schreiben (vgl. Mignolo 2000). Europa etablierte sich als Vorstellung eines universalen »Zivilisationsprojektes«. Die hegemonialen Signifikanten wie »Freiheit«, »Fortschritt«, »Zivilisation« und »christlicher Humanismus« konnten ohne die Konstruktion eines »despotischen« und »dekadenten« Orients nicht gedacht werden.

\section{Europäische Identität und Orient}

Die Aufklärung kennzeichnet an dieser Stelle jenes Episteme ${ }^{8}$ im foucaultschen bzw. saidschen Sinne, in dem sich der Diskurs des Orientalismus formiert hat (vgl. Stråth 2000: 28). Die moderne westliche Identität wurde definiert in der Abgrenzung zu den nicht-westlichen Anderen, aber diese waren nicht lediglich physische Orte in der politischen Geographie, sie organisierten ebenso die Grenzen des westlichen Bewusstseins (vgl. Said 1981). Der Orientalismus als Diskurs und politische Phantasie ermöglicht dem westlichen Subjekt eine politische und psychologische Positionierung. Es geht um den Diskurs eines europäischatlantischen Subjektes, das unterschiedliche nicht-westliche Gesellschaften als uniform und ewig kohärent essentialisiert, wobei der Orient unfähig ist, sich selbst zu definieren (vgl. Said 1981: 339). Orientalismus

8 Der Begriff Episteme bezeichnet jene historische und kulturell wandelbare Erkenntnisstruktur, die bestimmte Erfahrungen möglich macht und auf der Ebene der wissenschaftlichen Symbole und der Sprachbildung in den semiotischen Dimensionen der Theorien verwirklicht ist. 
repräsentiert dabei weniger »orientale« Wirklichkeiten, er ist vielmehr eine symbolische Ordnung, indem er symbolische Grenzen zwischen »Okzident« und »Orient« zieht. Die Geschichte des Orientalismus ist vor allem die Geschichte der Eindringung, der Kontrolle des Westens über den Osten (vgl. Fröhlich et al. 2000: 287f; Passerini 2002: 195f). Der Orientalismus geht für Said über den akademischen Forschungsgegenstand ${ }^{9}$ des Ostens, oder europäische männliche sexuelle Phantasien hinaus. Er dient vor allem der wirtschaftlichen, politischen und militärischen Verwaltung des Ostens und wurde somit eine diskursive Strategie des Regierens (vgl. Kahraman 2002: 160). Im Prozess der »Orientalisierung« des Ostens markierte das westliche Bewusstsein nicht nur eine epistemologische und ontologische Andersartigkeit des Ostens, sondern es hob auch die Überlegenheit der westlichen Kultur hervor. »The Other was therefore both primitive, considered as a holder of positive values with which to rejuvenate a corrupt civilisation and a touchstone for the level of progress reached by Europe, and the savage to be exploited, converted and >civilized .« (Passerini 2002: 202). Der Orientalismus spaltet die Welt in zwei Teile, in Freunde und Feinde, und schreibt dem Westen Fortschrittlichkeit und dem Osten Rückschrittlichkeit zu. Diese überlegene Position legitimierte gleichzeitig die Intervention und das Eindringen des Westens in den Osten. Der Osten wurde das PhantasieObjekt des Westens, das ihn kulturell veränderbar machte.

Die Debatte um den türkischen Beitritt in die EU zeigt uns, um die grundlegende These dieser Arbeit noch einmal hervorzuheben, einen ambivalenten dialogischen Formierungsprozess des europäischen Selbst an der Schwelle seiner türkisch-islamischen Anderen, wobei die Grenzen eines vorgestellten Europas sichtbar werden. Diese Debatte beschleunigt die Verschränkung europäischer Diskurse um die Konstruktion einer europäischen Identität, weil kollektive Identitäten sich erst in öffentlichen Kommunikationsräumen entlang narrativer Formen dialo-

9 Stuart Schaar (2000) macht darauf aufmerksam, dass nach dem Zweiten Weltkrieg, mit dem Rückgang des europäischen Orientalismus und der Dekolonisation die prominentesten europäischen Orientalisten, wie Hamilton Gibb und Gustav E. von Grunebaum (gest. 1955), die Said im »Orientalismus « untersucht hat, in die Vereinigten Staaten, das neue Zentrum des Orientalismus gegangen sind. Während Louis Massignon (gest. 1962) sich für den Dekolonisationsprozess und die Befreiung Algeriens engagierte, wurde Sir Hamilton Gibb (gest. 1971) Vorsitzender der »Mittelost-Studien« an der Harvard Universität. Grunebaum war Mitbegründer eines ähnlichen Zentrums in Los Angeles, Bernard Lewis nahm eine Stelle am »Orientale Studien Programm« der Princeton Universität an. US-amerikanische Orientalisten rationalisieren und rechtfertigen Schaar zufolge die US-amerikanische Politik im Mittleren Osten (vgl. Schaar 2000: 186ff). 
gisch formieren. Sie ergeben sich weniger durch die Geschichte per se. Die passiven vergangenen Erfahrungen werden vielmehr in der aktiven Gegenwart in bestimmten ambivalenten Momenten in der Öffentlichkeit kommuniziert und beständig rekonstruiert (vgl. Stråth 2000: 18). Sie sind zwar historisch gewachsene symbolische Konstrukte, die aber erst als Folge dialogisch-diskursiver Artikulationen in der Gegenwart beständig rekonstruiert werden (vgl. Segers/Viehoff 1999: 35).

In diesem ambivalenten Begegnungsmoment sind interaktive diskursive Praktiken entscheidend. Was »Europäer« erzählen, hat bestimmte Effekte auf türkische Erzählungen und vice versa: Indem gesprochen und gehandelt wird, werden auch die anderen gezwungen zu sprechen und zu handeln (vgl. Risse 2001). In diesem symbolischen Prozess sind nicht nur deutsche bzw. europäische Diskurse, die die Spielregeln der Identität festlegen, sondern auch die Performanz von türkischen Diskursen von Bedeutung. Sie konstruieren ihre Identität performativ mit und erzeugen Repräsentationen über Europa, wobei die Bedeutung Europas ambivalent bleibt. Die Frage, an welchen Bedeutungen und Referenzpunkten eine europäische Identität fixiert wird und wie die Türkei darauf reagiert, wird an dieser Stelle maßgeblich.

\section{Aufbau der Arbeit}

Bevor ich die Bedeutung des Ostens in der europäischen Identitätsformation im Rahmen postkolonialer Theorien ausführlicher diskutiere (Teil III), werde ich zunächst die diskurstheoretischen methodologischen Grundlagen dieser Arbeit klären (Teil II). Dabei werde ich neben Michel Foucaults Ansatz die poststrukturalistischen Diskursperspektiven von Ernesto Laclau und Chantal Mouffe, Slovaj Žižek und Michail Bakhtin einführen.

Diskurse sind für Foucault eine Form sozialer Praxis und spiegeln die gesellschaftlichen Wirklichkeiten nicht bloß wider, sondern bringen ihre Gegenstände performativ hervor. Sie werden gesellschaftlich produziert, sie prägen, gestalten und verändern wiederum gesellschaftliche Wirklichkeiten (vgl. Bublitz 1999: 23; Lorey 1999: 89). Ihre Macht liegt in den Konsequenzen, die durch Verflechtung spezifischer Diskurse mit institutionellen Feldern und sonstigen nicht-diskursiven Praktiken entstehen können (vgl. Keller 2004: 44ff). Foucault unterlässt jedoch, die Formierung von kollektiven Identitäten und die diskursive Organisation von Subjektivität und damit die dialogische Konstruktion des Selbst und des Anderen im Diskurs zu analysieren. Er rückt die Gewichtung auf die Seite der Machtverhältnisse und diskursiven Strukturen und spricht von 
Strategien der modernen disziplinären Macht, deren Reproduktion subjektlos funktioniert, und analysiert politische Subjektivitäten, die sich durch Identifikationsprozesse formieren, nur am Rande. Die foucaultschen Begriffe »diskursive Formation« und »Grenzen des Diskurses« implizieren eine geschlossene Struktur, die ungleiche Subjektpositionen für kollektive Akteure zur Verfügung stellen, die von den Akteuren zu besetzen sind (vgl. Foucault 1987; 1991).

An dieser Stelle liefern die hegemonietheoretische Diskurstheorie von Laclau und Mouffe und der psychoanalytische Diskursansatz von Žižek theoretische Impulse. Sie betonen aufgrund der Mehrdeutigkeit der Bezeichneten die Offenheit der Grenzen des Diskurses und somit die Unvollständigkeit der Identität. Identitäten sind die instabilen Identifikationspunkte oder Nahtstellen, die durch diskursive Knotenpunkte gebildet werden, indem der imaginäre Blick des Anderen konstitutiv wird. Sie sind prozesshafte diskursive Konstrukte, die keinen gesicherten Endzustand kennen und von Anderen nur durch fließende Grenzen getrennt sind (vgl. Hall 1994: 30ff). Identität bleibt somit stets unvollständig und gespalten und befindet sich immer im Prozess des Gebildetwerdens (vgl. Hall 1994: 195). Die Offenheit der diskursiven Struktur bzw. Unvollständigkeit der Identität dynamisiert das Verhältnis zwischen Subjekt und Struktur, bringt die politische Subjektivitäten hervor und ermöglicht somit den Subjekten, sich in bestimmten historischen Hegemonieformationen entlang privilegierter Knotenpunkte $\mathrm{zu}$ integrieren bzw. zu desintegrieren.

Die Identitätskonstitution von Žižek und Laclau ist zwar dialogischantagonistisch konzipiert. Die Botschaft des kommunikativen Zeichens wird jedoch in die Welt entlassen, ohne dass klar ist, wann und wie sie ihren Empfänger erreicht; ob sie bei ihren Adressaten jemals ankommt. Zum Schluss werde ich daher den Begriff Dialogizität von Bakhtin (2001) einführen. Damit möchte ich das dialogisch-diskursive SelbstAndere-Verhältnis konkretisieren, das bei Foucault unbehandelt bleibt und für Žižek weitgehend unmöglich ist. Diskurse existieren nicht isoliert, sondern im Dialog, meistens in Kontrast und Opposition zu anderen Aussagen und Diskursen (Bakhtin 2001: 312). Die Identifikation eines handelnden Subjektes formiert sich in ständiger Auseinandersetzung mit dem Blick des Anderen. Das Selbst ist konfrontiert mit vielfältigen Alteritäten. Es formiert sich in einem offenen dialogischen Artikulationsprozess, der einerseits von seiner Alterität lebt und andererseits von ihr negiert und in Frage gestellt wird (Mills 1997: 11; Irzık 2001: 14).

Stärker als Foucault akzentuiere ich also erstens die Heterogenität und Offenheit des Diskurses, was als die Unvollständigkeit der symboli- 
schen Ordnung bezeichnet werden kann, und zweitens die Subjektivität des Anderen, was die Unvollständigkeit des Selbst bedeutet. Diese doppelte Unvollständigkeit dynamisiert das Verhältnis zwischen dem Selbst und dem Anderen und stellt den Identifikationsprozess zwischen beiden auf Dauer. Um sich selbst zu konstruieren, ist das Selbst immer auf den betrachtenden Blick des Anderen angewiesen. Aufeinander Reagieren dynamisiert den Diskurs und somit ist niemand in der Lage, die Bedeutung endgültig zu fixieren. Die politische Subjektivität formiert sich aufgrund der Mangelhaftigkeit der symbolischen Strukturen.

Unter diesen beiden diskurstheoretischen Gesichtpunkten werde ich die Bedeutung des Ostens im Formierungsprozess der westeuropäischen Identität im Rahmen der postkolonialen Theorien rekonzeptualisieren, in der Edward Said eine wichtige Figur ist. Geprägt von der foucaultschen Diskurstheorie konzipierte Said den Orient als eine »imaginative kulturelle Geographie«, als eine westliche Erfindung, die als Folge diskursiver und institutioneller Praktiken der westlichen wissenschaftlichen Disziplinen und ideologischen Annahmen entstanden ist (vgl. Said 2003: 60, 199). Said bleibt jedoch, erstens, historisch und räumlich bei den heterogenen und widersprüchlichen westlichen Repräsentationen über den Orient stehen. Er übersieht die diversen diskursiven Positionierungen um die Hegemoniebildungen innerhalb der Kontexte westlicher Gesellschaften. Er ignoriert zweitens, die politische Subjektivität des Anderen im Kontext der nicht-westlichen Gesellschaften. In seiner Theorie des Orientalismus gibt es einen immanenten foucaultschen Diskursbegriff, der lediglich vom Westen generiert wird. Der Kolonisierte verbleibt in dieser Theorie passiv und sprachlos. Said vernachlässigte die komplexen und widersprüchlichen Aneignungspraktiken und Subjektivitäten des orientalischen Anderen sowie seine nach innen gerichteten Machtpraktiken im kolonialen Kontext. Dabei ist es von zentraler Bedeutung, welche diskursiven Interaktionen und symbolischen Zusammenhänge zwischen westlichen und nicht-westlichen Diskursen stattfinden, wie also die westlichen Figuren von nicht-westlichen internalisiert werden und auf welchen thematischen Feldern sich Dissense und Konsense formieren. An dieser Stelle werde ich den Begriff »Okzidentalismus« von Meltem Ahıska (2005) und Xiaomei Chen (2001) einführen. Okzidentalismus, verstanden als die Summe von (ambivalenten) Westund Ostrepräsentationen, die in nicht-westlichen Gesellschaften konstruiert werden, beschreibt die Performativität der diskursiven Praktiken des Anderen. Er formiert sich in einem hegemonialen dialogischen Verhältnis mit dem Orientalismus, in dem er stets versucht, ihn zu beantworten, wobei der Blick des Anderen angeeignet wird. 
Im Teil IV werde ich die zentralen Strukturelemente der türkischen Modernität und die Bedeutung Europas (des Westens) im türkischen nationalen Imaginären skizzieren. Die dominante These bezeichnet die türkische Modernität als »Imitation« nach einem vorgestellten westlichen Modell, das von oben initiiert wurde. Diese These problematisiert die »defizitären« Strukturelemente der Türkei und argumentiert, dass während die westlichen Gesellschaften die Modernisierung als Prozess erlebten, sie in der Türkei zu einem Projekt gemacht wurde, in Laufe dessen westliche Normen, Werte und Technologien in die Türkei importiert wurden (vgl. Mardin 1998; 2003a; 2003b; Keyder 1998; Göle 1998; Kadıoğlu 1996). Ferner wird die Rolle von Eliten im türkischen Modernisierungsprozess herausgearbeitet, insbesondere der Bürokraten und des Militärs, sowie die Kontinuität zwischen dem Osmanischen Reich und der Türkischen Republik bezüglich ihres autonomen Staatsverständnisses (vgl. Heper 1993; Karaosmanoğlu 1993).

Zum Schluss werde ich im Rahmen der Theorie des Okzidentalismus über das Argument der "von oben durchgesetzten Imitation« hinausgehen, um die Aufmerksamkeit auf die türkische Subjektivität und die internen symbolischen Ausschlusstechniken zu konzentrieren. Es geht dabei darum, zu zeigen, wie sich die diskursiven Praktiken des türkischen Anderen in Beziehung zum deutschen und europäischen Diskurs setzen oder abgrenzen und wie sie sich selbst und Europa repräsentieren. Die Subjektivität des türkischen Anderen formiert sich genau an dieser imaginären Schwelle, an der Grenzziehungspolitik zwischen »westlichen Ideen und Techniken« und »östlichen Werten und Traditionen«. Sie operiert zwischen dem, was als gut und nützlich gedeutet und angeeignet werden soll, und dem, was als schädlich und unangemessen betrachtet wird und abgelehnt werden soll.

In den folgenden beiden Teilen werde ich die empirischen Ergebnisse der vorliegenden Arbeit vorstellen. Dazu werde ich die Dezemberausgaben von drei türkischen und drei deutschen überregionalen Zeitungen von 1997, 1999, 2002 und 2004 untersuchen. Zuerst sollen Strukturmerkmale des türkischen und deutschen diskursiven Feldes anhand eines deskriptiven Verfahrens veranschaulicht werden (Teil V). Es geht mir hier darum, die Akteure, Themen(-auswahl), Deutungsstrategien und diskursiven Interdependenzen in den jeweiligen deutschen und türkischen Kontexten einzubetten. Folgenden empirischen Fragen wird dabei nachgegangen: Entlang welcher Regeln, thematischen Entscheidungen und Begriffe kommunizieren die Diskurse? Entlang welcher Deutungsund Argumentationsstrategien werden Gemeinsamkeiten und Differenzen markiert? In welchen thematischen Feldern formieren sich Konfliktlinien, welche diskursiven Verschränkungen bzw. diskursiven Löcher 
werden sichtbar? Die thematischen Entscheidungen, Diskursstrategien, Rahmen und gegenseitig erzählten Geschichten zeigen uns hierbei die Resonanzstrukturen in der jeweiligen Gesellschaft. Sie zeigen uns, wo und inwieweit die Akteure sich im Diskurs positionieren. Die Aufmerksamkeit wird dabei insbesondere auf die intertextuelle Formierung des Diskurses zwischen den türkischen, deutschen und europäischen Akteuren jenseits der nationalen Öffentlichkeiten gelenkt.

Nachdem die dominanten Topoi des diskursiven Feldes identifiziert und Typologien von europäischen und türkischen Diskursen rekonstruiert worden sind, soll in einem zweiten Schritt (Teil VI) anhand interpretativer Verfahren die Frage nach den Prozessen der Identitäts- und Hegemoniebildung im Verhältnis des europäischen Selbst zum türkischen Anderen im Mittelpunkt stehen. Dafür werden bestimmte exemplarische Artikel in den untersuchten Tageszeitungen ausgewählt und vertiefend analysiert, um die sprachliche Realisierung der Diskursstrategien in ihrer Dynamik zu erfassen. Wie repräsentieren die türkischen und deutschen bzw. europäischen Diskurse sich selbst und den Anderen in dem untersuchten Zeitraum? Entlang welcher Knotenpunkte setzten sich die diskursiven Praktiken des türkischen Anderen in dialogische Beziehung zu den europäischen Diskursen und entlang welcher dominanten Erzählungen grenzen sie sich $\mathrm{ab}$, in welchen diskursiven Feldern werden die türkischen und europäischen symptomatischen Stimmen sichtbar?

Im Folgenden werde ich die diskurstheoretischen Rahmenbedingungen der vorliegenden Arbeit vorstellen. 


\section{Diskurstheoretische Rahmen}

Mit dem Eintreten der Sozialwissenschaften in eine postpositivistische Phase seit den 1970er Jahren (»linguistic turn«) haben symbolische Ordnungen und Kommunikation zur Vermittlung der sozialen und politischen Beziehungen als Untersuchungsgegenstände an Bedeutung gewonnen. Der Prozess der diskursiven Produktion, Institutionalisierung und Transformation von Wissensverhältnissen ist somit ein zentraler Gegenstand der sozialwissenschaftlichen Untersuchungen geworden. Der Kampf um die politische Macht verwandelt sich in einen Kampf um die Deutungsmacht und deren Durchsetzung anhand symbolischer Grenzziehungen. Es geht dabei weniger um die Analyse gesellschaftlicher Ereignisse, sondern vielmehr um die über diese Ereignisse in den öffentlichen Räumen kommunizierten Diskurse ${ }^{1}$, wobei nicht das

1 Der Begriff »Discourse« bedeutet im angelsächsischen Sprachraum einfach ein Gespräch. In der romanischen Sprache ist »discours« (Discorso) die Bezeichnung für eine »gelehrte Rede«, eine Abhandlung, eine Vorlesung oder ein Predikt. Er hat sowohl empirische als auch normative Komponenten. Die empirische Verwendung des Diskursbegriffes umfasst die Analyse von mündlichen und schriftlichen Texten und untersucht die formalen Regel- und Inhaltstrukturen dieser Texte. Die normative Komponente des Begriffes versteht Diskurs als kommunikatives Verfahren, das an Regeln der Argumentation und Rechtfertigung orientiert ist. Die öffentlichen Konfliktlösungsprozesse sollen diskursiv, d.h. argumentativ und überzeugend sein. In der deutschen Sprache kennzeichnet »Diskurs« meist ein öffentlich diskutiertes Thema, eine spezifische Argumentationskette oder eine Position eines politischen Akteurs. Auch im sozialwissenschaftlichen Gebrauch wird er unterschiedlich definiert, sowohl bezüglich der theoretischen Konzeptionalisierung als auch in der methodischen Umsetzung. Insbesondere wirken sich französischer Strukturalismus und Poststrukturalismus, im Rückgriff auf die Sprachtheorie von Ferdinand de 
Schwert, sondern die Waffe des Wortes zum Einsatz gebracht wird (vgl. Eder 1998: 37). Dabei haben seitdem diskurstheoretische Perspektiven in Sozial- und Kulturwissenschaften an Bedeutung zugenommen, wobei insbesondere Michel Foucault eine zentrale Rolle einnimmt.

Foucault bemüht in seinen früheren $W_{\text {erken }}^{2}$ bestimmte Instrumente der Sprachwissenschaften, um eine Gesellschaftstheorie zu entwerfen und das soziale Leben auf ein Regelsystem zurückzuführen, welches das Unbewusste der Sprecher steuert (vgl. Dreyfus/Rabinow 1987: 133). Er beschäftigt sich mit der Frage, welche symbolischen Ordnungen in spezifischen historischen Zeitabschnitten bestimmte Wahrheiten als wahren Diskurs funktionieren lassen, ohne Stellung zu deren Wahrheits- und Sinngehalten genommen zu haben (vgl. Diaz-Bone 1999: 119). Dabei versucht er das in den Diskursen und Praktiken enthaltene epistemologische Grundmodell aufzuklären. Das Subjekt wird somit in den Erfahrungskontext eingebaut, wobei historische Erfahrungsstrukturen gegenüber der Idee eines erkennenden Subjektes in den Vordergrund gestellt werden (vgl. Kögler 1994: 30f; Megill 1998: 306f).

Für die foucaultsche Diskurstheorie ist somit eine Subjektivität außerhalb von Diskursen nicht möglich, da Diskurse sowohl unsere Wahrnehmung der Realität als auch unsere Identifikation und De-Identifikation strukturieren (Howarth/Stavrakakis 2000; Jäger 2001: 148). Das ist die Performativität ${ }^{3}$ des Diskursiven. Foucault weist darauf hin, dass der Diskurs einen Raum von ungleichen und differenzierten (Macht-)Positionen und Funktionen für die Subjekte ermöglicht (vgl. Mills 1997: 12ff). Es geht darum, wer legitimerweise an welchem Ort und zu wel-

Saussure (1967) und Levi Strauss`Ethnologie und Kulturanthropologie seit Mitte der 1950er Jahre, auf den heutigen theoretischen und konzeptionellen Gebrauch des Diskursbegriffes aus (vgl. Keller 2004: 14ff).

2 Die foucaultsche Diskurstheorie ist von Diskontinuitäten gekennzeichnet. Dabei ist die Rede von zwei bzw. drei Perioden. In seiner »diskursiven Periode $«$ - »Die Ordnung der Dinge und Archäologie des Wissens « - untersucht Foucault Denksysteme, die sich entlang diskursiver Praktiken materialisieren und anhand archäologischer Verfahren zu rekonstruieren sind. In der »machttheoretischen Periode $«$ - »Überwachen und Strafen«, »Der Wille zum Wissen«, »Geschichte der Sexualität I« - beschäftigt er sich mit Handlungssystemen und Machtverhältnissen, die Effekte auf andere Handlungen zur Folge haben. Und schließlich geht es ihm in der »ethischen Periode« um »subjekttheoretische Fragestellungen« und um das $\mathrm{Zu}$ sammenspiel zwischen Disziplinärtechnologien und ethischen Selbstbildungstechnologien (vgl. Bührmann 2004; Angermüller 2005; Dreyfus/ Rabinow 1987).

3 Die Ideologietheorien von Gramsci und Althusser prägen Foucaults Diskurstheorie bezüglich der Performativität von diskursiven Praktiken. Die Individuen haben für Althusser ein indirektes, imaginäres Verhältnis zu den realen Verhältnissen, unter denen sie leben (vgl. Althusser 2000). 
cher Zeit in welcher Form über bestimmte Gegenstände sprechen kann und darf.

»Niemand kann in die Ordnung des Diskurses eintreten, wenn er nicht gewissen Erfordernissen genügt, wenn er nicht von vornherein dazu qualifiziert ist. Genauer gesagt: nicht alle Regionen des Diskurses sind in gleicher Weise offen und zugänglich; einige sind stark abgeschirmt (und abschirmend), während andere fast allen Winden offen stehen und ohne Einschränkung jedem sprechenden Subjekt verfügbar erscheinen.« (Foucault 1991: 26)

Nach dieser Auffassung bedienen sich die Subjekte in den Erzählungen über sich Selbst und Andere symbolisch-diskursiver Ressourcen und Strategien, die ihnen in der entsprechenden Zeit und dem jeweiligen Raum zur Verfügung stehen, und somit explizieren sie sich Selbst und den Anderen (vgl. Jäger 2001: 133f). Durch die Wiederholung von Argumenten und Symbolen werden den Subjekten bestimmte Positionen angeboten, die von ihnen eingenommen werden. Anstelle von Diskursen sind es in der späteren foucaultschen Theorie ${ }^{4}$ Machtformen, die aus Individuen Subjekte machen (vgl. Foucault 1987: 246). Macht setzt individuelle oder kollektive »freie Subjekte« voraus. Nicht auf Sklaven, sondern auf freie Subjekte wird Macht ausgeübt. Die freien Subjekte können wiederum unterschiedliche Reaktionen und Verhaltensweisen gegenüber der Machtausübung zeigen: Entweder werden sie diese hinnehmen und internalisieren oder in bestimmten Fällen Resistenz zeigen und damit wiederum andere Machtbeziehungen produzieren und provozieren. Macht und Freiheit stehen in einem paradoxen Verhältnis, sie schließen einander nicht aus, sondern befinden sich in einem komplexen Spiel, in dem Freiheit die Existenzbedingung der Machtausübung wird. Statt von einem Antagonismus sollte Foucault zufolge von einem Agonismus zwischen »freien Subjekten« und Macht gesprochen werden, sie blockieren sich nicht, sie provozieren und reproduzieren sich dauerhaft gegenseitig (vgl. Foucault 1987: 255f).

4 Ab Mitte der 1970er Jahre beschäftigt er sich mit Handlungssystemen und Machtverhältnissen, der Disziplinierung des Körpers bzw. Disziplinarund Selbsttechnologien, die sowohl einen neuen Machttypus in den modernen (europäischen) Gesellschaften hervorbringen, der kontinuierlich, disziplinär und anonym ist, als auch neue Subjekttypen, die als Folge dieser Machtverhältnisse erschienen sind. Er macht auf das komplexe $\mathrm{Zu}$ sammenwirken zwischen Disziplinär- und Selbsttechnologien aufmerksam, die im engen Verhältnis zueinander stehen und als solche in die Herrschaftsstrukturen integriert sind (vgl. Dreyfus/Rabinow 1987: 200ff). 
»Subjektkonstruktion erfolgt durch Gegenstandskonstruktion, dadurch, dass es sich selbst und andere zum Gegenstand diskursiver Praktiken macht. Das >Andere «, Abweichende wird ebenso als Objekt von Wissenspraktiken konstruiert wie das >normale Subjekt, das sich zum Maßstab aller Dinge, so auch >der anderen «acht; darin bestehen Normalisierungsprozesse in modernen Gesellschaften. Normalität wird primär über das Abweichende konstituiert.« (Bublitz 1999: 35)

Die Objektivierung des Subjektes, die Foucault »Teilungspraktiken« nennt, führt einerseits zu gesellschaftlichen Hierarchien und Ausgrenzungen, zur Totalisierung und Vereinheitlichung der Bevölkerung andererseits (vgl. Kögler 1994: 47). Die Subjekte werden entweder von Inneren geteilt oder von Anderen abgeteilt, was sie zu Gegenständen macht. Das praktische Äquivalent zur symbolischen Ausgrenzung operiert dann gemäß der Aufteilung in Verrückte und geistig Normale, in Kranke und Gesunde, in kriminelle und anständige Jungs (vgl. Foucault 1987: 243). Eine zentrale Kritik Foucaults ist, dass die Vernunft durch Ausgrenzung und Objektivieren des Wahnsinns als ihr Anderes existieren und operieren kann. Gerade diese Erfahrung mit dem Wahnsinn erhält die eigentliche tiefere Wahrheit über die menschliche Existenz in der Welt. Das sich selbstherrlich etablierende Vernunftobjekt nimmt im Wahnsinn nur noch das Fehlen seiner Selbst, die Leere und Negation der Vernunft wahr (vgl. Kögler 1994: 19ff).

Die Stärke der foucaultschen Diskurstheorie ist der Versuch, sowohl die symbolisch-semantischen als auch die institutionell-praktischen Mechanismen, die das Auftauchen spezifischer Aussagen bestimmen, zu rekonstruieren. Ein zentrales Problem ist es jedoch, die Grenzen des foucaultschen Diskurses auszumachen. Foucault unterlässt erstens die diskursive Organisation von Subjekt und Subjektivität und damit die Stellung des Selbst und des Anderen im Diskurs genauer zu prüfen. Sein Begriff der »Subjektposition« geht auf die französischen Strukturalisten, insbesondere auf die »ideologische Anrufung« Althussers zurück: Es wird unterstellt, dass das ideologische Subjekt seine Position als Agent des sozialen Prozesses wahrnehmen und diese Position voll besetzen kann (vgl. Žižek 1989: 251f). Die Anrufung wirkt jedoch niemals vollständig, es gelingt ihr zwar, dem Subjekt einen Standort anzuweisen, aber es ist niemals mit diesem Ort deckungsgleich. Subjekte und symbolische Ordnungen bleiben aufeinander angewiesen.

Im foucaultschen Machtkonzept wird zweitens von globalen Machtstrategien gesprochen, die die Subjekte disziplinierten, überwachten und unterwürfen. Alle Widerstände und Oppositionen seien nur angebliche Widerstände, die die Macht nicht herausforderten, sondern reproduzier- 
ten und provozierten. Subjektivität wird somit die Existenzbedingung der Machtausübung. ${ }^{5}$ Foucaults Subjekt kann der Unterwerfung unter die moderne disziplinäre Machtmatrix nicht entkommen, es befindet sich in einer Sackgasse (vgl. Žižek 1989: 251f; 2003: 299ff). Macht ist omnipräsent und allgemein, so dass sie keine analytische Klärung mehr ermöglicht (vgl. Knoblauch 2001: 212). Sie kann für Foucault nicht geeignet werden, da sie aus vielfältigen und beweglichen Kräfteverhältnissen besteht und einen dezentralen und relationalen Charakter in einer bestimmten Zeit und Gesellschaft hat (vgl. Seier 1999: 81; Jäger 2001: 152f). Der hegemonietheoretische psychoanalytische Diskursansatz von Žižek sowie Laclau und Mouffe leistet in dieser Hinsicht einen entscheidenden Beitrag zur diskursiven Konstruktion von kollektiven Identifikationen, politischer Subjektivität und symbolischer Integration von gesellschaftlichen Differenzen, die Foucault nicht genau ausarbeitete.

\section{Identifikation und politische Subjektivität}

Laclau und Mouffe beobachten die Konstruktion von kollektiven Identitäten, die durch diskursive Artikulationsprozesse hergestellt werden. Diskurs wird dabei nicht als eine Ebene sozialer Wirklichkeit entworfen, sondern wird das »Medium«, in dem gesellschaftliche Wirklichkeit verhandelt und festgehalten wird. Ökonomie und Staat sind wie jede andere »Sphäre« der Gesellschaft diskursiv strukturiert und werden somit zum Terrain politischer und hegemonialer Artikulation (vgl. Marchart 2007: 108ff). Das Politische wird verstanden als strategisches Terrain hegemonialer Artikulationen, das alle Bereiche der Zivilgesellschaft, der Ökonomie wie auch des Staates im engeren Sinne umfasst.

Obwohl Diskurse bestimmte feststehende Subjektpositionen anbieten, stehen die Subjekte fast immer im Schnittfeld mehrerer und unterschiedlicher Diskurse und damit Subjektpositionen. Es hängt davon ab, inwieweit sich die Subjekte mit welchen Positionierungsangeboten identifizieren. Diese Identifikation ist allerdings auch nicht etwas Verfestigtes, sondern ein Prozess in Bewegung (vgl. Stäheli 1999: 155f). Jede Identität ist ex-zentriert, weil erst durch den Anderen eine (entfremdete) Einheit möglich wird: eine Lücke zwischen Selbst und seinem Anderen, die als solche ambivalent und ungefüllt bleibt (vgl. Žižek 1989: 254). Es wird versucht diese unvollständige symbolische Struktur bzw. diese Be-

5 Foucault unterscheidet laut Lisa Lowe zwischen kulturellen Designationen von Utopien, welche imaginäre Inversionen des realen Raumes von Gesellschaft sind, und Heterotopias, die den Raum der Alterität beschreibt, einen Raum von Krisen und Devianzen (vgl. Lowe 1991: 15f). 
deutungsüberschüsse durch soziale Phantasie aufzuheben, welche wiederum durch unterdrückte oder ausgeschlossene Stimmen (Symptome) versetzt wird. Diese Versetzung löst ihrerseits neue diskursive phantasmatische Artikulationen aus, um die »Risse « in der symbolischen Ordnung zu nähen. Der psychoanalytische Ansatz dynamisiert also den Identifikationsprozess und die Hegemonieformation, indem auch Möglichkeiten für Subjekte und Subjektivität entstehen. Es ist dies nicht der Fehlschlag der Identifikation, sondern des Identifikationsprozesses, in welchem die Erzeugung einer stabilen geschlossenen Identität misslingt. Dieser Fehlschlag, diese Unmöglichkeit, macht wiederum den Identifikationsprozess konstitutiv. Subjektivitäten entstehen durch Identifikationen aufgrund des strukturellen Mangels des Subjektes und der symbolischen Struktur (vgl. Alcorn 1994: 20ff).

Es werden zwei Formen von Differenzen sichtbar: einerseits die Differenzen innerhalb eines Diskurses, andererseits eine konstitutive Differenz, die den Diskurs von seinem Außen trennt (vgl. Stäheli 2001: 197). Der negative Bezug auf das, was eine Identität nicht ist, führt zur Neutralisierung der internen Differenzen und Elemente eines Diskurses und erzeugt eine Identität, indem sie sich vom konstitutiven Außen trennt. ${ }^{6}$ Diese »Logik der Äquivalenz« wird stets in Frage gestellt durch die »Logik der Differenz.« Letztere macht die Differenzen im Diskurs sichtbar, erweitert das sozial-politische Feld, macht es komplexer und somit die vollständige Schließung des Diskurses unmöglich (vgl. Laclau/ Mouffe 1992: 162ff).

»The logic of difference tends to expand the syntagmatic pole of language, the number of positions that can enter into a relation of combination and hence of

6 Die laclausche und žižeksche Diskurstheorie, die an Lacan anschließt, sprengt die geschlossene, kreisförmige Beziehung zwischen angerufenem Subjekt (Selbst) und anrufender Instanz (Ideologie bzw. diskursive Ordnung). Sie ist geprägt von der lacanschen Diskurs- bzw. Subjekttheorie. In der lacanschen Subjekttheorie führen weder das Imaginäre noch symbolische Identifikationen zur einen stabilen gesicherten Identität, da der Bruch, die Spaltung zwischen dem Bewussten und dem Unbewussten, sowohl auf der imaginären als auch auf der symbolischen Ebene bestehen bleibt. Die Konstruktion des Selbst ist unstabil, da es auf die Ansicht des Anderen angewiesen ist. Das Subjekt kann erst durch das Bild, das es sich von sich selbst macht, sich selbst überblicken, ein Subjekt, das unterworfen und dezentriert zugleich ist, welches Lacan »sujet décentré« nennt (vgl. Torfing 1999: 86). Es handelt von einem zerrissenen und entfremdeten Selbst, das ein externes Anderes braucht, um eine einheitliche Identität zu bekommen. Diese konstitutive Abhängigkeit einer jeden imaginären Identität von einer nie durch das Selbst vollständig internalisierbaren entfremdeten Externität unterwandert die Idee einer stabilen Identität (vgl. Stavrakakis 1999: 18; Lowe 1991: 145; Zima 2000: 260). 
continuity with each other; while the logic of equivalence expands the paradigmatic pole - that is the elements that can be substituted for one another thereby reducing the number of positions which can possibly be combined." (Laclau/Mouffe 1985, zit.n. Stavrakakis 1999: 76)

In der Logik der Äquivalenz wird dagegen das sozial-politische Feld durch die Spaltung der Gesellschaft auf zwei Fronten vereinfacht. Die Subjektpositionen werden auf zwei Pole reduziert, symbolisiert durch z.B. Paradies und Hölle oder Freund und Feind. Das politische Feld wird durch die Expansion der paradigmatischen Pole von Bedeutungen vereinfacht. Die Logik der Metapher wird dominant, sie ist exkludierend und spaltend. In der Logik der Differenz werden alle sozialen Spaltungen von einer illusionären Gesellschaftskonzeption, die alle Differenzen und Forderungen zu umgreifen verspricht, absorbiert (vgl. Howarth/ Stavrakakis 2000: 11f). Nach dem Motto: »wir sind eine Familie« oder »wir sind eine Nation«. Unterschiedliche gesellschaftliche Positionen werden gemäß einer metonymischen politischen Logik kombiniert. Sie ist einschließend (vgl. Laclau/Mouffe 1992: 162ff). Äquivalenz und Differenz stehen in einem antagonistischen ambivalenten Verhältnis, in dem keines sich endgültig zu etablieren in der Lage ist. Laclau zufolge sind diese beiden Logiken gleichzeitig vorhanden und wirksam. Da Differenzsysteme instabil sind, werden die symbolischen Ordnungen niemals vollständig konstituiert: Die Gesellschaft ist unmöglich. Irgendetwas fehlt immer, um die Bedeutung endgültig zu fixieren. Es gelingt also der Logik der Äquivalenz aufgrund dieses Widerspruches niemals vollständig, die nicht diskursiv artikulierten Elemente (aufgrund ihres Fluktuierens) in die diskursiv artikulierten Momente (differenzielle Positionen) zu transformieren und damit die Einheit der diskursiven Totalität herzustellen (vgl. Laclau/Mouffe 1992: 163). In diesem Sinne bedeutet die Unstabilität gesellschaftlicher Beziehungen, dass hier die Logik der Äquivalenz die Logik der Differenz dominiert. Das bedeutet, dass die antagonistischen Elemente und kollektiven Identitäten in dieser Gesellschaft so zunehmen, dass diese Zunahme die Versuche erschweren würde, ein diskursives hegemoniales Zentrum zu konstruieren. 


\section{Diskursive Knotenpunkte und politische Phantasie}

Laclau und Mouffe reformulieren Gramscis Hegemoniebegriff ${ }^{7}$ diskurstheoretisch. Die Frage, wie symbolische Schließungen möglich werden, wird von Laclau so beantwortet, dass die politischen Kämpfe Versuche sind, bestimmte privilegierte Signifikanten an bestimmte partikuläre Signifikat-Konfigurationen zu fixieren (vgl. Laclau 1993: 35). Laclau greift hier auf den lacanschen Begriff des »leeren Signifikanten« zurück. Die leeren Signifikanten sind jene privilegierten diskursiven Punkte, die die Aufgabe übernehmen, diskursive Differenzen zu entleeren und die Identität des Diskurses als etwas einheitliches Ganzes zu repräsentieren (vgl. Howarth/Stavrakakis 2000: 7ff). Es sind die Symbole und Begriffe, deren Bedeutung unbestimmbar geworden sind, wie z.B. Freiheit, Gerechtigkeit, Demokratie etc. »Je stärker der Signifikant von einer Bedeutung entleert werden kann, umso besser eignet er sich dafür, die Äquivalenz der unterschiedlichen diskursiven Elemente zu symbolisieren.« (Stäheli 2001: 201)

7 In der marxistischen Tradition wird die Hegemonie als politische Herrschaft bzw. ökonomische Unterdrückung der Arbeiterklasse durch die bürgerliche Klasse und ihre Verbündeten definiert. Gramsci erweitert diese Definition um komplexe Relationen von sozialen, kulturellen und ideologischen Praktiken, durch die die herrschende Klasse ihre politische und kulturelle Herrschaft ausübt. Sie beschreibt den gesamten Prozess von Verhandlungen, Dissens- und Konsensbildungen, indem andere gesellschaftliche subalterne Gruppen in einen »historischen Block« integriert werden. Hegemonie ist für Gramsci moralische kulturelle Führerschaft einer Klasse über alle anderen Klassen, indem auch der Konsens der gegnerischen Klassen organisiert wird. Das hegemoniale Subjekt ist bei Gramsci zwar eine soziale Klasse, sie wird jedoch nicht als völlig stabiles dauerhaftes Gebilde konzipiert, sondern sie ist dynamisch und prekär in einem Feld beständiger Kämpfe um die hegemoniale Position (vgl. Keller 2004: 28). Hegemonie kennzeichnet für Gramsci zwar die Interessen von herrschenden Klassen, aber das Subalterne erhält Möglichkeiten, Resistenz zu zeigen, welche wiederum mit Kompromissen der beiden Seiten reproduziert wird (vgl. Lowe 1991: 16f). Hegemonie wird als Organisation von Konsensbildung verstanden, wo die beherrschten Gruppen und Identitäten integriert werden, primär nicht durch Zwang, sondern vielmehr durch passive oder aktive Zustimmung. Die zentrale Frage ist: Wie kann der Staat ohne Zwang regieren? Diese Frage hat Gramsci dazu geführt, sich auf nicht zwingende Dimensionen der Herrschaftsstruktur zu konzentrieren, nämlich auf die symbolischen Praktiken und Mechanismen (vgl. Barrett 2004: 79 ff ). 
Jeder Signifikant bezieht sich auf andere Signifikanten, die metonymische Kombination und metaphorische Substitution ${ }^{8}$ kann als ohne Ende beschrieben werden. Aber dieses endlose Spiel wird von bestimmten prominenten Signifikanten gestoppt. Diese privilegierten Signifikanten oder Referenzpunkte werden »diskursive Knotenpunkte« (entlehnt Lacans »point de capiton«) genannt (vgl. Laclau/Mouffe 1992: 140). Sie stoppen die endlosen Bewegungen von Signifikation und fixieren die Bedeutung der gesamten Kette von Signifikanten. Diese Fixierung ist jedoch nicht stabil, sondern relativ und temporär. Der partikuläre Inhalt der diskursiven Knotenpunkte spiegelt keine pre-symbolische objektive Realität, sondern ist eben Ergebnis der symbolischen hegemonialen Kämpfe (vgl. Stavrakakis 1999: 60).

Für Laclau und Mouffe sind antagonistische Formationen im Prozess von Hegemoniebildungen für politische Subjektivitäten entscheidend. Hegemonie formiert sich genau an dem Ort, wo sich die Antagonismen schneiden, und sie setzt symbolische Äquivalenzen und Effekte von symbolischen Grenzen voraus. Die hegemoniale Artikulation hat also zwei Bedingungen, erstens das Vorhandensein von antagonistischen Kräften und zweitens die diffusen und unsicheren Grenzen zwischen diesen beiden Kräften. Es besteht die Möglichkeit, dass die Elemente sich zu gegensätzlichen Fronten zusammenschließen. Diese Fronten müssen stetig reartikuliert werden. Ohne die Äquivalenzen und diffusen symbolischen Grenzen kann nicht von Hegemonie gesprochen werden, sondern nur von totalitären Machtstrukturen. Es ist der Moment der Äquivalenz, in dem die Hegemonie durch diskursive Knotenpunkte hergestellt und ein relativ einheitliches gesellschaftliches und politisches Gebilde konstruiert wird; Gramsci verwendet hierfür die Bezeichnung »historische Blöcke«. Die Verbindung zwischen (Klassen-)Interessen, ihren Identitäten und Subjektpositionen im Diskurs ist nicht essentiell, sondern kontingent (Laclau/Mouffe 1992: 98ff, 152ff, 170f). Relevant ist, dass Differenzen erst durch symbolische Praktiken eliminiert werden, diskursive Elemente durch artikulatorische Praktiken in Verbindung gebracht, Bedeutungen fixiert und überhaupt hegemoniale kollektive Identifikationen und Subjektpositionen erst auf dieser symbolischen Ebene möglich werden.

8 Laut Howarth/Stavrakakis (2000) unterscheidet Jacobson zwischen Metonymie und Metapher: Metonymie betont die Dimension von Kontinuität und Verkettung. Metapher ist dagegen die Dimension der Substitution (Auswechslung, Ersatz). Diese beiden sind der Schlüssel für die Produktion von Bedeutung, aber auch die Möglichkeit zur Artikulation neuer Bedeutungen. Geprägt vom jacobsonschen Unterschied entwickeln Laclau und Mouffe die Begriffe Äquivalenz und Differenz (vgl. Howarth/Stavrakakis 2000: 5). 
Die Hegemonialität eines Diskurses ist jedoch lediglich eine Tendenz, da die verfügbaren Sinnordnungen aufgrund Antagonismen, Brüchen und Konflikten immer in Bewegung sind (vgl. Keller 2004: 53). In einem System von Äquivalenzen und Differenzen, in dem die Bedeutung jedes Momentes fixiert und geschlossen wäre, in dem Diskurse und Identitäten sich vollständig realisiert hätten, gäbe es für die hegemonialen Praktiken keinen Platz und alle Praktiken hätten lediglich eine sich wiederholende Funktion (Laclau/Mouffe 1992: 168). Diverse Gruppen integrieren sich also durch einen Begriff, der alle politischen Differenzen zu eliminieren und partikuläre Bedeutungen miteinander zu vernähen in der Lage ist, für ein gemeinsames Ziel. ${ }^{9}$ Hegemonie wird hier somit als ein Kampf von partikulären Bedeutungen verstanden.

Wenn Žižek (und Laclau und Mouffe) von der Unmöglichkeit der Identität sprechen, dann meinen sie damit, dass das Soziale um eine konstitutive Unmöglichkeit herum strukturiert ist, um einen Antagonismus, und es ist die Aufgabe des ideologischen Phantasmas, diesen Antagonismus zu maskieren. Die strukturelle Unmöglichkeit einer geschlossenen Gesellschaft, der Riss, der die Gesellschaft durchzieht, wird mittels der Verkörperung der Unmöglichkeit in der Gestalt des fremden Anderen abgedeckt. Mit anderen Worten: Der Diskurs versucht, die grundlegende Differenz zwischen dem Realen, verstanden als Überschuss von Bedeutungen, und dem Symbolischen zu verdecken, indem er innerhalb der symbolischen Ordnung ein Objekt (Anderes) erzeugt, das den Blick auf die Differenz verdeckt. An die Stelle der strukturellen Unmöglichkeit wird dieses Objekt gesetzt, welches für eben diese Un-

9 Žižek gibt diesbezüglich ein Beispiel aus Osteuropa Ende der 1980er Jahre. Es sei kein Zufall, dass der Name des stärksten oppositionellen Widerstands »Solidarität« (Solidarność) war, es sei dies jener nicht-politische Signifikant, der voll mit einer partikulären politischen Phantasie gefüllt wurde und unter den Gruppen Äquivalenz herstellte. Alle die gegen die Kommunisten an der Macht waren, vereinigten sich mittels dieses gegenhegemonialen Signifikanten. Die konservativen Nationalisten warfen Ihnen vor, das Land an die Russen verkauft zu haben, für die Arbeitsgeber waren sie das Hindernis für den kapitalistischen Fortschritt, für die katholische Kirsche waren die Kommunisten morallose Atheisten, für die Intellektuellen waren sie autoritäre Zensuristen. Für die Bauern waren sie die Modernisten, die ihren Habitus zerstört hatten, die Arbeiter meinten, es gehe ihnen nicht um das Proletarische, sondern um die Partei und den bürokratischen Apparat, die Linken betrachteten das existierende Regime als Verrat am wirklichen Sozialismus. Jede Position beharrte auf ihrer eigenen Füllung, dass diese und nur diese die einzige und richtige Definition sei. Welche dieser Bedeutungen hegemonial wird, hängt davon ab, wer überzeugend seine partikuläre Bedeutung für die anderen lesbar macht (vgl. Žižek: 2003: 214ff). 
möglichkeit verantwortlich gemacht wird, und damit wird ein handlungsfähiges Subjekt (Selbst) erst ermöglicht.

Die Phantasie okkupiert genau den Platz, wo es an Bedeutung mangelt. Als ein imaginäres Szenario möchte sie den Mangel der sozialsymbolischen Struktur durch Maskieren von konstitutiven Antagonismen und Differenzen füllen. Die Beziehung zwischen dem Phantasma und dem Realen ist ambivalent; auf der einen Seite verdeckt es den »Schrecken des Realen«, auf der anderen Seite kommt es zu einer Hypostasierung des Realen: Das Reale wird fassbar. Phantasie ist z.B. die Logik des Nationalstaates eine harmonische Gesellschaft hervorzubringen (vgl. Stavrakakis 1999: 80). Die Gestaltung der Welt als harmonisch strukturiertes Ganzes ohne Intervention der Phantasie wäre also nicht möglich (vgl. Žižek 1989: 49).

\section{Symptom und Dislokation}

Die gesellschaftliche Harmonie wird für Laclau und Žižek über die Maskierung von Antagonismen konstruiert. Der vorübergehend aufgehobene Mangel wird wiederum herausgefordert durch die symptomatischen Artikulationen. Es ist das Symptom, das unsere Konstruktion von Realität destabilisiert. Das Symptom ist das, was von der harmonischen Symbolisierung ausgeschlossen wurde. Es ist die Begegnung des Symbolischen mit dem unterdrückten Unbewussten, ein traumatischer Punkt, der der Symbolisierung Widerstand leistet (vgl. Žižek 2003: 214ff). Die politische Phantasie stellt das Symptom als für die Harmonie fremden, störenden Eingriff heraus. Die soziale Phantasie zur harmonischen Konstruktion von Gesellschaft kann also lediglich dadurch aufrechterhalten werden, dass alle beharrende Unordnung als störend stigmatisiert wird und deshalb eliminiert werden darf.

Soziale Konstruktion wird dann eine neue Konstruktion, wenn das Moment der Dekonstruktion mitgedacht wird, ein Moment, das gleichzeitig destruktiv und konstruktiv ist. Es ist dies ein Prozess, in dem die Kontingenz des Diskurses sichtbar gemacht und Strukturen dezentriert werden. Dieses Moment der Dislokation bringt wiederum neue Artikulationen hervor. Traumatische Dislokationen »bedrohen auf der einen Seite Identitäten und Diskurse, auf der anderen Seite sind sie Fundamente, auf denen neue Identitäten konstituiert werden« (Howarth/Stavrakakis 2000: 13). Dislokation (Laclau) oder Symptom (Žižek) sind also Begegnungsmomente mit den unterdrückten ausgeschlossenen Differenzen (dem Realen), die die symbolische Struktur zerreißen, welche wiederum versucht wird durch neue Artikulationen genäht zu werden. Das symp- 
tomatische Reale ist genau das, was zerstört, was die phantasmatische Realität versetzt, was zeigt, dass die Realität, verstanden als soziale Strukturen, mangelt.

Das Politische ist diese Begegnung mit dem nicht symbolisierten Realen (Unbewussten). Das unbewusste Reale ist als verdrängte Bedeutungen zu verstehen, die sich der Symbolisierung entziehen und sich auf der symbolischen Ebene als ein Netz von Symptomen bilden und bedrohlich für die symbolische Ordnung werden (vgl. Zima 2000: 263). Somit scheitern die Versuche, eine volle Identität zu erlangen, sowohl auf imaginärer als auch auf symbolischer Ebene. Man gehorcht der symbolischen Ordnung, um Subjekt zu werden, doch dieser Wunsch wird nie vollständig erfüllt. Es bleibt immer ein Rest vom Realen, der sich der Symbolisierung entzieht und der wiederum bedrohlich und symptomatisch für die symbolische Ordnung wird (vgl. Žižek 1989: 254). Das Moment des Politischen ist das Moment des Fehlschlags par excellence. Laclau und Žižek zufolge ist das Begehren, der Gesellschaft eine harmonische Totalität zu verleihen, deshalb eine Illusion.

Wie jede andere Realität ist die politische Realität, verstanden als Interessen, Identitäten und Hegemonie, konstruiert auf der symbolischen Ebene. Sie ist konstruiert durch diskursive Knotenpunkte. Diese symbolische Konstruktion ist unterstützt von einer phantasmatischen Füllung, die der politischen Konstruktion eine imaginäre Kohärenz stiftet, indem die Phantasie diese Konstruktion im Realen zu verankern verspricht. Die Bedeutungen, Identifikationen und die Hegemonie können jedoch trotz aller imaginären Szenarien und diskursiven Performanzen nicht auf Dauer fixiert werden. Die diskursive Formation, die Konstruktion von kollektiver Identität und Hegemonie als eine geschlossene Struktur ist aufgrund der fehlenden transzendentalen Signifikanten unmöglich, deswegen ist es notwendig stetig an ihrer Konstruktion zu arbeiten. Die Subjekte konstruieren sich auf dem diskursiven Feld, sie werden von Diskursen angerufen und die Positionen werden von ihnen besetzt. Doch diese Identifikation erfolgt nie vollständig. Die artikulatorischen Praktiken verknüpfen zwar die soziale Handlung mit der symbolischen Bedeutung der Handlung, die diskursive Sinnerzeugung durch die Artikulation ist jedoch kontingent und es bestehen immer mehrere Möglichkeiten für andere Sinnverbindungen (vgl. Laclau 1982: 15). Welche von diesen möglichen Bedeutungen vorübergehend fixiert werden, kann nicht allein auf linguistische Regeln reduziert werden. Die Begegnung mit dem Andersartigen führt zwar zum reflexiven Nachdenken über sich selbst und die eigene Subjektkonstitution, aber nicht in einem machtfreien Raum, sondern in einem permanenten diskursiven Machtkampf, in dem die Frage der Hegemonie ins Spiel kommt (vgl. Torfing 1999: 98). 
Die diskursiven dialogischen Praktiken sind bei Laclau und Žižek entscheidend für die Konstituierung von Selbst und Anderem, doch es wird davon ausgegangen, dass die Kommunikation zwischen dem Selbst und dem adressierten Anderen grundsätzlich unmöglich ist. Der Andere ist ein imaginärer Anderer des Diskurses, an dem das Zeichen notwendig in einem bestimmten Ausmaß vorbeigeht: Der Andere ist deshalb imaginär, da er nur aus dem imaginären Winkel der Position des Subjektes im Diskurs sichtbar ist. Mit dem bakhtinschen Begriff »Dialogizität« soll im Folgenden stärker hervorgehoben werden, dass die diskursiven Konstruktionen und die Beziehung zwischen Selbst und Anderem sich nicht isoliert formieren, sondern sich aufeinander beziehen (vgl. Bakhtin 2001).

\section{Dialogische Diskursivität}

Dialogizität ist für Michail Bakhtin (2001) die primäre Bedingung des Diskursiven. Sie bedeutet, dass sich der Text bzw. der Autor schon während der Artikulation an seinem jeweiligen Adressaten orientiert. Es findet ein Dialog zwischen Signifikantem und Signifikat, zwischen Erzähler und Zuhörer, zwischen sprechendem Subjekt und seinen Worten, zwischen über denselben Gegenstand anderswo artikulierten Aussagen statt (vgl. Bakhtin 2001: 52). Alle Konversationen und Texte sind sozial und dialogisch, sie sind immer eine Reaktion auf andere gesprochene oder geschriebene Sprachformen, die zitiert, nachgeahmt oder pervertiert werden. Die Sprache versteht er im Gegensatz zu Saussure nicht als abstrakte grammatikalische Kategorie, sondern als völlig mit Ideologien gefüllte konkrete Welt der Ideen (vgl. Bakhtin 2001: 46f). In einem Dialog tauchen die Signifikanten als eine lebendige Antwort auf, und sie formieren sich als Folge von Kommunikation mit fremden Signifikanten, die an demselben Gegenstand oder denselben Themen hängen. Doch es wird nicht nur mit an dem Gegenstand hängenden fremden Signifikanten kommuniziert, sondern jedes Wort taucht auch als eine Antwort auf etwas auf, das sie anruft. Erst im Prozess dieser Interaktion formieren sich die Äußerungen.

Die Paarung von Signifikanten und Signifikat entsteht als Folge der simultanen Präsenz von Anderen, keine von diesen Elementen existiert an sich, sie haben auch von selbst keine Bedeutung (vgl. Bakhtin 2001: 312). Die Welt (das Andere) adressiert uns stets, wir sind immer adressierbar, wir sind von außen gezwungen, ihr zu antworten. Wir geben der Welt also stetig Antworten, weil wir stetig adressiert werden (vgl. Holquist 2002: 30ff; Mills 1997: 11). In einer Unterhaltung richtet sich der 
Signifikant unmittelbar nach einer kommenden Antwort, er provoziert eine Antwort, bereits während der Artikulation setzt er eine Antwort voraus und strukturiert sich in dieser Atmosphäre. Die noch nicht ausgesprochene Äußerung wird angerufen von davor artikulierten Äußerungen. Das Rhetorische richtet sich auch nach dem Zuhörer und seiner Antwort, es ist eine Beziehung, in der der Erzählende sich a priori nach seinem Publikum orientieren und mit ihm rechnen muss. Das Publikum ist dabei nicht passiv, sondern mitkonstruierend (vgl. Bakhtin 2001: 56ff). Die Bedeutung ist immer relativ in der Hinsicht, dass sie lediglich als Folge der Relation zwischen zwei Körpern entsteht, die sich aber gleichzeitig in unterschiedlichen Räumen befinden. Es sind die zeitlichen und räumlichen Arenen, in denen Wahrnehmungen sich entfalten, und nichts kann von selbst wahrgenommen werden (vgl. Holquist 2002: 17ff). ${ }^{10}$

Der psychoanalytische bzw. hegemonietheoretische Diskursansatz geht davon aus, dass die Symbolisierung lediglich mit dem Widerstand von Gegenständen konfrontiert ist. Sie ist jedoch auch mit anderen Begriffen und Aussagen konfrontiert, die irgendwann anderswo artikuliert wurden. Alle Gegenstände sind mit anderen Perspektiven, Werten und Betonungen belastet. Wenn die Wörter sich nach einem Gegenstand richten, so geraten sie in eine spannungsgeladene komplexe Beziehung und in einen Dialog. Das Terrain der Symbolisierung ist sozusagen kein Niemandsland, auf dem die Signifikanten sich frei bewegen (vgl. Bakhtin 2001: 53). In der Sprache gehört das Wort zur Hälfte dem Anderen. Füllt das Selbst das Wort mit eigenem Zweck, so gehört das Wort vorübergehend dem Selbst. Das dem Anderen gehörende Wort, welches ihm

10 Die theoretische Ausgangsposition von Bakhtin besteht in der Annahme, dass das Selbst immer auf den betrachtenden Blick des Anderen verwiesen ist, um sich selbst zu konstruieren. Der žižeksche Mangel des Selbst während der imaginären Identifikation im Spiegelstadium wird hier zum Mangel auf der symbolischen Ebene: Das Problem ist nicht (nur) das invertierte entfremdete Abbild, sondern (auch) der im Spiegel fehlende Blick des Anderen. In dieser Hinsicht macht es keinen Sinn, sich im Spiegel zu betrachten, um zu erfahren, wie wir für das Andere erscheinen. Von welchem Winkel aus wir auch uns selbst zu beobachten wünschen, aufgrund des fehlenden Blickes des Anderen ist unser Gesicht eine fehlendes Gesicht. Das Selbst kann sich lediglich durch den »Überschuss des Sehens« des Anderen ergreifen, sich lediglich durch den Blick eines extern positionierten Anderen konstruieren (vgl. Irzık 2001: 7f). Die dialogische Subjektivität ist ausgerichtet auf Alterität, sie lebt von ihrem Anderen und ihrem Gegenteil (vgl. Zima 2000: 369; Neumann 1999: 13). Um uns zu verstehen, müssen wir unseren Blick auf den Anderen werfen, um das Andere zu verstehen, müssen wir unsere Position nicht verlassen. Das Dialogische wird somit für Bakhtin die epistemologische Grundvoraussetzung des Wissens bzw. des Diskursiven. 
in anderen Kontexten zur Verfügung steht, wird in den Kontext des Selbst importiert und mit eigenen Zwecken und Deutungen gefüllt. Mehr noch: Nicht jedes Wort ist gleichermaßen zu okkupieren. Manche zeigen mehr Resistenz, manche bleiben im Mund des Okkupierten fremd, lassen sich schwer in Besitz nehmen und bleiben außerhalb des Kontextes, als ob sie zitiert oder in Anführungsstriche gesetzt werden. Der Prozess der Okkupation eines Wortes mit eigener Füllung und eigenem Zweck ist also insofern kompliziert, als mehrere Kontexte aufeinander prallen (vgl. Bakhtin 2001: 72).

\section{Fazit}

In diesem Teil habe ich die diskurstheoretischen Rahmenbedingungen der vorliegenden Arbeit vorgestellt. Die zentrale Ausgangsposition der Diskurstheorie ist, dass das, was wahrgenommen und gespürt wird, über gesellschaftlich konstruierte symbolische Ordnungen vermittelt wird. Diskurse repräsentieren weniger die Wirklichkeit, sie fungieren vielmehr als eine symbolische Ordnung, indem sie symbolische Grenzen zwischen Wahrem und Falschem ziehen (vgl. Bublitz et al. 1999: 12f; Hajer 2003). Da sie institutionalisiert, geregelt und an Handlungen gekoppelt sind, sind die Diskurse nicht nur als Ausdruck gesellschaftlicher Praxis von Interesse, sondern auch als Hinweis auf eine bestimmte Konzeption von Zweckgebundenheit, und als Machtstruktur zu verstehen (vgl. Jäger 2001).

Ausgehend von der Diskurstheorie Laclaus und Žižeks habe ich erstens stärker als Foucault die Heterogenität, Intertextualität und Offenheit des Diskurses betont. Diskurse sind nicht auf Dauer fixiert, sondern sind sich durch Artikulationen verändernde Formationen, die durch die symptomatischen Praktiken des Anderen stets versetzt werden. Jedes versetzende Ereignis ist dabei destruktiv und konstruktiv gleichzeitig. Es ist destruktiv, weil es den Mangel der symbolischen Ordnung sichtbar macht. Konstruktiv, weil es ein Begehren nach neuen politischen Identifikationen und sozialen Phantasien erzeugt, die den »Riss « zu nähen versuchen. Phantasie ist dabei eine Abwehrformation gegenüber der Unabgeschlossenheit der symbolischen Ordnung und der Unabgeschlossenheit des Selbst. Die Realität kann erst bestimmte Kohärenz erlangen durch Flüchten in die Phantasie, die verspricht, den Mangel im Anderen abzudecken (Stavrakakis 1999: 46f). Phantasie ist ein ideologisches Versprechen, eingebettet in Mythen, Erzählungen, Geschichte, als retroaktiver Effekt der Symbolisierung. Die politische Mythisierung und Konstruktion von Bedrohung kann z.B. als imaginäre Füllung oder Maskierung des politischen Mangels verstanden werden. Die Gemein- 
schaft reguliert somit ihre Realität durch die stabilisierende Seite des Phantasmas, indem die inhärente Unmöglichkeit, der Antagonismus des Sozialen verleugnet wird, indem sie die Verleugnung positiviert, ihr einen Körper gibt. Die Äußerungen sind dabei als diskursive Bemühungen zur vollständigen symbolischen Integration zu begreifen. Mit anderen Worten sollen Äußerungen als diskursive Performanzen verstanden werden, mit denen die konstitutiven Lücken des Symbolischen artikuliert werden (vgl. Angermüller 2005: 11f). Jede diskursive Konstruktion, die die Universalität ihrer Wahrheit behauptet, konstruiert dabei ein partikuläres »intimes Außen«, das ausgeschlossen wird. Dabei werden die Mehrdeutigkeiten verdrängt bzw. bestimmte Stimmen in einer Gesellschaft maskiert, die sich immer wieder mittels Symptomen hören lassen (vgl. Zima 2000: 261). Diese verdrängten Bedeutungen, die sich der Symbolisierung entziehen, bilden sich auf der symbolischen Ebene als ein Netz von Symptomen und werden wiederum bedrohlich für die symbolische Ordnung. Die »symptomatische« Lesart wäre dann, diesen »symptomatischen Überschuss « zu zeigen, nämlich, welche Differenzen ausgeschlossen bzw. unterdrückt worden sind (vgl. Žižek 2003: 217ff).

Ich habe den Begriff »diskursive Knotenpunkte« eingeführt, worunter ich jene Schlüsselbegriffe und Metaphern verstehe, die eine tragende Botschaft übernehmen, um die herum die Aussagen im Diskurs strukturiert werden. Es geht gewissermaßen um eine Art von netzwerktheoretischem Ansatz, der jedoch weniger nach Schlüssel-Akteuren in einem sozialen Umfeld, sondern mehr nach Schlüssel-Begriffen auf diskursiver Ebene sucht. Dabei bleibt unbehandelt, ob tatsächlich soziale Netzwerke zwischen sprechenden Akteuren entstehen. Die diskursiven Kontenpunkte, verstanden auch als dominante Phantasie, zeigen was in einer Gesellschaft bzw. in einem Diskurs als für relevant und »wahr« gehalten wird. Sie lenken die gesellschaftliche Aufmerksamkeit und zeigen ihre Resonanzstrukturen. Als historisch und kulturell tradierte Bedeutungen bringen sie Erfahrungen, Phantasien und Interessen historisch gebildeter sozialer Gruppen hervor, deren Konflikte und Machtverhältnisse zum Ausdruck kommen. Es geht gewissermaßen um eine »topische Macht«, als eine Form der Hegemonie auf symbolischer Ebene (vgl. Knoblauch 2001: 221). Der Begriff Hegemonie von Laclau und Mouffe zeigt im Gegensatz zum späten Machtbegriff Foucaults die relative Zentrierung der symbolischen Macht um die diskursiven Knotenpunkte herum. Die Macht ist im Signifikanten enthalten. Die Hegemonie zeigt zum einen den präkeren Zusammenschluss zwischen Macht von Oben und von Unten durch Konsensbildungen mittels eines diskursiven Knotenpunktes. 
In diesem Rahmen werde ich im folgenden Teil von diversen Formen von Orientalismen sprechen, die sich entlang bestimmter diskursiver Knotenpunkte verflechten oder sich voneinander abgrenzen können. Der Europa- bzw. Okzidentbegriff wird in diesem Sinne ein ständig zur Disposition gestellter hegemonialer Kampfbegriff: Europa als eine räumlich-zeitliche imaginäre Konstruktion wird in diverse politische und ideologische Projekte übersetzt: Europa als Gemeinschaft von Nationalstaaten oder als rechtlich regulierte Diskursgesellschaft, Europa als christliche Wertegemeinschaft etc. Jede Vorstellung von Europa hat ein relativ breites Spektrum von Anderem und unterschiedliche Formen von Inklusion und Exklusion: von der »Festung Europas« bis zur rechtsstaatlichen Diskursgesellschaft mit relativ offenen Grenzen (vgl. Stråth 2000; Jacobs/Maier 1998; Malmborg/Stråth 2002). Den Europa- bzw. Okzidentbegriff kennzeichnet somit eine semiotische Leere, die mit unterschiedlichen phantasmatischen Szenarien gefüllt wird. Die Bedeutungen des Europabegriffes formieren sich dabei nicht isoliert, sondern sie verknappen sich immer in spezifischen historischen Momenten diskursivdialogisch in der Abgrenzung zu Anderen.

Zweitens habe ich die Frage der politischen Subjektivität, verstanden als die Art und Weise, wie soziale Akteure handeln, im heterogenen Diskurs im Verhältnis von Eigenem und Anderem in den Vordergrund gerückt. Foucault nimmt eine geschlossene Struktur des Diskurses an, wobei das Subjekt seine Position im Diskurs als Agent des sozialen Prozesses einnehmen und diese voll besetzen kann. Subjektpositionen werden jedoch produziert als Folge von kontingenten artikulatorischen Prozessen. Der Ort des Subjektes im Diskurs ist nicht pre-determiniert, sondern ein leerer Raum, der erst durch Identifikation gefüllt werden muss. Diese Positionen und Identifikationen sind nicht als solche gegeben, sondern sie wandeln sich vielmehr durch Artikulationen in Serien von Äquivalenzen durch den metaphorischen Überschuss von Bedeutungen. Subjekte können handeln und dadurch ihre Identität erhalten, eben weil die diskursiven Strukturen kontingent und durchlässig sind (Laclau/ Mouffe 1992: 136ff; Žižek 1989: 250). Somit ist die Emergenz der politischen Subjektivität das Ergebnis des Mangels in den Strukturen. Es ist der Prozess der Identifikation, die politische Subjektivitäten hervorbringt (Howarth/Stavrakakis 2000: 13f). Das heißt, weder der Diskurs verstanden als Struktur noch das Subjekt können sich selbst abschließen, sie bleiben wechselseitig aufeinander angewiesen.

In diesem Rahmen werde ich im folgenden Teil argumentieren, dass, obwohl die nicht-westlichen Gesellschaften von westlichen Subjekten zum Anderen gemacht werden, diese »orientalen« Gesellschaften nicht lediglich Opfer dieses Prozesses waren und sind. Die nicht-westlichen 
Gesellschaften reagierten auf das ihnen auferlegte Modell mit unterschiedlichen Strategien unter unterschiedlichen historischen Bedingungen, die spezifische Subjektivitäten bzw. Identitäten in den nichtwestlichen Gesellschaften hervorbringen. Die orientalistischen Repräsentationen können der Expression von Kolonialismus, Kontrolle und Eindringung dienen. Sie können von den kolonisierten Anderen aber auch pervertiert oder anders gedeutet werden.

Die türkische Subjektivität formiert sich, so werde ich ebenfalls im folgenden theoretischen Teil argumentieren, an der imaginären Schwelle zwischen West und Ost, wobei Eliten der nicht-westlichen Gesellschaften einerseits das Wissen, die Technologien und Normen von modernen westlichen Gesellschaften adaptieren, andererseits relativ frei sind, die Grenzen dieses Adaptierens zu bestimmen bzw. ihre Bedeutung zu verändern. Von hier aus werde ich argumentieren, dass die Türkei »Europa« nicht nur imitiert, sondern intertextuelle Repräsentationen über Europa erzeugt und zugleich akzeptiert und zurückweist.

Um das Zusammenwirken zwischen europäischen und türkischen Diskursen zu akzentuieren habe ich zum Schluss den Begriff Dialogizität von Bakhtin eingeführt. Es ging mir dabei nicht um den normativen Inhalt des Begriffes ${ }^{11}$, der die Herstellung einer konsensuellen Basis auf einen geteilten Sinn impliziert, sondern darum zu zeigen, wie und inwieweit der imaginäre Blick des Anderen in der Diskurs- bzw. Identitätsformation des Selbst konstitutiv wirkt. Das Dialogische gibt uns einfach die Möglichkeit zu erfahren, was das Andere über uns erzählt, zu hören, was das Andere darüber erzählt, was wir einmal über das Andere erzählt haben. Die dialogische Perspektive hebt die Verbindung zwischen dem artikulierten Wort und seinem Objekt, zwischen dem sprechenden Autor und seinem Text hervor und zieht auch anderswo artikulierte Aussagen in Betracht.

Unter diesen Gesichtspunkten werde ich im Folgenden die Alterität des Orients im Formierungsprozess der westeuropäischen Identität im Rahmen der Orientalismustheorie von Said näher darlegen.

11 Der Begriff Dialogizität hat für Zima eine normativ-ethische Dimension, $»[\ldots]$ die eine Brücke vom Partikulären zum Universalen schlagen möchte, ohne dem Partikulären Gewalt anzutun « (Zima 2000: 367) und unterscheidet sich somit von der habermasschen Kommunikationstheorie, in der das Universalistische einseitig privilegiert wird. 


\section{ORIENTALISMUS UND SUBJEKTIVITÄt DES ANDEREN}

Mit dem »linguistic turn« und insbesondere dem »cultural turn« in den 1990er Jahren hat Saids Orientalismustheorie ${ }^{1}$ in Sozial- und Kulturwissenschaften auch im deutschsprachigen Raum an Bedeutung zugenommen. Said analysiert im »Orientalismus« (1981) mittels Foucaults diskurstheoretischer Methodologie den französischen, englischen und amerikanischen Orientalismus (als Disziplin), indem er ein breites Spektrum von Texten (wissenschaftlichen, politischen, literarischen und Reiseberichte) untersucht. ${ }^{2}$ Said geht es dabei darum, Kohärenzprinzipien des orientalistischen Diskurses, das in den Diskursen und Praktiken enthaltene epistemologische Grundmodell aufzuklären sowie seine politischen Implikationen ausfindig zu machen. Sein Diskursbegriff hat somit die strategische Funktion, die Wahrheitsansprüche der Aussagen über den Orient zu zeigen (vgl. Nehring 2003: 42f). Dabei unterscheidet er zwischen drei Formen von Orientalismus, die miteinander verflochten sind: der akademische Orientalismus als Disziplin, der allgemeine Orientalismus als westliche Mentalität, die sich durch mehrere Jahrhunderte zieht, und der institutionelle Orientalismus, als der Diskurs, der den westlichen

1 Mit der ersten Wende wurde der Orient als Gegenstand westlicher Imagination und Erfindung erkannt. Mit der zweiten Wende fand in den westlichen und nicht-westlichen Gesellschaften eine diskursive Kulturalisierung der (Identitäts-)Politik statt, wobei der Orient bzw. die »Islamische Welt« als das konstitutive Andere des Westens reartikuliert wird (vgl. Polaschegg 2005: 21ff).

2 Die Texte der Politiker Balfour, Cromer, Kissinger sowie der Schriftsteller/Akademiker Chateaubriand, Lamartine, Nerval, Flaubert, Renan, Massignon, Grunebaum, Gibb, Marx und Lewis. 
Kolonialismus rechtfertigte (vgl. Said 1981; siehe auch Menon 1993: 68; Wilson III. 2000: 243; Jalal al-Azm 2000).

Orientalismus ist für Said eine spezifische Art des Denkens, das entlang essentialistischer Kategorien zwischen dem "westlichen Selbst« und dem »orientalen Anderen« operiert und dabei ein Subjekt konstruiert, das über den Orient spricht. Der Orient gehe aus einer westlichen Imagination hervor, er sei nicht aufgrund naiver Vorstellungen und Vorurteile, sondern als »Episteme«, als komplexe koloniale Investition des westlichen Subjektes entstanden (vgl. Kahraman 2002: 154ff; Schaar 2000: 182). Der Orient sei etwas, das gefürchtet werde und deshalb mittels Forschung und Entwicklung sowie durch direkte Okkupation kontrolliert werden müsse. Es gibt eine »islamische Gesellschaft«, einen »arabischen Geist«, eine »orientale Psyche«, die der Modernisierung, Kolonisierung und alltäglichen Politik scheinbar entgehen (vgl. Said 1981: 339). Der Orientalismus als Diskurs orientalisiert den »Orient«, er konstruiert ihn als eine fixe Entität mit zeitlosem Essentialismus.

Geprägt von Gramscis Konzept der Hegemonie, akzentuiert Said die Dauerhaftigkeit und Stärke der kulturellen Herrschaft des westlichen Subjektes. Der Orient wurde orientalisiert, »weil er orientalisch gemacht werden konnte« (Said 1981: 13). Dass der Orientalismus in der Lage war, Revolutionen und Weltkriege zu überleben, zeigt die Dauerhaftigkeit seiner Hegemonie. Die akademischen und literarischen Texte produzieren also nicht nur Wissen über den Orient, sondern konstruieren auch hegemoniale Repräsentationen über ihn. Sie halten dadurch die hegemoniale Beziehung zwischen Orient und Okzident aufrecht (vgl. Said 1981: 249ff). Die Repräsentationen, verstanden als Formationen oder Deformationen, haben für Said Absichten, sie sind die meiste Zeit überrepräsentativ, sie erfüllen Aufgaben (vgl. Said 1981: 307). Die Beziehung zwischen Osten und Westen ist die Geschichte der »Entwicklung« und »Unterentwicklung«, nicht lediglich die Beziehung von kulturellen Differenzen. Sie ist ein Diskurs, der den Osten als sein unterlegenes Anderes konstruiert. Die Weltgeschichte ist dabei die Geschichte des privilegierten Westens. Die nicht-westlichen Gesellschaften werden auf ein anthropologisches Objekt reduziert, das sich selbst zu repräsentieren nicht in der Lage ist (vgl. Kahraman/Keyman 1998: 65f).

Said hat gezeigt, wie orientalistische Repräsentationen die kolonisierenden Praktiken vereinfacht und gerechtfertigt haben. Er hat gezeigt wie die Eindringung des westlichen Subjektes in den Osten und die orientalistischen Repräsentationen sich wechselseitig in einem Zusammenspiel von Macht und Diskurs getragen haben. Er ließ aber die heterogenen westlichen Repräsentationen und antagonistischen Subjektpositionen um die Hegemoniebildungen im Diskurs innerhalb des westlichen 
Diskurses außer Acht, so eine zentrale Kritik von postkolonialen Theoretikern $^{3}$, die ich mir hier zu Eigen mache (vgl. Porter 1983; Lowe 1991; Chen 2001 Turner 2000b).

\section{Heterogenität des Orientalismus}

Eines der Hauptprobleme des saidschen Orientalismus liegt in seiner methodologischen Ausgangsposition, der Foucaults Diskurstheorie zugrunde liegt, welche eine geschlossene Struktur des Diskurses impliziert. Foucault legt seinen Akzent auf diese Strukturregeln einer hierarchisch organisierten symbolischen Ordnung, in einer Zeit und an einem Ort (vgl. Foucault 1991). Sein zentrales Anliegen konzentriert sich um die Frage, welche bestimmten Grundbegriffe bzw. Erkenntnisprinzipien und

3 Die saidsche Theorie des Orientalismus hat den postkolonialen Feministen zufolge die konstitutive Rolle der Sexualität und Repräsentationen über Geschlechter in der Formierung des Orientalismus unzureichend fokussiert (vgl. Mills 1997; Lowe 2001; Yeğenoglu 1996; Lewis 1996). Porter (1993) weist darauf hin, dass Said einen Diskursbegriff in seiner Analyse verwendet, der sich von dem Foucaults erheblich unterscheidet, indem er die epistemologischen Brüche nicht berücksichtigt (vgl. Porter 1983: 179ff). Er habe den foucaultschen Diskursbegriff nicht konsequent angewendet. Er reduziere Foucault auf Terminologien (Diskurs, Repräsentation, epistemische Differenzen), lehne es aber ab die Konsequenzen des foucaultschen Geschichtsverständnisses zu akzeptieren, das von Diskontinuitäten gekennzeichnet ist. Während Foucault ab dem 16./17. Jahrhundert einen modernen epistemischen Bruch feststellt, umfasst epistemische Konstruktion Saids sowohl die pre-kapitalistische als auch die kapitalistische Periode (vgl. Ahmad 2000: 288ff). Jalal al-Azm (2000) zufolge kann Said keinen bestimmten Zeitpunkt für die Entstehung des institutionellen und akademischen Orientalismus feststellen. Said führt den Ursprung der orientalistischen Diskursformation bis in die Antike zurück (vgl. Jalal alAzm 2000: 218f). Er stellt eine Kontinuität von Homer, Aischylos, Euripides über Dante und Karl Marx bis zu A.H.R. Gibb und Bernard Lewis fest. Dadurch würden die Kategorien von Orient und Okzident essentialisiert und transhistorisiert. Auf diese Weise reproduziert er für Samir Amin die eurozentristische These, die die Antike als »Vater Europas «, als Wiege der Vernunft und des Fortschritts des Westens artikuliert (vgl. Amin 2001: 1676ff). Die Geschichte des Orientalismus solle im Zusammenhang mit der Entstehung des Kapitalismus und des Kolonialismus gedacht werden. Denis Porter (1983) und Aijaz Ahmad (2000) machen darauf aufmerksam, dass Said einerseits zwischen »Wahrheit« und Ideologie, Realität und Repräsentation, objektivem und politischem Wissen keinen Unterschied mache, andererseits von einem »Orient« rede, der tatsächlich existiere, aber missrepräsentiert werde. Somit gerate er in einen Widerspruch, indem er die Möglichkeit für alternative (»richtige«) Repräsentationen über den Orient offen lasse (vgl. Porter 1983: 181; Ahmad 2000: 292). 
Bedingungen die Überzahl von Aussagen, Argumenten und Narrativen in einem bestimmten Zeitraum organisieren (vgl. Kögler 1994: 40; Keller 2004: 43). Es ist nicht die Intention des Autors, dahinter verborgene Klasseninteressen oder Willensabsichten einzelner Subjekte aufzudecken, sondern die Analyse dessen, was tatsächlich gesagt wurde, also die Schilderung der Diskursformation, und die Analyse seiner Formationsregeln ${ }^{4}$, die sich durch den Sprachgebrauch materialisiert haben (vgl. Angermüller 2005: 4). Diese Formationsregeln bestimmen die Regeln der Sagbarkeit und strukturieren, welche Aussagen in einem bestimmten historischen Kontext erscheinen können (vgl. Keller 2004: 45).

»In dem Fall, wo man in einer bestimmten Zahl von Aussagen ein ähnliches System der Streuung beschreiben könnte, in dem Fall, in dem man bei den Objekten, den Typen der Äußerung, den Begriffen, den thematischen Entscheidungen eine Regelmäßigkeit (eine Ordnung, Korrelationen, Positionen und Abläufe, Transformationen) definieren könnte, wird man übereinstimmend sagen, dass man es mit einer diskursiven Formation zu tun hat [...].« (Foucault 1973: 58)

Diskurse sind zwar geregelte Formationen, wie im vorherigen Teil (II) gezeigt, sie sind jedoch heterogene Gebilde. Ihre Äußerungen verweisen auf unterschiedliche Sinnebenen. Daher ist der Orientalismus als Summe von ambivalenten heterogenen Repräsentationen zu verstehen und soll in den dialogischen Praktiken mit den Diskursen des Anderen untersucht werden. Dabei sollen sowohl Kontinuitäten als auch auf Diskontinuitäten seit der Kolonialgeschichte Europas hervorgehoben sowie die miteinander konfligierenden unterschiedlichen Diskurse um Hegemonie und Gegenhegemonie in den jeweiligen westeuropäischen Gesellschaften vor Augen gehalten werden. Der Orientalismus als Diskurs und Phantasie ist nicht stabil und geschlossen, sondern komplex, instabil und widersprüchlich. Dies liegt in seiner Dialogizität und Historizität sowie in der Tatsache begründet, dass es unmöglich ist, Bedeutung auf Dauer zu fi-

4 Foucault unterscheidet in der »Archäologie des Wissens« (1973) zwischen vier Formationsregeln eines Diskurses: 1. Formation der Gegenstände: Welche formativen Regeln bilden Gegenstände, über die gesprochen wird, welche wissenschaftlichen Disziplinen sind wie an dem Gegenstand Konstruktion beteiligt, welche Klassifikationsmuster werden im Diskurs sichtbar?; 2. Formation der Äußerungsmodalitäten: Wer ist legitimer Sprecher, von welchen institutionellen Orten und welcher Subjektposition aus wird gesprochen?; 3. Formation der Begriffe: Welche rhetorischen Mittel werden angewendet, wie werden Texte miteinander verbunden, wie werden Argumente formuliert?; 4. Formation der Strategien: Wie bezieht der Diskurs sich auf andere Diskurse? (vgl. Foucault 1973). 
xieren, da die Natur von Identitäten unvollständig ist und Hegemonien prekär sind.

Die Konstruktion des Selbst und der Andersartigkeit ist weder endgültig fixiert noch kontinuierlich (vgl. Sayyid 1997: 32). Die Repräsentationen über das eigene Selbst und über Andere sind multivalent und bezeichnen in unterschiedlichen partikulären sozialen und historischen Kontexten unterschiedliche Bedeutungen. Die kollektiven Identitätsvorstellungen und Deutungssysteme (von Eliten) in Europa unterscheiden sich in diesem Sinne von einem historischen Moment, von einem Land und von einem politischen Diskurs zum anderen. Es gibt keine einheitliche konsistente Bedeutung des Begriffes Europa, keine einzige kontextdurchquerende transhistorische Tradition, sondern relativ heterogene Repräsentationen mit historischen und räumlichen Differenzen (vgl. Stråth 2000; Malmborg/Stråth 2002; Pocock 2002; Pagden 2002).

Turner (2000b) macht auf zwei Dimensionen des Orientalismus aufmerksam: Zum einen unterscheidet er zwischen internem und externem Orientalismus. Der Diskurs ist diesbezüglich entweder nach innen oder an externe bzw. externalisierte Andere gerichtet. Zum anderen unterscheidet er zwischen positivem und negativem Orientalismus. Turner gibt die europäischen Romantiker des 19. Jahrhunderts als Beispiel für den positiven Orientalismus an. Diese hätten sich mit dem Osten identifiziert und positive Stereotype erzeugt, wie T.E. Lawrence, der den »Orient" als Land der »Versprechen«, »Sensibilitäten« und »Freude« beschrieb. Orientalismus ist für Turner auch nach innen gerichtet, indem auch bestimmte Gesellschaften in Europa positiv oder negativ repräsentiert würden, wie »sympathische« Schotten oder »bedrohliche« Iren (vgl. Turner 2000a: 17ff).

Lisa Lowe (1991) stellt in ihrer Analyse der »Turkish Embassy Letters « (1717-1718) von Mary Wortley Montagu fest, dass diese bestimmte Bilder über die »türkischen $\aleph^{5}$ Frauen und die »türkische« Gesellschaft vermittelt, die sich von den zeitgenössischen orientalistischen Bildern unterschieden. Montagus Sprache verfolgt eine Rhetorik der Identifikation mit den elitären »türkischen « Frauen am osmanischen Hof und eine Rhetorik der Differenzierung der »türkischen « Gesellschaft im Allgemeinen (vgl. Lowe 1991: 324f). Der englische Orientalismus formierte

5 Hier möchte ich darauf hinweisen, dass die vermeintlich »türkischen« Frauen in dieser Zeit tatsächlich ganz unterschiedlicher Herkunft waren und sich nicht als »türkisch«, sondern eher als »osmanisch« verstanden. In dieser Hinsicht kann auch von keiner »türkischen Gesellschaft«, sondern nur von einer osmanischen Gesellschaft gesprochen werden. Paradoxerweise war »türkisch« eine orientalistische Bezeichnung, was Lisa Lowe als Orientalismuskritikerin nicht in Betracht zieht. 
sich Lowe zufolge deshalb nicht lediglich in der Distinktion zwischen Orient und Okzident, sondern überlappend mit Differenzen und Gemeinsamkeiten bezüglich geschlechter- und klassenspezifischer Merkmale.

Lowe spricht weiterhin von einem »poststrukturalistischen« Orientalismus der 1970er Jahre in Frankreich, in dem der »Orient« als ein Objekt der Phantasie imaginiert wurde, welches mit der Kolonisierung des Orient (China) nichts zu tun hatte, sondern eine romantische Erfindung von kritischen französischen Intellektuellen war. Lowe weist dabei auf die französischen maoistischen Intellektuellen (der Zeitschrift »Tel quel«) und postrukturelle Autoren hin, wie Julia Kristeva und Roland Barthes, die nach der »gescheiterten Revolution« der 1968er Bewegung in Frankreich 1974 nach China gereist sind. ${ }^{6}$

Dieser postkoloniale französische Orientalismus markiert für Lowe einen essentiellen Unterschied zwischen China und Europa: Die Idealisierung der Mutter und die Orientalisierung Chinas finden dabei zugleich

6 Laut Lowe hat Roland Barthes in seinem Buch »Alors la Chine« (1975) orientalistische Repräsentationen konstruiert, in denen die französische Gesellschaft als »[...] a society structured on difference, differences being the source of occidental desire, meaning, and eroticism « konzipiert wurde. Als Gegenpol zur französischen wurde eine chinesische Gesellschaft konstruiert, die $»[\ldots]$ neutral smooth, and prosaic, profoundly lacking conflict or difference« war (Lowe 1991: 161). Während Barthes dem westlichen modernen Binarismus zu entkommen versuchte, so Lowe, gerate er in einen Okzident-Orient-Binarismus, in dem der ideelle Osten privilegiert werde. Barthes vergleiche die japanische und chinesische Kultur mit der westlichen französischen und schlussfolgere, dass diese nicht miteinander kompatibel seien. Über diesen Vergleich versuche Barthes zu definieren, was die westlichen Gesellschaften nicht seien. Selbst die japanischen Städte würden sich von den westlichen unterscheiden, sie seien nicht zentralisiert wie die französischen Städte. Westliche Gesellschaften seien paternalistisch, die östlichen maternalistisch. Als eine weitere Vertreterin des postkolonialen Orientalismus gibt Lowe die feministische Psychoanalytikerin Julia Kristeva an, die in ihrem Buch »Des chinoises« eine homogene chinesische Gesellschaft konstruiere, in der keine sozialen Klassen, keine Arbeiter und Bauern existierten. Während Kristeva die chinesische premoderne Kultur als imaginär und pre-ödipal auffasse, bezeichnete sie die jüdisch-christliche europäische Kultur als männlich, phalluszentriert und kastriert. Sie entwerfe China als kulturelles sexuelles Andere des Westens. Diese postkolonialen Repräsentationen ähneln Lowe zufolge den Repräsentationen der französischen Romantiker im 19. Jahrhundert, wie Flauberts Bilder von orientalen Frauen (»la femme orientale «) in seinem Buch »Kuchuk Hanem《. »In both situations the oriental is represented by the French writers as speechlessly other, indiscriminate rather than distinguishing among observers [...] In both the French readers are the audience who receive and, as addressees, participate in these representations.« (Lowe 1991: 187) 
statt, indem eine matriarchale Gesellschaft in einem vorgestellten Orient erfunden wird. Es gehe um eine konstruierte frauendominierte presymbolische Phase in der chinesischen Geschichte und Gesellschaft (vgl. Lowe 1991: 137ff). Kennzeichnend für die postkolonialen Orientalisten sei, dass das orientale Andere (China) kein kolonisierter Raum, kein Objekt des Wissens im foucaultschen und saidschen Sinne, sondern ein begehrter Ort der Phantasie sei, der im Vergleich mit der westlichen rationalen Politik und Signifikation privilegiert werde. Paradoxerweise habe diese postkoloniale Refiguration China weiterhin als Anderes konstruiert, nicht als kolonisiertes, aber als Objekt der Phantasie. Diese romantische Repräsentation habe wenig mit China oder dem Orient zu tun, sondern lediglich mit dem französischen Kontext bzw. den Enttäuschungen der 1970er Jahre. Es sei ein linker distanzierter orientalistischer Blick, der die westliche Staatsmacht und seine Hegemonie kritisiere, den französischen (linken) Leser adressiere und sich mit einer erdachten chinesischen orientalen Gesellschaft identifiziere (Lowe 1991: 187ff).

Said unterscheidet zum einen zwischen manifestem und latentem Orientalismus. Ersterer wird als eine Menge von geäußerten Sichtweisen über die orientalischen Gesellschaften verstanden, während er mit Letzterem mehr oder weniger unbewusste Performativitäten meint. Im manifesten Orientalismus gehe es um die Form und den persönlichen Stil und selten um den grundlegenden Inhalt. Während bestimmte Veränderungen im Wissen über den Orient im manifesten Orientalismus zu sehen sind, so Said, ist der latente Orientalismus dauerhaft und stabil. Die untersuchten Texte (z.B. von Renan und Marx) hielten Said zufolge »[...] die Andersartigkeit des Orient aufrecht, seine Exzentrizität, Rückständigkeit, seine stille Gleichgültigkeit, seine weibliche Durchdringbarkeit, seine träge Formbarkeit« (Said 1981: 231).

Er unterscheidet zum anderen zwischen dem deutschen und dem anglo-französischen Orientalismus des 19. Jahrhunderts. In der deutschen Wissenschaft konnte sich für Said während der ersten beiden Drittel des 19. Jahrhunderts niemals ein enges Zusammenspiel zwischen den Orientalisten und strategischen nationalen Expansionsinteressen etablieren (vgl. Said 1981: 28). Es gebe nichts in Deutschland, so Said, das mit der anglo-französischen Präsenz in Indien, dem Nahen Osten oder Nordafrika korrespondiere.

$»[\ldots]$ der deutsche Orient [war] fast ausschließlich ein wissenschaftlicher oder zumindest ein klassischer Orient: er wurde Thema der Lyrik, von Phantasien und selbst von Romanen [...] was der deutsche Orientalismus jedoch mit dem anglo-französischen und später amerikanischen Orientalismus gemein hatte, 
war eine Art von intellektueller Autorität über den Orient innerhalb der westlichen Kultur.« (Said 1981: 28)

Er übersieht jedoch, wie Sheldon Pollock (2000) bemerkt, die Verbindung zwischen dem deutschem Orientalismus und der Herausbildung deutscher Identität. Der deutsche Orientalismus war für Pollock zwar nicht primär auf den Orient und seine Kolonisierung gerichtet, doch er formierte sich im dialogischen Verhältnis zum französischen und englischen Orientalismus ${ }^{7}$ und versuchte, die Rolle Deutschlands gegenüber Frankreich und England in Europa zu definieren. Der deutsche Orientalismus $»[\ldots]$ directs our attention momentarily away from the periphery to the national political culture and the relationship of knowledge and power at the core - directs us, potentially, towards forms of internal colonialism, and certainly toward the domestic politics of scholarship « (Pollock 2000: 304).

Die rassistische Formierung einer indogermanischen Identität als Gegenidentität zu den Semiten konnte für Pollock ohne den deutschen romantischen Orientalismus nicht funktionieren. Dieses orientalistische Wissen sei ein Teil der ideologischen Grundlage des »Dritten Reiches« geworden, die dazu diente, Juden zu verfolgen und Europa zu besetzen (vgl. Pollock 2000: 304ff). ${ }^{8}$ Die deutschen Kleinstaaten und ihre politische Machtlosigkeit machten es laut Nehring (2003) den Deutschen unmöglich, eigene Kolonien zu besitzen. Das habe die romantischen Dichter nach »geistigen Kolonien« suchen lassen, die sie in Indien bzw. im Sanskrit entdeckten. Deutscher Orientalismus und wachsender Nationalismus verbanden sich miteinander, wobei die Deutschen nach außereuropäischen kulturellen Wurzeln suchten (vgl. Nehring 2003: 42f). Es formierte sich die Phantasie, einen Ursprung der Kultur finden zu wollen, der sich von Aufklärung und französischer Revolution abgrenzte, wobei die Kultur als Begriff in Abgrenzung zum französischen Begriff der Zivilisation fungierte. Laut Nehring akzentuiert Norbert Elias, dass die deutsche Mittelschicht seit dem 18. Jahrhundert im Gegensatz zum französischen missionarischen Zivilisationsbegriff den Kulturbegriff einsetzt, welcher die nationalen Unterschiede in den Vordergrund stellt,

7 Die deutschen Orientalisten waren für Nehring zu Beginn im Wesentlichen von Texten über Indien geprägt, die von Engländern herausgegeben und übersetzt wurden (vgl. Nehring 2003: 43).

8 Pollock spricht von ca. 25 Indologie-Professoren der NS-Zeit. Ein Drittel waren aktive Partei- oder SS-Mitglieder. Abgesehen von den vom Arierparagraphen betroffenen jüdischen Professoren und solchen, die mit Juden verheiratet waren, hat sich keiner gegen das Regime positioniert oder das Land verlassen (Pollock 2000: 315). 
wobei die Sprache als Ausdruck und Charakter der nationalen Identität verstanden würde

»[...] durch die Entdeckung des Sanskrit als einer strukturell und semantisch dem Griechischen, Lateinischen und Deutschen verwandten Sprache und durch die Parallelisierung von griechisch-lateinischer Kultur und Religion mit der Sanskritkultur [...] [sollte] eine tiefere Verbindung hergestellt werden als zu Frankreich, von dem man sich mit der gleichen Sprachtheorie distanzieren wollte« (Nehring 2003: 44f).

Die deutschen Intellektuellen sahen die Deutschen somit als legitime Erben der indischen Tradition. Die Indologen Friedrich Schlegel, Max Müller, Franz Bopp und Paul Deussen sind wichtige Figuren, die im 19. und 20. Jahrhundert hohes Ansehen nicht nur in ihrem Fach genossen. Diese Namen waren seit dem Ende des 18. bis zum 20. Jahrhundert mit deutschen Interessen in Indien verbunden. Der deutsche Orientalismus war für Nehring politisch motiviert, auch wenn sich der Kulturbegriff von Politik und sozialen Fakten abgrenzte. Auch Andrea Polaschegg (2005) weist auf die Verbindung zwischen deutscher Identität und Orientalismus hin. Im deutschen (und europäischen) Diskurs der Romantik im 19. Jahrhundert hätten die Osmanen eine Funktion für die Bildung einer deutschen Identität erfüllt. Während des griechischen Befreiungskrieges gegen die Osmanen (1821-1828) hätten die deutschen Romantiker (Philhellenistische Literatur) das griechische Volk heroisiert, wobei das Bild der nicht-christlichen »Türken« zu erfinden einen kulturgeschichtlichen Ursprung des Eigenen in der Antike ermöglicht habe (Polaschegg 2005: 250ff).

Ähnlich argumentiert Andre Gingrich (1999), wenn er von einem »frontier«-Orientalismus spricht. Der klassische französische und englische Orientalismus sei für die Rechtfertigung einer Ideologie kolonialer Herrschaft einflussreich, für nationalistische Strömungen in England und Frankreich jedoch nie besonders fruchtbar gewesen. Der »frontier«Orientalismus dagegen sei seit dem 19. und 20. Jahrhundert für nationalistische Ideologien vor allem in Österreich, Deutschland und Spanien aktiviert worden. Im Gegensatz zum klassischen Orientalismus in Frankreich, England oder den Niederlanden, der sich primär an die einheimischen Oberschichten wandte, ist für Gingrich der »frontier«-Orient alismus vielmehr Gegenstand der Volks- und Populärkultur. Während der klassische Orientalismus exotische und erotische Abenteuer als Hauptsujets habe, so formuliere der »frontier«-Orientalismus Geschichten von Blut und Boden, Geschichten wie etwa von der Belagerung Wiens 1683. Er organisiere eine symbolische Anordnung von Raum und 
Zeit, von Landschaft und Geschichte. Es sei daher kein Zufall, dass vom späten 19. Jahrhundert an bis in die 60er Jahre des 20. Jahrhunderts die Metapher von Österreich als »Bollwerk» gegen den Osten dominant war. »Habsburgerischer Patriotismus und Deutschlands Nationalismus, ständestaatlicher Konservatismus und Nationalsozialismus, aber auch Varianten der Ideologien vom Kalten Krieg haben sich auf jeweils unterschiedliche Weise dieser Bollwerk- und Grenzlandmythen über Jahrzehnte bedient.« (Gingrich 1999: 33)

Es ist wichtig, auf die Differenzen und Brüche im OrientalismusDiskurs zu achten, deswegen muss er re-konzeptionalisiert werden. Die Theorie des Orientalismus von Said hat diese Veränderungen auf globaler Ebene nicht in Betracht gezogen (vgl. Turner 2000a: 7f). Der moderne Orientalismus war ja Expression des Kolonialismus, in der postkolonialen Phase brachen die orientalistischen Annahmen zusammen. Insbesondere markieren das Ende des Zweiten Weltkrieges und das des Kalten Krieges jene Phasen, in denen westliche Gesellschaften und diesbezüglich die orientalistischen Diskurse nicht zu unterschätzende Transformationen und Risse erlebt haben. ${ }^{9}$

»Infolge dieser Transformationen müssen sich Imperien der Gegenwart jetzt in neu konfigurierten Räumen im In- und Ausland mit subalternen Subjekten auseinandersetzen, da sich der Andere, der einst auf fernen Kontinenten gehalten wurde oder auf abgegrenzte Regionen im eigenen Land beschränkt war, zugleich vervielfältigt und auflöst. Kollektive Identitäten werden jetzt an fragmentierten Orten definiert, die sich nicht mit antiquierten Kategorien abbilden lassen [...].« (Coronil 2002: 215)

Wenn der Raum fließend wird, so Coronil, lässt sich Geschichte nicht mehr so leicht an festgelegte Territorien binden. Zwar führt die Deterritorialisierung zu einer Reterritorialisierung, aber dieser Prozess lässt lediglich die soziale Konstruiertheit des Raumes sichtbarer werden, denn sein »Einschmelzen« wird zum Teil durch das »Einfrieren« der Geschichte ausgeglichen. Diese Verräumlichung der Zeit dient als Ort neu-

9 Seitdem haben sich, Turner zufolge, die Rollen des Staates und der Intellektuellen verändert. Die elitären Institutionen haben weniger Einfluss auf die politischen Entscheidungsprozesse in der Innen- und Außenpolitik des Nationalstaates als während des Nationsbildungsprozesses im 18. und 19. Jahrhundert. Die Eliten sind nicht mehr kulturelle Legislaturen, sondern Interpretatoren (vgl. Turner 2000: 10). Während der Formierung von Nationalismus und Orientalismus übernahmen die Eliten die führende diskursproduzierende Rolle. Sie bestimmen jedoch nicht mehr, was der Inhalt und Standard der nationalen Kultur sein sollte. Massen- und Medienkultur und Kommerzialisierung transformierten die Funktion von gesellschaftlichen Eliten und Intellektuellen in den westeuropäischen Gesellschaften. 
er sozialer Bewegungen wie auch neuer imperialer Kontrolle; sie weitet den Bereich imperialer Unterwerfung, aber auch den politischer Auseinandersetzungen aus.

\section{Okzidentalismus und Subjektivität des Anderen}

Wenn die Erzeugung des Orients im Westen, »signifies the Wests own dislocation from itself, something inside that is presented, narrativised, as being outside« (Young 1990: 139), was für eine Rolle spielt dann die Bedeutung des »Westens « in den nationalen Identitäten der nichtwestlichen Gesellschaften? Said ist geprägt von der oben ausgeführten foucaultschen Diskurs- bzw. Machttheorie, der der französische Strukturalismus zugrunde liegt. Die globalen Machtstrategien regulieren und überwachen die Interaktionen von Subjekten, sie unterwerfen die Subjekte. Diskurs ist nicht unbedingt einseitig der Macht unterworfen, wirkt aber auch nicht notwendigerweise gegen sie. Er stellt lediglich Machtbeziehungen her. Es gibt Praktiken außerhalb des Diskurses, aber nichts abseits von Machtverhältnissen, da die Macht aus allem hervorgeht (vgl. Foucault 1983: 94ff).

Diese von Foucault geprägte Ausgangsposition Saids hindert ihn, den alternativen, kontra-hegemonialen Diskurs sowohl in westlichen als auch in nicht-westlichen postkolonialen Kontexten zu sehen (vgl. Porter 1983: 183; Menon 1993: 6). Das »orientale« Subjekt kann der westlichen Herrschaft nicht entgehen, es wird eingesperrt. Wenn jedoch die Hegemoniebildung des westlichen Diskurses eine gewisse Zustimmung oder Integration des Anderen erfordert, so bedeutet das, dass ohne Identifikationen des Anderen keine westliche Hegemonie in »orientalen« Gesellschaften hergestellt werden kann. Weil Macht individuelle oder kollektive »freie Subjekte« voraussetzt, auf die Macht ausgeübt wird, und nicht auf Sklaven (vgl. Foucault 1987: 255f), und weil die Hegemonialität eines Diskurses lediglich eine Tendenz ist, da die verfügbaren Sinnordnungen aufgrund von Antagonismen, Brüchen und Konflikten relativ in Bewegung sind (vgl. Keller 2004: 53), können die freien Subjekte und Subalternen unterschiedliche Prozesse der Identifikation und Verhaltensweisen gegenüber der hegemonialen Machtausübung zeigen.

Wie im zweiten Teil dieses Buches geschildert, werden Subjektpositionen als Folge von kontingenten artikulatorischen Prozessen produziert und sie transformieren sich durch neue Artikulationen. Die Formierung politischer Subjektivität resultiert genau aus einem Mangel in den Strukturen und es ist der Prozess der Identifikation, konstituiert durch diskursive Knotenpunkte, der politische Subjektivitäten hervorbringt. Die ko- 
loniale Unterwerfung wirkt insofern nicht vollständig, es gelingt ihr zwar, dem kolonisierten Subjekt einen Standort zuzuweisen, aber dieser angebotene Ort wird nicht voll besetzt. Das Andere fängt an für sich selbst zu sprechen und seinerseits Repräsentationen über den Westen zu konstruieren. Die Subjektivität des Anderen formiert sich in einem diskursiven dialogischen Prozess zwischen den europäischen und den nicht-europäischen Diskursen, wobei der imaginäre Blick des Anderen konstitutiv wirkt. Es geht um aktive macht- produzierende diskursive Praktiken des Anderen, die die normativen Grenzen des Adaptierens bzw. Imitierens westlicher Annahmen und Phantasien bestimmen. Die Verwestlichung führt insofern nicht zur Homogenisierung des Restes der Welt, sondern zu ihrer Transformation unter unterschiedlichen historischen Bedingungen (Coronil 2002: 213).

Die politische Beziehung zwischen Dominanten und Subalternen, zwischen Kolonisierenden und Kolonisierten ist, mit anderen Worten, ambivalenterer und komplexerer Natur, als Said (und G. C. Spivak) annehmen. ${ }^{10}$ Die Formierung des kolonialen Diskurses und seiner Machtstrukturen ist relativ unvollständig, konfliktgeladen und unsicher. Um sich zu konstruieren, sind beide Seiten aufeinander angewiesen. Die dominanten und subalternen Kulturen entstehen für Bhahba in einem dritten Raum, in dem Negationen, Identifikationen und KontraIdentifikationen stattfinden. Es besteht einerseits eine ambivalente Partnerschaft zwischen Kolonisierenden und Kolonisierten, andererseits bietet diese »Liminalität«, dieser Zwischenraum den Subalternen unerwartete, nicht anerkannte Wege, die kolonisierende Macht herauszufordern (vgl. Bhahba 2001: 619ff). Bhahba geht davon aus, dass, wie alle anderen Machtformen, auch koloniale Autoritäten »systematisch « aber »unintendiert« zur Herausforderung und Ablehnung einladen (vgl. MooreGilbert 2001).

10 Geprägt von Said, spricht Spivak (2001) von der Abwesenheit von Räumlichkeit, in der die Subalternen sich artikulieren und ihre Interessen und Erfahrungen mit ihren eigenen Begriffen und Repräsentationen für die anderen zugänglich machen können. Spivaks Kritik richtet sich in erster Linie gegen kritische europäische Intellektuelle, wie Foucault, Deleuze und Kristeva. Diese gingen davon aus, dass marginalisierte Gruppen sowohl in westlichen als auch in nicht-westlichen Gesellschaften autonome Subjekte sein und für sich sprechen könnten. Jene selbst nicht subalternen Aktivisten und Forscher konstruierten imaginäre utopische Subjektpositionen für Subalterne und Kolonisierte. Es gehe um Enttäuschungen und Desillusionierungen in den Kontexten westlicher Gesellschaften, in denen diese Aktivisten und Forscher eingebettet sind. Die Feministinnen der westlichen Gesellschaften beispielsweise erfanden die Frauen der Dritten Welt, um sich selbst konstituieren zu können (vgl. Spivak 2001: 1427). 
Die Frage, wie orientalistische Annahmen und Repräsentationen durch den nationalistischen Diskurs des Anderen im kolonialen Kontext eingebettet werden, ist insofern entscheidend. Partha Chatterjee zeigt diesbezüglich einflussreiche Impulse auf. Als die Eliten den nationalistischen Diskurs im kolonialen Kontext formulierten, so Chatterjee, adaptierten sie die westlichen Technologien und gaben die »Rückschrittlichkeit ihrer Nation « im Hinblick auf den von Westen festgelegten globalen Standard zu. Doch diese Nationalismen, die die »Stufe« der westlichen Modernisierung zu erreichen wünschten, konnten nicht die »fremde Kultur« einfach imitieren, denn sie hätten dadurch ihre Differenz verloren. Deshalb seien diese nationalen Identitäten »zerrissen«: Sie wollen auf dem materiellen Feld mit dem Westen gleichziehen, dabei aber gleichzeitig kulturell ihre Distinktion bewahren. Sie akzeptieren die Epistemologien und Methodologien des westlichen modernistischen Diskurses, beharren jedoch auf der »authentischen« Identität ihrer nationalen lokalen Kultur. Sie akzeptieren und lehnen sie zugleich ab (vgl. Chatterjee 1993: 11). Chatterjee zufolge unterscheiden die Nationalismen der (kolonialen) nicht-westlichen Gesellschaften während des Modernisierungsprozesses zwischen materiellen und immateriellen Feldern. Sie unterscheiden zwischen westlichen Institutionen und Technologien auf dem materiellen Feld, auf dem diese Nationalismen die koloniale westliche Überlegenheit internalisieren, und nationalen lokalen Werten/Normen/Traditionen auf dem immateriellen Feld. Das materielle Feld kennzeichnet das Außen, während das immaterielle Feld die »Essenz« der kulturellen Identität im Innen charakterisiert. Genau auf Basis dieser Spaltung operiert der Nationalismus in nicht-westlichen Gesellschaften, wobei er das immaterielle Feld als sein souveränes Gebiet deklariert, auf dem die koloniale Macht sich nicht einmischen darf. Das bedeutet nicht, dass dieses immaterielle Feld als solches konserviert bleibt. Der nationalistische Diskurs versucht, hier eine moderne aber nicht-westliche nationale Kultur zu gestalten. Da die Nation eine imaginäre Gemeinschaft ist, ist in nicht-westlichen Gesellschaften genau dieses immaterielle Feld der Ort, wo die Nation imaginiert wird.

Chatterjees Hauptthese ist, dass »Dritte-Welt-Nationalismen« den orientalistischen Diskurs zwar nicht brechen konnten, sondern die Hegemonie des Orientalismus reproduzierten, indem sie ihn adaptierten. Doch ist die Beziehung zwischen Nationalismus in nicht-westlichen Gesellschaften und Orientalismus nicht eine einfache einseitige Imitation. Ihr Nationalismus selektiert, was er imitiert und was er lässt. Dieser Diskurs muss sich zu seiner Rechtfertigung von der kolonialen Herrschaft distanzieren und gegen sie antreten, um der »Nation« zu zeigen, dass er sich vom kolonialen Diskurs abhebt. Insofern unterscheidet sich der Na- 
tionalismus der nicht-westlichen Gesellschaften vom kolonialen Diskurs, doch er ist dominiert von ihm. Chatterjee zufolge akzeptieren nationalistische Eliten die epistemologischen und ontologischen Annahmen des orientalistischen Diskurses auf der Ebene der »Thematik«. Sie seien jedoch nicht passiv, sondern reagierten auf der Ebene der »Problematik« als aktives Subjekt. ${ }^{11}$ Ihr Diskurs sei eine Version des Orientalismus auf der Kehrseite (vgl. Chatterjee 1993: 38ff).

Sadik Jalal al-Azm (2000) beschreibt einen »Orientalism in Reverse«. In der »arabischen Welt« formiere sich eine Art islamischer Nationalismus, der einen ontologischen Unterschied zwischen »westlichem« und »arabischem Geist « macht, der entweder den Orientalismus verinnerlicht und sich selbst primitiv und primordial wahrnimmt oder einen überlegenen »arabischen Geist« einem primordial-primitiven »westlichen Geist« gegenüberstellt (vgl. Jalal al-Azm 2000: 231ff). Chen (2001) kritisiert Said dahingehend, dass er zum einen den sich gegen die westliche Expansion positionierenden kritischen Gegendiskurs in den westlichen Gesellschaften ignoriert habe, der die westliche Dominanz wenig unterstützte, sondern sie vielmehr subversierte. Zum anderen habe er kritische Gegendiskurse innerhalb der »orientalen« Gesellschaften ignoriert, die ihrerseits den offiziellen nationalistischen okzidentalistischen Diskurs vesetzten. In seiner Analyse des chinesischen Modernisierungsdiskurses bzw. des Anti-Traditionalismus der maoistischen Staatseliten seit der »Kulturrevolution« stellt Chen fest, dass China extrem orientalisiert und der Orientalismus auch stark sich selbst auferlegt wurde. Da die Inhalte und Formen des Orientalismus in China modifiziert wurden, soll er Okzidentalismus genannt werden. Okzidentalismus ist für Chen $»[\ldots]$ a discursive practice that by constructing its own Western Other, has allowed the Orient to participate actively and with indigenous creativity in the process of self - appropriation, even after being appropriated and constructed by Western Others« (Chen 2001: 935). Es formierte sich ein neuer Diskurs, der aus der Kombination der westlichen Konstruktion Chinas mit der chinesischen Konstruktion des Westens besteht, während beide Kompetenten interagieren und miteinander verschmelzen. Die einheitlich aussehenden diskursiven Praktiken des Okzidentalismus befinden sich in einer paradoxen Beziehung mit den

11 »Thematik« entspricht den epistemologischen und ethischen Rahmenbedingungen für Elemente sowie den Regeln zur Bildung von Beziehungen zwischen diesen Elementen. Es geht um die zentralen Annahmen und Regeln eines ideologischen Systems, das sich im Hinblick auf Epistemologie (Annahmen darüber, wie Wissen strukturiert ist) und Ethik (was moralisch korrekt ist) ausdrückt. «Problematik» bedeutet dagegen eine Serie von möglichen konkreten Strategien, wie auf der Ebene der Thematik gehandelt werden könnte (Chatterjee 1993: 38f). 
diskursiven Praktiken des Orientalismus und teilen seine ideologischen und ethischen Annahmen und Strategien.

Doch beide haben unterschiedliche ideologische Funktionen. Während Orientalismus im saidschen Sinne die diskursiven Strategien der westlichen Dominanz bedeute, so Chen, sei Okzidentalismus ein Diskurs, der unterschiedliche Funktionen für unterschiedliche miteinander streitende Gruppierungen in der chinesischen einheimischen Politik gehabt hätte: Okzidentalismus sei der Diskurs der Unterdrückung und der Befreiung zugleich. Es gibt Chen zufolge zwei unterschiedliche diskursive Formationen oder Aneignungsstrategien insbesondere in der postmaoistischen Phase innerhalb desselben okzidentalistischen Imaginären. Diese unterschiedlichen Aneignungsstrategien und Positionierungen führten zu unterschiedlichen politischen Resultaten in der chinesischen Gesellschaft. Er unterscheidet dabei zwischen offiziellem und antioffiziellem Okzidentalismus. Das, was Chen »offizieller Okzidentalismus « nennt, »[...] uses the essentialization of West as a means for supporting a nationalism that effects the internal suppression of its own people« (Chen 2001: 936).

In diesem Prozess hat die Konstruktion des Westens durch die chinesische Imagination nicht zum Ziel, den Westen zu dominieren, sondern die eigene Nation zu disziplinieren. Dabei hat der offizielle Okzidentalismus den Westen als städtisch-bourgeois und den Osten als bäuerlich-proletarisch konstruiert. Der Kampf sollte ein Kampf des bäuerlichen Ostens gegen den städtischen imperialistischen Westen sein und es sei China, das die Befreiung der bäuerlichen Dritten Welt übernehme. Chen betont dabei die unmittelbaren politischen Wirkungen des offiziellen Diskurses nach innen: Es gehe um die diskursiven Strategien zur Hegemoniebildung innerhalb der einheimischen Gesellschaft und weniger in der globalen Welt.

Unter anti-offiziellem Okzidentalismus versteht Chen » $[\ldots]$ a powerful anti- official discourse using the Western Other as a metapher for the political liberation against ideological oppression within totalitarian society « (Chen 2001: 938). Okzidentalismus kann insofern von marginalen und peripheren Diskursen gegen die interne zentralistische dominante Macht in einer partikulären Kultur benutzt werden. Unter bestimmten Umständen gegen kulturellen Imperialismus auf der internationalen Ebene zu argumentieren, ist Chen zufolge gefährlich, denn es könne dem Status Quo der herrschenden Ideologie dienen. In dieser Hinsicht bedeutete Akzeptanz der westlichen Hegemonie eine politische Gelegenheit der Befreiung der marginalisierten Anderen (vgl. Chen 2001: 939ff). Insofern sollte die Aufmerksamkeit auf die antagonistisch positionierten Subjekte sowohl innerhalb der westlichen als auch der »orien- 
talen« 'Gesellschaften gerichtet werden. ${ }^{12}$ Während der Diskurs der orientalen Anderen zur Unterdrückung ihrer eigenen Gesellschaft funktionalisiert werden kann, können bestimmte westliche Diskurse die westliche Dominanz in Frage stellen. Chen kommt zu einer ähnlichen Schlussfolgerung wie Chatterjee, dass der chinesische offizielle Okzidentalismus ein Produkt des westlichen Orientalismus ist, auch wenn sie unterschiedlichen Zielen dienen.

\section{Fazit}

Orientalismus essentialisiert, wie Said feststellt, die unterschiedlichen nicht-westlichen Gesellschaften als uniform und ewig kohärent. Dabei geht es weniger um die Korrespondenz zwischen Wissen und Realität und weniger um die Missrepräsentation »orientaler« Wirklichkeiten, sondern vielmehr um eine symbolische Ordnung, in der symbolische Grenzen zwischen »Okzident« und »Orient« gezogen werden, wobei Wissen und Phantasie im Diskurs immanent sind. Mit den Begriff Orientalismus werde ich die Summe von westlichen Repräsentationen und Phantasien meinen, die nicht nur Differenzen zwischen West und Ost markieren, sondern auch von einer Überlegenheit der westlichen Kultur ausgehen. Die orientalistischen Äußerungen sind gleichzeitig als diskursive Bemühungen zu verstehen, die eigenen Widersprüche und Mängel zu maskieren und selbst vollständig zu werden.

Im Gegensatz zu Said jedoch werde ich erstens die Heterogenität bzw. Plurarität und Offenheit des Orientalismus akzentuieren. Wenn der Europabegriff plurale Signifikaten bezeichnen und mehrere Interpretationen zulassen kann, so kann der Orient als Signifikant heterologische Bedeutungen und Interpretationen in den verschiedenen unfixierten

12 Chen gibt als Beispiel die unterschiedlichen politischen Entwicklungen und diskursiven Formationen des Okzidentalismus in Süd- und Nordkorea nach dem Zweiten Weltkrieg. Bezogen auf die Arbeit von Chungmoo Choi (1993), formierten sich Chen zufolge beide Diskurse während des Kalten Kriegs zwischen den amerikanischen und russischen Ideologien. In Südkorea entwickelte sich nach der Dekolonisierung ein pro-amerikanischer Okzidentalismus, als »colonization of consciousness«, wobei die nationalen Eliten sich als privilegierte Gruppen, die an der westlichen Kultur teilnehmen durften, betrachteten und sich von der »unterlegenen rückschrittlichen« einheimischen Kultur distanzierten (vgl. Chen 1995: 944). Dagegen formierte sich in Nordkorea ein offiziell anti-amerikanischer und anti-westlicher Okzidentalismus, währenddessen sich das Land ebenfalls modernisierte und von der lokalen Kultur distanzierte. In der Tat hatten beide offiziellen okzidentalistischen Diskurse unmittelbare politische Folgen für die einheimische Bevölkerung und die Stabilisierung der politischen Herrschaft. 
Kontexten hervorrufen. Die Anwendung der orientalen Figuren kann sich von einem historischen Moment zum anderen und von einer Diskursformation zur anderen unterscheiden. Die Bedingungen der diskursiven Formationen sind nicht singulär, sie operieren in Ambivalenzen und Antagonismen. Die Bedeutung des Orients verändert sich relational zur Verschiebung der Bedeutung des Okzidents. ${ }^{13}$

Zweitens akzentuiere ich, dass Saids Theorie im Prozess der Orientalisierung des Orients für die Subjektivität des Anderen kaum Handlungsräume lässt. Der orientalistische Diskurs wird für Said nur vom »Westen« generiert, der sich auf Kosten des »Ostens« maximiert (vgl. Moore-Gilbert 2001; Jalal al-Azm 2000). Es ist dahingehend von zentraler Bedeutung zu fragen, wie diese westlichen Annahmen und Repräsentationen durch den nationalistischen Diskurs im Kontext der nicht westlichen Gesellschaften eingebettet werden. Diese Frage bleibt bei Said unbeantwortet. Die kollektiven Akteure handeln nicht einfach nach bestimmten Deutungsmustern, die ihnen zugeschrieben sind, sondern gestalten mit, sie pervertieren oder, in bestimmten Fällen, verändern diese Zuschreibungenperformativ durch Konsolidierung oder Infragestellung ihrer Selbst und ihrer Position als Anderer.

Ich werde an dieser Stelle »Okzidentalismus« als einen synthetischen Begriff für den türkischen Gesamtdiskurs vorschlagen, um die türkische Subjektivität $\mathrm{zu}$ erfassen. Okzidentalismus, verstanden als strukturiertes nationales Imaginäres, liefert eine Antwort auf die Frage, wie und inwieweit die westlichen und östlichen Figuren in der türkischen nationalen Identität eine konstitutive Rolle spielen. Okzidentalismus formiert sich nicht (allein) gegen den Orientalismus, sondern in einem dialogischen Prozess mit ihm, er beantwortet ihn, indem er sich den Blick des Anderen aneignet (vgl. Ahıska 2005). Der Begriff »Westen « ist dabei der permanente Signifikant in der Sprache des türkischen öffentlichen Raumes und übt eine effektive Macht in der Imaginierung der modernen türkischen Identität, sowohl als Bedeutung für »Fortschritt«, »Demokratie« und »Wohlstand« als auch als Figur der Entfremdung bzw. Bedrohung aus. Die Analyse des Okzidentalismus beschäftigt sich nicht nur mit der ambivalenten Identität des nichtwestlichen Subjektes, wobei das Bild und der Blick vom Westen ein integraler Teil dieser Identität geworden sind, sondern auch mit dem Sichtbarmachen von Widersprüchen innerhalb des Okzidentalismus so-

13 In vielen Texten des 18. Jahrhunderts bezeichnete der Begriff Orient, Lowe zufolge, das vom Osmanischen Reich okkupierte Territorium (die Levante, arabische Halbinsel und Mittelost). Im 19. Jahrhundert impliziert der Begriff zusätzlich Nordafrika und im 20. Jahrhundert auch das zentrale und südliche Asien (vgl. Lowe 1991: 7). 
wie mit seinen vor allem nach innen gerichteten Strategien des Regierens und Disziplinierens.

Welche Formen von Orientalismus und Okzidentalismus werden im deutschen und türkischen Europadiskurs sichtbar, wie reagieren und wie beziehen sie sich aufeinander? Bevor ich auf diese Fragen im empirischen Teil ausführlich eingehe, werde ich im Folgenden das türkische diskursive Feld seit der osmanischen bzw. türkischen Modernisierungsgeschichte mit seinen Kontinuitäten, Brüchen und Widersprüchen rekonstruieren. Dabei soll die ambivalente Bedeutung Europas in der türkischen nationalen Identität in den Vordergrund gestellt werden. Es soll gezeigt werden, wie die osmanischen und türkischen Diskurse historisch auf westliche Repräsentationen und Handlungen reagierten, inwieweit sie sich mit europäischen Diskursen verflochten und inwieweit sie sich von ihnen abgrenzten. 


\section{TÜRKISCHE IDENTITÄT und Bedeutung des Westens}

Im türkischen Modernisierungsprozess werden von den kritischen Perspektiven aus vornehmlich zwei Strukturmerkmale akzentuiert: Die Modernisierung in den westlichen Gesellschaften sei in einem »natürlichen « Prozess vonstatten gegangen, während sie in der Türkei auf Anordnung von oben initiiert wurde. Die türkische nationale Identität wird als imaginäre Kopie der westlichen Normen und Werte und als nicht "gewachsen« betrachtet. Des Weiteren wird der kontinuierliche Einfluss der Bürokraten und des Militärs im Osmanischen Reich und der Türkischen Republik beobachtet. Der Staatsapparat sei ohne Brüche vom alten System ins neue tradiert worden. Dabei werden zumeist die Subjektivität und die internen Machtpraktiken der Türkei aus den Augen verloren. Türkische Akteure haben nicht nur die ihnen aufgezwungene westliche Modernität imitiert, so habe ich oben argumentiert, sie haben nicht nur die westlichen Annahmen internalisiert, sie produzierten darüber hinaus die Repräsentationen über West und Ost und fingen an von diesen Positionen aus zu sprechen. Es geht hier vor allem um die subjektive Bestimmung der normativen Grenzen im Bildungsprozess der türkischen Nation. 


\section{Der osmanische Modernisierungsprozess}

Die osmanischen Reformen seit der sogenannten »Tanzimat-Periode ${ }^{1}$ bis zur Gründung der türkischen Republik 1923 werden von den dominanten Thesen als Anfang des »Verfalls« des Osmanischen Reiches bzw. als Anfang des Modernisierungsprozesses und als erstarkende europäische Hegemonie über die osmanischen Eliten interpretiert (vgl. Heper 1993; Lewis 1993). Die osmanische Modernisierung in diesem Jahrhundert sei im Wesentlichen von dem Motiv geleitet worden, den »verfallenden osmanischen Staat zu retten«. Heper zufolge waren die Träger der Modernisierung die osmanischen Eliten, denen es nicht darum ging, einen gesellschaftspolitischen Wandel herbeizuführen, sondern pragmatische Maßnahmen einzuleiten, die das Reich »retten« sollten (vgl. Heper 1993: 37). Die Modernisierungsbemühungen, insbesondere bis zur Jungtürken-Revolution (ITC) ${ }^{2}$ im Jahre 1908 könnten als eine Art von pragmatischer »defensiver Modernisierung« bezeichnet werden, weil man nahezu ausschließlich versucht habe, die Funktionen der staatlichen Institutionen zu rationalisieren, um den »Zerfall« zu verhindern (Mardin 1998; Çaha 2000).

Politökonomische Ansätze heben dagegen hervor, dass bereits seit dem 16. Jahrhundert die Produktionsverhältnisse und die Sozialstruktur

1 Die Reformperiode zwischen 1839 und 1876 ist als »Tanzimat-Periode« bekannt. Der Begriff Tanzimat bedeutet »ordnen« oder »umordnen« und verweist auf eine Reihe von Modernisierungsreformen, die 1839 mit der Verkündigung des »Gülhane-Erlasses« eingeleitet wurden. Der Erlass wurde in Anwesenheit aller europäischen Botschafter am Sultanshof in Gülhane in Istanbul verkündet. Dabei wurde der Schwerpunkt auf drei Punkte gelegt: Den Untertanen wird die volle Sicherheit für ihr Leben, ihre Ehre und ihr Vermögen garantiert; die Steuern werden gerecht und geregelt festgesetzt und eingetrieben; die Wehrdienstpflichtigen werden geordnet einberufen und ihre Wehrdienstzeit wird geregelt (vgl. Somel 2001: 96).

2 ITC (Gesellschaft von Einheit und Fortschritt), wurde 1889 zuerst als Itti$h \bar{a} d-i$ Osmani (Osmanische Einheit) in der militärischen Medizinakademie (Askeri Tıbbiye) gegründet und wurde 1894 in Ittihād ve Terraki Cemiyeti umbenannt (Mardin 2003b: 98). ITC gab ab 1895 die Zeitschrift »Meşveret« in Paris und Genf heraus, in der neben der gegen den Sultan gerichteten Kritik auch die Einmischung der westlichen Länder in die inneren osmanischen Angelegenheiten häufig zur Sprache gebracht wurde (Mardin 2003a: 188ff) Die wichtigsten Reformen der ITC Regierung betrafen die Säkularisierung von Erziehung und Justiz. Zum einen wurden nun die gesamten Schulen und Universitäten dem Erziehungsministerium unterstellt, zum anderen unterwarfen die Gerichte sich der Autorität des Justizministeriums. Damit schufen die Jungtürken die Dualität zwischen den herkömmlichen Regelungen und den aus den Reformen resultierenden neuen $\mathrm{ab}$. 
des Reiches angefangen hatten, sich zu transformieren (Wallerstein et al. 1990; İslamoğlu-İnan 1990). Insbesondere in Rumeli (europäischer Teil des Reiches) ist ab dem 17. Jahrhundert die Herausbildung eines Großbauerntums und einer Handelsklasse zu beobachten, die sich der politischen Kontrolle der osmanischen Herrschaft entzogen. Wallerstein et al. zufolge sollten deshalb die osmanischen Reformprozesse nicht auf die bürokratischen Eliten und militärischen Niederlagen reduziert werden. Die osmanischen Reformprozesse dürften nicht isoliert betrachtet werden, sondern müssten vor dem Hintergrund einer wirtschaftlichpolitischen Inkorporation ${ }^{3}$ des Reiches im Kontext der kapitalistischen Weltökonomie gesehen werden, welche zu einer Semi-Kolonialisierung und Peripherisierung des Reiches führte. Relevant für diesen Ansatz sind vor allem der Eintritt des westlichen Finanzkapitals in das Osmanische Reich im 18. und 19. Jahrhundert und die Handelsbeziehungen mit den europäischen Staaten, welche die Transformationsprozesse des Staatsapparats und der Sozialstruktur begünstigt hätten (vgl. Wallerstein et al. 1990: 92ff).

Auch die Rolle der Handelsklasse, welche von den christlichen und jüdischen Millets ${ }^{4}$ dominiert wurde, solle dabei nicht unterschätzt werden. Der Außenhandel wurde insbesondere zwischen den über Fremdsprachenkenntnisse verfügenden nicht-muslimischen Untertanen und westlichen Handelsunternehmern abgewickelt, was die ökonomischen Beziehungen vertiefte und den Akkumulationsprozess beschleunigte. Es sei daher kein Wunder, dass Nationsbildungsprozesse vor allem in jenen Industrie- und Handelsgebieten vorangetrieben worden waren, wo sich kapitalistische Marktverhältnisse mehr oder weniger etablierten. Unter

3 Unter Inkorporieren versteht Wallerstein, dass die Produktionsprozesse einer Region ein Teil der integrierten Arbeitsteilung des kapitalistischen Weltwirtschaftssystems wurden und den Befehlen von Kapitalakkumulationstrieben Folge leisteten. Dies hatte oft Änderungen in Eigentumsstrukturen und in sozialen Produktionsbeziehungen zur Folge. Darüber hinaus setzte die Peripherisierung voraus, dass, sobald ein Weltreich inkorporiert war, ein gewisser Rückgang der Einflussnahmefähigkeit des Staatsapparates im Rahmen der Weltwirtschaft durch verschiedene produktive Faktoren einsetzte.

4 Millet-System ist die besondere Form der sozialen, religiösen und administrativen Organisation des Osmanischen Reiches. Die osmanische Gesellschaft bestand aus zwei Hauptteilen: Muslime und Nichtmuslime. Der soziale Status der Individuen wurde hauptsächlich von der Religion bestimmt. Die osmanische Gesellschaft war auf der Grundlage des Glaubens in verschiedene Millet aufgeteilt. Millet bezeichnete eine bestimmte Religions- bzw. Konfessionsgemeinschaft, Orthodoxe (Griechen), Armenier, Katholiken, Juden und Protestanten (vgl. Eryılmaz 1996). 
den Untertanen seien es wiederum jene christlichen gewesen, bei denen sich die Idee der Nation am ehesten verbreitete.

Diese politökonomischen Studien machen darauf aufmerksam, dass die Gründe für die starke Repräsentation der nicht-muslimischen Untertanen des Reiches im Handel auf die Tatsache zurückzuführen sei, dass ihnen Grundbesitz und Beamtentum versagt waren, was zu einer Art ethnisch-religiösen Ökonomie im Handel und Finanzbereich geführt habe. Der Handelsbereich sei in den osmanischen Großstädten insbesondere ab dem 17. Jahrhundert am wenigsten unter der Kontrolle des Sultans gewesen, jedoch hatte er auch kaum politischen Einfluss auf die osmanische Obrigkeit. Ab dem 17. Jahrhundert seien Nichtmuslime hingegen für die europäischen Staaten die Kanäle der politischen und wirtschaftlichen sowie missionarisch-religiösen Einflussnahme gewesen (vgl. Göçek 1996: 93ff). Neben den militärischen Niederlagen, territorialen Verlusten auf dem Balkan und in Kaukasien Ende des 19. Jahrhunderts und Anfang des 20. Jahrhunderts (Keyder 2003: 77ff) und der Peripherisierung des Reiches sei es vor allem seit der »Tanzimat-Periode« darum gegangen, die Integrität des Reiches im Inneren gegen wachsende Nationalismen von christlich-ethnischen Gruppen zu gewährleisten, deren Anteil ca. 40 Prozent der Gesamtbevölkerung des Reiches ausmachte (vgl. Çetinsaya 2001a: 54). Es sollten institutionelle und politische Reformen durchgeführt werden, um diese Minderheiten zu reintegrieren.

In der »Tanzimat-Periode« traten neue Begriffe und Narrationen der Aufklärung in den Diskurs ein, wie »Zivilisation« (Medeniyet) und »Fortschritt« (Teraki). In den narrativen Strukturen des reformistischen Diskurses in der ersten Periode der Tanzimat bis zur Mitte des 19. Jahrhunderts werden allerdings islamische Medeniyet und europäische »Zivilisation« (noch) nicht voneinander getrennt gesehen. Die europäische Zivilisation wird als das verlorene Erbe der islamischen Zivilisation wahrgenommen (vgl. Çetinsaya 2001a: 57; Kara 2001: 238). Unter dem Begriff Zivilisation wurden laut Çetinsaya (2001a) in erster Linie Materielles, Wissenschaften, Wohlstand, technischer Fortschritt etc. verstanden. Für die Tanzimat-Reformisten habe kein Widerspruch zwischen Zivilisation und Fortschritt einerseits und islamischer »Essenz« andererseits bestanden, weil Wissenschaft und Zivilisation als universal und auf Vernunft und Rationalität basierend betrachtet worden seien. Es sei ihnen demnach nicht um die klimatische, territoriale und religiöse Bedeutung des Begriffes gegangen. Die Übernahme der westlichen Technologien würde der Mentalität, Kultur und Religion des muslimischen Volkes nicht widersprechen. Die Reformisten seien überzeugt gewesen, dass, wenn die Osmanen bestimmte institutionelle und politische Reformen verabschiedeten, sie den europäischen Fortschritt einholen wür- 
den. Ihr Import in das osmanisch-islamische Reich solle nicht $\mathrm{zu} \mathrm{Be-}$ denklichkeiten (z.B. dem Verlust kulturell-sozialer Werte) führen, sondern umgekehrt, es gebe keinen Ausweg, sich selbst und den Islam zu retten, wenn man sich nicht europäische Wissenschaften und Technik aneigne. Der Islam würde davon nur profitieren und nur dadurch könne er die europäische Zivilisation aufholen (vgl. Çetinsaya 2001a: 55ff).

In diesem Rahmen hätten die Reformisten nicht nur vom Nutzen der Zivilisation und des Fortschritts in militärischen, wirtschaftlichen und bürokratischen Bereichen, sondern auch im politischen Bereich gesprochen, indem Individual- und Eigentumsrechte garantiert und die Willkür der politischen Herrschaft unter Kontrolle gebracht worden seien. Ein Rechtsstaat solle etabliert werden. Das alles seien zwingende Notwendigkeiten der Zivilisation, um den Fortbestand des Reiches zu sichern. Die Reformen würden sowohl die nicht-muslimische Bevölkerung reintegrieren als auch die europäischen Interventionen im Inneren verhindern. Ein Zuwachs an Freiheiten würde die Loyalität der Nichtmuslime verstärken. Unter Freiheit (Hürriyet) sei weniger die politische, sondern vielmehr die wirtschaftliche und individuelle Freiheit verstanden worden (vgl. Çetinsaya 2001: 58ff). Für Kara (2001) waren in den nach innen gerichteten diskursiven Praktiken islamische Elemente artikuliert worden, um die neuen Institutionen und Reformen zu rechtfertigen. Diese hätten in erster Linie in islamischen Texten nach Legitimation gesucht. $\mathrm{Zu}$ reformieren bedeutete, den »Staat $\mathrm{zu}$ retten«, was wiederum den »Islam zu retten« bedeutete (vgl. Kara 2001: 253).

\section{Republik und Imitation von Oben}

Mit der Gründung der Republik stieg Kahraman (2002) zufolge der Begriff »Verwestlichung« zum privilegiertesten Signifikanten des modernistischen Diskurses auf. Die westliche Modernität wurde in ein totales Projekt übersetzt und bekam einen teleologischen Charakter (vgl. Kahraman 2002: 162). Ziel sei nicht mehr die »Rettung« bzw. Reformierung des Staates durch pragmatische Maßnahmen, wie es im 19. Jahrhundert der Fall war, sondern eine selbst-missionarische Reinkarnation, die Erziehung eines neuen Menschen- und Gesellschaftstypus nach einem vorgestellten westlichen Vorbild (vgl. Kaliber 2002: 106).

Ein gesamtgesellschaftlicher Wandel wurde jedoch nicht vollzogen. Insofern sei die türkische »Revolution« eine »Reformation« gewesen, die den institutionellen und staatlichen Superstrukturen verschrieben blieb. Die türkischen Eliten seien der Überzeugung gewesen, dass die institutionellen Regulierungen bzw. Imitationen für das neue »Projekt« 
ausreichend wären. Das Ziel sei die Erschaffung und Erziehung einer Gesellschaft gewesen, jedoch gliche diese mehr einer »Imitation«, so dass die Gesellschaft zwar eine westliche Erscheinung bekam, sich aber nicht wirklich transformierte. Während diese Reformen verabschiedet wurden, dominierte im Diskurs nicht der Begriff »westlich werden« ( $b a$ tılı olmak), sondern »zivilisiert werden« (medeni olmak). »Die Regierung bestraft diejenigen, die gegen Gesetze verstoßen, und die Zivilisation bestraft diejenigen, die ihren Regeln nicht gehorchen. Diejenigen, die nicht fortschreiten, die nicht zivilisiert werden, sind verurteilt, die Sklaven von Anderen zu sein [...]« (Abdulbaki (1927), zit.n. Üstel 2005: 177).

Der Dualismus zwischen Zivilisation und Kultur - Zivilisation als Import von westlicher Technik, Kultur als domestische Normen und Werte - wurde, Kahraman zufolge, mit Gründung der Republik in ein totales Zivilisationsprojekt aufgelöst. Für die neuen Eliten bedeuteten $»$ Westen« und »Zivilisation«, »zivilisiert sein« und »national werden« von nun an dasselbe: "Wir möchten unser Land verwestlichen. Alle unsere Bemühungen gehen dahin, eine zeitgemäße, das heißt westliche Staatlichkeit (Regierungsform) zu gründen. Welche Nation kann sich Zivilisation wünschen, ohne sich dem Westen zuzuwenden« (Atatürk 1990: 66).

In diesem Formierungsprozess besaßen die Akteure der türkischen Republik Şerif Mardin (1998) zufolge nach wie vor keine Methode und keine theoretische Basis. Da sie die Ausbildungsinstitutionen und kulturellen Gewohnheiten des Westens lediglich imitiert hätten, verfügten sie nicht über das Wissen von deren Bedeutung und Ontologie. Einerseits übernahm die neue Republik die alten staatlichen Mechanismen und Gewohnheiten des "patrimonialen« osmanischen Staates, andererseits imitierten sie die »westliche Kultur.« Insofern existiert für Mardin keine radikale Diskontinuität zwischen den neuen republikanischen und den osmanischen Reformisten. Die osmanischen Modernisierungsbestrebungen zur Verhinderung des »Staatsverfalls« entsprächen auch denen der neuen republikanischen Reformisten. Es ginge seit den ersten Reformen der Osmanen bis zu den 1950er Jahren nach wie vor um die Stärkung des Staates und des Regierens und nicht etwa um die Stärkung der Demokratie und politischen Partizipation (vgl. Mardin 1998: 55f).

Die Reformer pflegten eine dominante positivistische Mentalität, die unter Politik eine Art soziale Technik verstand, die danach trachtete, eine völlig neue Gesellschaft und ein neues soziales System zu produzieren. Dieser monologische Diskurs war überzeugt, dass der Staat durch sozial-technische Mittel diese neue türkische Gesellschaft erschaffen könne und zu einer totalen Kontrolle derselben in der Lage sei. Nur da- 
durch könne die Sicherheit des Staates gewährleistet werden: fabrizieren und kontrollieren, unter Ausschluss von öffentlichen Räumen - eine Republik ohne Öffentlichkeit und politische Partizipation. Anders formuliert, man wollte einen autoritären Staat, der sich als Eigentümer der Öffentlichkeit verstand und letztere als solche »kolonisierte« (vgl. Toker/ Tekin 2002: 84ff). Die Gesellschaft ist dabei das Objekt der Verwirklichung von zentralistischen staatlichen Projekten und pragmatischen Experimenten geworden (vgl. Çaha 2000: 190ff), und was für den Staat und die Gesellschaft gut und nützlich war, hatten nach wie vor die Eliten zu entscheiden (vgl. Sarıbay 1995: 168). Dies stellte den primären Status des Staates vor der Gesellschaft sicher und reproduzierte die patrimoniale bürokratisch-militärische Staatstradition (vgl. Kaliber 2002: 121).

Nilüfer Göle (1998) und Ayşe Kadıoğlu (1999) zufolge folgte der türkische Modernisierungsstil einem Muster, nach dem die herrschenden lokalen Eliten ihre Vorstellungen von einem westlichen Kulturmodell durchsetzten. Nach Kadıŏlus Interpretation verstanden sich sowohl die türkischen als auch die osmanischen Eliten als Gesellschaftsingenieure. Sie waren davon überzeugt, dass, wenn sie die westlichen Institutionen übernähmen, die osmanische bzw. türkische Gesellschaft ebenso westlich sein würde. Diese ahistorische Vorstellung von Verwestlichung habe $\mathrm{zu}$ einer rein formalen Übernahme von westlichen Institutionen geführt (Kadığlu 1999: 28). Der real vollzogene und antizipierte Aufklärungsprozess in den westlichen Gesellschaften sei von diesen Ingenieuren in ein positivistisches Projekt transformiert worden. Dieser von den zeitgenössischen französischen Positivisten stark geprägten Denkweise fügten sie von oben Rationalismus, Nationsbildung und Laizismus hinzu und kodifizierten jede Art von politischen, ideologischen, ethnischen oder religiösen Differenzen in der türkischen Gesellschaft als eine Gefahr für den »Fortschritt« und die »Einheit des Staates« (vgl. Göle 1998: 73). Die nicht-westlichen Lokalitäten sind für Göle als Phänomen zu betrachten, in dem die Menschen sich selbst modernisierten und nicht passiv modernisiert bzw. entfremdet würden. Die Analyse der Modernität, verstanden als Verhältnis zur Gegenwart und zu sich selbst, solle nicht auf sequentieller Chronologie basieren, sondern auf Gleichzeitigkeit. Die Türkei ist für Ahıska ein paradigmatisches Muster für nichtwestliche Gesellschaften, insofern sei die Lücke zwischen Gegenwart und Zukunft in der türkischen Modernität nicht kontingent. Die Türkei sei als ein nicht-westliches Peripherieland von seiner Gegenwart entfremdet. Das »Verspätetsein« kennzeichne deshalb die türkische nationale Identität, und die symptomatische Angst, die die »Zug-Metapher« verkörpert. Diese »Zeitlücke« sei das zeitlose Element der Selbstdefinition von nicht-westlichen Ländern. Die Metapher »Catching the Train« 
der modernen Zivilisation wird der zentrale Motor und die Rechtfertigung dieses Imitationsprozesses (vgl. Ahıska 2003: 354).

In nicht-westlichen Gesellschaften ist für Gülalp (1998) die Rede von einem besonderen Bruch zwischen traditionellen und modernen Epistemien. ${ }^{5}$ Diese Gesellschaften sind nicht mehr traditionelle, sondern enttraditionalisierte Gesellschaften. Der »freiwillige« Bruch mit der Tradition und das »Zusammenflicken« seien radikal, denn es werde davon ausgegangen, dass die lokale islamisch geprägte Tradition der universellen Modernität Hindernisse in den Weg stellt. Die Modernität hätte die Tradition nicht in einem Prozess transformieren können, so musste Letztere ersetzt werden. Eine Fortführung der Tradition sei nur am Rande des Systems möglich gewesen. Als Folge der Ersetzung der Tradition lebten für Gülalp die neuen und alten Epistemien nebeneinander, ohne dass Prämoderne und Postmoderne miteinander kommunizierten (vgl. Gülalp 1998: 53).

Altan (2002) und Keyder (1998) suchen die Gründe dieser politischen Kultur in der wirtschaftlichen Organisation der Türkei. Die Ökonomie habe in den 1920er Jahren keinen institutionellen und autonomen Raum entstehen lassen können, das Bürgertum sei nicht in der Lage gewesen, einen unabhängigen politischen Status zu entwickeln. Der bürokratische Staatsapparat konstruierte sich in erster Linie durch die Reformierung der gesellschaftlichen Superstrukturen. Bis in die 1950er Jahre hinein habe die türkische Ökonomie die osmanische Sozialstruktur konserviert, die überwiegend von Kleinbauern und Familienunternehmen bestimmt war (vgl. Altan 2002: 142f). Der Staat deutete jeden gesellschaftlichen Dissens seitens der »Untertanen« als Bedrohung des wirtschaftlichen Einkommens und des politischen Staatsgefüges. Während der Regierung der ITC 1908-1918 sei dieses autoritär-hierarchische System durch die Instrumentalisierung der Wirtschaft gewährleistet worden. Der Staat habe ein Wirtschaftssystem konstruiert, in dem er selbst bei den Produktions- und Umverteilungsverhältnissen eine entscheidende Rolle spielte. Er habe damit ein neues von sich abhängiges türkisches Bürger- und Beamtentum geschaffen, während die im Handel- und Finanzbereich dominante christlich-griechische Bevölkerung eliminiert und ihre Ressourcen okkupiert wurden. ${ }^{6}$

5 Ähnlich argumentiert Daryush Shayegan (2002). Er spricht von einer kulturellen Schizophrenie in traditionellen nicht-westlichen Gesellschaften, in seinem Fall der iranischen, in denen die Ambivalenz und der Bruch als Folge der Begegnung dieser Gesellschaften mit westlicher Modernität entstanden seien (vgl. Shayegan 2002: 88).

6 Der Anteil von nicht-christlichen Minderheiten im Territorium des Osmanischen Reiches umfasste bis 1890 ca. 40 Prozent. Während 191320 Prozent der Bevölkerung im Osmanischen Reich nicht-muslimische Minder- 
Da die insbesondere im Handel tätige christlich-griechische Mittelklasse nach Griechenland abgeschoben wurde und es in Anatolien kein Großbauerntum gab, stießen die bürokratischen Eliten bei diesem Prozess kaum auf Opposition. In dieser Lücke wurde die Rolle der konservativen Opposition wiederum von jenen Bürokraten übernommen, die mit den Reformen nicht einverstanden waren (vgl. Keyder 1998: 32f). Die türkische Revolution fand, Keyder zufolge, deshalb nicht gegen eine soziale Klasse statt, sondern war ein Versuch, von oben die Reformen zu institutionalisieren. Sie sei ein modernes Projekt gewesen, das in den Köpfen eines sehr begrenzten Kaders verwirklicht wurde. Die Souveränität gehörte bis in die 1950er Jahre allein dem zentralistischen Staat, der unter der Aufsicht und Kontrolle der Bürokraten und des Militärs stand (vgl. Çaha 2000: 198).

Şerif Mardin (1998) macht auf ein anderes türkisches bzw. osmanisches »Defizit« aufmerksam. Das Fehlen einer Zivilgesellschaft und einer rechtlich legitimen organisierten Stadtbewegung hätte einen starken Staat und eine Führerfigur hervorgebracht. Die neue Republik habe den Islam neutralisiert und ihn aus dem öffentlichen Raum verdrängt. Sie habe ein jakobinisches zentralistisches System gegründet, welches insbesondere die »Integrität« und »Einheit« der Republik betonte. Der Laizismus sei demnach nicht etwa zur Trennung von Religion und Staat eingeführt worden, sondern manifestierte den Kontrollmechanismus der Bürokraten über die Religion. Das alte Reich beruhte, so Mardin weiter, auf einer gesellschaftlichen Symbiose und tolerierte die gesellschaftliche Heterogenität. Die Funktion der religiösen Einrichtungen in der Lebenswelt wurde in der Republik eliminiert, während sie im Osmanischen Reich nicht nur eine Institution gewesen waren, sondern auch nichtinstitutionelle Beziehungen zwischen den staatlichen Eliten und der Gesellschaft gebildet hatten. Die organische Verbindung zwischen Staat und Gesellschaft sei also einseitig gebrochen und die Rolle der Religion neutralisiert worden, was wiederum eine (subalterne) Volks- bzw. Widerstandskultur auf einer zweiten Ebene erzeugte (vgl. Mardin 1998: 63ff).

In ähnlicher Weise argumentiert Sarıbay (1995). Die osmanischen Eliten und Intellektuellen standen sowohl mit den staatlichen Mechanismen als auch mit den gesellschaftlichen Organen in Verbindung. Mit der Republik brach man den Kontakt mit letzteren und es blieben lediglich staatliche Mechanismen übrig. Diese Tradition dauerte Sarıbay zu-

heiten waren, ist dieser Anteil 1923 auf zwei Prozent »reduziert« worden Während des Ersten Weltkriegs umfasste der Anteil von nicht-muslimischen Minderheiten ca. 18 Prozent der osmanischen Gesamtbevölkerung. 1924 wurde dieser Anteil auf 2,6 Prozent reduziert. 
folge bis 1960 an (vgl. Sarıbay 1995: 68). Im Unterschied zu Mardin behauptet er jedoch, dass die neuen Eliten nicht den »Fehler« der Osmanen wiederholten, sich mit der Restauration des alten Regimes zu begnügen, sondern seine Elemente zu eliminieren und ein neues Staatsund Volkssystem zu etablieren versuchten. Für dieses neue Telos propagierte man einen türkischen Nationalismus (Millet), der die Rolle der Religion (Ümmet) aus dem alten Regime ersetzen solle (vgl. Keyder 1998: 33f). Auch Sarıbay akzentuiert die Kontinuität der neuen und alten Reformisten bezüglich der Staatstradition. In der Republik blieben die Reformen elitär und weiteten sich nicht auf die gesellschaftliche »Umwelt« aus (vgl. Sarıbay 1995: 59ff; Kadığlu 1999: 30).

Die türkischen Modernisten setzten Modernisierung mit Verwestlichung gleich und identifizierten diese mit der Teilhabe an der westlichen Zivilisation. Modernität war demnach ein einheitliches Projekt, das alle gesellschaftlichen Bereiche umfassen sollte. Nicht nur die westliche Rationalität, Effektivitätssteigerung von Organisation und Bürokratie, sondern auch Religion, Frauen und Jugendliche seien Objekte dieses Projektes geworden, das der lokalen Kultur nur im Rahmen von Folklore Raum gab (vgl. Keyder 1998: 29). Auch Keyder betont die Rolle der von der Gesellschaft abgekoppelten staatlichen Eliten in diesem Prozess. Unter »Dritte-Welt-Bedingungen« seien in der Türkei die Modernitätsfrage und die Bildung eines Nationalstaates miteinander verschmolzen. Somit wurde der Nationalismus die konstitutive Ideologie des Staates, welcher ebenfalls von oben initiiert wurde: Anstelle von Religion, die den »Rückschritt« symbolisierte, seien Nation und Nationalstaat gesetzt worden, die wiederum den »Fortschritt« symbolisierten (vgl. Keyder 1998: 33f).

Auf der einen Seite haben die neuen Eliten sich von dem Osmanischen Reich und seiner Politik abgegrenzt, auf der anderen Seite regulierten bzw. begrenzten sie im Rahmen des politischen modernen Projektes und des Nationsbildungsprozesses die gesellschaftspolitischen und normativen Grenzen der Verwestlichung. Diese Neustrukturierung der Gesellschaft und des Staates gab den neuen Eliten die Möglichkeit, die epistemologischen und normativen Grenzen der türkischen Modernisierung allein zu bestimmen (vgl. Kaliber 2002: 110; Üstel 2005: 180). Für Toker und Tekin (2002) basiert die Republik weder auf einer liberalen politischen Philosophie, die Natur- und Menschenrechte garantiert, noch auf einer republikanischen »Volkssouveränität.« Erstere garantiere dem Individuum den moralischen Schutz gegenüber der Gesellschaft und dem Staat und Letztere ermögliche die politische Partizipation durch das Konzept des »Öffentlichen Raumes« und sichere die politische Freiheit. In der Türkei sei jedoch im Zuge der Gründung die Volks- 
souveränität in eine unbestimmte Zukunft verschoben worden, statt politische Partizipation zu verbürgen, wurde sie eliminiert. Es ging nicht um den Schutz des Individuums vor Staat und Gesellschaft, sondern um den Schutz des Staates und der Gesellschaft vor dem Individuum. Politik wurde insofern nicht als partizipatorische Tätigkeit, sondern, wie oben erwähnt, als soziale Technik verstanden.

Des Weiteren sei es nicht das Ziel gewesen, eine Regierungsform herauszubilden, in der die Regierung den politischen Willen des Volkes repräsentierte, sondern eine Gesellschaft nach einem vorgestellten westlichen Modell zu schaffen (vgl. Toker/Tekin 2002: 84). Mit anderen Worten wurde Politik auf Verwaltung reduziert, wobei öffentliche Räume als ein Feld der Verwaltung galten. Unter diesen Bedingungen verfolgten die staatlichen Eliten eine doppelte Strategie zur politischen Legitimation. Der Staat nahm die wirtschaftlichen und gesellschaftlichen Felder in seinen Besitz, um damit von sich abhängige Gruppierungen zu erzeugen, und versuchte gleichzeitig, durch Verbreitung einer politischen Mythologie und staatlichen Religion die politische Integration zu gewährleisten.

Die republikanischen Eliten konzipierten die Gesellschaft als moralische, ästhetische Einheit, deren politische Integration nicht durch diverse gesellschaftliche Interessen, sondern vielmehr durch symbolische Elemente erzielt werden sollte. Gesellschaft wurde als eine Art symbolischer Form betrachtet, die die Moral des Individuums bestimmen sollte. Die ideologische Substanz dieser neuen Form war nicht Religion, sondern die türkische Nation (vgl. Yıldız 2004). Sarıbay zufolge hängt die Existenz dieser moralischen Ordnung von der gesellschaftlichen Harmonie ab und für die gesellschaftliche Harmonie sei der Gehorsam dem Staat gegenüber notwendig (vgl. Sarıbay 1995: 148). Die türkische »harmonische klassenlose Einheit« habe ihren Ursprung in der prämodernen islamischen Konzeption von der »Harmonie der Gesellschaft« (vgl. Saribay 1995: 123) und im modernen rousseauschen Begriff des »Gemeinwohls«, das einen normativen Orientierungspunkt sozialen und politischen Handelns bezeichnet, das als Gegensatz zum Individualoder Gruppeninteresse gesetzt wird (vgl. Çaha 2000: 185f).

Hilmi Yavuz (2002) zufolge ist die Semiologie der türkischen Modernisierung eine fragmentarische Verwestlichung. Nicht Philosophie, Wissenschaft, Kultur, Demokratie und Menschenrechte, sondern Klavierspielen, Huttragen und Französischsprechen wurde als Westlich- und Europäischsein verstanden. Ähnlich den europäischen Orientalisten, die Harem und Hamam mit Orient gleichsetzten, hätten die türkischen Eliten Klavier und Hut mit Europäischsein gleichgesetzt (vgl. Yavuz 2002: 212ff). Aufgrund dieses fragmentarischen Charakters der türkischen 
Modernisierung wurde die Türkei paradoxerweise nicht verwestlicht, sondern orientalisiert, da auch der Orientalismus die Fragmente als Totalität darstellt, so Yavuz.

Diejenigen Politikwissenschaftler, die zentrale Institutionen des türkischen Staates zum Gegenstand ihrer Analyse machen, wie Heper (1993) und Karaosmanoğlu (1993) gehen von einer eigenständigen institutionellen Geschichte des türkischen Staates aus und argumentieren, dass der Staat jenseits der Gesellschaft eine eigenständige Identität besitze, die über der Gesellschaft stehe. Demnach verfüge der türkische Staat über eine rationale, unitäre und transzendentale Tradition. So habe er ein ontologisches Primat vor anderen gesellschaftlichen Institutionen, die das soziopolitische Leben mitgestalten. Die Souveränität und Autonomie des Staatlichen sei immanent in seiner Natur. Heper und Karaosmanoğlu richten deshalb in ihren Analysen ihre besondere Aufmerksamkeit auf die diskursiven Praktiken und Handlungen der bürokratischen Intelligenzija (Bürokraten und Militär). Seit der »Tanzimat«Periode (1839-1876) sind Heper zufolge die Bürokraten die wichtigsten Akteure, die den osmanischen bzw. türkischen Modernisierungsprozess antreiben. Sie hätten eine defensive Vorstellung von der Modernisierung gehabt, weil sie lediglich die Funktionen der staatlichen Institutionen zu rationalisieren wünschten. Die Mehrheit der Bürokraten stellt sich, so Heper, ein elitäres, aristokratisches Regieren vor, das als ein Instrument für ein aufgeklärtes rationales policy making angesehen wird. Ihre Idee sei die eines depersonalisierten bürokratischen Staates, der seine eigenen Normen und Ziele verfolge, die jenseits von sozialen Gruppen und ihren Interessen formuliert sind (vgl. Heper 1993: 39). »Modernization was conceived as defensive; the bureaucratic reforms wished to rationalize the way the state institutions functioned. They thought the solution lay in substituting reason for religion, as the major premise for public decision-making « (Heper 1993: 37).

Diese zentrale Rolle der staatlichen Eliten in der türkischen Modernisierungsgeschichte führte zur »Verselbständigung« der staatlichen Institutionen. Die dominanten Akteure dieses Prozesses seien deshalb das Militär und der bürokratische Apparat, nicht etwa das Bürgertum und die Zivilgesellschaft. Wie Mardin und Keyder kommt auch Heper zu dem Schluss, dass die öffentliche Autorität die politischen und öffentlichen Sphären unter ihr Monopol nahm. Dies führte dazu, dass Militär und Bürokratie sich als diejenigen betrachten, die allein die Normen und Rahmenbedingungen der Politik bestimmen sollten. Sie etablierten eine autoritär strukturierte politische Kultur, in der politische Dissensen eliminiert wurden, wenn es zu ihnen kam. In dieser Hinsicht manifestiert sich für Altan eine Kontinuität zwischen türkischem Staat und Osmani- 
schem Reich. Die türkischen Eliten hätten die mechanische osmanische Staatstradition übernommen. Die Kader der neuen Republik bestanden bis in die 1960er Jahre aus den Bürokraten und Offizieren des Osmanischen Reiches, welche auch damals schon wichtige Positionen besetzt hätten. Es gebe kaum einen von ihnen, der nicht von der Ittihadi Terraki (ITC) herkomme (vgl. Altan 2002: 145). Auch das diskursive Element der osmanischen Eliten vom »Schutz des Staates« bleibe in der kemalistischen Idee bestehen. Der türkische Staat nehme ebenfalls eine zentrale Stelle im politischen Diskurs der neuen türkischen Eliten ein. Insofern gebe es auch eine Kontinuität zwischen osmanischen und türkischen Eliten im Hinblick auf den Diskurs um das Staatsverständnis. Während die republikanische Türkei die zentralistische Staatstradition erbte, hätte sie die anderen Erbschaften, nämlich Multikulturalität und Pluralität, eliminiert. Alle sekundären Strukturen zwischen dem Individuum und dem Staat seien beseitigt worden: Ein Staat ohne Staatsvolk sei entstanden.

Wie schon im Osmanischen Reich stabilisierte sich auch in der türkischen Republik eine Mentalität, die davon ausging, dass die Aufgabe des Staates in der Sicherstellung von gesellschaftlicher Integration bestehe. Darunter sei nicht die Versöhnung von differenten gesellschaftlichen Interessen verstanden worden, sondern die Anordnung dessen, was für den Erhalt des Staates gut und nützlich sei. Alles basierte auf der Sorge um die »Rettung oder Bewahrung des Staates«. Dies hätte dazu geführt, dass der Staat geheiligt wurde, was ihn wiederum von der Gesellschaft abkoppelte. Je mehr der Staat sich von der Gesellschaft distanzierte, um so mehr wurde er transzendentalisiert, je transzendentaler er wurde, um so mehr entfernte er sich (vgl. Sarıbay 1995: 156). Insofern seien die Bürokraten die primären Initiatoren der Verwestlichung. Sie vertraten kein partizipatorisches, sondern ein elitäres Demokratieverständnis, ein aufgeklärtes, rationales Politikmachen. In den Köpfen der Bürokraten herrschte eine Staatsvorstellung »with its own norms and goals, formulated virtually independently of social groups « (Heper 1993: 39). Sie zielten auf eine pragmatische materielle Modernisierung und Rationalisierung von staatlichen Funktionen, die sich stets an den westlichen Vorbildern orientierte, doch nicht die Übernahme von westlichen Normen und Werten anstrebte. Für Heper handelt es sich daher um eine rein oberflächliche und formalistische Verwestlichung.

»The primary goals of the Republican elite - a homogeneous secular nation within a unitary state - were in close harmony with the prevailing European norms of the time. From this perspective, the `Europeanization attempts of the Turkish elites were mainly instrumental in nature; they were, after all, mod- 
elled on the European nation-states of the late nineteenth and early twentieth centuries.«(Oğuzlu 2003: 67)

Karaosmanoğlu (1993) macht auf die besondere Rolle des türkischen Militärs in der Politik aufmerksam. Diese sei das Ergebnis des Modernisierungsprozesses, in dem das Militär Subjekt des Prozesses geworden sei: Das Militär sei die Institution, die als direkte Folge der militärischen Niederlagen zuerst modernisiert worden sei. Die ersten laizistischen Schulen, türkischen Grammatikbücher und die Übernahme des lateinischen Alphabets sind vom Militär eingeführt worden. Laut Oğuzlu (2003) bedeutet der Modernisierungs- und Europäisierungsprozess auch für das Militär nicht etwa die Sicherung der Demokratie und Menschenrechte, sondern Sicherheit und Garantie für den türkischen Staat. Die Sicherheit wäre demnach nur dann gewährleistet, wenn die Europäer die Türkei als europäisch anerkannten. Es betrachte die Europäisierung als die zentrale Sicherheitsstrategie, wenn der türkische Staat von den Europäern nicht als Feind, sondern als zu Europa gehörend angesehen würde. Diese Bestätigung würde die Sicherstellung des türkischen Staates begünstigen, solange beide Seiten einander als »Sicherheitsanbieter« sehen (Oğuzlu 2003: 29ff). Das Militär verfolgt dabei eine komplexe Strategie:

»[S]taying out of politics because it is harmful to professional integrity, but intervening in politics whenever it is necessary for the protection of the secular and democratic regime; safeguarding the democratic regime and contributing to the process of democratization (because democratization is part and parcel of Westernization), but refraining from acting as an instrument of the political government, joining the Western community of nations to become an integral part of it, but maintaining a guard against the West.« (Karaosmanoğlu 1993: 32)

Obwohl die Militärführung das Mehrparteiensystem als einen integralen Bestandteil der Demokratie sieht, ist sie der Ansicht, dass die politischen Parteien die Nation nicht in unterschiedliche Gruppierungen spalten dürften. Nicht Interessenkonflikte, sondern die »Wohlfahrt der Nation« und die Entwicklung des Landes sollten das zentrale Anliegen von politischen Parteien sein. Sie müssten im Einklang mit dem Atatürkismus (Kemalismus) handeln und die nationale Unabhängigkeit und territoriale Integrität des Landes schützen. Die Existenz von diversen Interessengruppen und ihr Streit miteinander werden von den Militärs als zentrale Probleme der türkischen Demokratie angesehen und dienen als Hauptrechtfertigung für die militärischen Interventionen (vgl. Karaosmanoğlu 1993: 24ff). Das türkische Militär ist nicht nur in der Waffenindustrie tätig, sondern ist ein wirtschaftlicher Akteur, der auf mehreren Feldern 
der Kapitalzirkulation (Produktion, Austausch und Finanzen) aktiv ist. Es ist eine Kapitalgruppe, die sich in verschiedenen Strukturen organisiert: Es ist Industrieller, Handelsunternehmer, finanzieller Investor. ${ }^{7}$ Somit ist das Militär eine Schnittstelle zwischen Markt, Staat und Zivilgesellschaft und übt gleichzeitig auf allen diesen Ebenen Einfluss aus (vgl. Akça 2003; Cizre 2004; Demirel 2003).

\section{Fazit: Türkischer Okzidentalismus}

Die oben skizzierten kritischen Perspektiven gehen im türkischen Fall von einem imitativen modernistischen Verwestlichungsprozess aus und betonen dabei die zentrale bürokratisch-elitäre Rolle. Den staatszentrierten Theoretikern zufolge sind die türkischen Bürokraten und das Militär die Hauptakteure des türkischen Modernisierungs- und Europäisierungsprozesses, und ihr Europäisierungsanliegen ist pragmatischer und ambivalenter Natur. Durch die Übernahme von westlichen Institutionen und Technologien wolle man sich dem Westen gegenüber absichern. Die im Westen als Prozess erfahrenen Praktiken würden in ein radikales Projekt umgewandelt und mittels einer positivistischen Methode realisiert. Es handele sich dabei um ein nicht vollständig gelungenes, »fehlerhaftes Projekt«, weil es von oben veranlasst und der lokalen Kultur aufgezwungen worden sei.

Die Modernität bleibt demnach an der Oberfläche und brachte keinen radikalen Wandlungsprozess hervor. Gegen die türkischen staatlichen Eliten gerichtete Kritik hat zwar zum Ziel, die Agenten der Modernisierung und Geschichtsschreibung zu entmystifizieren. Indem sie aber diese bürokratischen Eliten als die autonomen und transhistorischen Hauptakteure sieht, die unabhängig von den komplexen gesellschaftlichen Machtverhältnissen handeln, übersieht sie die domestischen und globalen Möglichkeitsbedingungen des derzeitigen Formationsprozesses des modernistischen Diskurses und ignoriert die ambivalente dialogische Beziehung zum westlichen orientalistischen Diskurs. Die Fragen, warum die Türkei einerseits seit ungefähr hundertfünfzig Jahren performative Leistungen erbringt, um Europa nachzuahmen, andererseits sich gleichzeitig von Europa bedroht fühlt, und wie die hegemonialen westlichen Figuren im zeitlichen und räumlichen Kontext des Formierungsprozesses der türkischen nationalen Identität eine konstitutive Rolle spielten, werden mit den oben skizzierten Ansätzen kaum geklärt.

7 OYAK und ASELSAN sind die zwei großen Kapitalgruppen, die als Solidaritätsfonds des Militärs funktionieren, sie produzieren gleichermaßen Autos (Renault) wie Tomatenmark, Strom und Beton, sie sind Tourismusinvestoren und produzieren Kleidung und Waffen. 
Betrachtet man die Geschichte des osmanisch-türkischen Verwestlichungsprozesses insgesamt von der »Tanzimat-Periode« (1839-1876/78) über den Neo-Liberalismus seit den 1980ern, und schließlich, - wie in der folgenden Analyse gezeigt wird - die Reformen im Beitrittsprozess in die Europäische Union, wirkt der europäische Blick konstituierend. Die Akteure des Modernisierungsprozesses akzeptierten von Beginn an die Hegemonie der westlichen Epistemologie, artikulierten sich mit ihren Konzepten, um der westlichen Modernität ebenbürtig zu werden. Die türkische Modernisierung ist insofern im globalen hegemonialen Feld der Modernität zu lesen.

Der Westen (Europa) symbolisiert dabei nicht einen geographischen Raum, sondern einen Diskurs und eine Summe von Repräsentationen und Identitäten. Die türkische Modernisierung wird hierbei als ein Teil der globalen Modernität betrachtet, und nicht als außerhalb von ihr stehend und gegen sie gerichtet. Doch die türkische Modernisierung als »Imitationsprozess « zu bezeichnen, führt dazu, dass die türkische Subjektivität und Widersprüche in dem Prozess übersehen werden. Das Konzept des »imitativen Projektes« übersieht die türkische Subjektivität, ihre Perversionen, Umdeutungen und Grenzen. Das Konzept vom »verinnerlichten Orientalismus « ${ }^{8}$ übersieht, dass die türkischen Akteure anfangen, Repräsentationen über den Westen zu konstruieren. Ihm entgehen die widersprüchlichen hegemonialen und gegenhegemonialen Dynamiken im türkischen Kontext. Die türkische Subjektivität manifestiert sich durch Grenzziehungstechniken an der Schwelle zwischen West und Ost, wobei bestimmte Ideale der westlichen Modernität lediglich teilweise angeeignet und realisiert werden und als unangemessen betrachtete Ideale ausgeschlossen werden. Die Standardisierung seiner Peripherie gelingt Europa also nur teilweise, es bleiben Differenzen erhalten. Der türkische Andere imitiert in diesem Rahmen den Westen, pervertiert und missversteht ihn gleichzeitig, reagiert auf und gegen ihn.

8 Taner Timur (1986) weist darauf hin, dass die türkischen Nationalisten vor allem von den ungarischen orientalistischen Linguisten des 19. Jahrhunderts geprägt sind. Sie beziehen sich auf diese orientalistischen Erzählungen und suchen mit deren »Hilfe« den türkischen Ursprung in chinesischen Quellen und der Ergenekon-Legende, mit dem Ziel, ein imaginäres kollektives Gedächtnis zu erzeugen. Auch wenn der nationalistische Diskurs anti-westliche Elemente beinhaltet, ist er westlich orientiert und ein Produkt des verspäteten Modernisierungsprozesses (vgl. Timur 1986: $21 \mathrm{ff}$ ). Denn allein die Bezeichnungen »Türken und Jungtürken« waren eine westlich-orientalistische Schöpfung. Die osmanischen Eliten empfanden bis Ende des Jahrhunderts den Begriff »Türkisch" als eine Beleidigung, für sie waren »Türken« anatolische Bauern mit provinziell-rabiatem Charakter. 
Ich habe diesbezüglich im zweiten Teil »Okzidentalismus« als einen synthetischen Begriff für den türkischen Gesamtdiskurs eingeführt. Okzidentalismus formiert sich in einem dialogischen Prozess, er beantwortet die europäischen Diskurse, indem er sich den Blick des Anderen zu Eigen macht. Er charakterisiert die Subjektivität des türkischen Anderen, die sich in der ambivalenten Zone zwischen Orient und Okzident formiert. Wie Chatterjee (1993) festgestellt hat, formiert sich der Diskurs auf dem orientalistischen epistemologischen Feld, er unterscheidet sich im Hinblick auf seine konkreten Strategien auf der Ebene der Problematik. Die Nationalismen nicht-westlicher Gesellschaften unterscheiden zwischen westlichen Institutionen und Technologien auf dem materiellen Feld, auf dem diese Nationalismen die koloniale westliche Überlegenheit akzeptieren, und nationalen Werten/Normen auf dem immateriellen Feld, auf dem eine Überlegenheit zurückgewiesen wird. Auf Basis genau dieser Spaltung operiert der türkische Okzidentalismus seit der osmanischen und türkischen Modernisierungsgeschichte, seit der zweiten Hälfte des 19. Jahrhunderts, wobei er das immaterielle Feld als sein souveränes Gebiet deklariert, in das das Andere sich nicht einmischen darf. Die türkische Identitätspolitik bewegt sich an der Grenze von Anerkennung und Ablehnung, die zur einer Reihe von Brüchen und Lücken in der nationalen Identität geführt hat (vgl. Ahıska 2000: 94). Der Diskurs konstruiert die östliche und die westliche Repräsentation in einem imaginären dialogischen Verhältnis. In diesen Praktiken erzeugt das türkische Selbst seine eigenen internen Anderen, unterdrückt und eliminiert sie.

Auch im Prozess der türkischen Integration in die EU spielen Westund Ostfiguren eine zentrale Rolle, wobei einerseits bestimmte europäische politische Normen und Institutionen, die für »westlich« gehalten werden, adaptiert werden, andererseits sich von bestimmten störenden politischen »westlichen Verunreinigungen«, die das Wohl der Nation bzw. des Staates gefährden, distanziert wird. Dabei ist relevant zu untersuchen, welche sozialen Spaltungen und Antagonismen im türkischen Beitrittskontext erfahren, maskiert oder versetzt werden und welche westlichen Repräsentationen für interne Machtstrategien mobilisiert werden.

Bevor ich auf diese Fragen im empirischen Teil eingehe, werde ich im Folgenden einen kurzen Überblick über den politischen Kontext in der Türkei in den 1990er Jahren geben. 


\section{Exkurs: Politische Dynamik in der Türkei in den 1990er Jahren}

In den 1990er Jahren wurden die islamistische und die kurdische Bewegung in der türkischen Öffentlichkeit sichtbar. Der türkische Staat und die Partei der Arbeiter Kurdistans (PKK) führten zwischen 1984 und 1999 einen »Krieg geringer Intensität«. Im Zuge der Festnahme von Abdullah Öcalan (Vorsitzender der PKK) im Jahre 1999 bis zum Jahr 2004 erlebte die kurdische Organisation einen dramatischen Wandel, sowohl in Bezug auf ihre diskursiven wie auch auf ihre nichtdiskursiven Praktiken. Es formierten sich neue Begrifflichkeiten und Symbole und neue narrative und argumentative Strategien. Der Krieg wurde vom öffentlichen Protest abgelöst. Die PKK war bestrebt, sich von einer »machtorientierten« modernen nationalen Bewegung zu einer postmodernen »reformorientierten« kulturellen Bewegung zu transformieren, indem sie neue Themen wie »Demokratie« und »Ökologie« in den Diskurs einband. ${ }^{9}$ Die kurdische Teilbewegung versuchte einerseits, ihre Legitimität und ihren Geltungsanspruch in den türkischen modernen Gründungsmythen zu finden, indem sie die türkische Nationalgeschichte anders interpretierte. Dabei blieb sie jedoch im Rahmen des kemalistischen Diskurses, anders als vorher, als dieser gegen sie gerichtet war. Sie stellte nun die türkischen nationalen Grenzen nicht mehr in Frage, wies auf das gemeinsame Schicksal von Türken und Kurden während des Ersten Weltkrieges hin und sah sich als »konstitutiver Bestandteil der Republik«. Andererseits wurde aus der militärischen und politischen Niederlage ein kurdischer »völkischer« Opfermythos rekonstruiert: Der bisherige Kriegsheld Öcalan wurde zum Freiheits- bzw. Friedenshelden (vgl. Küçük/Grojean 2005). Die kurdische Teilbewegung engagierte sich zu dieser Zeit für den EU-Beitritt der Türkei, für mehr Demokratie, Menschenrechte und kulturelle Rechte der kurdischen Minderheit. Ihr

9 A. Öcalan hat dabei als integratives Symbol und als autorisiertes Subjekt sein Definitions- und Interpretationsmonopol im Diskurs eingebüßt, bleibt aber nach wie vor »agenda setter«. Die Machtverhältnisse innerhalb der kurdischen Teilbewegung sind dadurch nicht mehr so stabil wie vorher, sondern beweglich und multipel geworden (vgl. Küçük/Grojean 2004/ 2005). Der kurdische Diskurs formiert sich in einem dialogischen Verhältnis zum Kemalismus, er beantwortet ihn stets. Wie der türkische Staat verleiht auch die kurdische Teilbewegung ihrer Gemeinschaft durch die politischen Mythen Sinn und Identität. Deren Dekonstruktion scheint sehr problematisch, weil der Versuch mit der Auflösung der kurdischen Identität gleichgesetzt wird. Es werden also gegen die türkische Identitätspolitik und ihre Gründungsmythen eine Gegen-Identitätspolitik und GegenGründungsmythen (re)konstruiert. Das Paradox dabei ist, dass die kurdische Bewegung ebenfalls gegen eine kritische Reflexion immunisiert wird. 
diskursiver Transformationsprozess führte dazu, dass europäische politische Kriterien, die für kulturelle Rechte von Minderheiten plädierten, mit den Forderungen der kurdischen Teilbewegung überwiegend übereinstimmten (vgl. Küçük 2006). ${ }^{10}$

Auch die islamische Bewegung tritt ab den früheren 1990er Jahren häufiger in der türkischen Öffentlichkeit hervor. Der Wahlerfolg der Wohlfahrtspartei (RP) in mehreren Großstädten (darunter Istanbul und Ankara) bei den Kommunalwahlen von 1994 war diesbezüglich ein Wendepunkt. Die türkischen Massenmedien verbreiteten die Angst, die Islamisten würden die Grundprinzipien der Republik allmählich durch islamistische ersetzen. Als der gegenwärtige Premierminister Tayyip Erdoğan (damals Refah Partisi) Mitte der 90er Bürgermeister von Istanbul wurde, wurde er nicht selten gefragt, ob er die Bordelle in Istanbul schließen wolle (vgl. Navaro-Yashin 2002: 37). In den Medien wurde thematisiert, ob die Islamisten Atatürks Bilder aus öffentlichen Gebäuden entfernen und durch andere Bilder ersetzen würden oder ob Frauen von nun an gezwungen würden, das Kopftuch zu tragen.

In einem dialogischen Verhältnis zur islamistischen Herausforderung und zur kurdischen Bewegung wurde der kemalistische Nationalismus, der bis dahin vorherrschend als Staatsideologie fungierte, von den etablierten politischen Parteien und den Massenmedien popularisiert. Das Militär hatte bislang die maßgebliche Rolle in der Produktion und Kontrolle dieser Ideologie gespielt. Die kemalistische Sorge manifestierte sich an der Parole: »Die Türkei wird nicht der Iran sein.« In diesen Jahren erlebte Atatürks Mausoleum in Ankara, das sog. Anıtkabir $^{11}$ eine politische Karriere. Immer wieder, wenn sich die Konflikte zwischen Islamisten und Kemalisten intensivierten, organisierten die

10 Dieser Transformationsprozess ist sowohl auf der Seite der kurdischen Bewegung als auch auf der Seite des türkischen Staates widersprüchlich: Trotz diskursiver und strategischer Transformation bleibt die hierarchische Organisationsstruktur der kurdischen Organisation bestehen. Darüber hinaus wurde der seit 1998 erklärte einseitige Waffenstillstand im Juni 2004 wieder aufgehoben. Einerseits ließ die türkische Regierung u. a eine Sendung in kurdischer Sprache im türkischen öffentlich-rechtlichen Fernsehen zu. Andererseits führt das türkische Militär nach wie vor gegen die kurdischen Guerilla militärische Operationen durch und versucht die politischen Reformen in der Praxis zu blockieren. Das zeichnet einen Dissens innerhalb der bürokratisch-militärischen Eliten auf. Diese Entwicklungen zeigen, wie prekär und symptomatisch der beidseitige Transformationsprozess ist.

11 Inspiriert von der Akropolis in Athen, wurde das Anıtkabir 1953 als massive neoklassizistische Architektur mitten im Zentrum von Ankara errichtet. Das Bauwerk kann und soll von überall in Ankara aus gesehen werden. 
Kemalisten Wallfahrten zum Anıtkabir, um sich bei Atatürk über die Islamisten zu beklagen. Politische Parteien, Rektoren von Universitäten, Offiziere, Beamte, Bauern und Gewerkschaften besuchen ihren Gründungsvater im Anttkabir immer dann, wenn sie sich über die politischen Missstände, soziale Ungerechtigkeit, Armut, korrupte Politiker, islamischen Fundamentalismus und kurdischen Separatismus beschweren wollen. Diese symbolische Politik ruft nationalistische Emotionen hervor und mobilisiert »die Nation«.

Auch die nationalen Feiertage wurden vom türkischen Staat und den Medien etabliert. Die nationalen Feiertage wandelten sich in den 1990er Jahren von »Holiday of State « zu »Holiday of Nation« (Navaro-Yashin 2002: 147ff). Die davor unter institutionellem Zwang stattfindenden Aufmärsche und mit militärischer Präsenz von Panzern und Kampfflugzeugen inszenierten Feiertage wurden zu Massendemonstrationen, wobei die zivilen Bürger, die die Botschaft der Bedrohung der Republik verstanden hatten, mit Flaggen und Atatürk-Bildern die Einheit und den Laizismus des Staates verteidigten. Esra Ozyürek (2006) spricht in diesem Zusammenhang von einer kemalistischen Nostalgie, die sich seit den 1990er Jahren im öffentlichen Raum zeigt. Während bis in die frühen 1990er Jahre der Kemalismus, Ozyürek zufolge, eine offizielle Ideologie war, so begegnet man nun seiner Popularisierung, insbesondere und einhergehend mit dem zunehmenden Sichtbarwerden der islamischen Bewegung. Es fand ein radikaler Bruch in der Zirkulation des Imaginären über Mustafa Kemal Atatürk statt. Im Vergleich zu den alten ernsthaften (»serious, solemn and superhuman«) Bildern, die von ihm lediglich in allen öffentlichen Gebäuden zu sehen waren, vermitteln die neuen abgestaubten Bilder, "a smiling human happily engaged in social activities and mundane pleasures« (Özyürek 2006: 123). Während in den offiziellen Gebäuden, Schulen und Kasernen Bilder von Atatürk als Staatsmann und Offizier hängen, sieht man in Kaffeehäusern, Unternehmen, Privathäusern und auf Sportplätzen private Bilder: Atatürk im Restaurant Wein trinkend, im Ballhaus Tango tanzend, Golf spielend, schwimmend, in Badehäusern badend etc. Es findet eine Art von politischer kommerzieller Vermarktung Atatürks statt, als Botschaft und »Marke« zugleich. Menschen tragen ihn in der Öffentlichkeit auf ihren Jacken und T-Shirts als Button. Özyürek nennt dies eine »Miniaturisierung Atatürks«. Sie zeigen mit ihrer Ikone ihre kemalistische laizistische Identität, beispielsweise gegenüber kopftuchtragenden islamistischen Frauen (vgl. Özyürek 2006).

Am 28. Februar 1997 übte das Militär öffentlichen Druck auf die Koalition Necmettin Erbakan/Tansu Çiller (RP/DYP) aus, die Koalition 
wurde gezwungen, sich aufzulösen. ${ }^{12}$ Nach diesem sog. »28. FebruarProzess «, der auch als »postmoderner Putsch« bezeichnet wird, kam es zu einer Spaltung innerhalb der islamistischen Bewegung im Allgemeinen und in der islamistischen Partei (RP) im Besonderen. Kontrovers zur $\mathrm{RP}$ formierte sich ein liberaler islamistischer Diskurs aus der zweiten Generation von islamistischen Eliten. Tayyip Erdoğan und Abdullah Gül gründeten 2000 eine neue Partei (Partei für Gerechtigkeit und Entwicklung, AKP) die sich von der bisherigen konservativen und konfrontativen Politik der Refah distanzierte. Die AKP hat die Wahlen von 2002 mit einem erstaunlichen Stimmenanteil gewonnen und sich seitdem massiv für den EU-Beitritt der Türkei engagiert. Somit haben sich die islamistischen und kurdischen Diskurse - beide wichtige Oppositionen des zentralistischen staatlichen Diskurses - pro-europäisch eingestellt, während der kemalistisch-nationalistische Diskurs sich stärker kontraeuropäisch positioniert.

In den 1990er Jahren war in der Türkei die Liberalisierung der Finanzmärkte prägend und die ökonomische Entwicklung mündete in mehreren Finanzkrisen. Nach der Finanzkrise von 2001 wurden durch die Regierungen DSP//MHP sowie AKP weit reichende Reformen etabliert. Das Programm zielte primär darauf, die Kredibilität der türkischen Ökonomie zu erhöhen. Im Zentrum der Bemühungen stand, die inflationäre Dynamik durch eine Überbewertung der nationalen Währung zu brechen. Die geldpolitischen Maßnahmen bildeten dabei einen wesentlichen Bestandteil des Programms. Damit versuchten die Regierungen, die internationale Glaubwürdigkeit zu erhöhen, um einen dauerhaften Kapitalzufluss zu garantieren. Das monetäre Stabilisierungspro-

12 Das politische Spektrum in der Türkei ist insbesondere zwischen 1997 und 2002 zersplittert. In diesem Zeitraum gab es zwei Koalitionen aus jeweils drei verschiedenen politischen Parteien, in denen beiden pro- und kontraeuropäische Parteien beteiligt waren. Es ist schwierig die Programmatik der ANAP und der DYP zu unterscheiden, beide sind rechts-konservativ. Die DYP positionierte sich bis 1999 pro-europäisch: es war die Regierungskoalition von DYP und CHP unter Tansu Çiller und Deniz Baykal, die den Zollunions-Vertrag 1995 unterzeichnete. Ihre Regierung plante, das Datum der Unterzeichnung zum »nationalen Feiertag« zu erklären. Diese beiden Parteien positionieren sich jedoch ab 1999 bis heute kontraeuropäisch. Die CHP und die DSP stehen sich politisch ebenfalls sehr nahe, beide sind kemalistisch und beide sind in der Gegenwart kontraeuropäisch, jedoch war Bülent Ecevit (DSP) als Premierminister der Regierung von 1999 bis 2002 derjenige, der das Helsinki-Abkommen unterzeichnete. Die rechtsliberale ANAP, die liberale islamische AKP und die pro-kurdische Partei HADEP sind überwiegend pro-europäisch eingestellt. Kontra-europäische Parteien sind die Kemalistischen Sozialdemokraten (CHP und DSP), Rechtsliberale (DYP), Ultra-Nationalisten (MHP, BBP), Arbeiterpartei (IP). 
gramm wurde auch von politischen Reformen begleitet. Die Grundidee dieser Maßnahmen beruhte Ilker Ataç (2007) zufolge auf einer neuen Konzeptionalisierung des Staates. Im neuen Staatsdiskurs sollte sich die Politik an Effizienzkriterien messen lassen, insbesondere inwieweit sie auf nationalstaatlicher oder regionaler Ebene in der Lage sei, Wettbewerbsfähigkeit herzustellen. Während in den 1980er und 1990er Jahren die Liberalisierung und eine Deregulierungspolitik im Vordergrund standen, wurden nach der Krise einerseits Reregulierungsmechanismen sowie unabhängige Regulierungsbehörden und eine Technokratisierung der Entscheidungsmechanismen herbeigeführt. Die Legitimationsgrundlage für die neuen Reformen bildete andererseits die Kritik am Etatismus, der mit Rentierstaat und Korruption identifiziert wurde. In dieser Phase trieb die Regierung die Privatisierung von staatlichen Monopolbetrieben voran. Gleichzeitig bildeten die Umsetzung der IWF-Auflagen sowie die EU-Beitrittskandidatur einen doppelten Anker für einen kontinuierlichen Kapitalzufluss. Die EU-Mitgliedschaftsperspektive beschleunigte die Umsetzung von »governance«-Strukturen in der Türkei (vgl. Ataç 2007). 


\section{Struktur des diskursiven Feldes}

\section{Methodische Herangehensweise}

Die Diskursanalyse (DA) ist eine heterogene Forschungsperspektive, die je nach Gegenstand und Forschungsfrage makroanalytisch-quantitativ und/oder mikroanalytisch-interpretativ verortet werden kann (vgl. Foucault 1973: 40f). Ein wesentlicher Unterschied zwischen qualitativer Sozialforschung und Diskursanalyse ist, dass Erstere von einer »objektiven Wahrheit« ausgeht, wobei der Forscher das beschreibt, was »bloß ist.« Der Diskurstheorie geht es jedoch nicht um die Analyse einer gegebenen »objektiven Wahrheit«, sondern sie sieht nur jeweils gegebene historische Gültigkeiten vor, die als zeitweilig durchgesetzt gesehen, aber auch in Frage gestellt werden können. Ein absolutes Kriterium für Richtig und Falsch gibt es also nicht, deswegen ist es notwendig, die zeitweiligen Gültigkeiten zu problematisieren (vgl. Jäger 2001: 54; Lemke 1999: 182f; Keller 2004: 72; Knoblauch 2001: 214).

Die Diskursanalyse befindet sich jedoch in einem Dilemma zwischen der Untersuchung von umfangreichen Datenmengen und der exemplarischen Analyse einiger weniger Diskursbeiträge. Es geht um die Analyse von Deutungen, die in öffentlichen Auseinandersetzungen aufgeführt werden und die Handlungszusammenhänge herstellen. Die DA hat die Aufgabe zu rekonstruieren, wie und inwieweit diese kollektiven Deutungen in einer Gesellschaft produziert, stabilisiert und institutionalisiert werden. Die isolierte Analyse einzelner Diskursbeiträge ist dabei weniger relevant. Da die kollektiven Deutungen aus den dialogischen Beziehungen entstehen, die immer wieder in Frage gestellt, transformiert und reproduziert werden, werden die einzelnen Deutungen in ihren Relationen zu anderen Deutungskonstellationen untersucht (vgl. Schwab- 
Trapp 2003: 170). Für eine empirische Annährung kann von der Einheit eines Diskurses lediglich hypothetisch ausgegangen werden. Dabei können Problematisierungsweisen, Themenauswahl und Deutungsstrategien hilfreich sein, um dominante Regeln des Diskurses zu identifizieren und ihn damit zu rekonstruieren (vgl. Diaz-Bone 1999: 130). Die DA hat die Aufgabe, diskursive Formationen zu rekonstruieren, die erst aus dem Zusammenspiel von Aussagen erwachsen, daher sollten so viele Beiträge wie möglich in Augenschein genommen werden. Dem sind jedoch aus zeitökonomischen Gründen Grenzen gesetzt. Andererseits ergibt sich bei der Auswahl weniger Beiträge das Problem, dass diskursive Koalitionen und Verflechtungen nicht ausreichend analysiert werden können. Die Fragen, wie die Oberfläche und allgemeine Struktur eines Diskurses analysiert und gleichzeitig wie spezifische tiefe Deutungsund Argumentationsmuster sichtbar gemacht sowie wie die diskursiven Verschränkungen eines Diskurses mit seiner Umwelt und anderen Diskursen untersucht werden können, sind die maßgeblichen Herausforderungen. Der Vorteil der systematischen quantitativen Inhaltsanalyse liegt darin, sich auf eine große Textmenge beziehen und repräsentative Aussagen formulieren zu können, wohingegen beim qualitativen Vorgehen die Aussagen möglicherweise nicht genügend repräsentativ sind (vgl. Gerhards 2003: 306f). Die Anwendung quantitativer Techniken ist für die Schilderung von Diskursstrukturen und für die Methodenkontrolle besonders geeignet. Mit distributionalistischen Techniken können die quantitativen Eigenschaften der Gesamtstruktur dargestellt werden (Diaz-Bone 1999: 130). Der Nachteil der systematischen Inhaltsanalyse liegt darin, dass die interpretative Tiefe ihrer Kategorien unbefriedigend bleibt. Das qualitative Verfahren ist insbesondere für die Rekonstruktion von Bedeutungszusammenhängen und Exploration latenter Dimensionen zweckdienlich.

Im Folgenden werde ich in einem ersten Schritt die narrativen Strukturmerkmale bzw. die thematischen Routinen des deutschen, europäischen und türkischen diskursiven Feldes deskriptiv analysieren sowie die Interdependenzen zwischen diesen Feldern lokalisieren. Es soll gezeigt werden, wer die Träger diskursiver Beiträge sind, welche Themenfelder in der Debatte dominieren, welche besonders umstritten oder kollektiv geteilt sind. Themen bilden Sinnkomplexe einer Gesellschaft oder eines Diskurses, und ihre Auswahl kennzeichnet das, was in einer Gesellschaft bzw. einem Diskurs relevant ist und die Aufmerksamkeit bestimmt (vgl. Knoblauch 2001: 216ff). Welche Aussagen, Klischees und Formeln dominieren das Feld in welchen Ausdrucksformen, welche sind umstritten, schaffen Akzeptanz oder stoßen auf Ablehnung, wie werden sie aufgenommen und modifiziert? In welchen Diskursfeldern finden 
Auseinandersetzungen statt, was sind die spezifischen Konfliktlinien und Allianzen? Beziehen sich die Akteure in dem Diskurs aufeinander, in welchen Diskursfeldern kann von einer diskursiven Interaktion gesprochen werden? In welcher Weise sind diese Aussagen durch bestimmte Begriffe und Metaphern miteinander verbunden? Gemeinsame Argumente und Erzählungen zeigen, dass die Diskursbeiträge kollektive Deutungen teilen bzw. diese miteinander verknüpft sind. Die Unterschiede zeigen wiederum die Konfliktlinien und die Momente, in denen kommunikative Lücken entstehen.

Für die systematische Strukturanalyse des diskursiven Feldes habe ich inhaltsanalytische Kategorien entwickelt, um die Erzählstruktur des narrativen Feldes, d.h. das Erscheinen von typischen Akteuren, Themenfeldern, Deutungsstrategien bzw. Topoi zu restrukturieren und zu klassifizieren. Ich habe ein Codebuch erstellt und anschließend die Zeitungsartikel per SPSS (Statistisches Programm für Sozialwissenschaften) kodiert. Für die Interpretation der Daten habe ich neben SPSS-Kreuztabellen auch die Korrespondenzanalyse (KA) angewendet. KA ist ein statistisches exploratives Verfahren zur Visualisierung und Auswertung von Häufigkeitsmatrizen. Hierfür werden die Beziehungen zwischen jeweils zwei Variablen veranschaulicht. Daten einer Kreuztabelle werden graphisch abgebildet und Reihen und Spalten werden als Punkte gemeinsam in einem geometrischen Raum dargestellt. Die Distanzen zwischen den Objekten geben deren Ähnlichkeit bzw. Unähnlichkeit wieder. Je näher also zwei Objekte bzw. Merkmale beieinander liegen, desto ähnlicher sind sie. Ein weiterer Vorteil der KA liegt darin, dass Informationen auch auf einer sehr geringen Fallbasis darstellbar sind (Wittfeld 2001; Universitäts-Rechenzentrum Trier 1997; Clausen 1998). Mit der KA konnte ich somit Regelmäßigkeiten des diskursiven Feldes aufdecken, in graphischen Abbildungen übersichtlich visualisieren und somit eine erste Einschätzung der Struktur des dialogischen Diskurses liefern.

Zuerst wurden Akteure, Themen, Äußerungen auf typische Gemeinsamkeiten und Unterschiede hin kodiert (vgl. Viehöver 2003; Franzosi 1987; Donati 2001). Eine bestimmte Anzahl von Zeitungsartikeln aller untersuchten Zeitungen wurde hinsichtlich Wiederholungen und Gleichförmigkeiten gesichtet, um typische Akteure, thematische Felder und Diskursstrategien von politischen Akteuren herauszufinden und somit ein Analyseraster für das Kodieren zu entwickeln. Folgende thematische Felder werden sichtbar, wenn über die EU-Türkei-Beziehung zwischen 1997 und 2004 geschrieben wurde: Kulturelle Differenzen/Identität; Politik und Demokratie, Sicherheit/Geostrategische Relevanz; Moral; Zukunft Europas; Zypernfrage und Migration bzw. Integration von Mi- 
granten. Diese Felder wurden (bis auf Zypern) dann als Variablen konstruiert und per SPSS kodiert. ${ }^{1}$ Zunächst habe ich versucht, möglichst viele Aussagen in den jeweiligen Feldern zu erfassen, doch bei der Analyse ließ sich feststellen, dass die Anzahl an Aussagen sehr hoch war, deswegen habe ich sie nach ihren Ähnlichkeiten und Differenzen rekodiert, um ihre Zahl auf die typischen und dominanten zu reduzieren und somit für die statistische Analyse fruchtbar zu machen. Im politischen Bereich wurden z.B. 30 verschiedene Aussagen identifiziert und kodiert, die in einem zweiten Schritt auf sechs reduziert wurden.

Nachdem die Oberfläche der Erzähl- bzw. Argumentationsstrukturen von europäischen und türkischen Diskursen deskriptiv analysiert, d.h. die typischen Aussagen identifiziert, die Interaktionen lokalisiert und Typologien von Diskursformationen rekonstruiert werden, soll im Teil VI anhand des interpretativen Verfahrens im Rahmen postkolonialer Theorien die Frage nach den Prozessen der Identitätsbildung im Verhältnis des europäischen Selbst zum türkischen Anderen im Mittelpunkt stehen. In diesem Sinne geht es mir darum zu zeigen, welche West-OstFiguren wie im Diskurs platziert und gedeutet werden, um bestimmte Gemeinsamkeiten oder Differenzen zu markieren. Dafür sollen bestimmte exemplarische Artikel in den untersuchten Tageszeitungen ausgewählt und vertiefend interpretiert werden ${ }^{2}$, um die sprachliche Realisierung der Diskursstrategien zu erfassen: Entlang welcher diskursiver Knotenpunkten und in welchen Deutungsschemata werden symbolische

1 Ein Akteur argumentiert meistens auf mehreren dieser thematischen Felder. Er kann in einem Zeitungsartikel gleichzeitig kulturell, politisch und sicherheitsbezogen argumentieren oder nur politisch-demokratiebezogen. In einem Feld kann er mehrere Geschichten erzählen. Z.B. kann er auf dem politischen Feld die Rolle des Militärs problematisieren und von Menschenrechtsverletzungen und Minderheitenrechten sprechen. Ich habe von jedem thematischen Feld jeweils zwei Variablen konstruiert, z.B. Kultur 1 und Kultur 2, Politik 1 und Politik 2 etc. Dabei habe ich die ersten beiden erwähnten Argumente/Forderungen in einem thematischen Feld kodiert, das dritte habe ich gelassen. Bezogen auf das Beispiel habe ich also die Rolle des Militärs (Politik 1) und Menschenrechtsverletzungen (Politik 2) kodiert. Minderheitenrechte habe ich gelassen, wenn davon die Rede war.

2 Für die Bestimmung dieser Artikel wurde während des Kodierens jeder Artikel von eins bis fünf hinsichtlich folgender Kriterien bewertet: Wie lang ist der Artikel, wie bekannt/relevant ist der Verfasser/Akteur im Diskurs und wie typisch sind die Aussagen? Alle Artikel, die über 4,5 bewertet wurden, wurden dann als Schlüsseltexte ausgewählt, weil der Autor/Akteur renommiert ist oder ein erhebliches symbolisches Kapital hat, weil er viel zitiert wird, weil die Argumente typisch sind, d.h. am häufigsten vorkommen (ca. 100 Zeitungsartikel wurden für die interpretative Analyse ausgewählt). 
Äquivalenzen und/oder Differenzen zwischen dem deutschen bzw. europäischen und dem türkischen Diskurs artikuliert? Entlang welcher diskursiven Praktiken wird die Mehrdeutigkeit der dominanten Begriffe verknappt bzw. welche hegemonialen Bedeutungen werden konstruiert? Wie und inwieweit artikuliert sich die Intertextualität bzw. Dialogizität des Diskurses zwischen deutschen und türkischen Akteuren und wie und inwieweit strukturieren sich die symbolischen Lücken in der diskursiven Interaktion? Diese Fragen sind meines Erachtens deshalb von besonderem Rang, weil letztendlich der symbolische Deutungskampf zwischen den herrschenden deutsch-europäischen und türkischen Diskursen über die Fixierung einer europäischen Identität darüber entscheiden wird, ob die Türkei zu Europa oder zu einem nicht-europäischen »Anderen« gehören wird.

Akteure sind individuelle oder kollektive Erzeuger von Aussagen, sie sind in diskursiv strukturierten symbolischen Kämpfen über die Realitätsdefinition eingebunden. Sie verwenden bestimmte symbolischkulturelle Mittel, um ihre »Wahrheit« zur Geltung zu bringen, sie zu verbreiten. Dabei werde ich sowohl staatliche Organisationen als auch Kolumnisten/Korrespondenten von untersuchten Zeitungen sowie renommierte Intellektuelle und Akademiker, die im öffentlichen diskursiven Feld das Wort führen, als Akteure verstehen. Wenn in der Arbeit von der Bedeutung des EU-Beitritts der Türkei für die europäische Identität die Rede ist, dann geht es in erster Linie darum, wie diese Erzählungen in der deutschen und türkischen Öffentlichkeit in Umlauf gebracht und strukturiert werden.

Ich hätte diese Arbeit als eine Analyse des deutschen und türkischen Europadiskurses benennen können. Eine Verwirrung ergibt sich dabei, dass in diesen beiden Öffentlichkeiten sowohl EU-Akteure, als auch andere nationale Akteure aus anderen EU-Mitgliedsländern relativ häufig zu Wort kommen. Da ich nun auch die diskursiven Praktiken dieser Akteure in die Untersuchung einbeziehe, überschreitet meine Analyse sicherlich bis zu einem gewissen Grad die deutschen und türkischen öffentlichen Grenzen. Ich werde insofern zwischen deutschen, türkischen und EU- Akteuren bzw. europäischen Akteuren unterscheiden. Mit europäischen Akteuren sind jene Akteure gemeint, die mit EU-Institutionen verbunden sind und sich von dieser Position aus zu Wort gemeldet haben, seien sie Sprecher des Ministerrates oder der Kommission oder Abgeordnete des EU-Parlamentes. An dieser Stelle überschneiden sich häufig die deutschen oder sonstigen nationalen Akteure mit europäische Akteuren, weil sie ja zusätzlich als Vertreter europäischer Institutionen zu Wort kommen. Ganz abgesehen davon, dass die Akteure aus EU- 
Ländern, seien sie nun deutsche oder französische, sich als Europäer verstehen, wenn sie sich über die Türkei äußern.

\section{Auswahl des Untersuchungsmaterials}

Die untersuchten deutschen Zeitungen sind die Frankfurter Allgemeine Zeitung (FAZ), die Süddeutsche Zeitung (SZ) und die Tageszeitung (TAZ). Die türkischen Zeitungen sind Hürriyet (HÜR), Cumhuriyet (CUM) und Zaman (ZAM). Die Kriterien für die Auswahl sind, dass erstens alle überregional erscheinen, einen großen Verbreitungsgrad haben, und vor allem jeweils eine dominante politische Position in der jeweiligen Gesellschaft vertreten. Sie decken zweitens ein breites politisches Spektrum in Deutschland wie in der Türkei ab und haben erheblichen Einfluss auf die Meinungsbildung in der jeweiligen politischen Öffentlichkeit. Während die FAZ dem konservativen, die SZ dem liberalen und die TAZ dem linken/grünen politischen Spektrum zugeordnet werden, werden HÜR dem staatsnahen rechtsliberalen, CUM dem kemalistischen und ZAM (seit 2002) dem liberalen islamistischen Spektrum zugerechnet. $^{3}$

Der gewählte Untersuchungszeitraum umfasst die Dezemberausgaben der oben erwähnten Zeitungen aus den Jahren 1997, 1999, 2002 und 2004. Im Dezember 1997 hatte die EU in Luxemburg die Qualifikation der Türkei für eine EU-Mitgliedschaft bestätigt, schloss sie jedoch hinsichtlich des Erweiterungsprozesses aus. Die Türkei wurde zur Europakonferenz eingeladen. Beim Helsinki-Gipfel des Europäischen Rates im Dezember 1999 erhielt sie den Status eines Beitrittskandidaten zur EU. Beitrittsverhandlungen sollten aber erst beginnen, wenn die für einen

3 In jeder untersuchten türkischen Zeitung gibt es ein bis zwei Kolumnisten, die sich vom dominanten Kurs der Zeitung absetzen, wie die pro-europäisch eingestellten Journalisten Hadi Uluengin (HÜR), Etyen Mahçupyan (ZAM) und Oral Çalışlar (CUM). Jedoch geht es hier nicht um einzelne Autoren, sondern um die allgemeine Belegschaft der Zeitung. Während die Mehrheit der HÜR-Kolumnisten realpolitische pragmatische Ziele verfolgt, bilden der liberale Hadi Uluengin und der populistische Emin Çolaşan die beiden extremen Flügel. Bei der CUM dagegen sind - bis auf Oral Çalişlar - alle anderen Kolumnisten nationalistisch bzw. kontra-europäisch orientiert. In der ZAM sind seit 2002 diverse islamistische Positionen vertreten, von traditionellen bis zu liberal orientierten »postmodernen« islamistischen Autoren (wie Ali Bulaç). Lediglich Etyen Mahçupyan kommt aus einer kritischen postmodernen Tradition. In den Jahren 1997 und 1999 war die ZAM einstimmig konservativ und islamistisch geprägt, seit 2002 ist sie pro-europäisch ausgerichtet. Alle türkischen Zeitungsartikel wurden von mir übersetzt. 
Beitritt notwendigen politischen Kriterien der Europäischen Union vollständig erfüllt würden. Der Europäische Rat von Kopenhagen beschloss im Dezember 2002, der Türkei konkrete Beitrittsverhandlungen in Aussicht zu stellen, wenn sie bis Ende 2004 »die erforderlichen Voraussetzungen« aufweise. Schließlich entschied der Europäische Rat am 17. Dezember 2004 in Brüssel, die Beitrittsverhandlungen mit der Türkei am 3. Oktober 2005 aufzunehmen, falls die bestimmten Bedingungen erfüllt sein würden. Es sind dies die Zeiträume, in denen in der Türkei sowie in der BRD am häufigsten über die EU-Türkei-Beziehungen berichtet wurde.

Die Anzahl der Artikel war trotz der zeitlichen Eingrenzung sehr hoch und wurde zunächst nach thematischen Gesichtspunkten sortiert. Die Zeitungsartikel, die insbesondere im Bereich Politik bzw. Außenpolitik die EU-Türkei-Beziehungen entweder haupt- oder nebenthematisch oder als Referenzpunkt erörterten, sind in den Datenkorpus aufgenommen worden, einschließlich der Kommentare von Kolumnisten oder Türkei-Korrespondenten, Feuilletons, Dossiers etc. in den deutschen Zeitungen. Berichte im Bereich der Ökonomie wurden ausgeschlossen. In diesen untersuchten vier Perioden sind insgesamt 2670 Zeitungsartikel über die EU und die Türkei in deutschen und türkischen Zeitungen gesichtet und in den allgemeinen Datenkorpus aufgenommen worden, davon 2015 Artikel in den türkischen und 655 in den deutschen Zeitungen (Tabelle 1).

\section{Tab. 1. Artikelanzahl \& Zeitung}

\begin{tabular}{|c|c|c|c|c|c|}
\hline \multirow[b]{2}{*}{ Zeitung } & \multirow[b]{2}{*}{ Dez. 1997} & \multicolumn{2}{|c|}{ Artikelanzahl } & \multirow[b]{2}{*}{ Dez. 2004} & \multirow[t]{2}{*}{ Total } \\
\hline & & Dez. 1999 & Dez. 2002 & & \\
\hline FAZ & 58 & 54 & 81 & 97 & 290 \\
\hline SZ & 45 & 29 & 61 & 56 & 191 \\
\hline TAZ & 46 & 19 & 51 & 58 & 174 \\
\hline HÜR & 62 & 105 & 217 & 385 & 769 \\
\hline CUM & 55 & 150 & 190 & 100 & 495 \\
\hline ZAM & 118 & 137 & 157 & 339 & 751 \\
\hline Total & 384 & 494 & 757 & 1035 & 2670 \\
\hline
\end{tabular}


Die deutschen Zeitungen wurden über CD-ROM via Schlagwörter »EU und Türkei«, »Europa und Türkei«, »Türkei« und »Türken« recherchiert, die türkischen über das Online-Archiv der jeweiligen Zeitung im Internet über die Schlagwörter »EU«, »Avrupa Birliği ve Türkiye». Lediglich die CUM aus dem Jahre 1997 musste in ihrem Archiv (in Ankara) manuell recherchiert werden, da die Zeitung erst ab 1998 über ein Online-Archiv verfügt. Tabelle 1 zeigt die gesamten gesichteten Artikel aller Zeitungen im untersuchten Zeitraum und ihre zahlenmäßige Verteilung.

Die Entwicklung der Artikelanzahl über die untersuchten Jahre hinweg ist Tabelle 1 und Abbildung $1 \mathrm{zu}$ entnehmen. Es ist $\mathrm{zu}$ sehen, dass die Zahlen von 1997 bis 2004 insgesamt deutlich zugenommen haben, insbesondere haben sich in HÜR und ZAM die Nachrichten und Artikel zum Thema ungefähr verdreifacht. Im Jahr 2004 erscheinen in allen Zeitungen zusammengenommen über 1000 Artikel über EU und Türkei, während es 1997 lediglich 384 waren. Bei SZ, TAZ und CUM folgen die Zahlen einem anderen Zyklus. Während sie in SZ und TAZ 1999 deutlich abnehmen und ab 2002 wieder zunehmen, nehmen sie bei CUM $2004 \mathrm{ab}$.

\section{Abb. 1. Artikelanzahl \& Jahr}

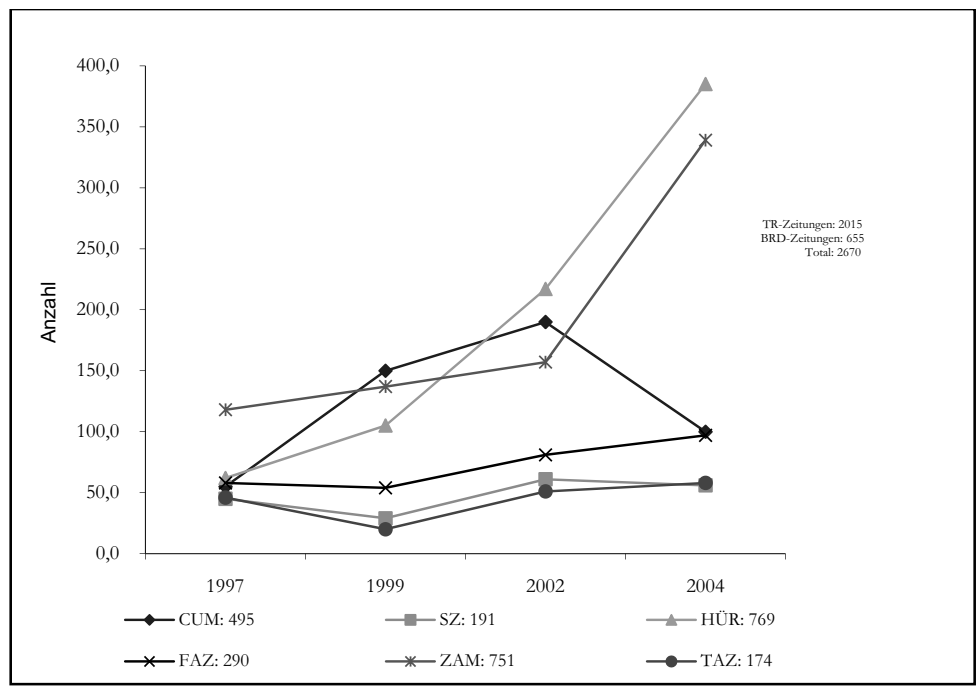

Die folgende statistische Analyse per SPSS basiert nicht auf der vollen statistischen Datenerhebung, ich habe, wie bereits erwähnt, aus zeitökonomischen Gründen eine zweite zielorientierte Auswahl getroffen. Von 
2670 Zeitungsartikeln habe ich 782 Artikel nach folgenden Gesichtspunkten in die engere Wahl für das Kodieren genommen: Nur die Artikel, in denen EU und Türkei als Hauptthema erscheinen, wurden kodiert. Alle drei türkischen Zeitungen haben jeweils mehr Kolumnisten, die gelegentlich über die EU-Türkei-Beziehungen schreiben, als die deutschen Zeitungen. Ich habe die exemplarischen Artikel der bekanntesten Kolumnisten und Meinungsführer im untersuchten Zeitraum ausgewählt und dabei darauf geachtet, dass alle Zeitungen und diskursiven Positionen repräsentiert sind. Alle politischen Akteure, die in den Zeitungsartikeln erschienen, wurden kodiert. Kam jedoch eine Äußerung in mehreren Zeitungen gleichzeitig vor, habe ich die ausführlich verfasste Nachricht kodiert und die anderen in folgende Variablen gefasst: »in mehreren türkischen Zeitungen«, »in mehreren deutschen Zeitungen«, »in mehr als einer deutschen und türkischen Zeitung«. Die Häufigkeit, mit der ein Akteur in mehreren Zeitungen auftaucht, zeigt die Relevanz der Aussage bzw. des Akteurs.

In diesen 782 ausgewählten Artikeln gibt es 1154 Äußerungen. Der Unterschied zwischen Artikel und Äußerung liegt darin, dass in einem Bericht öfter mehrere Akteure zu Wort kommen. In Tabelle 2 sind Zahlen von kodierten Äußerungen zu sehen. Die folgende Analyse basiert auf diesen Äußerungen und nicht auf der Zahl von Berichten.

\section{Tab. 2. Zeitung \& Jahr}

\begin{tabular}{|c|c|c|c|c|c|}
\hline $\begin{array}{c}\text { Kodierte } \\
\text { Ereignisse }\end{array}$ & \multicolumn{4}{|c|}{ Jahr } & \multirow[t]{2}{*}{ Total } \\
\hline Zeitung & 1997 & 1999 & 2002 & 2004 & \\
\hline \multirow[t]{2}{*}{ FAZ } & 32 & 36 & 53 & 70 & 191 \\
\hline & $16,8 \%$ & $18,8 \%$ & $27,7 \%$ & $36,6 \%$ & $100,0 \%$ \\
\hline \multirow[t]{2}{*}{ SZ } & 30 & 32 & 48 & 41 & 151 \\
\hline & $19,9 \%$ & $21,2 \%$ & $31,8 \%$ & $27,2 \%$ & $100,0 \%$ \\
\hline \multirow[t]{2}{*}{ TAZ } & 35 & 35 & 31 & 43 & 144 \\
\hline & $24,3 \%$ & $24,3 \%$ & $21,5 \%$ & $29,9 \%$ & $100,0 \%$ \\
\hline \multirow[t]{2}{*}{ HÜR } & 33 & 55 & 68 & 77 & 233 \\
\hline & $14,2 \%$ & $23,6 \%$ & $29,2 \%$ & $33,0 \%$ & $100,0 \%$ \\
\hline \multirow[t]{2}{*}{ CUM } & 54 & 48 & 65 & 54 & 221 \\
\hline & $24,4 \%$ & $21,7 \%$ & $29,4 \%$ & $24,4 \%$ & $100,0 \%$ \\
\hline \multirow[t]{2}{*}{ ZAM } & 35 & 39 & 51 & 89 & 214 \\
\hline & $16,4 \%$ & $18,2 \%$ & $23,8 \%$ & $41,6 \%$ & $100,0 \%$ \\
\hline \multirow[t]{2}{*}{ Total } & 219 & 245 & 316 & 374 & 1154 \\
\hline & $19,0 \%$ & $21,2 \%$ & $27,4 \%$ & $32,4 \%$ & $100,0 \%$ \\
\hline
\end{tabular}

In der Tabelle 3 sieht man die Verteilung der entsprechenden Beitragstypen in den jeweiligen Zeitungen. Die ausgewählten Zeitungsbeiträge 
gehören überwiegend der Kategorie Nachrichten an, gefolgt von den Kommentaren mit annähernd 29 Prozent. Als Artikel werden jene Beiträge bezeichnet, die zwar Kommentare sind, jedoch von zeitungsexternen Autoren verfasst wurden, also von Wissenschaftlern, Politikern und sonstigen Prominenten. Im Gegensatz zu den Kommentaren wurden alle Artikel kodiert.

Es ist auffällig, dass der Anteil von Kommentaren in den türkischen Zeitungen mit zwischen 33 und 40 Prozent wesentlich höher ist als in den deutschen Zeitungen, wo er lediglich zwischen 15 und 23 Prozent beträgt. Der Nachrichtenanteil in den deutschen Zeitungen liegt bei rund 70-75 Prozent, in den türkischen Zeitungen dagegen lediglich bei um die 50 Prozent. Der relativ hohe Anteil an von fremden Autoren geschriebenen Artikeln in der ZAM ist auffällig. Es ist die Zeitung, die ab 2002 am häufigsten externe Autoren zu Wort kommen lässt. Ihr folgen die FAZ und die SZ. CUM, HÜR und TAZ zeigen dagegen ähnliche Muster. Sie sind am wenigsten für fremde Autoren offen. Bei der ZAM hat im Untersuchungszeitraum ein Positionswechsel stattgefunden, sie war bis Anfang 1999 eher euroskeptisch und verglichen mit den anderen beiden türkischen Zeitungen erschienen wenig Artikel zu EU und Türkei. Ab 2002 berichtete sie dagegen immer häufiger und positiver und öffnete ihr Blatt pro-europäischen Autoren und Politikern. Dies ging auch mit einer sichtbaren personellen Umstrukturierung innerhalb der Zeitung einher.

\section{Tab. 3. Zeitung \& Genre}

\begin{tabular}{|c|c|c|c|c|c|}
\hline \multirow[b]{2}{*}{ Zeitung } & \multicolumn{4}{|c|}{ Genre } & \multirow[t]{2}{*}{ Total } \\
\hline & Nachricht & Kommentar & Artikel & Interview & \\
\hline \multirow[t]{2}{*}{ FAZ } & 145 & 32 & 12 & 2 & 191 \\
\hline & $75,9 \%$ & $16,8 \%$ & $6,3 \%$ & $1,0 \%$ & $100,0 \%$ \\
\hline \multirow[t]{2}{*}{ SZ } & 113 & 24 & 9 & 5 & 151 \\
\hline & $74,8 \%$ & $15,9 \%$ & $6,0 \%$ & $3,3 \%$ & $100,0 \%$ \\
\hline \multirow[t]{2}{*}{ TAZ } & 101 & 34 & 2 & 7 & 144 \\
\hline & $70,1 \%$ & $23,6 \%$ & $1,4 \%$ & $4,9 \%$ & $100,0 \%$ \\
\hline \multirow[t]{2}{*}{ HÜR } & 137 & 94 & 2 & 0 & 233 \\
\hline & $58,8 \%$ & $40,3 \%$ & $0,9 \%$ & $0,0 \%$ & $100,0 \%$ \\
\hline \multirow[t]{2}{*}{ CUM } & 145 & 74 & 1 & 1 & 221 \\
\hline & $65,6 \%$ & $33,5 \%$ & $0,5 \%$ & $0,5 \%$ & $100,0 \%$ \\
\hline \multirow[t]{2}{*}{ ZAM } & 114 & 72 & 19 & 9 & 214 \\
\hline & $53,3 \%$ & $33,6 \%$ & $8,9 \%$ & $4,2 \%$ & $100,0 \%$ \\
\hline \multirow[t]{2}{*}{ Total } & 755 & 330 & 45 & 24 & 1154 \\
\hline & $65,4 \%$ & $28,6 \%$ & $3,9 \%$ & $2,1 \%$ & $100,0 \%$ \\
\hline
\end{tabular}


Tabelle 4 stellt die Häufigkeit dar, mit der die Akteure in den jeweiligen Zeitungen Erwähnung finden. Die 1154 kodierten Äußerungen in allen Zeitungen stammen zu 51 Prozent von türkischen Akteuren, gefolgt von den deutschen Akteuren mit nahezu der Hälfte des Prozentsatzes. Mit geringem Abstand folgen die europäischen Akteure. Wie zu erwarten war, erscheinen in den deutschen Zeitungen am häufigsten deutsche Akteure, und diese am stärksten in der FAZ mit 57 Prozent, und ebenso in den türkischen Zeitungen vorwiegend türkische Akteure, und hier in der ZAM am häufigsten mit 76 Prozent. In SZ und TAZ ist ein relativ hoher Anteil von europäischen und türkischen Akteuren zu vermerken. Während die türkischen Akteure mit ca. 25 Prozent in den deutschen Zeitungen vorkommen, ist der Anteil von deutschen Akteuren in den türkischen Zeitungen mit ca. 10 Prozent mehr als doppelt so gering. Das liegt daran, dass diese Zeitungen auch über sonstige Akteure aus den EULändern berichten und Deutschland zwar ein wichtiges, aber nur eines von diesen ist. In SZ und HÜR treten am häufigsten europäische Akteure als Sprecher auf.

\section{Tab. 4. Artikelanzahl \& Jahr 104}

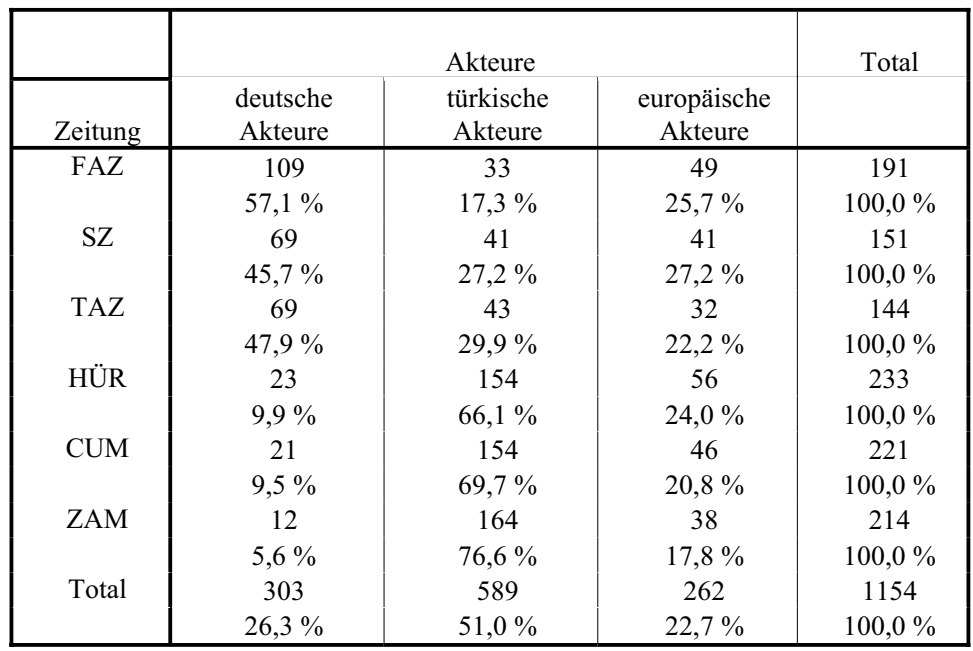

Chi-Square df.: 10, sig.: 000, 0 cells (0,0 \%) Cramer's V: ,377 Lambda: ,152

Wenn man die Tabelle 5 dahingehend betrachtet, welche deutschen Akteure in den untersuchten Zeitungen sichtbar werden, so kann man feststellen, dass in allen Zeitungen die Christdemokraten/Liberalen nahezu doppelt so häufig sprechen (ca. 35 Prozent) wie die Sozialdemokraten/ Grüne (ca. 19 Prozent). Unter 303 Äußerungen kommen die deutschen 
Akteure $56 \mathrm{Mal}$ (ca. 18 Prozent) in den türkischen Zeitungen zu Wort, wobei die politische Position dieser Akteure bei der türkischen Berichterstattung kaum eine Rolle spielt.

Tab. 5. Zeitung \& deutsche Akteure

\begin{tabular}{|c|c|c|c|c|c|}
\hline & \multicolumn{4}{|c|}{ deutsche Akteure } & Total \\
\cline { 1 - 1 } Zeitung & pro-türkische & kontra-türkische & Kolumnist & Sonstige & \\
\hline FAZ & 15 & 41 & 36 & 17 & 109 \\
& $13,8 \%$ & $37,6 \%$ & $33,0 \%$ & $15,6 \%$ & $100,0 \%$ \\
SZ & 12 & 26 & 21 & 10 & 69 \\
& $17,4 \%$ & $37,7 \%$ & $30,0 \%$ & $14,5 \%$ & $100,0 \%$ \\
TAZ & 10 & 18 & 30 & 11 & 69 \\
& $14,5 \%$ & $26,1 \%$ & $43,5 \%$ & $15,9 \%$ & $100,0 \%$ \\
HÜR & 9 & 7 & 2 & 5 & 23 \\
& $39,1 \%$ & $30,4 \%$ & $8,7 \%$ & $21,7 \%$ & $100,0 \%$ \\
CUM & 8 & 9 & 1 & 3 & 21 \\
& $38,1 \%$ & $42,9 \%$ & $4,8 \%$ & $14,3 \%$ & $100,0 \%$ \\
ZAM & 3 & 6 & 0 & 3 & 12 \\
& $25,0 \%$ & $50,0 \%$ & $0,0 \%$ & $25,0 \%$ & $100,0 \%$ \\
Total & 57 & 107 & 90 & 49 & 303 \\
& $18,8 \%$ & $35,3 \%$ & $29,7 \%$ & $16,2 \%$ & $100,0 \%$ \\
\hline
\end{tabular}

Tab. 6. Zeitung \& türkische Akteure

\begin{tabular}{|c|c|c|c|c|c|}
\hline \multirow[b]{2}{*}{ Zeitung } & \multicolumn{4}{|c|}{ türkische Akteure } & \multirow[t]{2}{*}{ Total } \\
\hline & $\begin{array}{c}\text { pro- } \\
\text { europäische }\end{array}$ & $\begin{array}{l}\text { kontra- } \\
\text { europäische }\end{array}$ & Kolumnist & Sonstige & \\
\hline \multirow[t]{2}{*}{ FAZ } & 11 & 8 & 5 & 9 & 33 \\
\hline & $33,3 \%$ & $24,2 \%$ & $15,2 \%$ & $27,9 \%$ & $100,0 \%$ \\
\hline \multirow[t]{2}{*}{ SZ } & 20 & 7 & 3 & 11 & 41 \\
\hline & $48,8 \%$ & $17,1 \%$ & $15,2 \%$ & $26,8 \%$ & $100,0 \%$ \\
\hline \multirow[t]{2}{*}{ TAZ } & 15 & 12 & 1 & 15 & 43 \\
\hline & $34,9 \%$ & $27,9 \%$ & $2,3 \%$ & $34,9 \%$ & $100,0 \%$ \\
\hline \multirow[t]{2}{*}{ HÜR } & 27 & 18 & 90 & 19 & 154 \\
\hline & $17,5 \%$ & $11,5 \%$ & $58,4 \%$ & $12,3 \%$ & $100,0 \%$ \\
\hline \multirow[t]{2}{*}{ CUM } & 20 & 36 & 75 & 23 & 154 \\
\hline & $13,0 \%$ & $23,4 \%$ & $48,7 \%$ & $14,9 \%$ & $100,0 \%$ \\
\hline \multirow[t]{2}{*}{ ZAM } & 26 & 44 & 71 & 23 & 164 \\
\hline & $15,9 \%$ & $26,8 \%$ & $43,3 \%$ & $14,0 \%$ & $100,0 \%$ \\
\hline \multirow[t]{2}{*}{ Total } & 119 & 125 & 245 & 100 & 589 \\
\hline & $20,2 \%$ & $21,2 \%$ & $41,6 \%$ & $17,0 \%$ & $100,0 \%$ \\
\hline
\end{tabular}

Chi-Square df.: 25 sig.: 000, 2 cells (5,6 \%), Lambda: ,361, Cramer's V: , 474

In 589 kodierten Äußerungen, in denen die türkischen Akteure sich zu Wort melden, sind - wenn man alle Zeitungen zusammen betrachtet pro-europäische und kontra-europäische Akteure mit gleicher Häufigkeit 
vertreten, wie Tabelle $6 \mathrm{zu}$ entnehmen ist. Die deutschen Zeitungen berichten zwar doppelt so oft über die türkischen Akteure (117 Mal) als die türkischen über die deutschen (56 Mal), prozentual gesehen ist der Unterschied jedoch geringer (19 Prozent). Die türkischen Akteure bzw. Zeitungen sprechen offensichtlich mehr über die EU-Türkei-Beziehungen, als die deutschen das tun. Alle deutschen Zeitungen und HÜR berichten mehr über die türkischen pro-europäischen Akteure, dagegen berichten CUM und ZAM eher über die kontra-europäischen.

Tab. 7. Zeitung \& europäische Akteure

\begin{tabular}{|c|c|c|c|c|c|}
\hline & \multicolumn{4}{|c|}{ europäische Akteure } & Total \\
& $\begin{array}{c}\text { Sozialdem./ } \\
\text { Grüne/ } \\
\text { Zeitung }\end{array}$ & $\begin{array}{c}\text { EU-Christ- } \\
\text { Sozialisten }\end{array}$ & $\begin{array}{c}\text { EU- } \\
\text { demokraten }\end{array}$ & $\begin{array}{c}\text { Sonstige } \\
\text { EU-Staaten/ } \\
\text { Institutionen }\end{array}$ & \\
\hline FAZ & 5 & 19 & 15 & 10 & 49 \\
& $10,2 \%$ & $38,8 \%$ & $30,6 \%$ & $20,4 \%$ & $100,0 \%$ \\
SZ & 0 & 10 & 23 & 8 & 41 \\
&, $0 \%$ & $24,4 \%$ & $56,1 \%$ & $19,5 \%$ & $100,0 \%$ \\
TAZ & 4 & 5 & 11 & 12 & 32 \\
& $12,5 \%$ & $15,6 \%$ & $34,4 \%$ & $37,5 \%$ & $100,0 \%$ \\
HÜR & 11 & 12 & 29 & 4 & 56 \\
& $19,6 \%$ & $21,4 \%$ & $51,8 \%$ & $7,1 \%$ & $100,0 \%$ \\
CUM & 3 & 4 & 24 & 15 & 46 \\
& $6,5 \%$ & $8,7 \%$ & $52,2 \%$ & $32,6 \%$ & $100,0 \%$ \\
ZAM & 7 & 5 & 15 & 11 & 38 \\
& $18,4 \%$ & $13,2 \%$ & $39,5 \%$ & $28,9 \%$ & $100,0 \%$ \\
Total & 30 & 55 & 117 & 60 & 262 \\
& $11,5 \%$ & $21,0 \%$ & $44,7 \%$ & $22,9 \%$ & $100,0 \%$ \\
\hline
\end{tabular}

Chi-Square df.: 15 sig.: 000, 3 cells (12,5\%), Lambda: ,066, Cramer's V: ,227

Auch Tabelle 7 zeigt, dass europäische christliche Konservative in den deutschen Zeitungen häufiger sichtbar werden als europäische Sozialdemokraten/Grüne und Sozialisten. In den türkischen Zeitungen ist diese Differenz nicht zu sehen. Verglichen mit deutschen Zeitungen berichten sie zwar weniger über europäische Abgeordnete, aber wenn, dann tauchen Konservative und Sozialdemokraten/Grüne/Sozialisten nahezu gleichermaßen auf. Insgesamt genommen kommen mit 21 Prozent die europäischen Christdemokraten in allen Zeitungen doppelt so häufig zu Wort wie Sozialdemokraten/Grüne/Sozialisten. Die Aufmerksamkeit wird mit insgesamt 44,7 Prozent vorwiegend den EU-Institutionen (Kommission, Rat) geschenkt, während die türkischen Zeitungen EUInstitutionen häufiger sprechen lassen, als die deutschen Zeitungen das tun. 
Im Folgenden werde ich die Strukturmerkmale der deutsch-europäischen und türkischen Diskurse von 1997 bis 2004 deskriptiv analysieren und die Interaktion zwischen türkischen und deutsch-europäischen Diskursformationen in Diagrammen veranschaulichen.

\section{Die Struktur des diskursiven Feldes}

Bis zum Luxemburger Gipfel in Dezember 1997 dominierte auf dem deutschen und europäischen diskursiven Feld primär die »Unfähigkeit« der Türkei zum EU-Beitritt (vgl. Alkan 1994; Gür 1998). ${ }^{\star}$ „Europa« wollte die Türkei durch die Integration demokratisieren und ihr dabei »helfen«, sich »auf dem Gleis nach Europa zu halten«, (Kinkel, SZ: 17.12.1997). Die Türkei könne derzeit kein Vollmitglied der EU werden, so Klaus Kinkel (FDP) damals, weil sie angesichts der Demokratiedefizite, des Kurdenproblems und der Schwierigkeiten mit Griechenland nicht reif für die Vollmitgliedschaft sei (HÜR: 16.12.1997; SZ: 17.12.1997). Es herrschte diesbezüglich ein Konsens zwischen Christdemokraten/Liberalen und Sozialdemokraten/Grünen.

Die türkischen Aussagen bezüglich der »religiösen Diskriminierung« nach dem Gipfel wurde von der CDU/FDP-Regierung mit dem Hinweis auf die in Deutschland lebenden muslimisch-türkischen Migranten abgewehrt. Helmut Kohl wies diesen Vorwurf des damaligen türkischen Premierministers Mesut Yilmaz zurück, den dieser anlässlich des Beschlusses des Europäischen Rates in Luxemburg 1997, den Antrag der Türkei auf den Kandidatenstatus für die Vollmitgliedschaft abzulehnen, äußerte. Yilmaz hatte vor allem Helmut Kohl vorgehalten, dass er aus der EU »einen Club der Christen« machen wolle (SZ: 20.12.1997; FAZ: 15.12.1997). Es gebe, so Kohl, zahlreiche Moscheen in Deutschland, was Yilmaz religiösen Diskriminierungsvorwurf widerlege (FAZ: 15.12.1997). Die Türkei solle keinen konfrontativen Kurs auf internationaler Ebene einschlagen. Sonst würden, Lamers (CDU) zufolge, sich nur diejenigen Kräfte bestätigt sehen, die sich gegen eine Zusammenarbeit mit der Türkei aussprächen (Lamers, FAZ: 16.12. 1997). Wolfgang Koydl (SZ) sprach von einer »kranken« Türkei, in der

4 In seiner Untersuchung der deutschen Massenmedien von 1960-1971 stellt Alkan (1994) fest, dass die Türkei in der deutschen massenmedialen Öffentlichkeit als ein Land dargestellt wird, das »nicht reif für die Demokratie $\ll$ ist. Alkan untersucht 612 Artikel aus FAZ, FR, SZ und BILD von 1960-1971. Eine ähnliche quantitative Forschung betrieb Gür (1998). Er analysierte in seiner Dissertation die deutsche Presse von 1987-1995 und fragte, welche Türkeibilder in den deutschen Massenmedien vermittelt würden. 
Arbeitslosigkeit, Inflation, Verschuldung, Verstrickung von Politik und Mafia und Krieg in Kurdistan herrschten (Koydl, SZ: 14.02.1997). Seit dem Helsinki-Gipfel im Dezember 1999 wurde sichtbar, dass Europa mehr als die Gesamtheit von EU-Institutionen, gemeinsamem Markt und politischer Integration war.

Der deutsche und europäische Konsens über die Stabilisierung und »securitization« von Osteuropa durch Integration, über die »Wiedervereinigung Europas« brach im türkischen Fall seitdem auseinander. ${ }^{5}$ Der damalige Bundeskanzler Schröder sprach von einem Gipfel (Helsinki 1999) von »historischer« Bedeutung und verteidigte das Einbeziehen der Türkei mit strategischen und kulturellen Deutungsstrategien. Der Beitritt der Türkei würde das Land stabilisieren und demokratisieren. Die Türkei sei das Land, das die »Brücke zwischen Europa und Islamischer Welt« bilde, sie würde ein »Modell für die Islamische Welt« sein und beweisen, dass die EU kein »christlicher Club« ist. Ein Beitritt würde ferner die Handlungsfähigkeit der EU im Bereich der europäischen Außen- und Sicherheitspolitik verstärken. Mit der Türkei werde die EU »glaubwürdiger« und »kosmopolitischer«. Der CDU-Vorsitzende Wolfgang Schäuble räumte ein, der Gipfel in Helsinki habe zwar »historische« Dimensionen, allerdings: „Es ist nur noch nicht sichergestellt, ob zum Nutzen oder zum Schaden Europas« (Schäuble, SZ: 17.12.1999). Schäuble und Lamers zufolge musste die EU »Klarheiten über den Zeitpunkt des Beitritts [zu] schaffen: dazu sind zwei Voraussetzungen erforderlich: die Beitrittsfähigkeit der Kandidaten und die Aufnahmefähigkeit der EU. Die EU droht ansonsten zu zerklüften« (Schäuble \& Lamers, FAZ: 7.12.1999).

Insbesondere seit 2002 verlagern sich die Diskursstrategien auf das thematische Feld »Zukunft Europas« und der Gesamtdiskurs hat sich massiv kulturalisiert. Der Beitritt eines Kandidaten in die EU hänge nicht nur von seiner Fähigkeit ab, sich an die europäischen Kriterien

5 Der Osterweiterungsdiskurs hat Anne Sher (2001) zufolge die diskursiven Strategien des Kalten Kriegs verfolgt. Er stellte den »brillanten Erfolg« des Westens gegenüber dem »Misserfolg der totalitären Regime« heraus, die Teilung Europas hätte der Osten zu verantworten gehabt. Ohne westliche Intervention würde dieses Territorium wieder in Armut und totalitäre Herrschaft zurückfallen. Osteuropa sollte integriert werden, um die »unsichere « Region zu stabilisieren und somit auch die Sicherheit Westeuropas zu gewährleisten. Andernfalls würden die »traditionellen Konflikte« in das europäische Territorium übertragen, der Osten wiederum in »Chaos« treten. Der Westen übernahm für Sher somit eine zivilisatorische Mission. Es sei somit eine »Wahrheit« über den Osten rekonstruiert worden, laut der dieser sich selbst zu regieren nicht in der Lage sei und deshalb regiert und kontrolliert werden müsse (vgl. Sher 2001: 248ff). 
anzupassen. Schäuble und Lamers sprechen im Jahre 1999 davon, dass neben der Beitrittsfähigkeit der Kandidaten die Aufnahmefähigkeit ${ }^{6}$ der $^{2}$ EU in Betracht gezogen werden solle. Christian Wernicke (SZ) zufolge ist es egal, ob die Türkei irgendwann reif für die EU ist. Brüssel sei nicht reif für die Türkei. »Eine Einladung der Türkei würde genau das Feuer schüren [...] Wer Europas Ostgrenze nach Kurdistan verlegt, der überdehnt die EU dermaßen, dass sie innerlich zu zerfallen droht.« (Wernicke, SZ: 13.12.2002)

Das Problem ist auch für den französischen Ex-Präsidenten D’Estaing nicht, ob die Türkei bereit für die Mitgliedschaft sei, sondern vielmehr, ob die europäischen Staaten und die EU bereit seien, ein Land wie die Türkei aufzunehmen. Denn die türkische Mitgliedschaft würde »die Natur des europäischen Projektes« verändern (D’Estaing, HÜR: 06.12.2004). Betrachtet man den deutschen europäischen Diskurs, so werden seit 1999 doppelte Repräsentationen über die Türkei sichtbar. Zum einen ist die Türkei politisch »verdächtig«, da sie die demokratischen Regeln der Rechtstaatlichkeit nicht einhält, Menschenrechte verletzt, Kurden unterdrückt etc. Zum anderen ist sie kulturell »verdächtig«, sie scheint irgendwie nicht wirklich »europäisch« zu sein.

Während im Jahre 1997 auf der deutsch-europäischen Ebene hauptsächlich die Beitrittsfähigkeit der Türkei thematisiert wurde, wurden auf der türkischen Ebene im selben Jahr moralische, kulturelle und geostrategische Aussagen ins diskursive Feld geführt. Vor dem LuxemburgGipfel wurde die strategische »Brückenfunktion« der Türkei »zwischen Westen und Osten« in den Vordergrund gestellt. Europa müsse, dem HÜR-Chefredakteur Özkök und dem HÜR-Kolumnisten Ergin zufolge, entscheiden, ob es eine »christliche Isolation« oder »eine multinationale und multireligiöse Zivilisation« aufbauen wolle. Letzteres sei nur mit dem türkischen Beitritt möglich (Özkök, HÜR: 14.12.1997; Ergin, HÜR: 18.12.1997). Der amtierende türkische Außenminister Cem (DSP) wies darauf hin, dass es falsch sei, zwischen den beiden Kontinenten zu trennen: Sein Land liege in der Mitte »Eurasiens« (Cem, FAZ: 11.12. 1997). Nach dem Gipfel verlagerten sich die türkischen Aussagen auf ein moralisches Feld. Europa sei nicht ehrlich, behandle die Türkei nicht gleich und sei ein »christlicher Club«. Die Schuld für das »Versagen« lag für die türkischen Akteure allein in der europäischen »Unehrlich-

6 Neben drei Beitrittskriterien, die im beim EU-Gipfel in Kopenhagen 1993 beschlossenen »Acquis Communautaire« beschrieben sind, gilt die »Aufnahmefähigkeit« der Europäischen Union als viertes Kopenhagener Kriterium. Es geht um »[d]ie Fähigkeit der Union, neue Mitglieder aufzunehmen, dabei jedoch die Stoßkraft der europäischen Integration zu erhalten [...] (vgl. Europäischer Rat Kopenhagen, 21.-22. Juni 1993). 
keit« und der »religiösen Diskriminierung«. Die türkische Regierung drohte mit einem Embargo gegen Firmen aus den EU-Ländern - wie etwa Deutschland, die Benelux-Staaten und Griechenland - die gegen die türkische Mitgliedschaft agiert hatten (FAZ: 17.12.1997). Als die europäischen Akteure 1997 den Kandidatenstatus aufgrund der »Menschenrechtsverletzungen und Folter« ablehnten, erklärte einer der Minister der Regierung Yilmaz, Mehmet Keçeciler (ANAP), dass es in der osmanischen und türkischen Geschichte und im Islam keine Folter gegeben habe. Folterkammern seien Teil der »mittelalterlichen europäischen Kultur«. Diejenigen, die »unter ihrem Palast Folterkammern« errichtet hätten, seien die Europäer gewesen (Keçeciler, ZAM: 15.12.1997). Der Ex-Minister Kamran İnan (ANAP) äußerte sich folgendermaßen:

»Diejenigen die uns über Menschenrechte unterrichten wollen, sollen die Genozide in den 30er und 90er Jahren in Bosnien anschauen und sich dafür schämen. Solange der Westen uns gebraucht hat, wollten wir immer mit ihm zusammen gehen. Jetzt wollen sie uns nicht mehr. Vor einem Alleingang haben wir uns in unserer Geschichte nie gefürchtet und tun dies auch heute nicht.« (İnan, HÜR: 16.12.1997)

Auf dem türkischen Feld waren bis Ende des 1990er Jahre insbesondere die konservativ-islamistische Wohlfahrt Partei (RP) und ZAM die Träger des kontra-europäischen Diskurses (vgl. Bora 2002). Der türkische Beitritt in die Zollunion würde den Verlust der türkischen Unabhängigkeit bedeuten. Er würde zur Folge haben, dass die Europäer nachträglich das Sèvres-Abkommen ${ }^{7}$ umsetzten. Das Land würde an den Westen verraten. Sie bezogen sich dabei immer auf die türkischen Gründungsmy-

7 Der Vertrag von Sèvres wurde am 10. August 1920 mit dem Osmanischen Reich geschlossen. Er markierte gewissermaßen das Ende des Osmanischen Reiches, doch er wurde wegen des türkischen Widerstandes nie umgesetzt. Durch diesen Vertrag verlor das Osmanische Reich einen Großteil seines Territoriums in Saudi-Arabien und Mesopotamien. Armenien sollte unabhängig werden. Kurdistan sollte erst autonom und nach Artikel 64 dann auch unabhängig werden. Als Völkerbundmandate wurden Mesopotamien (Irak) und Palästina an Großbritannien, Syrien und der Libanon an Frankreich übergeben, Thrakien (Trakya) und Smyrna (Izmir) fielen an Griechenland. Die Meerengen und das Marmarameer sollten entmilitarisiert und internationalisiert werden. Die Regierung in Ankara unter der Führung von Mustafa Kemal (später Atatürk genannt) lehnte den Vertrag ab und leistete der griechischen Armee bei der Invasion der Türkei Widerstand. Infolge des Griechisch-Türkischen Kriegs (1919-1922) wurde der Vertrag von Sèvres im Vertrag von Lausanne zugunsten der Türkei revidiert. 
then. Einer der prominenten islamischen Intellektuellen, Abdurrahman Dilipak, traf 1995 genau den kemalistischen Blick bezüglich der Zollunion, indem er sich so äußerte:

»After this, they will come to defend the (Greek Orthodox) Patriarchate. There is Armenia waiting in line. And we will have to accept all their (Europeans) directives with regard to the Kurdish problem. This agreement is placing dynamite to the foundation of Turkish Republic which was built after a war of liberation; it is threatening the independence of Turkey.« (Dilipak, zit.n. Navaro-Yashin 2002: 57)

Insbesondere ab 2002 wird in der Türkei offenbar, dass es nicht »fundamentalistische Islamisten«, sondern die ehemaligen Träger des Modernisierungsprozesses, also Kemalisten (CHP), Ultranationalisten (MHP/IP), nationalistische Gewerkschaften, und CUM-Kolumnisten sind, die sich entlang nationalistischer Bedrohungserzählungen kontraeuropäisch positionieren. Die liberal-pragmatischen Islamisten (AKP), Rechtsliberalen (ANAP), pro-kurdischen Organisationen (HADEP und PKK) und ZAM-Kolumnisten engagieren sich besonders ab 2002 zunehmend für die EU (siehe unten die Abbildungen 29 und 30). Das Militär wird in der EU-Türkei-Debatte zwar kaum öffentlich sichtbar, doch ist sein disziplinierender Blick stets präsent. (In dem untersuchten Zeitraum melden sich Militärsprecher lediglich zwei Mal offiziell zur Wort.) Die Akteure scheinen gezwungen zu sein, stets mit diesem Blick zu rechnen, um legitime Diskursteilnehmer zu bleiben.

Tab. 8. Themenfelder \& Akteure

\begin{tabular}{|c|c|c|c|c|c|c|c|}
\hline & \multicolumn{6}{|c|}{ thematische Felder } & \multirow[b]{2}{*}{ Total } \\
\hline Akteure & $\begin{array}{c}\text { Kultur/ } \\
\text { Identität }\end{array}$ & $\begin{array}{c}\text { Sicherheit/ } \\
\text { Geostrat. }\end{array}$ & $\begin{array}{c}\text { Politik/ } \\
\text { Demokra- } \\
\text { tie }\end{array}$ & Moral & $\begin{array}{l}\text { Zukunft } \\
\text { Europas }\end{array}$ & $\begin{array}{l}\text { Sonstige } \\
\text { (Zypern) }\end{array}$ & \\
\hline \multirow{2}{*}{ deutsche } & 154 & 34 & 115 & 16 & 93 & 32 & 444 \\
\hline & $34,7 \%$ & $7,7 \%$ & $25,9 \%$ & $3,6 \%$ & $20,9 \%$ & $7,2 \%$ & 100,0 \\
\hline \multirow[t]{2}{*}{ türkische } & 156 & 51 & 352 & 92 & 32 & 126 & 809 \\
\hline & $19,3 \%$ & $6,3 \%$ & 43,5 & 11,4 & $4,0 \%$ & 15,6 & 100,0 \\
\hline \multirow[t]{2}{*}{ europ. } & 95 & 19 & 144 & 13 & 51 & 73 & 395 \\
\hline & $24,1 \%$ & $4,8 \%$ & $36,5 \%$ & $3,3 \%$ & $12,9 \%$ & $18,5 \%$ & 100,0 \\
\hline \multirow[t]{2}{*}{ Total } & 405 & 104 & 611 & 121 & 176 & 231 & 1648 \\
\hline & $24,6 \%$ & $6,3 \%$ & $37,1 \%$ & $7,3 \%$ & $10,7 \%$ & $14,1 \%$ & 100,0 \\
\hline
\end{tabular}

Chi-Square df.: 12, sig.: 000, 0 cells (0,0 \%), Lambda: ,072, Cramer's V: ,253. Prozente und Total basieren auf Responsen. 1154 gültige Ereignisse 
Kultur, Sicherheit, Politik/Demokratie, Moral, Zukunft Europas und Integration von Migranten sind die dominanten thematischen Felder, auf denen die Akteure für oder gegen den EU-Beitritt der Türkei unterschiedliche Geschichten erzählen. Die Tabelle 8 zeigt, welche Akteure in welchen thematischen Feldern über EU und Türkei sprechen. Während die Aussagen der deutschen Akteure sich am häufigsten im kulturellen Feld bewegen, äußern sich türkische und europäische Akteure am meisten im politischen bzw. demokratiebezogenen Bereich. Insofern zeigen die türkischen und europäischen Akteure, wenn auch mit unterschiedlicher Häufigkeit, doch eine ähnliche Tendenz bezüglich der thematischen Auswahl. Der Bereich der Sicherheit und Geostrategie nimmt bei allen Akteuren einen relativ geringen Anteil ein. Während die türkischen Akteure ihre Aussagen moralisch deuten, thematisieren die deutschen Akteure kulturelle Differenzen oder Gemeinsamkeiten sowie die »Zukunft Europas«.

Die kulturalistischen Deutungen nehmen im Laufe der Zeit zu, wie der Abbildung $2 \mathrm{zu}$ entnehmen ist. Im Jahr 2002 erreicht der kulturelle Rahmen seinen Höhepunkt, hier werden die Differenzen zu Europa oder die Brückenfunktion der Türkei in den Vordergrund gestellt. Kulturelle Topoi werden somit nahezu genauso häufig zur Sprache gebracht wie politische, die am stärksten vertreten sind, seit 2002 jedoch einen deutlichen Rückgang zeigen. Auf die Zukunft Europas bezogene Erzählungen erleben ebenfalls eine kontinuierliche Zunahme. Seit 2002 treten neben kulturellen Deutungsstrategien die »Zukunft und Grenzen Europas« zunehmend hervor. Die moralische Rahmung wurde immer wieder dann relevant, wenn die Türkei keinen Kandidatenstatus (1997) oder kein Datum für Verhandlungen (2002) bekam, und verringerte sich schlagartig, als die Türkei den Kandidatenstatus 1999 und 2004 eine Zusage für Verhandlungen erhält.

Tabelle 9 gibt wieder, welche Akteure welche spezifischen kulturalistischen Aussagen ins diskursive Feld führen. Mehr als die Hälfte aller deutschen Akteure führt die Aussage »die EU ist eine kulturelle Wertegemeinschaft« an. Diese Position wird ebenfalls als Haupttopos von europäischen Akteuren vertreten, allerdings mit etwas weniger starker Gewichtung. Mit etwa einem Sechstel sind die Positionen der Türkei als Brücke und der EU als politischer Gemeinschaft bei den deutschen Akteuren gleichermaßen vertreten. Die Türkei als »Brücke« und »Modell« ist die Hauptposition der türkischen Akteure. Diese wird von europäischen Akteuren zu etwa einem Viertel eingenommen. 
Abb. 2. Jahr \& Themenfelder

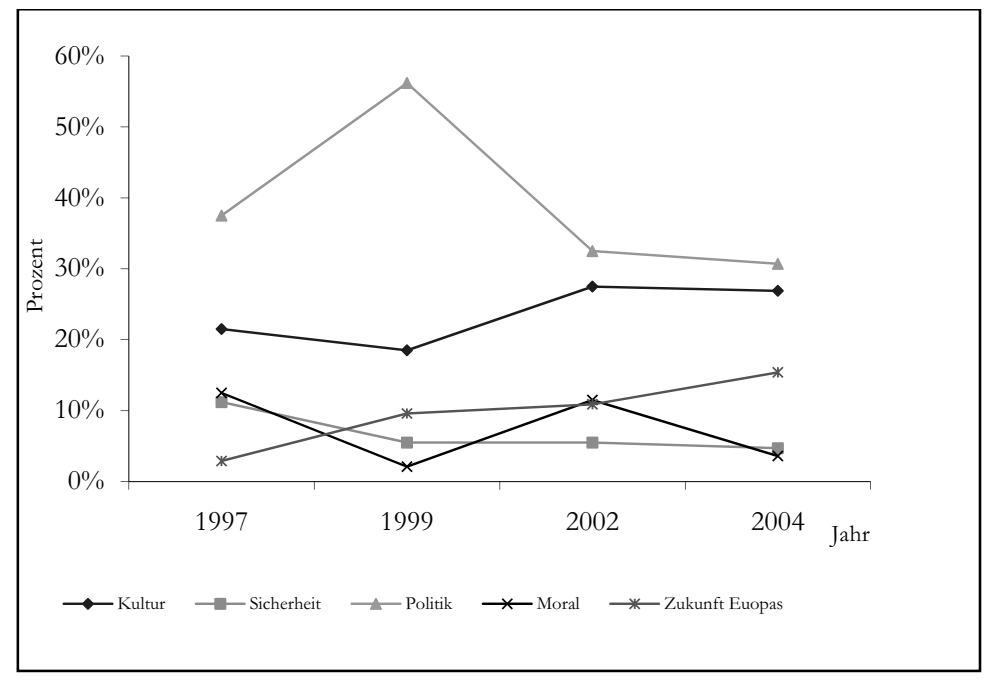

Die türkischen Akteure vertreten mit etwa gleicher Stärke die Positionen, dass die Türkei eine »Brücke« und die EU ein »christlicher Club« sind. Letztere ist bei deutschen und europäischen Akteuren nur marginal vertreten. Diese Aussage findet in der deutschen und europäischen Öffentlichkeit offensichtlich keine Resonanz, während Europa als kulturelle Wertegemeinschaft bei türkischen Akteuren nur geringe Zustimmung findet. »Europa ist eine politische Gemeinschaft« wird von einem Viertel der europäischen Akteure vertreten. Diese Aussage nimmt bei den deutschen und türkischen Akteuren einen geringeren Stellenwert ein.

\section{Tab. 9. kulturelles Feld \& Akteure}

\begin{tabular}{|c|c|c|c|c|c|c|c|}
\hline \multirow[b]{2}{*}{ Akteure } & \multicolumn{6}{|c|}{ kulturelles Feld } & \multirow[t]{2}{*}{ Total } \\
\hline & $\begin{array}{l}\text { TR als } \\
\text { Brücke }\end{array}$ & $\begin{array}{l}\text { TR ist } \\
\text { nicht } \\
\text { europä- } \\
\text { isch }\end{array}$ & $\begin{array}{c}\text { EU als } \\
\text { kultur-elle } \\
\text { Wertege- } \\
\text { meinschaft }\end{array}$ & $\begin{array}{c}\text { EU als } \\
\text { politische } \\
\text { Gemein- } \\
\text { schaft }\end{array}$ & $\begin{array}{c}\text { christl. } \\
\text { Club }\end{array}$ & Sonstige & \\
\hline \multirow[t]{2}{*}{ deutsche } & 50 & 17 & 164 & 43 & 3 & 23 & 300 \\
\hline & $16,7 \%$ & $5,7 \%$ & $54,7 \%$ & $14,3 \%$ & $1,0 \%$ & $7,7 \%$ & $\begin{array}{c}100,0 \\
\%\end{array}$ \\
\hline \multirow{2}{*}{$\begin{array}{l}\text { türki- } \\
\text { sche }\end{array}$} & 127 & 19 & 9 & 33 & 112 & 75 & 375 \\
\hline & $33,9 \%$ & $5,1 \%$ & $2,4 \%$ & $8,8 \%$ & $29,9 \%$ & $20,0 \%$ & $\begin{array}{c}100,0 \\
\%\end{array}$ \\
\hline
\end{tabular}




\begin{tabular}{|c|c|c|c|c|c|c|c|}
\hline europ. & 54 & 18 & 72 & 57 & 1 & 13 & 215 \\
\cline { 2 - 8 } & $25,1 \%$ & $8,4 \%$ & $33,5 \%$ & $26,5 \%$ & $0,05 \%$ & $6,0 \%$ & $\begin{array}{c}100,0 \\
\%\end{array}$ \\
\hline \multirow{2}{*}{ Total } & 231 & 54 & 245 & 133 & 116 & 111 & 890 \\
\cline { 2 - 8 } & $26,0 \%$ & $6,1 \%$ & $27,5 \%$ & $14,9 \%$ & $13 \%$ & $12,5 \%$ & $\begin{array}{c}100,0 \\
\%\end{array}$ \\
\hline
\end{tabular}

Chi-Square df.: 10, sig.: 000, 0 cells $(0,0 \%)$, Lambda: ,229, Cramer's V: ,455. Prozente und Total basieren auf Responsen. 569 gültige Ereignisse, 585 Missing.

Betrachtet man die Erzählstrukturen im kulturellen Bereich hinsichtlich der Frage, was Europäischsein ausmacht, so ist zu sehen, dass während die stark vertretene Aussage von der Türkei als »Brücke« insgesamt nur wenig zugenommen hat, sich die Häufigkeit der Aussage »Europa ist eine kulturelle Wertegemeinschaft« insbesondere ab 1999 fast verdoppelt und 2002 ihren Höhepunkt erreicht (Abbildung 3). Die Aussage, die Türkei sei asiatisch/islamisch und gehöre deshalb nicht zu Europa, ist ihre Kehrseite. Diese hat zwar 2002 stark abgenommen, nimmt jedoch 2004 wieder ihren anfänglichen Stellenwert ein. Beim institutionalisierten europäischen Selbstverständnis »Europa ist eine politische Gemeinschaft« ist eine kontinuierliche Abnahme zu sehen. Diese soll jedoch im Zusammenhang mit der Aussage »Türkei als Brücke/Modell« gedacht werden. Die pro-europäischen und pro-türkischen Akteure sprechen anstelle von politischer Gemeinschaft immer häufiger über die Brückenfunktion der Türkei bzw. ihre Modellfunktion für die »Islamische Welt«. »Europa ist ein christlicher Club« wurde1997 sehr stark vertreten, als Mesut Yilmaz Helmut Kohl ebendies vorwarf. Diese Aussage ist zwar 1999 drastisch zurückgegangen, gewinnt aber seit 2002 wieder kontinuierlich an Bedeutung.

\section{Abb. 3. Jahr \& kulturelles Feld}

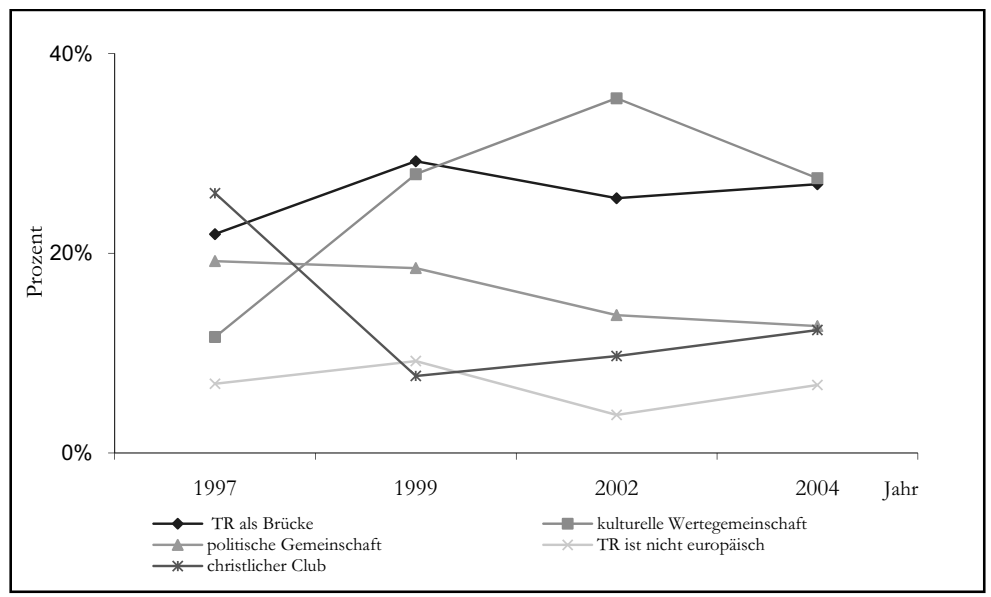


Abb. 4. kulturelles Feld \& deutsche Akteure

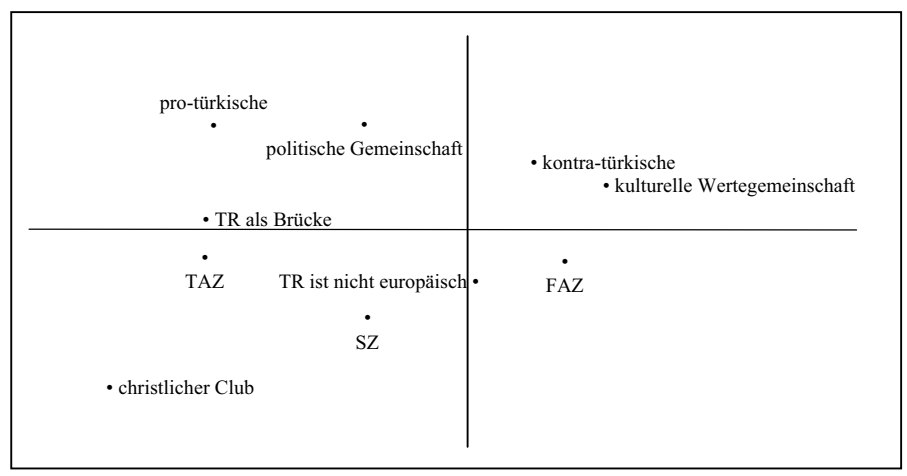

Die Christdemokraten/FDP und FAZ bezeichnen die EU hauptsächlich als »kulturelle Wertegemeinschaft«, während sie für die Sozialdemokraten/Grünen und TAZ »eine politische Gemeinschaft« und die Türkei eine »Brücke zwischen West und Ost« bedeutet. Auf dem kulturellen Feld hebt sich die SZ von TAZ und Sozialdemokraten/Grünen ab, indem sie das türkische »Asiatischsein« akzentuiert (Abbildung 4).

Abb. 5. kulturelles Feld \& türkische Akteure

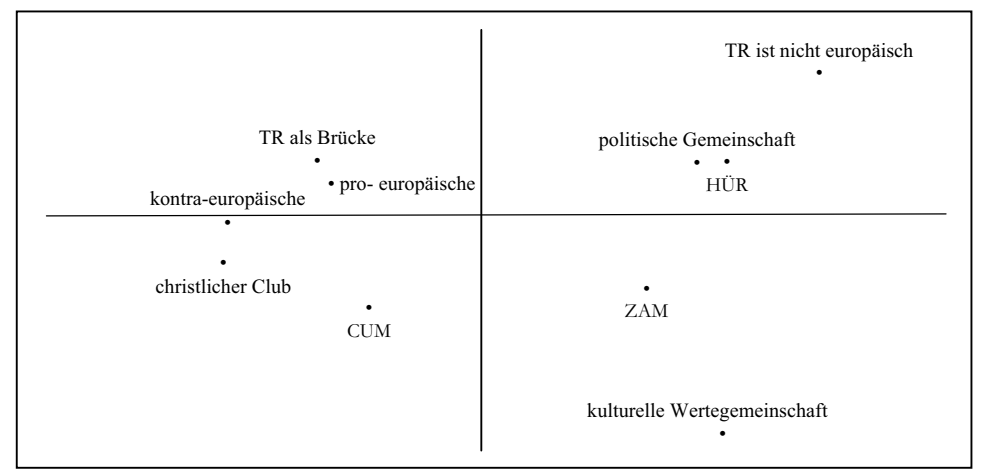

Die Abbildung 5 zeigt, dass die Aussage »die Türkei ist eine Brücke zwischen islamischer Welt und Europa « türkischer Gesamtkonsens ist. Die ambivalente Bedeutung Europas wird dadurch sichtbar, dass es gleichzeitig im türkischen Interdiskurs als »christlicher Club« repräsentiert wird. Europa als »kulturelle Wertegemeinschaft« ist die Kehrseite hiervon und ist daher selbst als Erzählung nicht repräsentiert. Die HÜR betont einerseits die EU als »politische Gemeinschaft«, andererseits aber auch das »Asiatischsein« der Türkei. 
Abb. 6. kulturelles Feld \& europäische Akteure

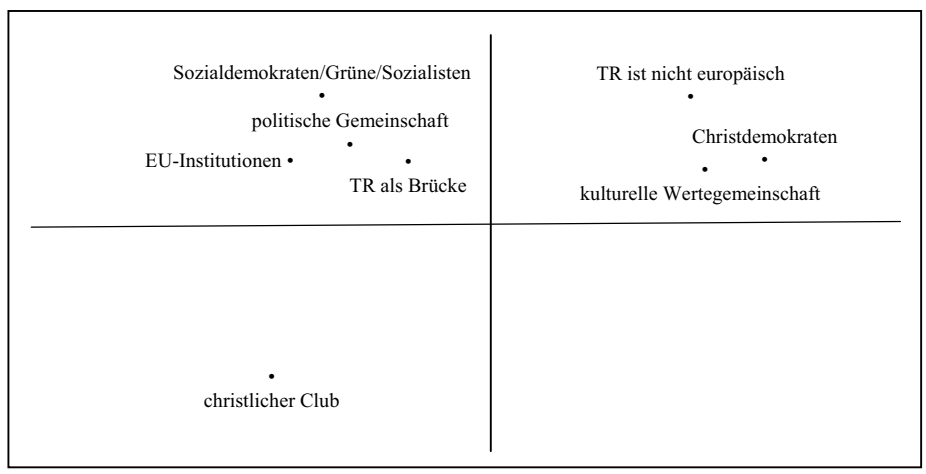

Die »EU ist eine politische Gemeinschaft« und die »Türkei ist eine Brücke zwischen West und Ost« sind die gemeinsamen Positionen von europäischen Sozialdemokraten/Grünen und sonstigen EU-Akteuren/ Ländern und den europäischen Institutionen. »Die EU ist eine kulturelle Wertegemeinschaft« ist die Hauptopos von europäischen Christdemokraten und Konservativen. „Die Türkei ist asiatisch bzw. nicht europäisch« wird auf der EU-Ebene kaum zur Sprache gebracht, doch Europa als Wertegemeinschaft impliziert das Nicht-Europäischsein der Türkei. »Europa ist ein christlicher Club« findet auf der EU-Ebene kaum Resonanz (Abbildung 6).

\section{Tab. 10. Sicherheitsfeld \& Akteure}

\begin{tabular}{|c|c|c|c|c|c|}
\hline \multirow[b]{2}{*}{ Akteure } & \multicolumn{4}{|c|}{ Sicherheitsfeld } & \multirow[t]{2}{*}{ Total } \\
\hline & $\begin{array}{l}\text { geostrat. } \\
\text { Relevanz/ } \\
\text { Sicherheit }\end{array}$ & $\begin{array}{l}\text { geostrat. Rele- } \\
\text { vanz nicht aus- } \\
\text { reichend }\end{array}$ & $\begin{array}{c}\text { Einheit und } \\
\text { Laizismus der } \\
\text { TR }\end{array}$ & Sonstige & \\
\hline \multirow[t]{2}{*}{ Deutsche } & 60 & 42 & 0 & 11 & 113 \\
\hline & $53,1 \%$ & $37,2 \%$ & $0,0 \%$ & $9,7 \%$ & $30,4 \%$ \\
\hline \multirow{2}{*}{ Türkische } & 78 & 3 & 92 & 24 & 197 \\
\hline & $39,6 \%$ & $1,5 \%$ & $46,7 \%$ & $12,2 \%$ & $53, \%$ \\
\hline \multirow[t]{2}{*}{ europ. } & 51 & 10 & 0 & 1 & 62 \\
\hline & $82,3 \%$ & $16,1 \%$ & $0,0 \%$ & $1,6 \%$ & $16,7 \%$ \\
\hline \multirow[t]{2}{*}{ Total } & 189 & 55 & 92 & 36 & 372 \\
\hline & $50,8 \%$ & $14,8 \%$ & $24,7 \%$ & $9,7 \%$ & $100,0 \%$ \\
\hline
\end{tabular}

Chi-Square df.: 6, sig.: 000, 0 cells (8,3\%), Lambda: ,170, Cramer's V: ,483. Prozente und Total basieren auf Responsen. 257 gültige Ereignisse, 907 Missing. 
Sicherheit ist ein weiteres diskursives Feld, in dem unterschiedliche Aussagen miteinander konkurrieren. Wie bereits erwähnt, kommen zwar Aussagen, die gemäß der geostrategischen Bedeutung der Türkei und der europäischen Sicherheit und Interessen argumentieren, nicht so stark wie politische und kulturelle Argumente zur Sprache. Jedoch, wenn nun in diesem diskursiven Bereich gesprochen wird, dann sind es die europäischen Akteure, die am stärksten die Türkei-Integration mit dem Argument ihrer geostrategischen Relevanz verteidigen. Die geostrategische Bedeutung der Türkei ist auch ein deutsches Anliegen, aber hier ist auch die Gegenerzählung stark vertreten, sie sei für eine Vollmitgliedschaft nicht ausreichend. Auch diese Auffassung wird in der türkischen Öffentlichkeit selten geteilt. Türkische Akteure betonen entweder die geostrategische Relevanz der Türkei für die europäische Sicherheit, oder aber sie behaupten, dass die europäischen politischen Bedingungen eine Gefahr für die türkische Einheit und den Laizismus seien. Diese Bedrohungserzählung hat wiederum keinen Platz im deutschen und europäischen Gesamtdiskurs. Dieser Aspekt wird in den folgenden Abschnitten näher analysiert. Hinter der Rubrik »sonstige« verbergen sich entweder »islamischer Fundamentalismus« oder "Auslösung von Migration« durch den Beitritt. Sowohl die türkischen als auch die deutschen Akteure sind hier zwar mit geringer Häufigkeit, aber doch mit ähnlichem Gewicht vertreten (Tabelle 10).

\section{Abb. 7. Jahr \& Sicherheitsfeld}

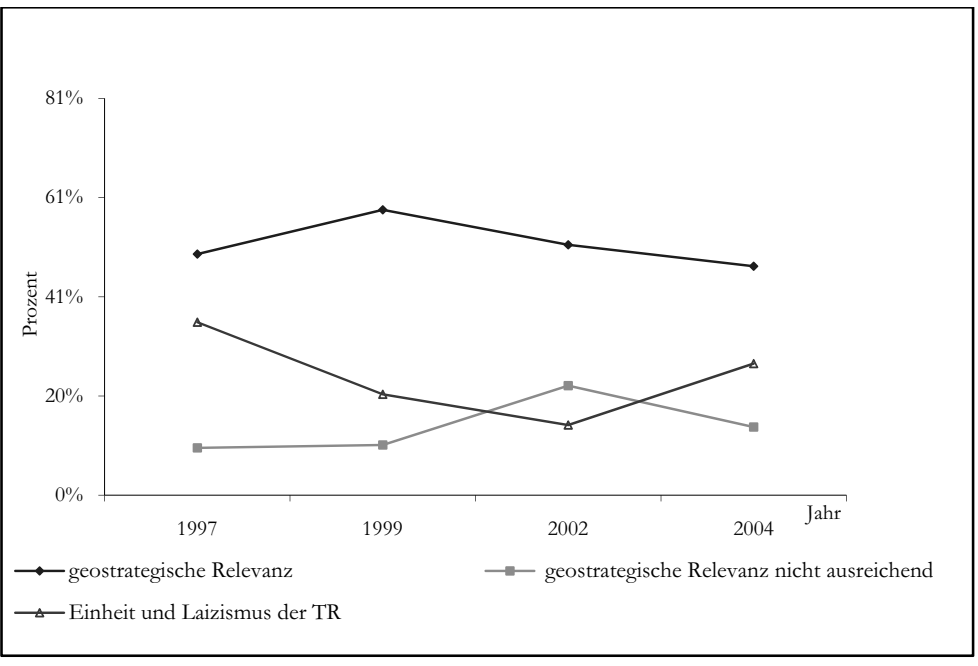


Wie oben erwähnt, sind Sicherheitsargumente und die Betonung der geostrategischen Relevanz der Türkei für die EU hauptsächlich eine protürkische und pro-europäische Aussage, die zwar nicht so häufig wie die kulturellen und politischen Aussagen zur Sprache kommt, doch in allen untersuchten Jahren eine konstante Entwicklung zeigt (Abbildung 7). Die kontra-türkische Position, „die geostrategische Relevanz ist nicht ausreichend für den Beitritt« nimmt zwar ab 2002 deutlich zu, geht hingegen ab 2004 wieder zurück. Auch die türkische nationalistische Position, welche Einheit und Laizismus des Staates gefährdet sieht, ist zwar verhältnismäßig schwach repräsentiert und bis 2002 noch mehr zurückgegangen, erhält 2004 jedoch wieder Konjunktur, nachdem die türkische Europaambition wahr wird. Ab 2004 wird der nationalistische Diskurs lauter und sichtbarer, es sind für ihn Europa, die Minderheiten und die Islamisten, die die Einheit des Staates gefährden.

\section{Abb. 8. Sicherheitsfeld \& deutsche Akteure}

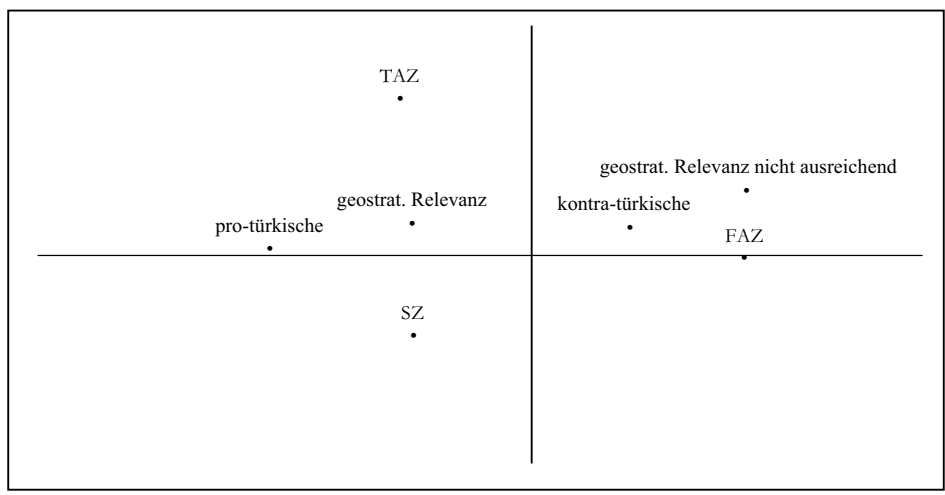

Auch im Themenfeld »Sicherheit« ist eine Zwei-Fronten-Konstellation auf der deutschen Ebene zu erkennen (Abbildung 8). Während die protürkischen Akteure (Sozialdemokraten/Grüne) und die SZ den TürkeiBeitritt wegen ihrer »geostrategischen Relevanz« befürworten, positionieren sich die kontra-türkischen (Christdemokraten) und die FAZ gegen dieses Argument. Sie sei zwar wichtig für eine Partnerschaft, aber nicht ausreichend für einen Beitritt. Es kämen andere Optionen in Frage, um die Türkei »in Europa zu verankern«. Sie solle zwar Partner bleiben, jedoch kein Mitglied werden. Die geostrategische Relevanz wird also nicht grundsätzlich bestritten, jedoch als nicht ausreichend für die Mitgliedschaft erklärt. Auch die pro-europäischen ZAM-Kolumnisten und sonstige türkische Akteure teilen die Meinung mit den deutschen Sozialdemokraten/Grünen und der SZ, dass die Türkei aus geostrategi- 
schen Gründen der EU beitreten solle (Abbildung 9). Den kontraeuropäischen Akteuren zufolge sollte die Türkei zwar aus diesem Grunde integriert werden, doch die europäischen Bedingungen sind für sie eine Bedrohung für die Einheit des türkischen Staates. Es liegen jedoch nicht zwei stabile Blöcke vor, wie es in der deutschen Öffentlichkeit der Fall ist.

Abb.9. Sicherheitsfeld \& türkische Akteure

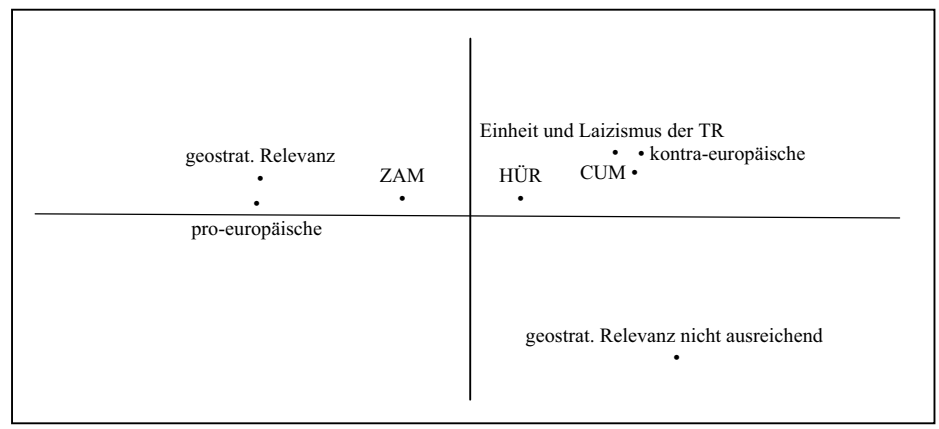

Die Positionen der türkischen Akteure differieren von einem Feld zum anderen. HÜR-Kolumnisten sind dafür ein gutes Beispiel. Auf dem kulturellen Feld vertreten sie den Standpunkt, Europa sei eine politische Gemeinschaft, und positionieren sich eher pro-europäisch, während sie gleichzeitig die europäischen politischen Bedingungen als Bedrohung für den Staat darstellen. Ebenso wie die kontra-europäischen Akteure artikuliert sich die Mehrzahl der HÜR-Kolumnisten nationalistisch. Proeuropäische Akteure, ZAM-Kolumnisten und sonstige türkische Akteure bilden dagegen Diskursblöcke, sie betonen die geostrategische Bedeutung der Türkei für Europa und stellen die europäischen politischen Bedingungen relativ selten als Gefahr dar.

\section{Abb. 10. Sicherheitsfeld \& europäische Akteure}

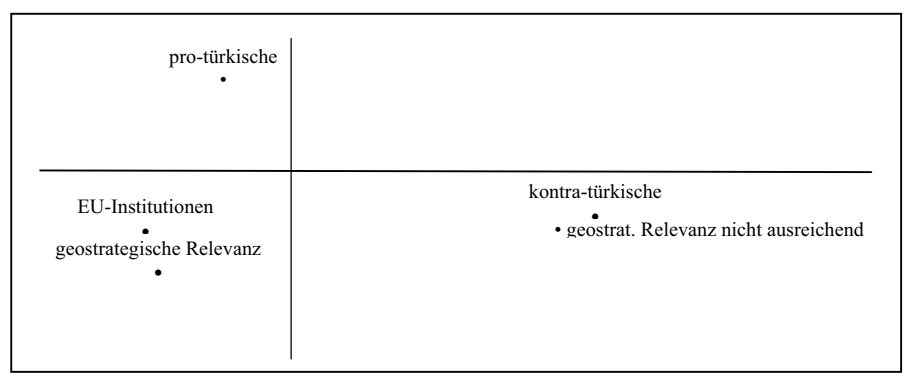


Während die europäischen Christdemokraten sich von den deutschen Christdemokraten nicht absetzen, indem auch sie die geostrategische Relevanz der Türkei als nicht ausreichend erklären, unterscheiden sich die europäischen Sozialdemokraten/Grünen von den deutschen Sozialdemokraten/Grünen insofern, als sie das geostrategische Argument kaum ins Feld führen. Es sind die EU-Institutionen, die die Position der deutschen pro-türkischen und türkischen pro-europäischen Akteure teilen (Abbildung 10).

\section{Tab. 11. politisches Feld \& Akteure}

\begin{tabular}{|c|c|c|c|c|c|c|c|}
\hline \multirow{2}{*}{ Akteure } & \multicolumn{6}{|c|}{ politisches Feld } & Total \\
\cline { 2 - 8 } & $\begin{array}{c}\text { Demo- } \\
\text { kratie/ } \\
\text { Menschen- } \\
\text { rechts- } \\
\text { defizit }\end{array}$ & $\begin{array}{c}\text { Demokrati- } \\
\text { sierung } \\
\text { durch } \\
\text { Beitritt }\end{array}$ & $\begin{array}{c}\text { Minder- } \\
\text { heiten- } \\
\text { problem }\end{array}$ & $\begin{array}{c}\text { kein } \\
\text { Minder- } \\
\text { heiten- } \\
\text { problem }\end{array}$ & $\begin{array}{c}\text { türkische } \\
\text { Sensi- } \\
\text { bilitäten }\end{array}$ & $\begin{array}{c}\text { Sons- } \\
\text { tige }\end{array}$ & \\
\hline $\begin{array}{c}\text { deut- } \\
\text { sche }\end{array}$ & 140 & 100 & 54 & 0 & 2 & 4 & 300 \\
\cline { 2 - 8 } & $46,7 \%$ & $33,3 \%$ & $18,0 \%$ & $0,0 \%$ & $0,7 \%$ & $1,3 \%$ & $\begin{array}{c}19,8 \\
\%\end{array}$ \\
\hline \multirow{2}{*}{$\begin{array}{c}\text { türki- } \\
\text { sche }\end{array}$} & 112 & 142 & 86 & 326 & 126 & 96 & 888 \\
\cline { 2 - 8 } & $12,6 \%$ & $16,0 \%$ & $9,7 \%$ & $36,7 \%$ & $14,2 \%$ & $10.8,0$ & $\begin{array}{c}42,1 \\
\%\end{array}$ \\
\hline \multirow{2}{*}{\begin{tabular}{c} 
europ. \\
\cline { 2 - 8 }
\end{tabular}} & 108 & 126 & 66 & 4 & 12 & 10 & 326 \\
\hline \multirow{2}{*}{ Total } & 231 & $36,7 \%$ & $20,2 \%$ & $1,2 \%$ & $3,7 \%$ & $3,1 \%$ & $\begin{array}{c}24,2 \\
\%\end{array}$ \\
\cline { 2 - 8 } & $26,0 \%$ & $24,3 \%$ & $13,6 \%$ & $21,8 \%$ & $9,2 \%$ & $7,3, \%$ & $\begin{array}{c}100,0 \\
\%\end{array}$ \\
\hline
\end{tabular}

Chi-Square df:: 10, sig.: 000, 0 cells (0,0 \%), Lambda: ,229, Cramer's V: ,455. Prozente und Total basieren auf Responsen. 757 gültige Ereignisse, 397 Missing.

Das diskursive Feld »Politik« (Demokratie und Menschenrechte) nimmt neben dem Bereich »Kultur/Identität« einen zentralen Platz in der EUTürkei-Debatte ein. Wie bereits erwähnt, äußern die türkischen Akteure sich hier am häufigsten (mit 42,1\%). Aus der Tabelle 11 ist abzulesen, dass fast die Hälfte der deutschen Akteure über die Demokratie- bzw. Menschenrechtsdefizite in der Türkei spricht und diese Defizite als Hindernis für die Integration ansieht. Den deutschen folgen die europäischen Akteure. Die türkischen Akteure dagegen sehen diese Defizite weniger problematisch, aber sie bestreiten sie auch nicht. Die Konfliktlinie bildet sich entlang der Minderheitenfrage. In der türkischen Öffentlichkeit wird fast doppelt so häufig über »Minderheitenrechte« und »die Türkei hat keine Minderheiten« gesprochen wie in der europäischen und deutschen. Die Minderheitenfrage wird in der Türkei als eine der »türkischen Sensibilitäten« verstanden. Die politische Position, die Türkei habe »keine Minderheiten« und habe »Sensibilitäten«, ist nahezu allein 
eine türkische Aussage, die im deutschen und europäischen Raum kaum vorkommt. Die »Demokratisierung durch den Beitritt« ist seit 1999 eine deutsch-europäische Strategie, die zwar den türkischen politischen Mangel zugibt, jedoch vorschlägt, dieses Defizit über den Beitrittsprozess aufzuheben.

\section{Abb. 11. Jahr \& politisches Feld}

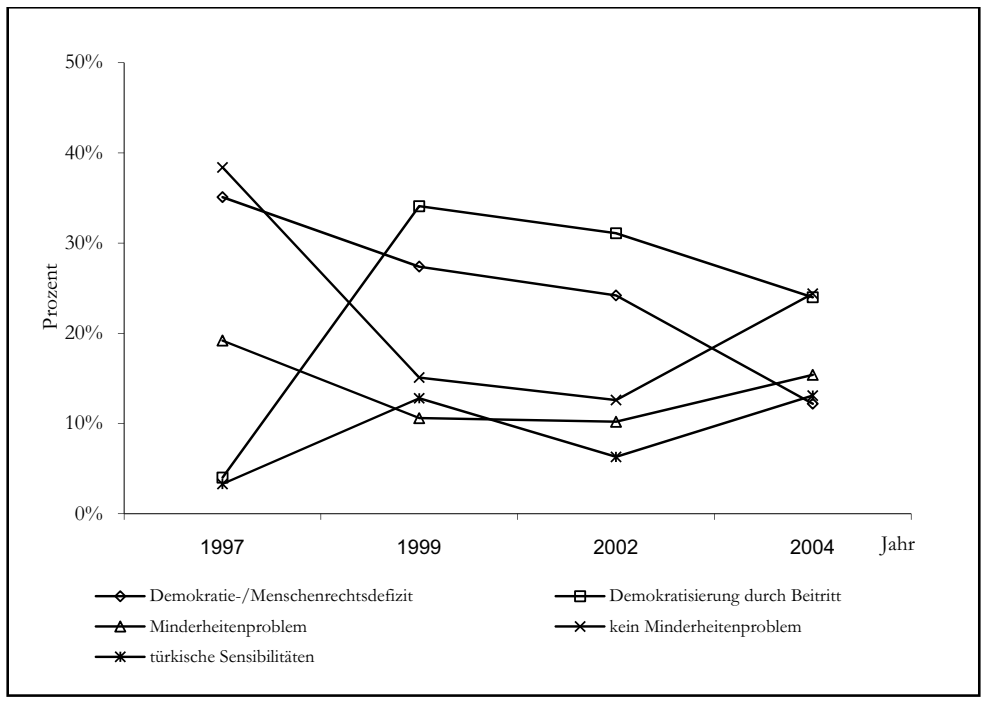

Die Erzählstrukturen im politischen Feld unterliegen im Laufe der Zeit einem teilweise beträchtlichen Wandel, wie die Abbildung 11 zeigt. 1999 erlebt die bis dahin lediglich von türkischen Akteuren vertretende Position der »Demokratisierung durch den Beitrittsprozess« einen erheblichen Aufschwung, da sie seitdem auch von deutsch-europäischen Sozialdemokraten/Grünen geteilt wird. Die Abnahme der davor von den deutsch-europäischen Akteuren eingenommenen Konsensposition der Demokratie- und Menschenrechtsdefizite bzw. „Türkei ist politisch nicht reif für den Beitritt« ist in diesem Zusammenhang zu betrachten. Bis 1999 wurde gefordert, die Türkei solle zuerst die Kriterien erfüllen und erst dann den Kandidatenstatus bekommen. Nach 1999 sollte die Türkei zuerst einen Kandidatenstatus erhalten und erst dann die Kriterien erfüllen. Das hängt in erster Linie mit dem Regierungswechsel in der BRD im Jahre 1998 zusammen, im Zuge dessen ein Strategiewechsel zu beobachten war, denn die Türkei selbst hatte noch kaum eines der politischen Kriterien erfüllt. 
Die sowohl vom kontra-türkischen als auch vom pro-türkischen Diskurs formulierte Aussage »die Türkei soll die Minderheitenfrage lösen« nimmt, verglichen mit 1997, in den Jahren 1999 und 2002 ab, 2004 dann wieder leicht zu. Die türkische Gegenposition »die Türkei hat keine Minderheiten« nimmt denselben Verlauf, erhält jedoch ab 2004 wieder Auftrieb. Wenn man die Zunahme bei den »türkischen Sensibilitäten« 2004 berücksichtigt, wie im Bereich Sicherheit zu sehen ist, ist auch im politischen Feld eine zunehmende kontra-europäische nationalistische Resistenz zu erkennen.

\section{Abb. 12. politisches Feld \& deutsche Akteure}

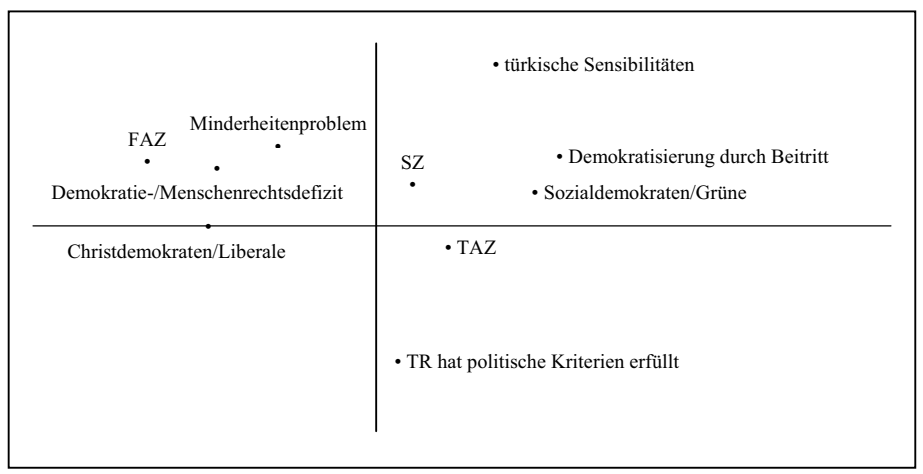

Betrachtet man in der Abbildung 12 näher, welche deutschen Akteure welche Aussagen auf dem politischen Feld zur Sprache bringen, so sieht man, dass die Christdemokraten und FAZ u.a. das Menschenrechtsdefizit als Hindernis für den Türkei-Beitritt ins Feld führen. Sozialdemokraten/Grüne, TAZ und SZ verfolgen ab 1999 eine andere Strategie: Erst der Beitrittsprozess würde die Türkei demokratisieren, da die internen Dynamiken allein nicht ausreichten. Abwarten, bis die Türkei sich an den europäischen politischen Standard anpasse, sei demnach viel zu riskant. »Die Türkei hat die politischen Kriterien erfüllt« und »türkische Sensibilitäten«, die von Europa »nicht verstanden werden«, bleiben allein türkische Aussagen.

Im wichtigen Feld Politik/Demokratie, auf dem sich die proeuropäischen und kontra-europäischen türkischen Diskurse formieren, sind drei Gruppierungen zu sehen (Abbildung 13). Die erste ist der Konsens zwischen kontra-europäischen Akteuren und CUM. Beide sprechen von »türkischen Sensibilitäten«, die von den Europäern nicht berücksichtigt würden. Es wird argumentiert, dass Europa nicht beabsichtige, die Türkei zu integrieren, sondern sie lediglich in ihrem »Orbit« halten 
werde. Ferner würden die europäischen politischen Bedingungen »Einheit und Laizismus des türkischen Staates« gefährden. Die Frage der Minderheiten sei seit dem Lausanner Abkommen 1923 gelöst, Kurden und Aleviten seien keine Minderheiten, sondern »konstitutiver Bestandteil der türkischen Nation«. Europa versuche nur, noch Minderheiten zu »erzeugen «, um die Bedingungen des Sèvres-Abkommens durch geheime, hinterhältige Diplomatie Schritt für Schritt umzusetzen.

\section{Abb. 13. politisches Feld \& türkische Akteure}

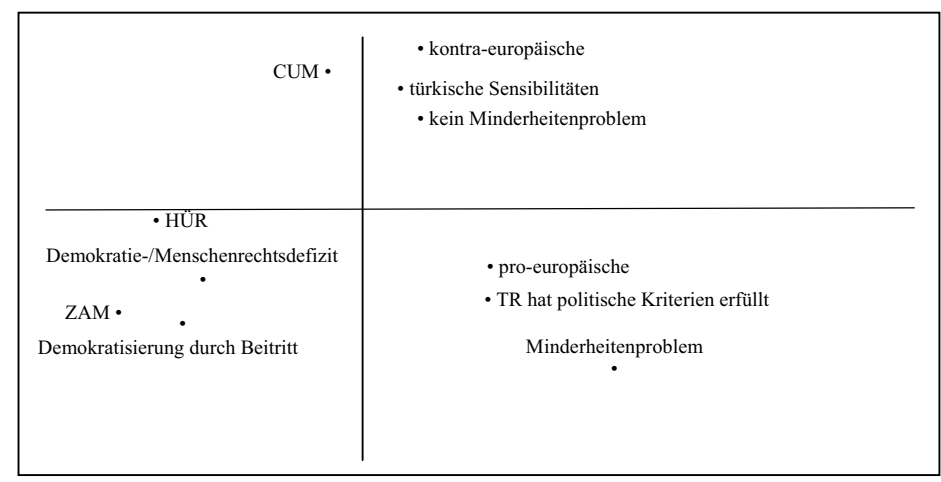

Die zweite Gruppe besteht aus HÜR- und ZAM-Kolumnisten, die argumentieren, dass die Türkei sich erst demokratisieren würde, wenn sie in den Beitrittsprozess eingeschlossen würde. Die deutsch-europäischen pro-türkischen Diskurse und diese beiden türkischen Zeitungen teilen also dieses Argument. Doch die türkischen Zeitungen unterscheiden sich insofern, als sie sich vom »Minderheitenproblem« distanzieren, indem sie sich dazu kaum äußern. Die dritte Position ist die der pro-europäischen Akteure. Das ist die politische Haltung der AKP seit 2002, die argumentiert, die Türkei habe die notwendigen Kriterien »genügend« erfüllt und den Minderheiten bestimmte kulturelle Rechte eingeräumt, welche ausreichend für einen Beitritt in die EU seien.

Wie im nächsten Kapitel ausführlich dargelegt wird, sind pro-europäisch eingestellte islamistische Akteure nicht fähig, sich vom kemalistischen Nationalismus gerade im Hinblick auf Minderheitenrechte abzuheben. Die kemalistischen Nationalisten, konservative und pro-europäisch eingestellte liberale Islamisten bilden einen nationalen Konsens insbesondere im Hinblick auf die Einstellung, dass in der Türkei bis auf nicht-muslimische Minderheiten keine weiteren Minderheiten existierten. Auf europäischer Ebene ist interessant zu sehen, dass die europäischen Institutionen zum einen von »Menschen- und Minderheitenrech- 
ten« sprechen, zum anderen die Meinung vertreten, dass die Türkei erst durch den Beitritt demokratisiert werden könne, und, wie später gezeigt wird, ab 2004 zur Meinung gelangen, die Türkei habe die politischen Kriterien rechtlich erfüllt, müsse sie aber noch umsetzen (Abbildung 14). Die europäischen Konservativen positionieren sich ebenso wie auf der deutschen nationalen Ebene. Sie erwähnen wenig die »Menschenund Minderheitenrechte« oder die »Demokratisierung durch den Beitritt«. Auch hier auf der europäischen Ebene findet die Aussage, dass die Türkei keine Minderheiten habe, keine Resonanz.

Abb. 14. politisches Feld \& europäische Akteure

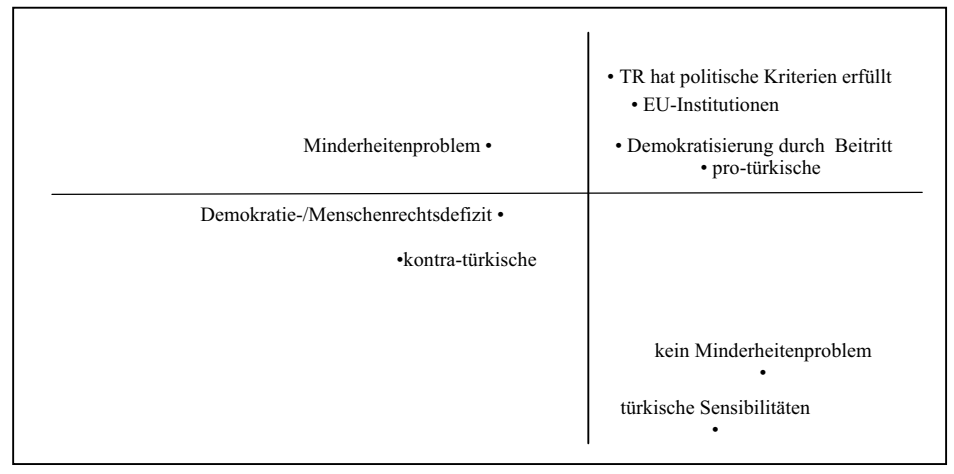

Zusammenfassend: Die »Demokratisierung durch den Beitritt« ist der kollektiv geteilte Topos zwischen deutschen und europäischen Sozialdemokraten/Grünen, EU-Institutionen sowie türkischen pro-europäischen Akteuren. Während vor allem die türkischen nationalistischen Aussagen, die »Türkei hat keine Minderheiten« oder die »türkischen Sensibilitäten« weder auf deutscher noch auf europäischer Ebene $\mathrm{Zu}$ stimmung erhalten, findet die Erzählung, die »Türkei hat Menschenrechtsprobleme und soll deswegen nicht integriert werden « insbesondere seit 2002 auf der türkischen Ebene kaum Resonanz.

Es wurde oben gezeigt, dass die moralisch gerahmten Erzählungen nicht so dominant sind wie die von Kultur/Identität und Politik. Das moralische Feld ist jedoch ein wichtiger diskursiver Rahmen, vor allem für die türkischen nationalistischen und deutschen konservativen Diskurse. Die türkischen Akteure bringen am stärksten moralische Erzählungen in die Kommunikation ein. Mit 85 Prozent wird die »Unehrlichkeit« bzw. »Doppelgesichtigkeit Europas« akzentuiert (Tabelle 12). Die türkischen Akteure fühlen sich von Europa nicht gerecht behandelt. Es führe türkeispezifische unerfüllbare Bedingungen an, die die türkische Sicherheit 
und Einheit aufs Spiel setzten. In der BRD dagegen ist der Anteil von »keine falschen Hoffnungen erwecken« relativ hoch. Auf der Kehrseite wird also die türkische Erzählung bestätigt, da auch die kontratürkischen Akteure die »deutsche bzw. europäische Unehrlichkeit« zur Sprache bringen. Eine nicht erfüllbare Vollmitgliedschaft zu versprechen, sei nicht ehrlich der Türkei gegenüber. Auf beiden Seiten wird also mit unterschiedlichen Intentionen und rhetorischen Rechtfertigungsmitteln die europäische/deutsche »Ehrlichkeit« bezweifelt. Es herrscht ein Konsens über einen gemeinsamen Dissens, der gegenseitig Grenzen zu ziehen beabsichtigt. Beide markieren eine Gefahr: eine für den türkischen Staat, die andere für das europäische Projekt. Auf der europäischen Ebene ist zu sehen, dass sowohl von europäischer als auch von türkischer Unehrlichkeit mit ca. 44 Prozent gleichermaßen gesprochen wird.

Tab. 12. moralisches Feld \& Akteure

\begin{tabular}{|c|c|c|c|c|c|}
\hline \multirow{2}{*}{ Akteure } & \multicolumn{5}{|c|}{ moralisches Feld } \\
\cline { 2 - 6 } & $\begin{array}{c}\text { Erweckung } \\
\text { falscher } \\
\text { Hoffnungen }\end{array}$ & $\begin{array}{c}\text { europäische } \\
\text { Unehrlichkeit }\end{array}$ & $\begin{array}{c}\text { türkische } \\
\text { Unehrlichkeit }\end{array}$ & Sonstige & Total \\
\hline deutsche & 34 & 21 & 13 & 8 & 76 \\
\cline { 2 - 6 } & $44,7 \%$ & $27,6 \%$ & $17,6 \%$ & $10,5 \%$ & $100.0 \%$ \\
\hline türkische & 0 & 257 & 27 & 19 & 303 \\
\cline { 2 - 6 } & $0,0 \%$ & $84,8 \%$ & $8,9 \%$ & $6,3 \%$ & $100.0 \%$ \\
\hline \multirow{2}{*}{ europ. } & 5 & 20 & 19 & 0 & 44 \\
\cline { 2 - 6 } & $11,4 \%$ & $45,8 \%$ & $43,2 \%$ & $0,0 \%$ & $100,0 \%$ \\
\hline \multirow{2}{*}{ Total } & 39 & 298 & 59 & 27 & 423 \\
\cline { 2 - 6 } & $9,2 \%$ & $70,4 \%$ & $13.2 \%$ & $6,4 \%$ & $100,0 \%$ \\
\hline
\end{tabular}

Chi-Square df.: 6, sig.: 000, 0 cells (25,0 \%), Lambda: ,192, Cramer's V: ,489.

Prozente und Total basieren auf Ereignissen.

Die Abbildung 15 zeigt erstaunlicherweise, dass 1997, als die Türkei abgelehnt wurde, und 2004, als sie angenommen wurde, die kontraeuropäische türkische Resistenz im moralischen Feld gleich hoch ist. 1997 war das Jahr, in dem alle türkischen Akteure von der »europäischen Doppelgesichtigkeit« sprachen, das war sozusagen gesamttürkischer Konsens. Seit 1999/2002 sind es überwiegend die türkischen Nationalisten, die die »europäische Doppelgesichtigkeit« anführen. Die Argumente »Erweckung falscher Hoffnungen« und die »Unehrlichkeit der Türkei« werden in den Jahren 1999 und 2002 durch die kontratürkischen Diskurse lauter, die auf den wahrscheinlicher werdenden Beitritt reagieren.

Auf dem moralischen Feld sind, Abbildung 16 entsprechend, drei Gruppierungen zu sehen. Die deutschen Christdemokraten und die FAZ 
sprechen davon »keine falschen Hoffnungen« zu erwecken. TAZ und SZ setzen sich von Sozialdemokraten und Grünen $a b$, indem sie fordern, dass die EU die Türkei mit den anderen Kandidatenländern gleich behandeln solle. Die Sozialdemokraten/Grünen dagegen sagen, dass die EU die Türkei gleich behandle und die politischen Bedingungen, die zu erfüllen und umzusetzen seien, für alle Beitrittsländer gälten. Also sollte für die deutschen pro-türkischen Akteure eher die Türkei ehrlich sein, wenn sie tatsächlich Mitglied werden wolle.

Abb. 15. moralisches Feld \& Jahr

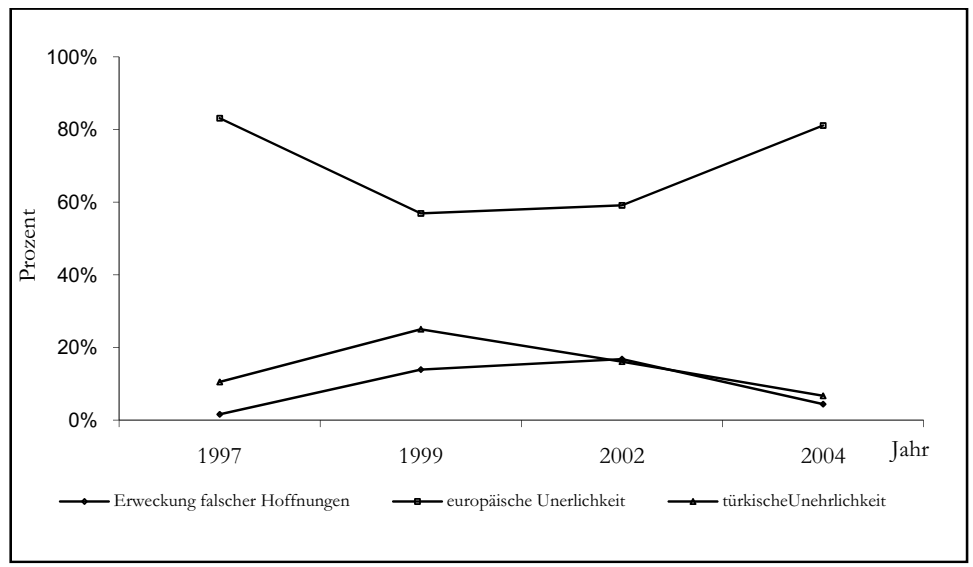

Abb. 16. moralisches Feld \& deutsche Akteure

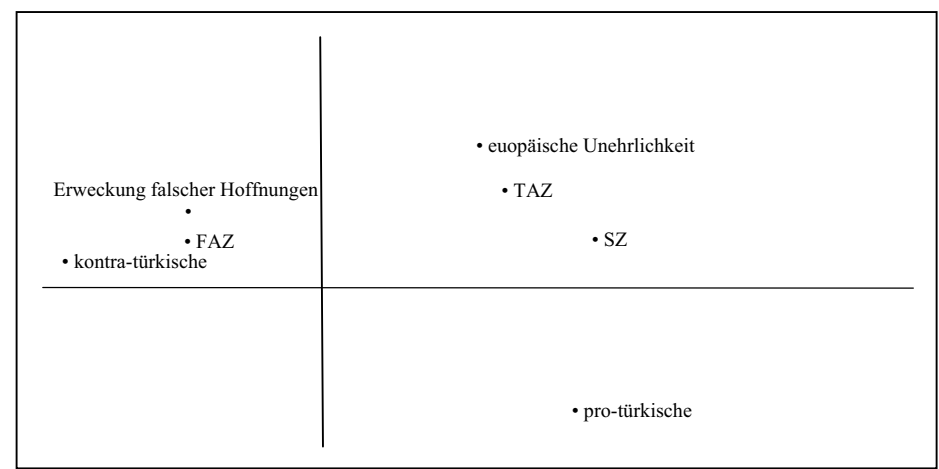

Die Abbildung 17 zeigt, dass in der türkischen Öffentlichkeit ein klar erkennbarer Konsens im Hinblick auf das »doppelgesichtige Europa» 
herrscht. Sowohl pro-europäische Islamisten als auch kontra-europäische Kemalisten und die CUM konstruieren diese negative Repräsentation. HÜR und ZAM zeigen ab 1999 eher die diskursive Position, dass Europa die Türkei gleich behandelt und die türkischen Akteure Europa gegenüber nicht ehrlich genug seien, da die Bedingungen nur »halbherzig« erfüllt würden. Damit teilen sie die Position der deutschen Sozialdemokraten/Grünen und der europäischen Institutionen.

\section{Abb. 17. moralisches Feld \& türkische Akteure}

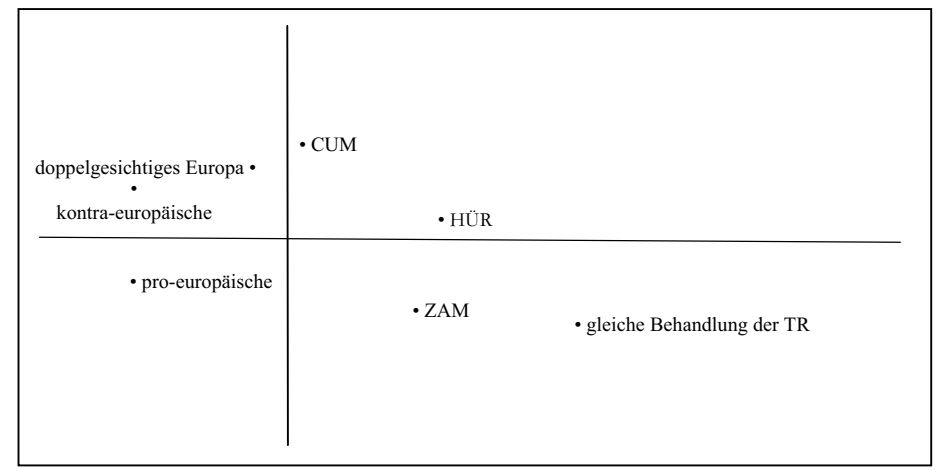

Für die Kolumnisten der CUM ist es lediglich dem türkischen Militär zu verdanken, dass die Türkei 1999 in Helsinki den Kandidatenstatus für den EU-Beitritt erhalten hat. Mitte der 1990er Jahre habe sich die Türkei in einer schweren Krise befunden, und die Situation sich erst seit kurzer Zeit verbessert. Die Niederlage der PKK, die Festnahme von Abdullah Öcalan und der erfolgreiche Kampf gegen den islamischen Fundamentalismus vom 28. Februar 1997 hätten die »Einstellungen der ausländischen Mächte«, die »die türkische Macht prüfen« wollten, verändert. »Doch wir wundern uns, ob es ein anderes Land gibt, das über seine nationalen Interessen verhandelt, um EU-Kandidat zu werden.« (CUM 13.12.1999)

Das moralische Feld ist bezogen auf die europäischen Akteure zwar relativ unwichtig, doch wenn sie einmal moralisch argumentieren, so unterscheiden sich die europäischen kontra-türkischen Akteure kaum von den deutschen kontra-türkischen, insofern als sie beide von der »Erweckung von falschen Hoffungen" sprechen (Abbildung 18). Europa solle der Türkei kein leeres Versprechen geben. Dagegen unterscheiden sich die europäischen Sozialdemokraten/Grünen/Sozialisten und sonstige EU-Akteure/Länder von den deutschen pro-türkischen Akteuren, indem sie von »europäischer Doppelgesichtigkeit« reden. Europa solle 
sein Versprechen halten und die Türkei mit den anderen Kandidatenländern gleich behandeln. Somit teilen sie die dominante türkische Erzählung, dass Europa die Türkei nicht gleich behandle. Die europäischen Institutionen (der Ministerrat, die Kommission) positionieren sich wie der deutsche pro-türkische Diskurs, sie argumentieren, Europa behandle die Türkei mit den anderen Kandidatenländern gleich.

Abb. 18. moralisches Feld \& europäische Akteure

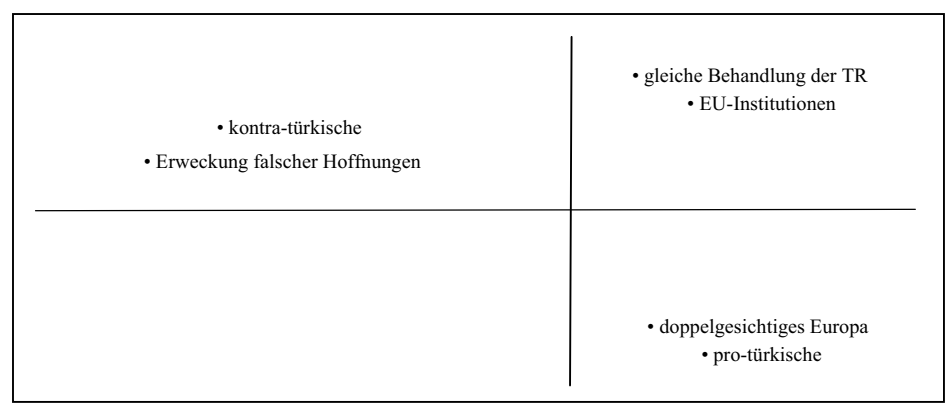

Zusammenfassend: Die moralische Rahmung kommt auf der deutschen und europäischen Ebene zwar nicht so häufig vor wie die kulturelle und politische, jedoch ist sie ein wichtiges Strukturelement vor allem der deutschen kontra-türkischen und gesamttürkischen Diskurse. Während die deutschen und europäischen kontra-türkischen Akteure von der »Erweckung falscher Hoffnungen« sprechen, weisen die türkischen Akteure insgesamt auf die »Unehrlichkeit« Europas hin.

Tab. 13. Zukunft Europas \& Akteure

\begin{tabular}{|l|c|c|c|c|c|c|}
\hline \multirow{3}{*}{ Akteure } & \multicolumn{7}{|c|}{ Zukunft Europas } \\
\cline { 2 - 7 } & $\begin{array}{c}\text { europäische } \\
\text { Überdehnung }\end{array}$ & $\begin{array}{c}\text { Klarheit } \\
\text { über EU- } \\
\text { Grenzen }\end{array}$ & $\begin{array}{c}\text { Europäische } \\
\text { Handlungs- } \\
\text { fähigkeit }\end{array}$ & $\begin{array}{c}\text { Kosmo- } \\
\text { politi- } \\
\text { sches } \\
\text { Europa }\end{array}$ & Sonstige & Total \\
\hline deutsche & 106 & 104 & 41 & 21 & 17 & 289 \\
\cline { 2 - 7 } & $36,7 \%$ & $36,0 \%$ & $14,2 \%$ & $7,3 \%$ & $5,9 \%$ & $44,9 \%$ \\
\hline türkische & 21 & 7 & 45 & 68 & 45 & 186 \\
\cline { 2 - 7 } & $11,3 \%$ & $3,8 \%$ & $24,2 \%$ & $36,6 \%$ & $24,2 \%$ & $28,9 \%$ \\
\hline europ. & 57 & 48 & 36 & 22 & 6 & 169 \\
\cline { 2 - 7 } & $33,7 \%$ & $28,4 \%$ & $21,3 \%$ & $13,0 \%$ & $3,6 \%$ & $26,2 \%$ \\
\cline { 2 - 7 } Total & 184 & 159 & 122 & 111 & 68 & 644 \\
\hline & $28,6 \%$ & $24,7 \%$ & $18,9 \%$ & $17,2 \%$ & $10,6 \%$ & 100,0 \\
& & & & & & $\%$ \\
\hline
\end{tabular}

Chi-Square df.: 8, sig.: 000, 0 cells (0,0 \%), Lambda: ,201, Cramer's V: ,405. Prozente und Total basieren auf Responsen. 396 gültige Ereignisse, 758 Missing. 
Die »Zukunft Europas« ist eines der wichtigsten diskursiven Felder in der EU-Türkei-Debatte. Die Tabelle 13 zeigt, dass unter 1154 Äußerungen ca. 400 Ereignisse bzw. 644 Responsen die Zukunft Europas betreffen, insbesondere wenn die deutschen Akteure sich zum Thema äußern. Artikulieren die deutschen Akteure sich in diesem Bereich, so reden sie entweder über die »Integrationskraft der EU« oder über die Grenzen Europas. Bekäme die Türkei die Vollmitgliedschaft, so würde die EU sich »überdehnen«. Die EU habe ihre Grenzen erreicht und könne ein Land wie die Türkei mit seiner Bevölkerungszahl und in diesem wirtschaftlichen Zustand nicht integrieren. Da keine Gemeinschaft ohne klare Grenzen funktioniere, würde auch die EU nicht mehr zusammenhalten können. Es müsse deshalb über die europäischen Grenzen gesprochen und darüber Klarheit geschaffen werden, wo sie aufhörten. Kurz: Man müsse von der Finalität Europas sprechen. Dabei ist für die deutschen Akteure die europäische Handlungsfähigkeit in der internationalen Politik und Sicherheit weniger relevant. Ähnlich wie die deutschen sprechen auch die europäischen Akteure von der Integrationskraft Europas und von seinen Grenzen. Beide Akteure argumentieren also in der gleichen diskursiven Rahmung und benutzen ähnliche Argumente.

\section{Abb. 19. Jahr \& Zukunft Europas}

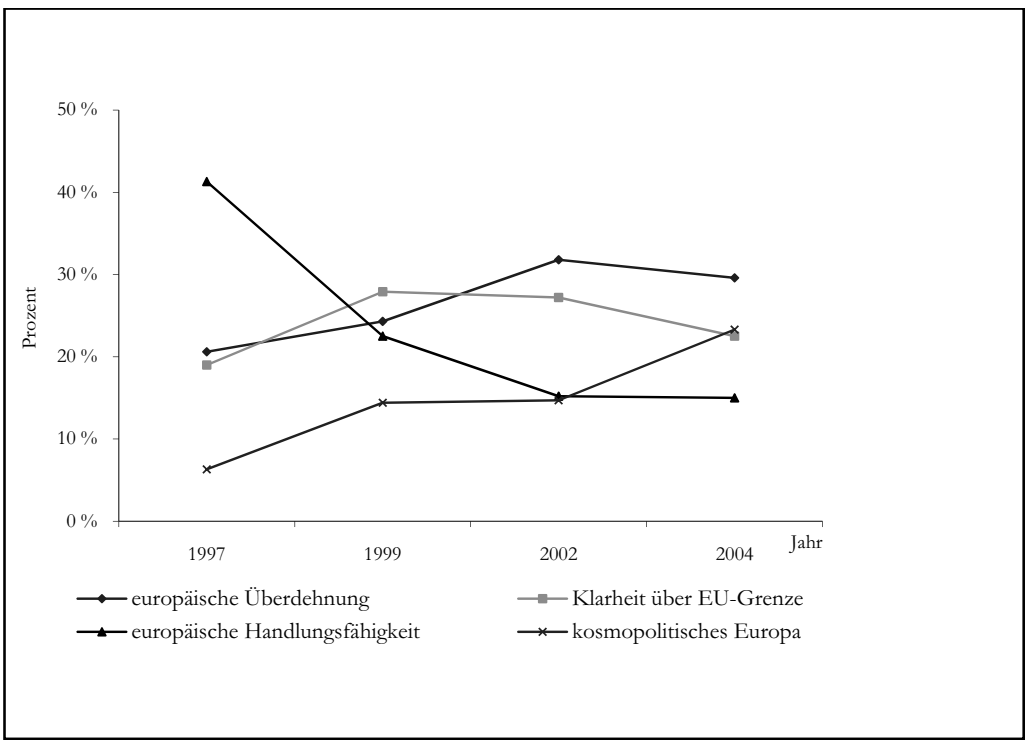

Die türkischen Akteure dagegen differieren in ihren Standpunkten erheblich. Wenn sie zu diesem Thema Stellung nehmen, bedienen sie sich 
eines doppelten Argumentes: Mit der Türkei würde die EU zum einen glaubwürdiger und kosmopolitischer, zum anderen würde die Integration die internationale Handlungsfähigkeit und die Sicherheitspolitik aufgrund der geostrategischen Bedeutung der Türkei, ihrem wirtschaftlichen Potenzial und der jungen demographischen Struktur erheblich vermehren. Die Türken reden kaum über die europäischen Grenzen und die Integrationskraft der EU.

Betrachtet man die Entwicklung der Erzählstrukturen im Bereich Zukunft Europas, so ist zu sehen, dass die Doppelerzählung im exklusiven deutsch-europäischen Diskurs, »europäische Überdehnung« und »Klarheit über die EU-Grenzen« relativ stabil bleibt. Insbesondere die »Überdehnung« erreicht 2002 einen Höhepunkt, nimmt aber 2004 leicht ab (Abbildung 19). Wie oben erwähnt wurde, ist die Zukunft Europas ein deutsch-europäisches Terrain, auf dem die Konservativen die meisten Argumente einbringen, jedoch wird es auch von pro-europäischen türkischen Akteuren mit dem Argument betreten, »Europa wäre glaubwürdiger und kosmopolitischer«, wenn die Türkei EU-Mitglied würde. Interessant ist zu sehen, dass die Aussage, »Europa wird mit dem türkischen Beitritt in die EU handlungsfähiger« im Laufe der Zeit sehr stark abgenommen hat. Daraus lässt sich schließen, dass auch die pro-türkischen bzw. pro-europäischen Akteure mit der Zeit weniger sicherheitsund interessenbezogen, sondern stärker kulturalistisch argumentieren. Die Zunahme im Bereich »kosmopolitisches Europa« kann dahingehend interpretiert werden.

\section{Abb. 20. Zukunft Europas \& deutsche Akteure}

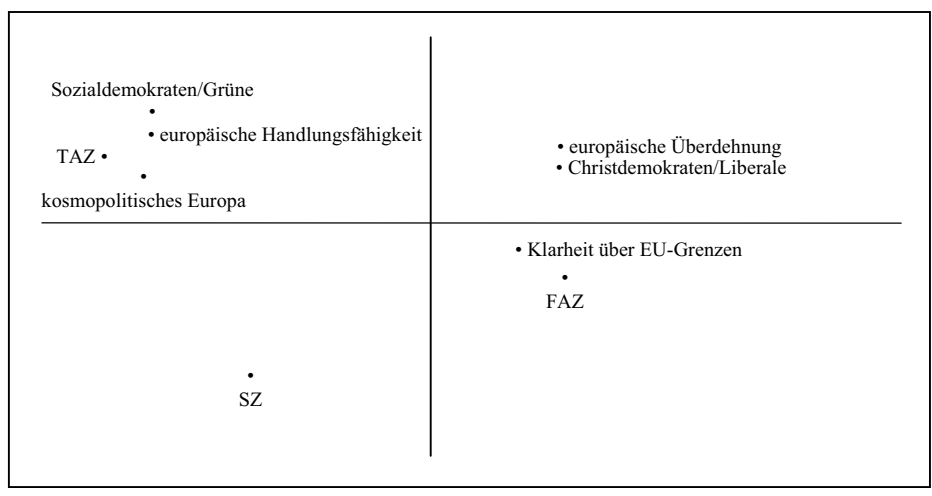

Die Abbildung 20 zeigt, dass es Sozialdemokraten/Grüne und TAZ-Kolumnisten sind, die von einem »kosmopolitischen« und »handlungsfähigen Europa« durch den türkischen Beitritt reden, während Christdemo- 
kraten und FAZ-Kolumnisten die europäischen Grenzen und die »Integrationskraft« der EU problematisieren.

Es ist also eine deutliche Zwei-Fronten-Konstellation zu sehen mit jeweils zwei Akteur-Allianzen.

\section{Abb. 21. Zukunft Europas \& türkische Akteure}

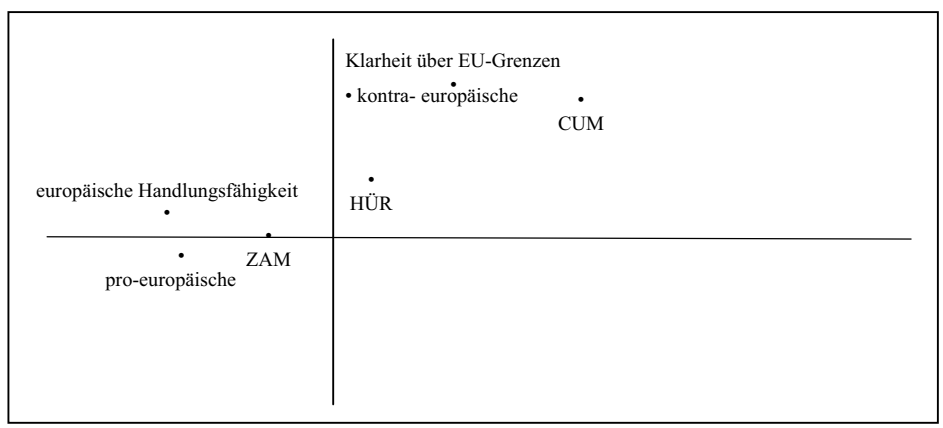

In der türkischen Diskursformation spielt die »Zukunft Europas« eine relativ geringe Rolle (Abbildung 21). Es ist zu sehen, dass auch auf diesem Feld keine klaren Blöcke herrschen, wie es hingegen in der deutschen Öffentlichkeit der Fall ist. Pro-europäische Akteure, ZAM und sonstige türkische Akteure sprechen von einem »kosmopolitischen und glaubwürdigen« und »handlungsfähigen Europa« durch den Türkei-Beitritt, während die kontra-europäischen Nationalisten sich irgendwo zwischen »Klarheit über europäische Grenzen« und »handlungsfähiges Europa« befinden.

Abb. 22. Zukunft Europas \& europäische Akteur

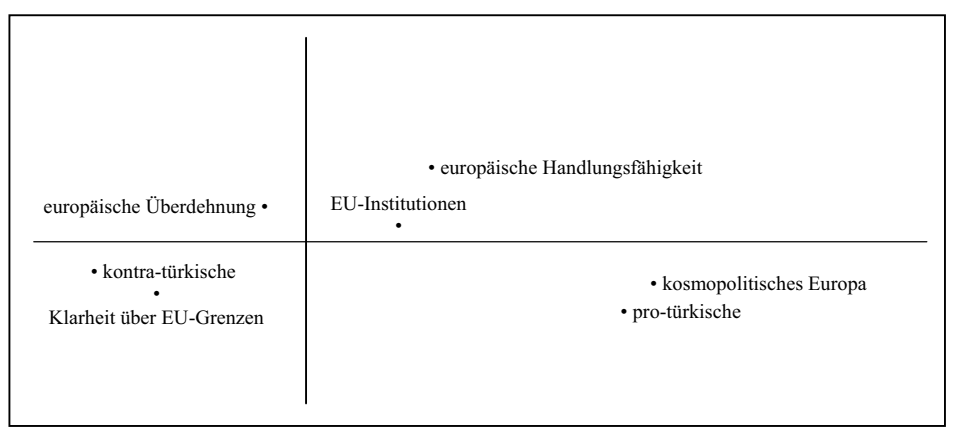


Die Positionierung der europäischen Akteure ähnelt, wenn es um die Zukunft Europas geht, der der deutschen Akteure (Abbildung 22). Auch die europäischen kontra-türkischen Akteure reden von »Überdehnung« und den »Grenzen Europas«. Die europäischen Sozialdemokraten/ Grünen/Sozialisten bringen das »kosmopolitische Europa« durch den Türkei-Beitritt zur Sprache. Die europäischen Institutionen und sonstige EU-Länder/Akteure unterscheiden sich von diesen, indem sie die »Vermehrung der Handlungsfähigkeit« Europas durch einen Türkei-Beitritt in den Vordergrund stellen.

\section{Die diskursive Interdependenz}

Es wurde oben gezeigt, wie sich die deutsch-europäischen und die türkischen Diskurse in der jeweiligen nationalen Öffentlichkeit von 1997 bis 2004 formiert haben, welche Akteure auf welchen Themenfeldern mit welchen Deutungsrahmen sichtbar werden und welche Kontinuitäten und Diskontinuitäten dabei festzustellen sind. Im Folgenden wird nun gezeigt, welche thematischen Entscheidungen, Argumentations- und Deutungsstrategien türkischen und deutsch-europäischen Diskursen gemeinsam sind, welche differieren sowie wie türkische und deutsch-europäische Diskurse aufeinander reagieren. Die Korrespondenzanalyse bietet abstrakte Räume, in denen sichtbar wird, wie die Diskurse in einer quasi »postnationalen Öffentlichkeit» aufeinander reagieren und in welcher Distanz sie zueinander stehen. Die nachstehende Analyse basiert auf der Rekodierung der Diskursakteure. Es wird nicht länger zwischen deutschen und europäischen Akteuren unterschieden, sie wurden über ihre Subjektposition im Diskurs kodiert, als pro- oder kontra-türkische Akteure. Zeitungskolumnisten wurden nicht miteinbezogen.

Abb. 23. Akteure \& thematisches Feld

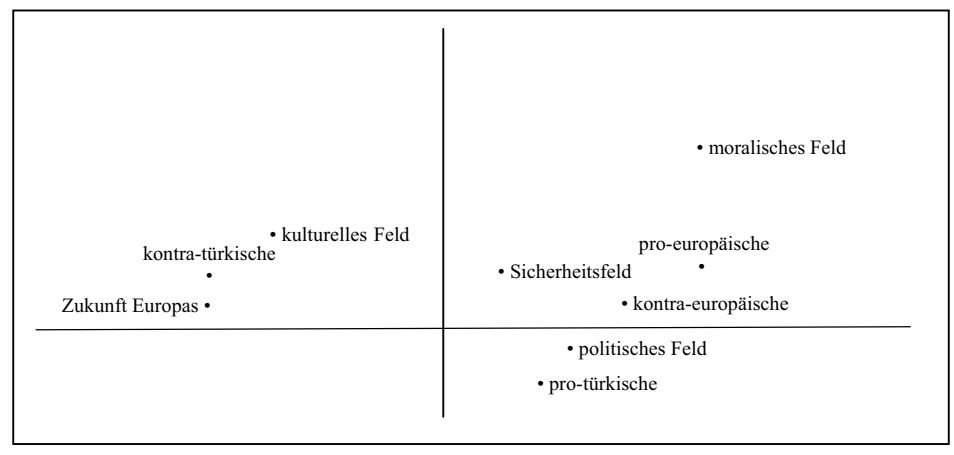


In der Abbildung 23 sind zwei Gruppen erkennbar. Während die deutscheuropäischen kontra-türkischen Akteure hauptsächlich in den Bereichen »Kultur» und »Zukunft Europas« sprechen, argumentieren türkische pro- und kontra-europäische Akteure und deutsch-europäische pro-türkische Akteure in erster Linie auf den Feldern »Politik/Demokratie« und »Sicherheit«.

Die Türkei als »Brücke zwischen Islamischer Welt und Europa« oder als »ein Modell für die Islamische Welt« ist auf dem Feld der Kultur ein diskursiver Knotenpunkt zwischen pro-europäischen und protürkischen Diskursen (Abbildung 24). Beide türkischen Positionen entsprechen sich interessanterweise nahezu in dem Punkt, dass die EU ein »christlicher Club« sei. »Europa ist eine politische Gemeinschaft» ist hauptsächlich eine pro-türkische Aussage, während »Europa ist eine kulturelle Wertegemeinschaft« eine allein kontra-türkische Erzählung bleibt. Zwar findet die kontra-europäische Aussage »Europa ist ein christlicher Club« in der deutschen Öffentlichkeit kaum Zustimmung, und »Europa ist eine kulturelle Wertegemeinschaft« findet bei türkischen Akteuren wenig Gehör, doch die Begriffe »christlicher Club« und »Wertegemeinschaft« weisen auf die kulturelle und religiöse Bedeutung Europas hin. Während »Wertegemeinschaft« auf bestimmte europäische ethno-kulturelle Elemente hindeutet und eine Selbstbeschreibung des kontratürkischen Diskurses ist, beantwortet der »christliche Club« genau diesen Diskurs, indem er ihn stigmatisiert, wobei der kontra-europäische den kontra-türkischen Diskurs als europäischen Gesamtdiskurs repräsentiert.

\section{Abb. 24. Akteure \& kulturelles Feld}

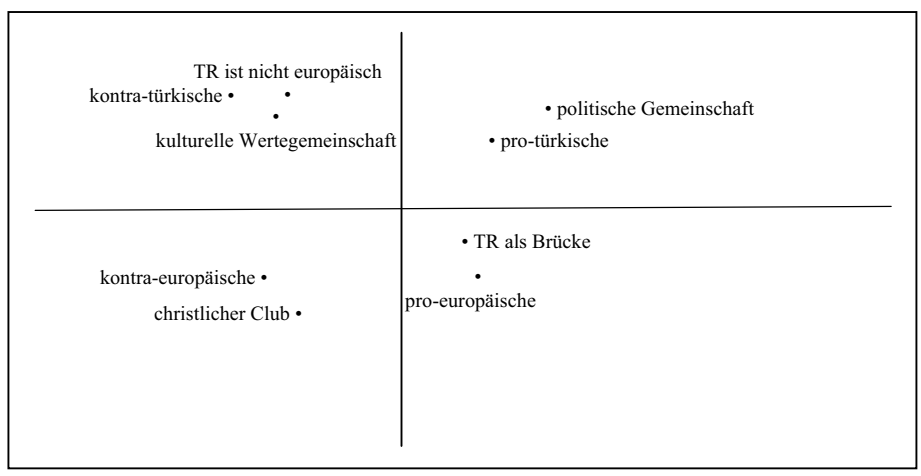


Abb. 25. Akteure \& Sicherheitsfeld

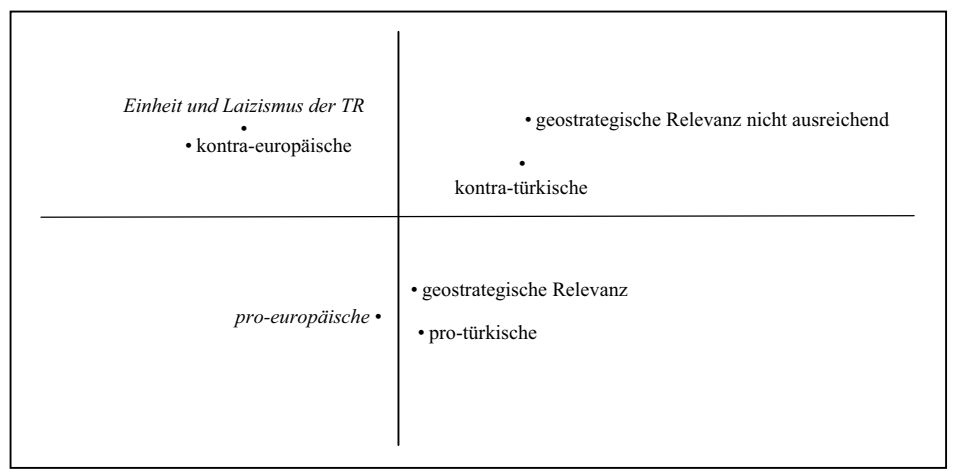

Auf dem Feld der »Sicherheit« ist die geostrategische Relevanz der Türkei für einen EU-Beitritt ein weiterer diskursiver Knotenpunkt zwischen pro-türkischen und pro-europäischen Diskursen. Es ist deutlich zu sehen, dass beide Diskurse eine Türkei-Integration aufgrund ihrer geostrategischen Relevanz befürworten (Abbildung 25). Die geostrategische Bedeutung der Türkei ist laut kontra-türkischem kulturalistischem Diskurs für eine europäische Vollmitgliedschaft der Türkei nicht ausreichend. Diese Erzählung findet in der türkischen Öffentlichkeit wenig Erwähnung. Den kontra-europäischen Akteuren zufolge integriert Europa die Türkei aufgrund ihrer Relevanz für die europäische Sicherheit (oder soll sie lediglich aus diesem Grund integrieren), doch die europäischen politischen Bedingungen gefährdeten die türkische »nationale Einheit« und die laizistischen Strukturen. Diese Bedrohungserzählung findet wiederum keinen Platz in der deutschen Öffentlichkeit.

\section{Abb. 26. Akteure \& politisches Feld}

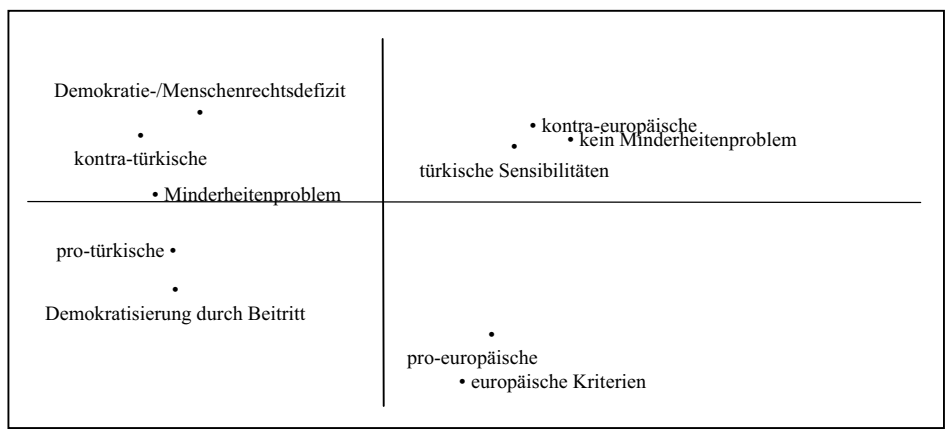


Während sich die kontra-türkischen Akteure aufgrund der »Menschenrechtsverletzungen« und der »Kurdenfrage« gegen den türkischen Beitritt positionieren, bestreiten die pro-türkischen Akteure diese Argumente wenig, verfolgen aber die Strategie zu versprechen, dass mit der Integration das Land demokratisch stabilisiert werde (Abbildung 26). Es gibt kaum türkische Akteure/Autoren, die offen artikulieren, dass die Türkei kein Demokratie- und Menschenrechtsdefizit habe. Während die pro-europäischen Akteure der Ansicht sind, dass die Türkei die politischen Kriterien schon seit 1999 erfüllt habe, stellen die kontra-europäischen Akteure diese Bedingungen entweder unter Verdacht (,SèvresSyndrom“) oder reden von »türkischen politischen Sensibilitäten« und »roten Linien«, verstanden als »Gefahr des politischen Islam« und »spalterischer Terror« (PKK).

\section{Abb. 27. Akteure \& moralisches Feld}

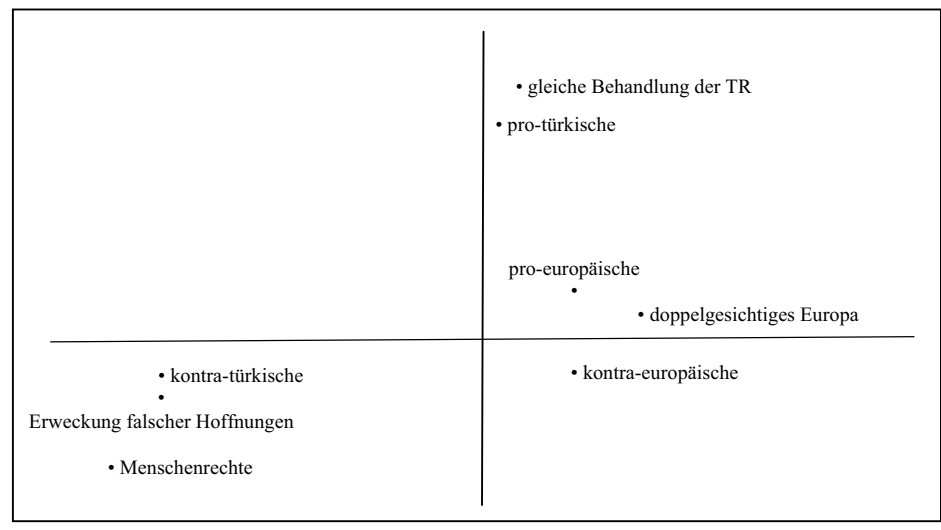

Neben der »Brückenfunktion der Türkei zwischen West und Ost« auf dem kulturellen Feld bildet die »europäische Unehrlichkeit« auf dem moralischen Feld ebenfalls einen gesamttürkischen Konsens. Fast 85 Prozent aller türkischen Äußerungen, die auf dem moralischen Feld artikuliert werden, sprechen von der »Unehrlichkeit Europas der Türkei gegenüber« oder vom »doppelgesichtigen Europa« (Abbildung 27). Dem türkischen Gesamtdiskurs zufolge gibt die EU »unerfüllbare Bedingungen« vor. Die türkischen Akteure fühlen sich also von Europa nicht gerecht behandelt. In der deutschen Öffentlichkeit dagegen ist die Anzahl von »keine falschen Hoffnungen erwecken« relativ hoch. Auf der Kehrseite wird die »europäische Unehrlichkeit« bestätigt, indem der kontra-türkische Diskurs die deutsche bzw. europäische Unehrlichkeit 
zur Sprache bringt. Hier liegt also sozusagen ein Konsens über einen gemeinsamen Dissens zwischen kontra-türkischem und vor allem kontra-europäischem Diskurs vor, der darauf abzielt, sich voneinander abzugrenzen.

Abb. 28. Akteure \& Zukunft Europas

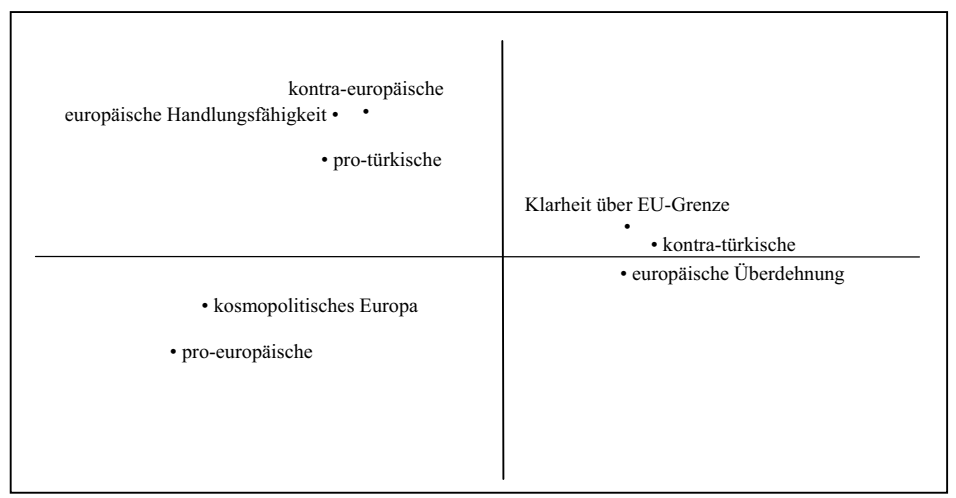

Wie oben geschildert bringen die kontra-türkischen Akteure, wenn sie sich seit 1999 zum Türkei-Beitritt äußern, ihre Argumente zur Zukunft Europas mit einer Bedrohungsrhetorik zum Ausdruck. Paradoxerweise sprechen sowohl die deutsch-europäischen pro-türkischen als auch die türkischen kontra-europäischen Akteure von zunehmender Handlungsfähigkeit Europas in der Außen- und Sicherheitspolitik, während die pro-europäischen Akteure (AKP) vor allem seit 2002 ein »kosmopolitisches Europa« hervorheben (Abbildung 28).

\section{Fazit}

Im theoretischen Teil habe ich die Heterogenität, Offenheit und Dialogizität des Diskurses auf der einen Seite und die Subjektivität des Anderen auf der anderen Seite hervorgehoben. Weder der Orientalismus als dominanter Diskurs des Westens noch der Okzidentalismus als Diskurs des Anderen sind, so habe ich argumentiert, isolierte, einheitliche und stabile Diskursformationen. In diesem Rahmen habe ich von verschiedenen miteinander konkurrierenden Formen von Orientalismen bzw. Okzidentalismen gesprochen, die verschiedene Umgangsformen mit Anderen vorschlagen und somit sich diskursiv unterschiedlich nach innen und nach außen auswirken. Während dabei die europäische Hegemonie instabil ist, bleiben auch die Aneignungsstrategien des Anderen unvoll- 
ständig, ihre Beziehung ist dialogisch und relativ prekär. Nicht-westliche Gesellschaften adaptieren einerseits das orientalistische Wissen und die Erfahrungen, andererseits sind sie aber auch frei, ihre Bedeutung zu modifizieren, sie zu verdrehen bzw. abzulehnen. Es geht also um die diskursiven Performanzen bzw. die politische Subjektivität des Anderen in seinem Orientalisierungsprozess.

Abb. 29. Mapping des diskursiven Feldes 1997

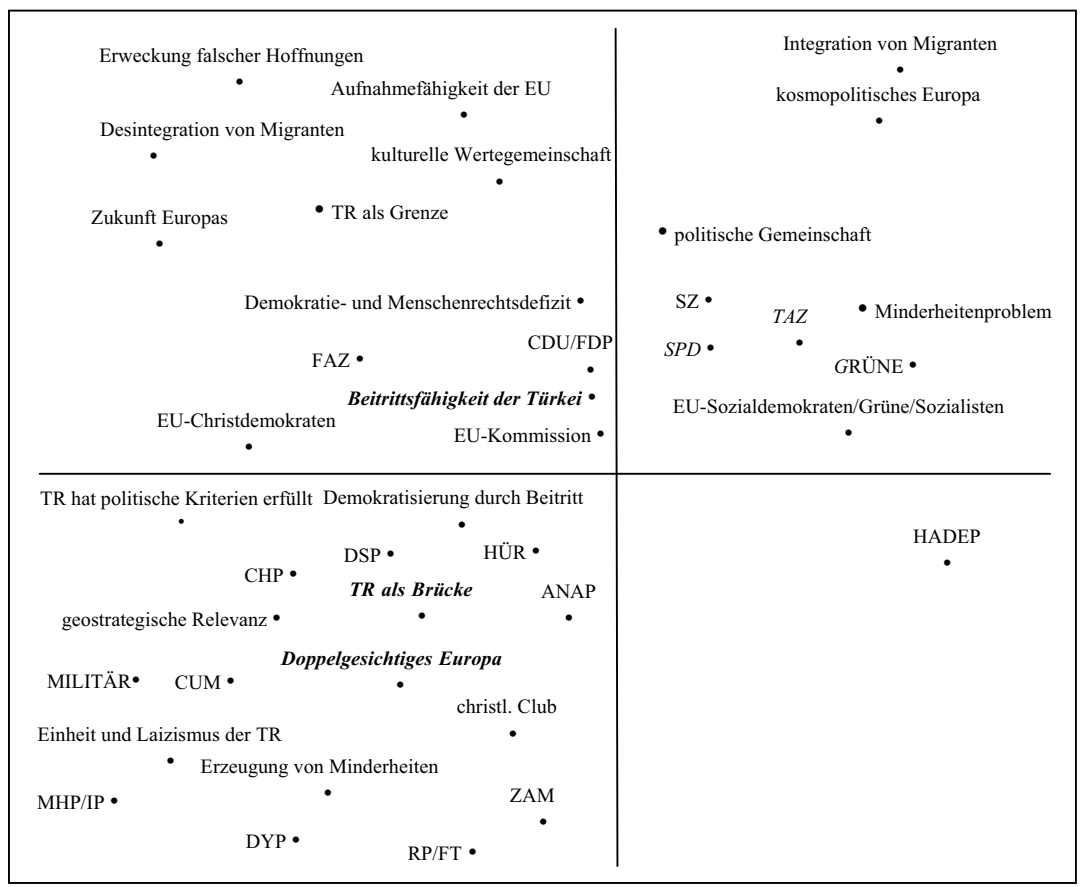

Die Ergebnisse dieser Arbeit zeigen, dass in beiden Kontexten insbesondere seit 1999 hegemoniale Auseinandersetzungen stattfinden, in denen auf bestimmten thematischen Feldern entlang bestimmter diskursiver Schnittpunkte und Topoi diskursive Zusammenhänge hergestellt und antagonistische Verhältnisse sichtbar werden, wo die Logik der Äquivalenz herrscht. Während im Jahre 1997 auf beiden Feldern die Logik der Differenz regiert, wobei weder auf der deutschen und europäischen noch auf der türkischen Seite Konfliktlinien sichtbar werden (siehe Abbildung 29), sind ab 1999 vier hegemoniale Diskursformationen zu sehen, die sich miteinander verflechten oder voneinander abgrenzen (siehe Abbildung 30). Türkische und deutsch-europäische Diskurse formieren sich 
dabei im Dialog, sie wenden sich aneinander und reagieren aufeinander, wobei die Repräsentationen von Europa und »Islamischer Welt« in den dialogischen Diskursformationen konstitutiv wirken.

Abb. 30. Mapping des diskursiven Feldes 2004

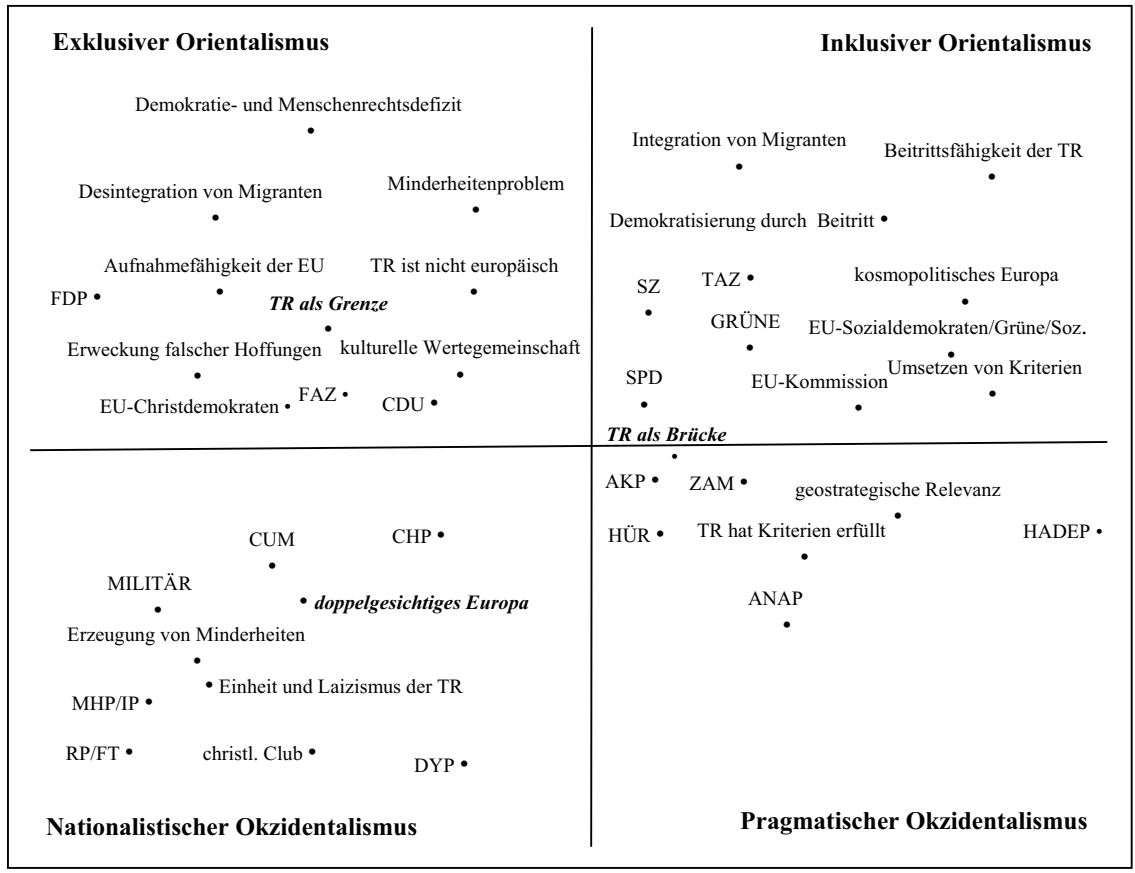

In den folgenden Analysen werde ich von zwei Formen von Orientalismus sprechen, die unterschiedlichen Zwecken dienen und unterschiedliche Diskurseffekte nach innen und nach außen zur Folge haben. ${ }^{8}$ Mit

8 Die von Abélès (2000) vorgeschlagene Unterscheidung zwischen der französischen und der deutschen diskursiven Tradition könnte auch dazu beitragen, zwischen beiden dominanten Diskursformationen zu differenzieren. Die französische ist für Abélès interventionistisch und zentralistisch, die deutsche basiert dagegen auf Subsidiarität, wonach die nationalen und regionalen Differenzen bewahrt bleiben sollen (vgl. Abélès 2000: 48). Die französische modernistische Tradition bedeutet Europas »Fortschritt« und säkulare territoriale Einheit, deren Außengrenzen prinzipiell offen sind. Die katholische habsburgische deutsche Tradition versteht unter Europa eine abendländische, kulturelle und christliche Einheit, deren Grenzen kulturell bestimmt sind und die prinzipiell geschlossen ist (vgl. Malmborg/Stråth 2002: 14f; Bellier/Wilson 2000: 17ff; Holmes 2000: 95f). Die beiden dominanten Diskurse nach nationalstaatlichen Kategorien zu typologisieren, ist jedoch problematisch, denn die Grenzen des Diskurses ver- 
dem Begriff inklusiver Orientalismus werde ich jenen pro-türkisch positionierten deutsch-europäischen Diskurs meinen, der die politische Stabilisierung der Türkei, ihre geostrategische Relevanz für die europäische Sicherheit sowie ihre kulturelle »Brückenfunktion" zwischen »West und Ost « in den Vordergrund stellt, wobei die EU als Träger der Demokratisierung und Stabilisierung seiner östlichen Peripherie repräsentiert wird. Dabei wird die Türkei prinzipiell eingeschlossen, wenn sie die politischen Bedingungen erfüllt. Den kontra-türkischen Diskurs werde ich exklusiven Orientalismus nennen, der die Türkei prinzipiell ausschließt, auch wenn sie die politischen Bedingungen erfüllt. Er akzentuiert eine »Überdehnung« der EU durch einen türkischen Beitritt und markiert die Türkei als »Grenze zwischen Ost und West«. Nicht die »Beitrittsfähigkeit der Türkei«, sondern die »Aufnahmefähigkeit der EU« wird hervorgehoben. Die Türkei wird dabei entweder als »Brücke« oder als »Grenze« zwischen Europa und islamischer Welt konstruiert. Während der inklusive Diskurs primär nach außen adressiert ist, richtet der romantische exklusive Diskurs sich eher nach innen, nach Europa, mit der Intention eine partikularistische europäische Identität herauszubilden. Beide Diskurse bringen einen möglichen Beitritt der Türkei mit der Integration der muslimisch-türkischen Migranten in Verbindung, welche als innere Symptome der deutsch-europäischen symbolischen Ordnung fungieren. Sie konstruieren auch einen Orient im europäischen Innen.

Wie beim Orientalismus werde ich auch von zwei Formen von Okzidentalismus sprechen, die auf dem nationalen symbolischen Feld verflochten sind und sich in unterschiedlichem Maße mit den orientalistischen Diskursen in Verbindung setzen oder von ihnen abgrenzen. Chens Unterscheidung zwischen »offiziellem« und »anti-offiziellem« Okzidentalismus innerhalb postkolonialer Gesellschaften (China seit der Kulturrevolution) könnte eine praktische Lösung für die analytische Differenzierung hegemonialer und gegenhegemonialer Positionierungen in den nicht-westlichen Gesellschaften anbieten. Denn auch auf dem türkischen diskursiven Feld formieren sich seit 1999 zwei miteinander konkurrierende Diskursformationen, die unterschiedliche Repräsentationen über

laufen im türkischen Fall weniger entlang nationalstaatlicher Imaginationen und widerspruchsloser Interessen, sondern vielmehr in ihren antagonistisch positionierten hegemonialen Diskursformationen auf dem jeweiligen nationalen symbolischen Feld. Das deutsche diskursive Feld ist hierzu ein gutes Beispiel, da auf ihm sich antagonistische pro- und kontratürkische Diskurse formieren, die an bestimmten hegemonialen Knotenpunkten miteinander verknüpft bzw. voneinander abgegrenzt sind, wobei zwei unterschiedliche dominante Bedeutungen Europas sichtbar werden, die für die Türkei unterschiedliche Effekte haben. 
sich selbst und über Europa produzieren, wobei die Grenzen zwischen beiden Diskursen nicht deutlich sind (vgl. Abbildungen 29 und 30). Den türkischen kontra-europäischen Diskurs werde ich als nationalistischen Okzidentalismus und den pro-europäischen Diskurs als pragmatischen Okzidentalismus bezeichnen. Der nationalistische Okzidentalismus deutet die politischen Kriterien der EU als eine Gefahr für die Einheit des türkischen Staates. Er versucht, sich über eine negative Bedeutung Europas national zu schließen. Europa ist folglich »unehrlich«, »doppelgesichtig«, »erzeugt« Minderheiten und stellt »unerfüllbare/ungleiche Bedingungen«. Der pragmatische Okzidentalismus dagegen deutet den türkischen Beitritt in die EU als einen Gewinn an Demokratie, Stabilität und wirtschaftlicher Wohlfahrt und akzentuiert die »Brückenfunktion«. Die Türkei sei als einziges islamisches Land »ein Modell für die Islamische Welt«. Der türkische Beitritt würde die europäische Außen- und Sicherheitspolitik handlungsfähiger machen. Dadurch würde die EU glaubwürdiger und würde beweisen, dass sie kein »christlicher Club« sei. Eine Ablehnung dagegen werde die Türkei politisch und wirtschaftlich destabilisieren.

Nachdem ich die allgemeine Topographie des dialogischen diskursiven Feldes gezeigt habe, nämlich wie Diskursträger, Themen und diskursive Knotenpunkte mit ihren Dynamiken und Routinen in dem Feld verstreut sind, werde ich im Folgenden diese oben festgestellten dominanten West-Ost-Repräsentationen bzw. Aussagen an der Schwelle zwischen europäischem Selbst und türkischem Anderen vertiefend interpretativ analysieren. Es wird dabei relevant, das hegemoniale dialogische Zusammenspiel zwischen europäischem Selbst und türkischem Anderen zu zeigen, sei es im Falle der (hegemonialen) Konsensbildung anhand universalistischer diskursiver Knotenpunkte oder im Falle der Dissensbildung anhand bestimmter partikularistischer Signifikanten. Es geht mir also darum zu zeigen, wie orientalistische und okzidentalistische Diskursformationen in der deutschen bzw. europäischen Öffentlichkeit sichtbar werden, wie und inwieweit sie sich miteinander in Beziehung setzen, wie und inwieweit sie sich voneinander abgrenzen. 



\section{OST-WESt REPRÄSENTATIONEN IM BEITRITTSDISKURS}

\section{Die Türkei als Brücke}

Es ist eine gewisse Ähnlichkeit zwischen den Deutungsstrategien des inklusiven Diskurses und des pragmatischen Diskurses bezüglich ihrer thematischen Entscheidungen und den eingesetzten Aussagen und Metaphern festzustellen. Als eine privilegierte Metapher funktioniert die Brücke als Medium der Verknüpfung, als ein gemeinsamer Topos zwischen inklusivem Orientalismus und pragmatischem Okzidentalismus. Insbesondere seit dem Kopenhagener Gipfel im Dezember 2002 heben die neue islamisch geprägte Regierung (AKP), die Kolumnisten von ZAM und HÜR und die SPD/Grünen und TAZ die kulturelle »Brückenfunktion« der Türkei hervor. Während in den vorherigen Jahren (1997, 1999) die strategische, sicherheitsbezogene Bedeutung der »Brücke« akzentuiert wurde, hat der Gesamtdiskurs sich ab 2002 massiv kulturalisiert.

\section{Pragmatischer Okzidentalismus}

Der damalige türkische Außenminister Ismail Cem (DSP) und der Premierminister Bülent Ecevit (DSP) artikulierten vor dem Helsinki-Gipfel im Dezember 1999, dass die Türkei nicht nur eine »Brücke zwischen Europa und Asien« sei, sondern auch »zwischen Judentum und Christentum《. Unter den islamischen Ländern sei sie die »Avantgarde der Demokratie und des Laizismus « (Ecevit, ZAM: 12.12.1999). Ex-Staatspräsident Süleyman Demirel (DYP) betonte, dass die Türkei beweise, dass »Demokratie, Laizismus und Islam kompatibel« seien, und dass sie die europäische Vielfältigkeit bereichern könne (Demirel, HÜR: 01.12. 2002). Premierminister Erdoğan und Ex-Außenminister Abdullah Gül (AKP) (seit August 2007 Staatspräsident) akzentuierten die »Brücken- 
funktion ${ }^{1}$ der Türkei zwischen den Zivilisationen«. Gül wünschte, dass »die Zivilisationen sich in der Europäischen Union versöhnen«. Eine Mitgliedschaft werde ein »Modell für das Treffen islamischer Kultur mit Demokratie« sein. Eine solche Türkei wäre ein gutes Vorbild für den Frieden im Mittleren Osten und für alle islamischen Länder.

Die Türkei versteht sich zwar als ein Teil der »Islamischen Welt«, aber als ein besserer. Die Übernahme von westlichen Normen verspricht mehr Anerkennung und Achtung durch das europäische Andere. Der pragmatische Diskurs beantwortet mit »Kompatibilität der Demokratie mit dem Islam« genau den orientalistischen Diskurs, der den Islam als etwas, das zu Modernität und Fortschritt im Widerspruch steht repräsentiert. Er versucht dabei, das orientalistische Stigma abzulegen und zu zeigen, dass Islam und Demokratie mindestens in der Türkei kompatibel sein könnten, wenn Europa dabei helfen würde. Die Türkei wird jedoch aus der Rolle des Östlichseins als Mitglied der islamischen Welt nicht entlassen. Entweder wird ihr von europäischen Diskursen in Erinnerung gebracht, dass sie nicht ganz dazu gehört, dass sie unvollständig ist, oder sie wird von internen maskierten Anderen darauf hingewiesen, dass ihr Wunsch, ein Teil der europäischen Gesellschaft zu werden, unmöglich ist. Insbesondere gibt sich der pragmatische islamistische Diskurs Mühe, zunächst als besserer Vertreter der »Islamischen Welt« Teil der westlichen Gesellschaft zu werden. Er verfällt dabei dem Wunsch, nicht nur sich von diesem orientalistischen Stigma freizumachen, sondern darüber hinauszugehen und der »Islamischen Welt«, der er sich auch zugehörig fühlt, behilflich zu sein.

Dieses Gefühl des Mangels liegt dem türkischen Modernisierungsprozess seit der zweiten Hälfte des 19. Jahrhunderts zugrunde. Die osmanischen und türkischen Akteure waren geprägt vom Orientalismus (von Montesquieu über Hegel und Renan bis zu Weber) und internalisierten die orientalistischen Annahmen. Ähnlich wie europäische Historiker Anfang des 20. Jahrhunderts, die den Verfall des Osmanischen Reiches mit der »Starrheit« der Türken und ihrer islamischen Religion begründeten (vgl. Adanır 2001: 119f), haben die osmanischen Reformisten die osmanische »Dekadenz« und »Rückständigkeit« und die militärischen Niederlagen nicht auf die sozioökonomischen Bedingungen und den westlichen Kolonialismus zurückgeführt, sondern erklärten sie mit kulturellen und religiösen Deutungsstrategien (Aberglauben, islamisch

1 Die Brückenmetapher spielt Ahıska (2005) zufolge seit der Gründung der Republik eine konstitutive Rolle. Dabei habe man Asien als das Weibliche, Europa als das Männliche repräsentiert und die Türkei sei das Bett für die Vereinigung, in der Verrat, Hass und Liebe miteinander einhergehen (vgl. Ahiska 2005). 
geprägte lokale Kultur und Fatalismus). Gegenüber dem orientalistischen Diskurs positionierte sich der Diskurs der osmanischen Reformisten wiederum defensiv, er versuchte, den Europäern zu beweisen, dass der Islam vereinbar mit europäischer Rationalität, Vernunft, Freiheit und Fortschritt sei. Hierbei idealisierte man Asr-l Saadet ${ }^{2}$ (vgl. Kara 2001: 238f). Nachdem sich zu Beginn des 20. Jahrhunderts der türkische Nationalismus herausbildete, standen die türkischen Eliten auch nach der Gründung der Republik unter Zwang, den Westen davon zu überzeugen, dass der »Islam« mit dem »Fortschritt« kompatibel gemacht werden könne, wenn ein gewisser traditioneller Aberglauben aus der Religion entfernt würde. Für den Zerfall des Osmanischen Reiches machten sie die islamisch geprägte lokale Kultur verantwortlich, die durch eine (imaginierte) westliche Kultur ersetzt werden sollte. Es sollte eine Art von »Kulturrevolution« stattfinden. Dieses beherrschende Gefühl des Mangels wirkte in der nationalen Identität konstitutiv.

Dem liberalen Kolumnisten Mehmet A. Birand (HÜR) zufolge hat die Türkei sich der Zielsetzung Atatürks, die »westlichen Zivilisationen einzuholen«, erheblich angenähert. Birand spricht von der »depressiven Krankheit« der Türken, welche ihre Erfolge in Europa nicht zu genießen in der Lage seien, und artikuliert, dass sie den Europäern gegenüber kein Selbstbewusstsein hätten, da sie »an Erfolge nicht gewöhnt« seien. Der 12. Dezember 2004 (Kopenhagener Gipfel) ist für Birand:

»[...] der Tag, an dem die seit Jahren andauernde Identitätsfrage der türkischen Nation gelöst wird. Es ist der Tag, an dem bekannt gegeben wird, dass die Türkei in der ersten Liga spielen darf und kann. Es ist der Tag, an dem man sich am meisten an Atatürk erinnern soll, an jenen, der die Türkei auf die westliche Zivilisation zu erheben beabsichtigt hat." (Birand, HÜR: 13.12. 2004)

Der pragmatische Diskurs bezieht sich auf die türkischen nationalen »Erfolgsgeschichten«, das Lausanner Abkommen und die nationalen Mythen, um den Kopenhagener Beschluss als »türkischen Erfolg« zu deuten: »Seit dem Lausanner Abkommen hat das Herz der Türkei nicht mehr so stark geschlagen. Seitdem war sie nicht mehr mit einem solchen Gipfel konfrontiert.« (Birand, HÜR: 13.12.2002)

Ertugrul Özkök (HÜR) zufolge beabsichtigten die türkischen Bürger auf dem Standard der entwickelten Länder zu leben, deswegen sei »unsere Richtung Entwicklung, Zivilisation und menschliche Werte«. Die Türken seien seit 600 Jahren »europäisch« und zum Westen hin

2 Asr-ı Saadet (»Zeitalter der Glückseligkeit «) ist die Idealisierung der Herrschaft des Propheten Mohammed in Mekka. 
orientiert (Özkök, HÜR: 12.12.1999). Özkök bezieht sich dabei auf Atatürk, der sich in seiner Begegnung mit dem französischen Schriftsteller Maurice Pernot folgendermaßen äußerte: »Seit Jahrhunderten wenden sich die Türken beständig in eine einzige Richtung. Wir liefen stets von Osten nach Westen [...] Wenn auch unser Körper sich im Osten befindet, so sind unsere Ideen doch nach Westen gerichtet« (Atatürk 1990: 66).

Ein verinnerlichter Orientalismus zeigt sich im pragmatischen Okzidentalismus, der mit dem Blick des Anderen sich selbst beobachtet, wobei die imaginierten West- und Ostbilder hierarchisch organisiert und westliche Repräsentationen privilegiert werden. In diesem Diskurs ist die Weltgeschichte die Geschichte des Westens, der dem dekadenten Osten ontologisch und normativ überlegen ist. Der Osten ist für Özkök unterentwickelt und unzivilisiert. Der Westen wird dabei Telos, er ist der Ort von Entwicklung, Zivilisation und menschlichen Werten, während der Osten zum gegenteiligen Ort wird. Der pro-europäische Diskurs kann sich mit den unerwünschten Mängeln des »Orients« nicht identifizieren und versucht, seiner »Dekadenz« zu entfliehen, indem er sich in die Phantasie eines fortschrittlichen Westens flüchtet. Er bestätigt damit die eurozentristische Logik, die die »Fundamente« einer europäischen Identität und »europäischen Zivilisation« in der Antike verortet und eine Kontinuität bis in die Gegenwart konstruiert. Um das »Westlichsein der Türken« zu legitimieren, bedient sich der Diskurs nationalistischer Geschichtsschreibung und Gründungsmythen, welche von den ungarischen orientalistischen Linguisten $^{3}$ des 19. Jahrhunderts geprägt und Anfang des Jahrhunderts von kemalistischen Eliten übernommen wurden. Türkische Eliten erfanden den Mythos vom Ursprung der »türkischen Rasse« bei den uralten anatolischen oder asiatischen Völkern und versuchten nachzuweisen, dass die »Türken« schon immer mit der »europäischen Zivilisation« vertraut waren. Mit der Gründung der Republik radikalisierte sich der türkische Modernisierungsdiskurs, in dem fortan rassistische Elemente eine wesentliche Rolle übernahmen (vgl. Maksudyan 2005). Im Formierungs- und Institutionalisierungsprozess des kemalistischen Diskurses in den 1930er Jahren wurden die Islamisierung der »Türken« und die gesamte osmanische Geschichte als eine Art von Ent-

3 Timur zufolge beziehen sich die türkischen Nationalisten in ihren Erzählungen auf diese orientalistischen Erzählungen und suchen mit deren »Hilfe« den türkischen Ursprung in chinesischen Quellen und der Ergenekon-Legende, um ein kollektives Gedächtnis zu erzeugen. Auch wenn der nationalistische Diskurs anti-westliche Elemente beinhaltet, ist er westlich orientiert und ein Produkt des verspäteten Modernisierungsprozesses (Timur 1986: 2ff). 
fremdung von der »westlichen Zivilisation« bzw. »türkischen Zivilisation« dargestellt. Die »türkische Kultur« habe sich auf dem Terrain der »westlich-griechischen Kultur« entwickelt, sie habe die »Griechen« gelesen. Nun werde die Rückkehr zum türkischen Ursprung notwendig. Die osmanischen Eliten empfanden jedoch, wie bereits erwähnt, bis Ende des 19. Jahrhunderts die Bezeichnung »Türkisch« als Abwertung (vgl. Timur 1986; Akçam 1995).

Der Hauptkolumnist der HÜR, Oktay Ekşi, argumentiert, dass in der Welt ca. 1,5 Milliarden Muslime lebten und in ca. 54 Ländern die Mehrheit der Gesellschaft bildeten. Wenn man die Türkei mit diesen islamischen Ländern vergleiche, werde man schnell zu sehen bekommen, dass es außer der Türkei kein einziges islamisches Land gebe, in dem der Laizismus eingeführt sei und die Demokratie praktiziert würde. Nirgendwo werde über Menschenrechte und Rechtsstaat so offen debattiert wie hier. Nirgendwo gebe es freie saubere Wahlen. In wie vielen dieser Länder gebe es eine Revolution in der Sprache, Kleidung, Rechtsystem, Frauenpolitik und Kultur, fragt er, und, wie sehen diese muslimischen Länder aus, und wie die Türkei. Vergleiche man die Türkei mit den europäischen Ländern, so sehe man, dass die türkischen Frauen in Berufsbildung, Arbeitswelt und Kultur und im gesellschaftlichen Leben viel aktiver seien als beispielsweise in Deutschland, Frankreich oder Dänemark.

Mit der Vorstellung von einer unterlegenen »Islamischen Welt «, die mit Demokratie nicht vereinbar sowie in ihrem Wesen vollkommen anders ist als die Türkei, kompensiert Oktay Ekşi sein Gefühl des Mangels gegenüber Europa. Während er sich vom orientalistischen Stigma freimachen will, verbleibt er doch im selben Argumentationsmuster. Gegenüber dem Westen fehlt es zwar an etwas, dieser Mangel wird jedoch entschädigt, etwa durch die imaginäre aktive Rolle der Frauen in der Gesellschaft. Wie beim nationalistischen Okzidentalismus, der im Folgenden analysiert wird, grenzt sich auch der pragmatische Diskurs gegenüber einem vorgestellten Osten $a b$ - und das ist der Hauptdissens zwischen pragmatischem und liberalem islamistischem Diskurs - der als das Andere des modernen Türkischseins definiert wird. Es ist dies der Versuch, dem Östlichsein zu entfliehen und gleichzeitig die Islamisten, also die internen Anderen, als nicht authentisch, als nicht-türkisch einzuordnen.

»Die Bilder der Demonstration für das Kopftuchtragen, >Hand-in-HandMenschenkette`(El ele insan zinciri), passen nicht zur europäischen Türkei, die sich angestrengt bemüht, ein Teil Europas zu sein. Frauen mit schwarzenKopftüchern erinnern an Saudi-Arabien und entsprechen nicht der zeitgemä- 
ßen Zivilisation. Auch der farbige Luftballon in ihrer Hand konnte diese schwarzen Bilder nicht retten. Dieses dunkle Bild mitten im Zentrum von Istanbul ist das schwarze Schicksal der europäischen Türkei.« (HÜR: 13.12. 1999)

Die politische Forderung, das Kopftuchtragen im öffentlichen Raum zuzulassen, wird nicht im politisch-demokratischen, sondern im orientalistisch-kulturalistischen Deutungsrahmen debattiert, wobei die Dichotomien von Modernität/Mittelalter, Innen/Außen, West/Ost von großer Bedeutung sind. Entlang der hierarchisch organisierten Dualismen wird nicht nur ein Bild von Westen und Osten im Außen konstruiert, sondern es werden bestimmte Gruppierungen im Innen ebenfalls als östlich oder westlich markiert. Um das »Verspätetsein« und die »Rückständigkeit« aufzuholen, wird wiederum eine Äquivalenz mit dem Westen angestrebt. Dabei wirken die Fragen »wie wir im Westen erscheinen« und »was sie von uns halten« konstitutiv (vgl. Ahıska 2003). Der pragmatische Diskurs leidet unter der Unzulänglichkeit, fortwährend auf Bestätigung durch die europäischen Anderen angewiesen zu sein. Er beantwortet beständig dessen imaginären beobachtenden Blick, und mit diesem Blick betrachtet man auch sich selbst. Die »schwarzen dunklen Bilder« lösen dabei Schamgefühle aus, sie manifestieren den Mangel des türkischen Selbst. Wenn die maskierten internen Anderen (Kopftuchträger) nicht so wären, wie sie sind, dann würde Europa wahrscheinlich die Türkei in die europäische »Wir-Gruppe« aufnehmen. Diese einheimischen »dunklen Bilder« funktionieren als Erinnerungsstücke, die das pro-europäische Subjekt an sein unterdrücktes Östlichsein mahnen. Die »schwarzen dunklen« Bilder von Frauen gehören nicht zur modernen türkischen Nation, sondern symbolisieren die islamische arabische Welt.

Navaro-Yashin (2002) macht diesbezüglich darauf aufmerksam, dass Saudi-Arabien und Iran seit den 1990er Jahren bevorzugte Metaphern des kemalistischen Diskurses sind - einhergehend mit dem Erstarken des politischen Islam -, die negativ belegt werden, um eben diesen politischen Islam in der Türkei außer Gefecht zu setzen. Iran und SaudiArabien symbolisieren dabei Mittelalter, Fundamentalismus, AntiModernität und Anti-Europäischsein, während der säkulare Kemalismus Modernität, Fortschritt und Westen symbolisiert (vgl. Navaro-Yashin 2002: 38ff). Die Türken sollten, so der Diskurs, ihre gegenwärtigen säkularen Werte genießen, die mit der Machtübernahme durch einen befürchteten Islamismus verloren gehen könnten, da die Wohlfahrtpartei und ihr Islamverständnis sich kaum von den saudischen religiösen Praktiken unterscheide. In der »arabischen Welt» herrschten die islamischen Gottesgesetze, Todesurteile würden immer noch mit dem Schwert auf 
öffentlichen Plätzen durchgeführt, die Frauen würden unterdrückt und gezwungen, Kopftuch zu tragen. Die Kemalisten wollen »die Nation« vorwarnen und über die Brutalität der islamischen und arabischen Gefahr aufklären.

Der Diskurs des politischen Islam eignet sich dagegen die negativen Repräsentationen an, die zuvor von den Kemalisten etabliert wurden und ihn dämonisierten, und kehrt sie ins Positive. Dabei werden die politischen Forderungen in den Rahmen von liberaler Demokratie, Menschenrechten und Multikulturalismus gefasst. Während für die Kemalisten beispielsweise das Kopftuch Rückschrittlichkeit und Unterdrückung bedeutet, so ist es für die Islamisten Symbol der Freiheit der Frauen und individuelles demokratisches Recht. Ihr Diskurs stellt osmanische Heldenfiguren dem Gründungsvater der Republik gegenüber. ${ }^{4}$ Der pragmatische islamistische Diskurs benutzt zwar seit 2002 den Begriff Europa als eine Metapher für mehr Demokratie, Pluralismus, Religionsfreiheit und Dezentralismus, indem er die Türkei als »kulturelle Brücke zwischen beiden Zivilisationen« repräsentiert. Auch er ist geprägt von der Trennung zwischen »westlicher Zivilisation« und nationalisierter »türkisch-muslimischer Kultur«. Er repräsentiert sich als die besseren friedlichen Muslime und spricht als »authentischer« Vertreter der »Islamischen Welt«. Doch auch er rekonstruiert einen ambivalenten Westen, der in seinem Zivilisationsbegriff immanent ist: eine Zivilisation mit einem Januskopf, die beneidenswert und gleichzeitig bedrohlich ist.

Diese Empfindungen, die durch verinnerlichte orientalistische Deutungen bewirkt werden, erweisen sich also als ein Handicap für das türkische Selbst. Um diesem entkommen zu können, akzentuiert der pragmatische Diskurs »türkische Authentizitäten« und »Sensibilitäten« gegenüber den politischen Anpassungswünschen Europas. Wenn der Westen auf die türkischen Symptome hinweist, nämlich auf das, was durch die türkische symbolische Ordnung ausgeschlossen wurde, flüchtet er in einen imaginären »Osten«, also in eine harmonische türkische »Nation«, die sich vom europäischen Anderen essentiell unterscheidet, wie im Falle der Minderheiten. Wie im Folgenden gezeigt wird, wird in diesem Fall der Westen als »unehrlicher Fremder« wahrgenommen, vor dem die Nation geschützt werden muss.

4 Der Eroberer von Istanbul von 1453, Fatih Sultan Mehmet, oder auch der oben erwähnte Sultan Abdulhamid II. werden bevorzugt hierfür eingesetzt. Das Osmanische Reich, figürlich vertreten durch seine Sultane, symbolisiert Multikulturalität, Toleranz und religiöse Freiheit, die moderne Republik dagegen Zentralismus, Monokulturalismus und »totalitäre Demokratie« (vgl. Navaro-Yashin 2002: 199f). 


\section{Inklusiver Orientalismus}

Wie ich oben erwähnt habe, funktioniert die »Brücke« als Medium der Verknüpfung, als ein gemeinsamer Topos zwischen dem deutschen inklusiven und dem türkischen pragmatischen Diskurs. Der inklusive Orientalismus kommuniziert mit dem pragmatischen Okzidentalismus und seine diskursive Formation ähnelt dabei dem Osterweiterungsdiskurs, den Sher und Böröcz (2001) den »Diskurs der Aufklärung« genannt haben. Der Diskurs der Osterweiterung formierte sich demnach hauptsächlich im Sicherheitsrahmen, wobei die »Konflikte« veröstlicht und als solche essentialisiert wurden: Osteuropa solle integriert werden, um der »unsicheren« Region Stabilität zu geben und somit auch die Sicherheit für Westeuropa zu verstärken. Er operiert mit den Begriffen »Mangel«, »Hindernisse«, »traditionell« und »Konflikte« (vgl. Kovác/Kabachnik 2001). Wenn der Osten nicht im Zaum gehalten würde, so würden $»$ traditional lines of conflict $[\ldots]$ shift from eastern Europe into the EU again« (Fischer, zit.n. Sher 2001: 256). »The prospect of enlargement dividing public opinion between hope and fear - hope for stability and progress, fear for a Europe without identity and frontiers [...] enlargement is essential if we are to spread peace, stability and shared values throughout the continent.« (Prodi, zit.n. Sher 2001: 262)

Auch die Türkei muss gemäß inklusivem Diskurs aus ähnlichen Gründen integriert werden. Gerhard Schröder (SPD) verteidigt im deutschen Bundestag den türkischen Beitritt und äußert, Europa solle diejenigen unterstützen, die für das laizistische System von Atatürk stehen, damit die Türkei nicht in den islamischen Fundamentalismus »abdriftet« (TAZ: 05.12.2002; SZ: 05.12.2002; HÜR: 05.12.2002). Die Türkei sei eine »wichtige Brücke« zu den Staaten des Nahen Ostens. Militärstrategisch erfülle sie diese Brückenfunktion schon jetzt (FAZ: 20.12.2002). Eine Zurückweisung der Türkei würde laut dem ehemaligen Außenminister Joschka Fischer (Grüne) »das Land in die Isolation treiben« und dieses würde ein $»$ Kollabieren der inneren Strukturen der Türkei riskieren«. Fischer akzentuiert die Bedeutung der türkischen geostrategischen Lage in Sicherheitsfragen, vor allem hebt er die strategische Bedeutung des Landes im »Kampf gegen den internationalen Terrorismus« hervor. Der türkische Beitritt in die EU würde einen »präventiven Sicherheitsgewinn« in den »östlichen Problemgebieten« ermöglichen (FAZ: 03.12.1999; SZ: 05.12.2002). Wie der pragmatische türkische Diskurs deutet auch Eberhard Seidel (TAZ) den Entschluss von Helsinki als einen »Durchbruch«, bei dem »das Europäischsein der Türkei bestätigt « wurde. »Die Türkei gehört zu uns, Atatürks Vision stößt bei den Staatsund Regierungschefs der 15 EU-Staaten endlich auf Unterstützung. 
Mustafa Kemal wollte vor 76 Jahren die Türkei nach Europa führen, sie ist nun angekommen.« (Seidel, TAZ: 11.12.1999)

Der inklusive Diskurs identifiziert sich mit den kemalistischen Mythen und kalkuliert dabei genau die vorausgesetzte Reaktion des kemalistischen Diskurses. Er kommt ihm entgegen, er schmeichelt ihm, indem er die türkischen nationalen Mythen referiert. Er scheint für die türkischen Symptome sensibilisiert zu sein, indem er z.B. seit 2002 kaum von Minderheitenrechten und dem Kurdenproblem spricht, wie der deutsche exklusive Diskurs, der insbesondere nach dem Helsinki-Gipfel immer stärker als Advokat der Menschen- und Minderheitenrechte in der Türkei auftritt. Wie der türkische nationalistische Diskurs argumentiert auch der inklusive Orientalismus im Sicherheitsrahmen, akzentuiert die geostrategische Relevanz der Türkei, wobei die Demokratisierung des Landes als Faktor der Stabilisierung und »Versicherheitlichung« Europas konzipiert wird.

Die >freundliche $<$ Botschaft des inklusiven Diskurses kommt jedoch beim kemalistischen Okzidentalismus nicht (mehr) an, es entsteht eine symbolische Lücke, die beiden Diskurse reden aneinander vorbei. Denn, wie im Folgenden geschildert wird, verändern die Kemalisten ihre Erzählstrategien, sie weigern sich in Europa sanzukommen`. Nach der Machtverschiebung auf dem türkischen diskursiven Feld seit 2002 verändert auch der inklusive Diskurs seine Strategien und bewegt sich zunehmend im kulturalistisch-orientalistischen Deutungsrahmen. Die kulturelle »Brückenfunktion« der Türkei, die seit Gründung der Republik ein türkisches ideales Selbstbild ist, wird immer mehr in den Vordergrund gestellt. Der inklusive Diskurs orientiert sich nun stärker am imaginären Blick einer vorgestellten »Islamischen Welt «.

Der britische Premierminister Tony Blair und sein Außenminister Jack Straw sehen den Beitritt der Türkei als ein »gutes Modell für die muslimische Welt« bzw. als ein Beispiel dafür, dass »die Demokratie und der Islam kompatibel« seien (CUM: 01.12.2002). Er sei ein Beweis gegen die »Spaltung« der Welt (ZAM: 15.12.2002). Der türkische Beitritt ist Cohn-Bendit (Grüne) zufolge für Europa strategisch wichtig, um auf globaler Ebene den islamischen Terrorismus bekämpfen zu können. Die Türkei würde ihre »kulturelle Evolution« fortsetzen und nicht nur sich selbst verändern, sondern auch den Islam beeinflussen sich zu verändern (Bendit, ZAM: 22.12.2004). Für Jürgen Gottschlich (TAZ) hat sich die »Brückenfunktion« der Türkei in den letzen Jahren verfestigt. Sie sei sowohl in der NATO und in diversen europäischen Institutionen, wie auch im OIC, dem Weltkongress islamischer Staaten vertreten. Den bekannten Orientalisten Bernard Lewis zitierend, welcher zu dieser Zeit 
in Istanbul einen Vortrag gehalten hatte, bedeutet Istanbul für Gottschlich die $»$ Nahtstelle zwischen Orient und Okzident $\ll$.

»Hilfreich für die Rolle als Maklerin zwischen zwei Welten ist es auch, dass die Türkei derzeit von einer Mannschaft regiert wird, die ursprünglich aus der islamistischen Bewegung kommt und darum mit mehr Legitimation als ihre Vorgängerinnen innerhalb der islamischen Welt zu Selbstkritik und Reformen aufrufen kann. Entscheidet sich die EU jetzt für den Beginn von Beitrittsverhandlungen mit der Türkei, wird diese ihren Einfluss in der muslimischen Welt mit umso mehr Gewicht wahrnehmen können.« (Gottschlich, TAZ: 15.12.2004)

Die »Maklerin«-Rolle erinnert an den deutschen Orientalisten und Islamwissenschaftler C.H. Becker, der sich von den dominanten deutschen und europäischen Orientalisten Anfang des 20. Jahrhunderts insofern unterschied, als er den Islam als integralen Teil des europäischen kulturellen »Zirkels« betrachtete (vgl. Todorova 2007). Die islamische Zivilisation steht hier nicht im Widerspruch zur europäischen Zivilisation, sondern sie sei die Summe des antiken Orients mit seinen jüdischen, persischen und babylonischen Elementen auf der einen, und den hellenistischen und christlichen auf der anderen Seite. Laut Maria Todorova war der Islam für Becker deshalb ein Mediator zwischen Europa und Asien:

»[Islam] is located exactly in the middle between Europe and Asia. Ethnographically, it belongs more Asia; however, from the point of view of decisive cultural issues that delineate cultural spheres, it has more in common with Europe $[\ldots]$ the line $[\ldots]$ run not between Europe and Islam, but rather between Europe and Islam on the one hand, and Asia on the other." (Becker 1924, zit.n. Todorova 2007: 2)

Die Logik dieser inklusiven Repräsentation, die revolutionär klingt, wie Todorova feststellt, basiert auf der (orientalistischen) epistemologischen Prämisse, die »Europa« und »Asien« als strenge Binaritäten, als abgeschlossene Zivilisationen bzw. »Kulturzirkel« versteht. ${ }^{5}$ Die Rolle, die Becker dem Islam zuwies, wird im gegenwärtigen Diskurs der Türkei zugeteilt, wobei sie weniger zwischen Asien und Europa, sondern viel-

5 Die Kehrseite dieser Logik spricht von der Unvereinbarkeit dieser beiden geschlossenen »Kulturzirkel«. Auf dem türkischen symbolischen Feld hingegen formiert sich in einem dialogischen Verhältnis ein afrozentristischer Okzidentalismus, der die Ursprünge der Weltzivilisation in Afrika und Zentralasien erfindet und entweder vom Dialog der Kulturen oder von deren Unvereinbarkeit spricht. 
mehr zwischen Europa und »Islamischer Welt« vermitteln soll. Die Türkei sei gerade zu diesem Zeitpunkt für diese »Maklerin«-Aufgabe geeignet, weil eine islamisch geprägte Regierung diese legitime Rolle glaubwürdiger für die islamischen Anderen übernehmen könne. Gottschlich argumentiert, die »Islamische Welt« könne sich durch die Türkei $\mathrm{zu}$ einer kritischen Selbstbetrachtung und zu Reformen bewegen lassen. Er stellt der EU durch den Beitritt der Türkei eine erhebliche Zunahme ihres Einflusses auf die »muslimische Welt« in Aussicht. Es solle mittels des türkischen Beitritts eine Botschaft an die »Islamische Welt« gesendet werden, die stets Europa und die Türkei beobachte, ja, die beide im Visier habe. Die »Islamische Welt« würde sich verändern, sie würde sich entwickeln, das in Bewegung setzen, was stehen geblieben ist. Die Europäer sollten diesen beobachtenden islamischen Blick beantworten, ihm entgegenkommen. ${ }^{6}$ Die Frage, wie Europa »drüben« erscheint, was die Anderen von Europa halten, scheint konstitutiv zu sein. Das Andere ist dabei nicht die Türkei, sondern die imaginäre »Islamische Welt« als »Superadressat«, wobei die islamistische Partei als ihr Vertreter repräsentiert wird und auch sich selbst als solcher versteht.

Die Beziehung zwischen Europa und der »Islamischen Welt« besteht dabei nicht lediglich im Markieren von kulturellen Differenzen. Die »Islamische Welt« leidet dabei, immer verglichen mit Europa, unter einem allgemeinen Mangel. Sie verhilft dem inklusiven Diskurs zu einer politischen und psychologischen Positionierung, in der nur auf das hingewiesen wird, was bereits existiert, was bereits different ist. Die »Islamische Welt« als imaginärer Ort, der immer wieder zitiert und zu Vergleichen herangezogen wird dient dazu, Europa mit einem dynamischen Modernisierungsprozess zu assoziieren, während sie selbst immer mit Dekadenz und Bedrohung in Verbindung gebracht wird. Die »Islamische Welt« wird dabei in die Kategorie von »traditionellen Gesellschaften« eingesperrt, sie wird zu einem kulturell-religiösen Objekt, das mit Hilfe des türkischen Beitritts verwandelt werden soll. Sie würde eventuell den türkischen Europa-Weg verfolgen, wenn ihr durch die Aufnahme der Türkei eine positive Botschaft gesendet werde. Nach dieser inklusiven orientalistischen Logik nimmt die Türkei Europa als Modell und die »Islamische Welt» nimmt die Türkei als Modell. Die »Islamische Welt» kann sich kein europäisches Land unmittelbar zum Modell nehmen,

6 Paradoxerweise aber möchten die westlich orientierten kemalistischen Laizisten und das Militär, denen die pro-türkischen europäischen Akteure helfen wollen, nicht mehr, dass ihnen geholfen wird. Wie oben geschildert, bedeutet für sie der EU-Beitritt, dass die islamistische Bewegung in ihrer Bemühung unterstützt wird, das türkische laizistische Regime zu stürzen. 
sondern nur über den Umweg eines türkischen Vorbildes, das in ihrer »muslimischen Klasse« ist.

Der imaginäre Blick der »Islamischen Welt« materialisiert sich, indem bestimmte muslimische Autoren in deutschen Zeitungen zur Sprache kommen. Diese muslimischen Autoren repräsentieren in einer gewissen Weise »die muslimische Welt«, sie reden in ihrem Namen. Als »authentische « Stimme des Anderen werden durch die Erzählungen von arabisch-muslimischen Autoren die eigenen orientalistischen Repräsentationen glaubwürdiger. Die Diskurse der liberalen islamistischen Zaman (seit 2002) und der TAZ ähneln sich in dieser Hinsicht. Beide reden stets vom »Dialog der Kulturen« und der türkischen »Brückenfunktion«, dem »türkische Modell«, und beide lassen die arabischen und muslimischen Autoren aus dem Ausland schreiben.

Karim El-Gawhary zufolge ist es weniger die politische als die kulturelle Dimension, von der vor allem viele liberale arabische Denker erwarten, dass der EU-Beitritt der Türkei ein mittleres Erdbeben mit gutem Ausgang auslöst, durch das festgefahrene Denkweisen zerstört werden könnten. El-Gawhary zufolge orientieren sich viele liberale islamische Bewegungen an der Türkei und meinen, dass die Türken einfach die »Grenzen niederreißen «, wenn sie ihr Europäischsein in den Vordergrund stellen. Auch El-Gawhary zufolge ist die Türkei ein »Modell für die Islamische Welt«. Denn der Türkeibeitritt stelle eines der großen »zivilisatorischen Projekte für viele muslimische Länder« dar. »Wenn Europa es schafft, ein muslimisches Land in seine Reihen zu integrieren, ohne ihm all seine kulturellen Werte aufzuzwingen, wird sich die Sicht Europas auf die islamische Welt genauso verändern wie das dortige schlechte Image des Westens." (El-Gawhary, TAZ: 15.12.2004). Ein EU-Beitritt der Türkei als ein islamisches Land könnte der Beginn eines »ernsthaften Dialoges der Kulturen« sein. Ein Europa aber, das sich als »christlicher Club« verstünde, stoße auf arabischer Seite auf vollkommenes Unverständnis. Obwohl damals die islamischen Gemäßigten und die arabischen Linken die Türkei gehasst hätten, vor allem während des Kalten Krieges und der türkischen Zusammenarbeit mit Israel, so Sadık Jalal Al-Azm, orientierten sie sich heute am türkischen Modell und betrachteten die Türkei »als das einzige Land, in dem die mittlerweile auch von ihr hochgehaltenen Werte des säkularen Humanismus zumindest teilweise Fuß gefasst haben [...] (Jalal Al-Azm, TAZ: 16.12.2004).

Die inklusiven und pragmatischen Diskurse betonen also die »Brückenfunktion« der Türkei zwischen Ost und West, wo sich »zwei Zivilisationen treffen«, indem sie ein kohärentes einheitliches Bild von Europa und »Islamischer Welt« rekonstruieren. Sie reproduzieren die orientalistische Dichotomie zwischen »West und Ost« als geschlossene Entitä- 
ten in einem dialogischen Verhältnis, wobei der Blick des Anderen konstitutiv wirkt. Beide Diskurse kommunizieren miteinander, indem der pragmatische Okzidentalismus sich den orientalistischen Blick zu Eigen macht. Dabei wird die imaginäre Grenze zwischen West und Ost nicht aufgehoben, sondern lediglich jenseits der Türkei verschoben, während die »Islamische Welt« das konstitutive Andere bleibt.

Es geht dabei um eine Identifikation des pragmatischen okzidentalistischen Subjektes mit den hegemonialen Repräsentationen des europäischen Subjektes, was Fanon als »schwarze Haut mit weißen Masken« bezeichnen würde (Fanon 1967: 25ff). Diese Identifikation mit orientalistischen Repräsentationen bleibt jedoch unvollständig. Der türkische Okzidentalismus, ob nationalistisch oder pragmatisch, lässt sich symbolisch integrieren, doch diese Integration bleibt partiell. Sie stößt auf dem politischen Feld an die Grenzen des Orientalismus bzw. Okzidentalismus. »The desire of nationalist elite in Turkey to become both Western and Turkish resonates with Western desire to see Turkey as a »bridge « that never crosses the distance between the West and the East; that becomes Western but never quite like it« (Ahıska 2000: 48).

Das westliche Modell wird vom europäischen inklusiven und türkischen pragmatischen Diskurs als Ideal betrachtet. Beide betonen, dass die Türkei sich die westliche Zivilisation zum Vorbild genommen und imitiert hat, ob erfolgreich oder nicht. Beide nehmen den räumlichen Transfer von westlichen Werten, Normen und Technologien an. Dabei werden einerseits die »erfolgreichen« Elemente der türkischen Imitation (z.B. Frauen in der Berufswelt) gelobt, andererseits werden die defizitären Elemente kritisiert (Frauen mit Kopftuch). Beide konstruieren die Türkei als zwischen zwei Welten liegend. Sie sei zwar eine »Brücke«, jedoch im Westen noch nicht angekommen und müsse sich dahingehend noch stark bemühen. Vergleiche man jedoch die Türkei mit anderen nicht-westlichen Ländern in Mittelost, so sei zu sehen, dass das »türkische Modell« bereits ein ganzes Stück Weg hinter sich gebracht habe. Die »Brücke« als Metapher setzt zwei grundsätzlich getrennte Teile voraus, die miteinander verbunden werden. Sie verbindet und trennt $\mathrm{zu}-$ gleich zwei verschiedene, einander berührende Dimensionen. Sie setzt für natürlich gehaltene »kulturelle Zirkel« voraus, die durch ein symbolisches Bauwerk überbrückt werden sollen. 


\section{Die Türkei als Grenze}

Während die Türkei für den inklusiven Diskurs eine ideale »Brücke« zwischen West und Ost bedeutet, so ist sie für den exklusiven Diskurs der ideale Ort der Grenzziehung. Auch er teilt die Welt in zwei Teile, die jedoch als miteinander unvereinbar gesehen werden. Der exklusive Diskurs erzeugt hegemoniale Repräsentationen von »Europa« und »Islamischer Welt«, mit deren Hilfe unterschiedliche kulturelle Phänomene von »westlichen« und »östlichen« Gesellschaften als unitär, integriert und kohärent dargestellt werden. Dabei dienen orientalistische Repräsentationen zur politischen und psychologischen Positionierung, zur Stabilisierung eines vorgestellten partikularistischen europäischen Selbst, das in der Abgrenzung zu einem islamischen Anderen gebildet wird.

\section{Exklusiver Orientalismus}

Der exklusive Diskurs operiert entlang zweier Deutungsstrategien: Zum einen werden die kulturelle Differenzen zwischen einem »Europa« und einer »Islamischen Welt« in den Vordergrund gestellt. Zum anderen wird die Fähigkeit der EU problematisiert, ein Land wie die Türkei mit ihrer differenten bzw. zerrissenen Kultur und mangelnden politischen Struktur aufnehmen zu können. Dieser Unterschied sollte Hans-Gerd Pottering zufolge ohne »Vorurteile« akzeptiert werden. Er meine damit nicht die religiöse Verschiedenheit, sondern einen »Unterschied des allgemeinen kulturellen Lebens« (ZAM: 22.12.2004) Die Türkei ist in diesem Diskurs entweder ein »asiatisches« Land, dessen »islamisches Menschenbild « sich von dem des »christlichen Europas« unterscheide (Glos, FAZ: 15.12.1999) - oder lediglich »teilweise europäisch« (Schäuble), ein Land, das nicht »im klassischen Sinne« europäisch, sondern »Teil einer islamischen Hochkultur ist, die ihr geistiges Zentrum im fernen Mekka hat« (Lersch, FAZ: 16.12.1997).

Die Beiträge von Winkler liefern diesbezüglich ein umfassendes Bild vom exklusiven orientalistischen Diskurs und schöpfen dessen diskursives Repertoire voll aus. Eine politische Union verlange ein »europäisches Wir-Gefühl«, welches gemeinsame »historische Erfahrungen und Prägungen« voraussetze. Die EU könne an dieses »Wir-Gefühl« nicht mehr appellieren, wenn sie die Türkei einschließe, da die »kulturellen Prägungen« der Türkei zu verschieden seien. Diese Unterscheide »[...] haben etwas mit Christentum und Islam zu tun. [...] Und nur im christlichen Okzident hat sich die Trennung von christlicher und weltli- 
cher Gewalt, die Urform der Gewaltenteilung, in einem Jahrhunderte währenden Prozess vollzogen« (Winkler, FAZ: 11.12.2002).

Diesem kulturdeterministischen exklusiven Diskurs, in dem auch Winkler sich positioniert, liegt Webers orientalistische religionssoziologische These zugrunde. Weber versuchte, in seiner Arbeit die okzidental-kapitalistischen (rationalen) Entwicklungen im Zusammenspiel von

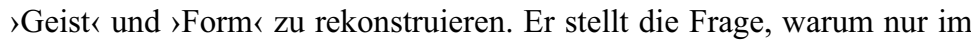
Okzident eine rational-methodische Lebensführung, rationaler Industriekapitalismus, rationale Staatlichkeit, rationale Wissenschaft und akkordharmonische Musik auftreten und warum diese Kulturerscheinungen sich nicht (in dem Maße) in anderen Orten und Religionen, sprich: im Orient (China, Japan, und Indien, Judentum und Islam), herausgebildet haben (vgl. Schluchter 1987: 15ff). Für Weber ist der Islam die Antithese zur modernen Lebensweise und somit stehen Kapitalismus, Rationalität und Demokratie im Widerspruch zum Islam (Stauth 2000: 236). Im Vergleich zum calvinistischen allgütigen und allgnädigen Gott sei z.B. im Islam Gott allmächtig und allwirksam. Deshalb sei im Islam die Gott-Mensch-Beziehung eine Herrscher-Untertanen-Beziehung, eine Beziehung der Unterwerfung. Im Islam beziehe sich die Prädestination nicht auf das Jenseits-, sondern auf das Diesseitsschicksal. Das führe zur einem Fatalismus, der, einfach gesagt, einerseits eine säkulare kapitalistische Entwicklung verhindert habe und andererseits die Todesangst der islamistischen Glaubenskämpfer reduziere, da ihnen nur das wiedergegeben würde, was Allah vorbestimmt habe (vgl. Schluchter 1987: 39ff). Weber spricht also vom »Erfolg« der westlichen Zivilisation, ohne den Kolonialismus zu erwähnen. Er spricht an keiner Stelle von den kolonialen Differenzen und der Subalternation des Wissens, und dies in einem Zeitalter, in dem die europäische Expansion und Kapitalakkumulation im modernen kolonialen Weltsystem ihren Höhepunkt erlebt hat (vgl. Mignolo 2000: 3f).

»Consider that in 1800 Western powers claimed 55 percent but actually held approximately 35 percent of the the earth's surface, and that by 1878 the proportion was 67 percent [...]. By 1914, [...] Europe held a grand total of roughly 85 percent of the earth as colonies, protectorates, dependencies, dominations, and commonwealths. No other associated set of colonies in history was as large, none so totally dominated, none so unequal in power to the Western metropolis.« (Said 1994: 8)

Auch Winkler verortet eine europäische säkulare politische Tradition in christlichen Werten und Normen und partikularisiert eine westliche Säkularität, die nirgendwo sonst in der Welt in Erscheinung getreten sei. 
Wie für D'Estaing ist auch für Winkler die Frage der kollektiven Identität von zentraler Bedeutung. Man begegnet einer kumulativen und sondierten kulturgeschichtlichen Entwicklung, die sich seit der Antike über Rom, Renaissance und Aufklärung bis in die Gegenwart (und nur in Europa) vollzogen hat und die sich von der türkisch-islamischen ontologisch unterscheidet, wobei zum einen Geschichte territorialisiert und transhistorisiert, zum anderen durch den geographischen Fetischismus der Raum naturalisiert wird (vgl. Coronil 2002: 212). Aus dieser Sicht wird Kultur nicht als Prozess, sondern als Struktur verstanden. Die Beteiligten teilen angeblich Normen, Werte und Überzeugungen, die zeitlich konstant sind. Er imaginiert eine »islamische Gesellschaft« und einen »islamischen Geist«, die der Modernisierung, Kolonisierung und alläglichen Politik entgehen. Die demokratischen Errungenschaften, die durch soziale Kämpfe erlangt wurden, werden als etwas gesehen, was man »besitzt«, nicht aber als etwas, das man »macht «.

»Das muslimische Osmanenreich hat rund 450 Jahre lang gegen das christliche Europa nahezu unablässig Krieg geführt; einmal standen seine Heere sogar vor den Toren Wiens. Das ist im Kollektivgedächtnis der europäischen Völker, aber auch der Türkei tief verankert. Es spricht darum nichts dafür, eine solche Inkarnation der Gegnerschaft in die EU aufzunehmen. Das mag man noch als Vorurteil eines Historikers abtun. Doch ändert das nichts an dem Tatbestand, dass eine politische Union über Kulturgrenzen hinweg noch nie und nirgendwo Bestand gehabt hat.« (Wehler, DIE ZEIT: 39/2002)

Wie Winklers basiert auch Wehlers epistemologische Prämisse auf der Annahme, dass die Kulturen als strenge Binaritäten und als abgeschlossene Zivilisationen klare Grenzen haben. Anders als Winkler, dessen Thesen wesentlich vom Diskurs der Aufklärung geprägt scheinen, lassen sich in Wehlers Aussagen zentrale Elemente des exklusiven romantischen Diskurses feststellen, den Andre Gingrich (1999) als »frontier«Orientalismus bezeichnet. Das entscheidende Paradigma dieser Grenzlandmetapher sind Geschichten von »Blut und Boden« bzw. die Türkenkriege, mit ihrer grausamen existenzbedrohenden ersten Phase vor 1683 und ihrer glorreichen Phase nach 1683, so Gingrich. Der »frontier«Orientalismus ist relativ beharrlich, sowohl in der österreichischen Alltagskultur als auch in der Elitenkultur. ${ }^{7}$ Die rhetorische Frage des Rechtspopulisten Jörg Haider im Anti-Ausländer-Volksbegehren lautete

7 Die Bollwerksmetapher wurde für Gingrich in der offiziellen Diktion in den 1970er und 1980er Jahren durch eine Brückenmetapher ersetzt: Österreich als eine Brücke zwischen Nord und Süd, Ost und West. Doch, wie oben diskutiert, ist die Grenze zwischen Brücke und Bollwerk ambivalent und beide reproduzieren die Dichotomie zwischen Ost und West. 
deshalb: „Wozu haben unsere Vorfahren denn gegen die Türken gekämpft, wenn wir sie heute wieder hereinlassen?« (Gingrich 1999: 33). Der damalige Premierminister Österreichs, Schüssel, bezieht sich ebenfalls auf diesen Grenzlandmythos, wenn er sagt, dass man die Türkei »vor der Tür« nicht »verhungern« lassen solle. »Wir« müssten zwar »ihr« die »Tür öffnen«, das müsse aber nicht mittels einer Vollmitgliedschaft geschehen (Schüssel, FAZ: 13.12.2004). Wehlers Ausführungen $\mathrm{zu}$ einer historischen »Inkarnation der Gegnerschaft» unterscheiden sich kaum von denen Haiders. Während bei Winkler die liberal-demokratischen Werte und kulturellen Differenzen ihren Sinn nur noch aus ihrem Einsatz gegen »Andere« beziehen, dient bei dem Sozialdemokraten Wehler das Bild vom nicht-christlichen aggressiven Türken dazu, die eigene Identität $\mathrm{zu}$ konstruieren. Beide zielen mit unterschiedlichen Deutungsstrategien auf die Exklusion des Anderen.

Insbesondere seit 2002 werden weniger die kulturellen Differenzen zwischen Türkei und Europa hervorgehoben und das Europäischsein der Türkei zur Disposition gestellt. Der Schwerpunkt wird, wie die folgenden Aussagen europäischer Politiker verdeutlichen, vielmehr auf die Aufnahmefähigkeit bzw. Finalität Europas verlegt und mit Begriffen wie »Zerklüften«, »Untergraben«, »Überdehnen« und »Zerfallen« gefüllt. Der Beitritt eines Kandidaten in die EU hängt jetzt nicht mehr allein von seiner Fähigkeit ab, sich den europäischen Kriterien anzupassen. Neben der Beitrittsfähigkeit der Kandidaten sollte nun die Aufnahmefähigkeit der EU in Betracht gezogen werden. Die Gründe dafür liegen, so Stoiber, »in der Größe des Landes, in seiner im Vergleich mit der EU sehr geringen Wirtschaftskraft sowie nicht zuletzt in den unterschiedlichen gesellschaftlichen Entwicklungen, die EU und Türkei in der Vergangenheit durchlaufen haben«. All das würde »gewaltige Veränderungen« für die »Natur« der EU bedeuten (Stoiber, SZ: 11.12.2002). Roland Koch und Angela Merkel zufolge wären durch einen türkischen Beitritt die europäischen Strukturen und die »Bindungskraft von gemeinschaftlichen Institutionen überfordert» (FAZ: 07.12.2002; FAZ: 20.12.2002). Dem französischen Innenminister Sarkozy (seit 2007 Staatspräsident) zufolge würde man es wissen, wenn die Türkei zu Europa gehörte. Es sei zwar gut, dass mit Verhandlungen begonnen würde, das Ergebnis solle jedoch keine Vollmitgliedschaft sein, sondern eine »privilegierte Partnerschaft« (Sarkozy, ZAM: 19.12.2004). Der türkische Beitritt ist Winkler zufolge »ein Problem von historischer Bedeutung«. »Über das künftige Verhältnis zwischen der Türkei und Europa darf man nicht ohne Rücksicht auf die Geschichte und Zukunft Europas entscheiden« (Winkler, FAZ: 11.12.2002). 
Der exklusive Diskurs verbindet also die »Zukunft Europas« mit einer orientalistischen Kulturvorstellung, und diese schlägt er als ein Ideal von politischer und kultureller Integration vor. Er geht davon aus, dass das nationalstaatliche Ideal auf die europäische kulturelle Identität Europas übertragbar ist. Die Methodologie des Nationalstaates soll nun nach ähnlicher Logik zur europäischen kulturellen Kohäsion führen. Er ähnelt dabei dem romantischen Diskurs des späten 19. und frühen 20. Jahrhunderts, den Andrea Polaschegg (2005) deutschen Orientalismus nennt, wobei die Osmanen im 19. Jahrhundert in der deutschen (und europäischen) Wahrnehmung eine Größe darstellten, welche sich für den deutschen Identitätsbildungsprozess als Katalysator bot. Das Gegenbild der nicht-christlichen »Türken« half, auf diese Weise einen kulturgeschichtlichen Ursprung des Eigenen zu konstituieren, der das christliche Moment aus seinen orientalischen Bindungen löste und gleichzeitig die Verbindung zur mythischen Vorzeit beibehielt (vgl. Polaschegg 2005: 250ff). Wie im theoretischen Teil erörtert, unterschied sich der deutsche Orientalismus vom englischen und französischen insofern, als er nicht an den Orient im Außen, sondern vielmehr nach innen, an Europa und den »internen Orient« gerichtet war. Es handelte sich um ein »deutsches Problem«, nach Pollock, und zwar ausschließlich um das der eigenen Identität, die auf der Suche nach einem mythischen authentischen (arischen) Ursprung war. Dieser orientalistische Diskurs konstruierte eine »historische deutsche Essenz«, um den »deutschen Platz« in Europa zu definieren (vgl. Pollock 2000: 305ff).

Der gegenwärtige exklusive Diskurs zielt darauf ab, als Machtbalance gegenüber den USA aus der EU einen starken handlungsfähigen Bundesstaat zu machen. Das erfordert, in eine europäische Identität zu investieren, die kulturell »belastbar« und politisch-strategisch handlungsfähig ist. ${ }^{8}$ Dabei mobilisiert er über den bedrohlichen Osten eine defensive europäische Identität. Er intendiert in diese imaginäre »Islamische Welt«, der die »zerrissene« Türkei »teilweise« angehört, zu penetrieren, möchte sie jedoch zugleich auf Distanz halten. Er zielt also auf die Aussperrung des Anderen $\mathrm{ab}$, möchte zwar nach »Osten« drängen, doch der türkische »Drang nach Westen« muss abgewehrt werden.

8 Die Forderung nach einem starken handlungsfähigen Europa begründet sich Balibar zufolge entweder als "a demand for a check and balance, in order to countervail the American (super) power, or a demand for mediation within the swar of civilizations $<$ that America is now apparently waging « (Balibar 2002/2003: 14). Im ersten Fall wird eine strategische Logik verfolgt, wo Machtbeziehungen sich in militärischen Begrifflichkeiten artikulieren, im zweiten Fall eine moralische normative Logik, die Gewaltbeziehungen nicht ausschließt, sie jedoch als einen Aspekt eines sich vertiefenden Prozesses der kulturellen Transformation betrachtet. 
Wolfgang Koydl (SZ) stellt die Frage, ob die Türkei einen selbstverständlichen Platz in Europa habe wie Polen oder Ungarn. Denn es seien nicht nur die schlechten Wirtschaftsdaten, die Demokratiedefizite und der Krieg in Kurdistan, die den türkischen Beitritt verhinderten, sondern religiöse Signale, die nach Osten und nicht nach Westen wiesen. Die türkische Gesellschaft selbst suche nach einem neuen Weg, wobei unklar sei, ob sie sich dabei am »Koran oder am Kemalismus« orientieren werde (Koydl, SZ: 11.03.1997). Die Türken sollten sich fragen, ob sie sich wirklich von Finnen, Portugiesen oder Griechen in ihre vielfältigen Interessen im Schwarzen Meer, im Kaukasus und in Zentralasien hereinreden lassen wollten. Eine ehrliche Antwort der Europäer würde den Türken helfen, sich von der »Euro-Fiktion zu befreien« und andere Modelle der Kooperation mit dem Westen zu entwickeln. Falls dies nicht geschehe, sei der weitere Weg vorgezeichnet: Doch dann gäbe es tatsächlich nur noch eine Alternative, die islamistische (Koydl, SZ: 14.02.1997).

Bezug nehmend auf das Bild vom »unehrlichen Europa« in der Türkei weist Koydl auf die europäische Unehrlichkeit hin, die der Türkei die "geheime Wahrheit« entzieht, indem es ihr keine ehrliche (abschlägige) Antwort gibt. Sein orientalistischer Text ist mit der türkischen nationalistischen Phantasie dialogisch verfasst. Koydl redet von einer »kranken Türkei«, die nicht europafähig sei, er sucht eine ehrliche Antwort des Westens, die die »Türken wieder gesund macht«, da sie sich dadurch von ihrer »Europafiktion« befreien und »andere Modelle der Kooperation« in Gang setzen würden. Die Bezeichnung »krank« knüpft an die orientalistische Bezeichnung für das Osmanische Reich im 19. Jahrhundert als »kranker Mann am Bosporus« an. Dabei rekonstruiert er ein Bild von der Türkei, in dem diese weder dem Westen noch dem Osten zugehörig ist. Sie liegt zwischen »zwei Stühlen«, hängen geblieben zwischen Europa und Islam, Moderne und Mittelalter, und weiß nach wie vor nicht, in welcher Richtung sie sich bewegen soll. Sie bildet weniger eine Brücke, sondern manifestiert vielmehr eine »Zerrissenheit« zwischen West und Ost, Fortschritt und Rückschritt, »Kemalismus und Koran«, sie befindet sich in einer Identitätskrise, wobei es auch dem Kemalismus für Koydl an westlichen Normen zu mangeln scheint, er scheint irgendwie nicht genug europäisch bzw. nicht modern genug zu sein, denn auch wenn die »Imitation« in der Türkei gut gelungen sein mag, kann sie für Koydl mit dem »Original« doch niemals identisch werden. Koydl verfolgt eine essentielle orientalistische Entweder-OderLogik. Das Europäische ist dabei das, was nicht islamisch ist, und das Islamische etwas, was nicht europäisch sein kann. Wie Winkler geht er von einer »Unvereinbarkeit« des Islams mit »westlicher Identität« aus. 
Er unterstellt, die kulturelle »Essenz« der Gesellschaften auf der anderen Seite des Mittelmeers sei der Islam, und diese gemeinsame islamische »Essenz« sei unvereinbar mit der westlichen Identität (vgl. Kutz/Weyland 2000: 26; Asad 2003: 165).

Für den romantischen exklusiven Diskurs existiert also insgesamt ein »Westen« und eine »Islamische Welt«, die selbstverständlich da sind und sich grundsätzlich voneinander unterscheiden. Er konstruiert zugleich ein imaginäres »Ost und West«, während Differenzen für natürlich erklärt werden und damit eine absolute, unabwendbare Präsenz erhalten. Türkei und »Islamische Welt« erhalten dabei die Funktion des Zitierens und Hinweisens, eine stetige Bezugname auf das, was bereits existiert, different und bedrohlich ist. Der exklusive Diskurs konstruiert die Türkei als »historisches Problem« und plädiert dafür, eine »Zukunft« auf der Basis einer mythischen partikularistischen »Vergangenheit« aufzubauen. Bei der Orientalisierung der diskursiven Formation betont der exklusive Diskurs nicht nur den normativen und ontologischen Unterschied zwischen (vorgestelltem) europäischem Selbst und türkischem Anderen bzw. »Islamischer Welt«, sondern darüber hinausgehend auch seine positionelle Überlegenheit. Er unterstellt dabei gleichzeitig die kulturelle Vorherrschaft eines vollkommenen, einheitlichen Europäischen mit Hilfe eines mangelnden chaotisch-bedrohlichen Anderen.

Bemerkenswert ist hierbei nicht, inwieweit dieser Diskurs die Türkei richtig oder falsch repräsentiert, sondern vielmehr, wie symbolische Grenzen gezogen und innereuropäische Antagonismen/Differenzen maskiert werden und somit welchem Zweck diese Geschichten dienen. Kaum hat die Türkei es seit 1999 nahezu geschafft sich »durch ihr Benehmen« zu integrieren, artikuliert der exklusive Diskurs die Gefährdung des europäischen Projektes und die prinzipielle Unmöglichkeit des türkischen Beitritts. Es ist die Verundeutlichung der Grenzlinie zwischen West und Ost in der Gestalt der Türkei, die die kulturalistische exklusive Identität beunruhigt. Es ist die symptomatische Ambivalenz des türkischen Fremden, die jene formative und versetzende Leistung hervorbringt, deren Präsenz in der deutsch-europäischen Gesellschaft die Frage hervorbringt, was das europäische Eigene und was das nichteuropäische Andere ist. Der Diskurs versucht die Risse seiner symbolischen Ordnung, die durch »unentscheidbare« Praktiken des türkischen Anderen verursacht werden, zu nähen. Insofern verhindert und ermöglicht die Türkei zugleich die Konstruktion einer solchen »robusten« europäischen Identität. Zum einen erinnert sich der exklusive Diskurs durch das interne (wie z.B. die muslimischen Migranten) und externe Andere, des eigenen Mangels einer »homogenen« harmonischen europäischen Gesellschaft, der Mangel selbst erhält eine Kohärenz und einen 
Körper wiederum durch dieses Andere. Es entsteht ein Moment der Äquivalenz, in dem die innereuropäischen Antagonismen zum Ausdruck kommen.

Wie der nationalistische Okzidentalismus, auf den im Folgenden eingegangen wird, popularisiert der exklusive orientalistische Diskurs über einen Diskurs von Gefahr eine orientalistische europäische Identität, die effektiv Europäer zu mobilisieren in der Lage ist. Durch diese diskursiven Praktiken transformieren sich somit Identität und Differenz in eine Selbst-Andere-Beziehung. Es wird eine robuste Identität sichergestellt, die allerdings dadurch verletzbar wird, dass sie im selben Zug ihre Gegenidentität konstruiert, die sie omnipräsent bedroht (vgl. Campbell 1998).

\section{Das doppelgesichtige Europa}

Der Streit zwischen Kemalisten und (konservativen) Islamisten über die Säkularität und die »authentische« türkische Kultur ist seit den 1970er Jahren eine der schärfsten Auseinandersetzungen in der türkischen Öffentlichkeit. Es ist ein symbolischer Kampf, der sich um die Frage dreht, was diese authentische Kultur ausmacht und was nicht. Die Islamisten würden die modernen Reformen von Atatürk zunichte machen, um einen islamischen Staat zu errichten, verteidigen sich die Kemalisten. Diese »unzeitgenössische Mentalität« würde das Land in die »Dunkelheit des Mittelalters« zurückwerfen. Sie würde rückschrittliche arabische Werte und Normen in die moderne europäische Türkei importieren.

Die konservativen Islamisten dagegen betrachten den Islam als authentisch türkisch und lasten den Kemalisten an, dass sie nicht nur die Technologien des Westens, sondern auch seine fremden kulturellen Werte imitieren würden. Anti-europäische Bekundungen sind etablierte Motive, die sowohl von Kemalisten als auch von Islamisten geteilt werden. Wie ich im Teil III über die Türkei aufgezeigt habe, bewegt sich dieser Antagonismus dabei zwischen dem Dualismus »Kultur« und »Zivilisation«. Dem Westen wird die Rolle des konstituierenden Anderen für die islamische Identität zugeschrieben und die Kritik am Kemalismus über die Dualismen Kultur-Zivilisation und Ost-West betrieben. Hierbei liegt eine essentialistische, okzidentalistische Betrachtung des Westens vor. Exemplarisch sollen dann vom Westen auch nur die »technischen« Elemente übernommen werden, während die eigene östliche sinnstiftende »Kultur« erhalten werden soll, denn die westliche Zivilisation sei sinngemäß ein Unglück, lediglich Maschinengetöse und Technik. Wie Chatterjee beobachtet, ist genau dieser Widerspruch der Aus- 
gangspunkt eines inversen Orientalismus, der sowohl den Westen als auch den Osten essentialisiert und gegenüber dem Eurozentrismus einen Afrozentrismus ${ }^{9}$ hervorbringt, wonach alles seinen Ursprung im Osten habe. Der Westen wird als einheitliches Subjekt konstruiert, der gleichzeitig eine leere Hülse ist, die die inneren Widersprüche ausschließt und somit als Schnittstelle die beiden Diskurse zusammenführt. ${ }^{10}$ Die Phantasie eines »unehrlichen, hinterhältigen Europas« kennzeichnet das Moment, in dem der Antagonismus zwischen beiden Diskursen maskiert wird und sich die Grenzen der ethnonationalistischen und okzidentalistischen Phantasie des Türkischseins manifestieren. Hierbei dominiert die Logik der Differenz, die nach innen eine türkisch-muslimische »Schicksalsgemeinschaft « konstituiert.

\section{Nationalistischer Okzidentalismus}

Die konservativen Islamisten (RP/FT) stellen eine Verbindung zwischen den Kopenhagener Kriterien und dem Reformprozess während der »Tanzimat-Periode« her, zwischen Tanzimat-Bürokraten und heutigen EU-Befürwortern, zwischen europäischen Staaten im Zeitalter der Kolonisierung und der EU. Im Gegensatz dazu manifestiert sich im kontraeuropäischen Diskurs jene obsessive Phantasie des türkischen Nationalismus, die sich Anfang des 20. Jahrhunderts herausbildete. Sie überlebte den Kalten Krieg, und hat mit der kurdischen Frage und den politischen Kriterien Europas einen »realen« Körper erhalten. Das Sèvres-Syndrom, das die Angst der Türken vor der Zerstörung ihres Staates begründet, ist

9 Laut Chen stellt Kwame Antony Appiah in seinem Buch »Europe Upside Down: Fallacies of the New Afrocentrism« fest, dass im Bereich der Afrikanischen Studien im Westen zwei diskursive Positionen zu sehen sind: Zum einen hat sich gegen den eurozentristischen Orientalismus ein sog. Afrozentrismus als eine Form des Okzidentalismus herausgebildet. Zum anderen formierte sich eine Position, für die Europa weder ein idealer Typus noch ein Modell ist, das von nicht-westlichen Gesellschaften imitiert werden sollte. Für die Ersteren ist der Ursprung der westlichen Kultur in der afrikanischen kulturellen Kreativität zu suchen. Demzufolge liege dieser Ursprung nicht in der griechischen Antike, sondern in Ägypten. Laut Chen wird dieser Afrozentrismus von Appiah als »simply Eurocentrism turned upside-down « bezeichnet. Er sei eine reine Reaktion auf den Eurozentrismus (vgl. Chen 1995: 941f).

10 Dabei handelt es sich um eine diskursive Koalition, die aus einer Reihe von politischen Parteien, Zeitungen, Journalisten, Gewerkschaften, Akademikern und Politikern besteht. Es sind Kemalisten (CHP, CUM, DSP; das Militär, bestimmte nationalistische Gewerkschaften), konservative Islamisten (FT), ZAM (bis 2002), Ultranationalisten (MHP, BBP), nationalistische Linke (IP), die sich entlang dieses negativen Bildes symbolisch integrieren. 
benannt nach dem Vertrag von Sèvres 1920, der die Aufteilung des Osmanischen Reiches geregelt und eine kleine Resttürkei vorgesehen hatte. Diese Phantasie, die ständig Verschwörungen der Nachbarstaaten und der westlichen Mächte artikuliert, bildet den zentralen Referenzpunkt des türkischen Nationalismus.

Der Diskurs weist darauf hin, dass die Beitrittsbedingungen eigentlich die alten Bedingungen des Sèvres-Vertrags seien. Europa möchte nun dieses alte "Versprechen" umsetzen und das Lausanner Abkommen ${ }^{11}$ Schritt für Schritt außer Kraft setzen, die Türkei spalten, das Land teilen. Das, was die Europäer mit militärischer Gewalt nicht geschafft hätten, würden sie mit Hilfe einer »schlauen hinterhältigen Diplomatie« umsetzen. Beide Diskurse ziehen unterschiedliche »staatliche Gesichter« an und verfolgen nationalistische Deutungsmuster. Der politische Islamismus ist zwar Symptom des säkularistisch-zentralistischen Kemalismus, er formiert sich jedoch in einem dialogischen Prozess mit ihm, wobei er sich kaum vom türkischen Nationalismus distanziert.

Ilhan Selçuk (CUM), einer der prominentesten kemalistischen Cumhuriyet-Kolumnisten, vergleicht den pro-europäisch eingestellten Primeminister Tayyip Erdoğan (AKP) mit den Tanzimat-Bürokraten. Mit Reşit Paşa (Hauptfigur der Tanzimat-Reformen) habe eine politische Tradition angefangen, in der bestimmte Politiker mit der Rückendeckung ausländischer Mächte im Inneren an Einfluss gewinnen wollten. So habe es bereits Politiker in der türkisch-osmanischen Geschichte gegeben, skandiert Selçuk, die derartig pro-europäisch und liberal eingestellt gewesen seien. Warum sei das Osmanische Reich dann trotzdem auseinandergefallen und aufgeteilt worden, warum sei es diesen Tanzimatisten nicht gelungen, das Reich zu retten, fragt er.

»Von Anfang an mögen die Europäer uns nicht, aber wir sind verliebt in sie, heute wie damals sind wir pro-europäisch, wir geben alles, was sie von uns wünschen. Es ist eine einseitige krankhafte und hoffnungslose Liebe. Amerika und Europa halten die Türkei in ihrer Hand, und sie spielen so, wie sie es wollen.« (Selçuk, CUM: 12.12.2002)

Die Kemalisten sprechen von einer »verlassenen, getäuschten« Türkei, deren »Stolz stets verletzt« würde. Sie verdiene nicht ständig »schika-

11 Im Vertrag von Lausanne (1923) wurden die Bestimmungen des nach dem Ersten Weltkrieg abgeschlossenen Vertrags von Sèvres revidiert. Die Türkei erhielt den Großteil Armeniens, Südostanatoliens, Ostthrakien (der europäische Teil der heutigen Türkei) sowie Smyrna (Izmir). Der Vertrag regelte die Rechte vor allem der nicht-muslimischen Minderheiten in der Türkei sowie der muslimischen Minderheiten in Griechenland und bezog sich somit auf Religionsangehörige, aber nicht auf Ethnien. 
niert« zu werden und solle Europa endlich ihre »Zähne zeigen«. Die Türkei müsse trotz ihrer Leiden sich selbst und der Außenwelt beweisen, dass sie »selbstständig auf eigenen Füßen« stehen könne (Ateş, CUM: 23.12.1997). Es entstehe eine Mentalität, die davon ausgehe, dass ohne europäische Ratschläge die »türkischen Missstände« nicht aufgehoben werden könnten, dass man ohne sie »nicht einmal ein Mensch wird" (Som, CUM: 18.12.2002). Kamran İnan sagt, Europa mische in den türkischen »nationalen Zement chemische Stoffe« ein, um das "große Stück in kleine Stücke zu zerteilen«, um so den Vertrag von Sèvres schrittweise umzusetzen (İnan, ZAM: 15.12.2004).

Der Angst, dass die gesamte Welt gegen »uns« sei, niemand »uns« möge, dass "wir« das ungewollte »Adoptivkind «" Europas seien und immer ungerecht behandelt würden, sind typische Komponenten dieses kontra-europäischen Diskurses, der die Symptome des Minderwertigkomplexes manifestiert: ein Zustand des Nicht- Verstanden-, NichtRespektiert-, Nicht-Anerkanntwerdens und das Gefühl der Isolation (vgl. Akçam 1995: 43ff). All das führt dazu, dass die konservativen Islamisten die osmanische Vergangenheit romantisieren, in der die Osmanen auf drei Kontinenten ihre Pferde ritten und vor deren Schwertern sich alle (europäischen) Nationen fürchteten. Die Kemalisten dagegen beziehen sich nostalgisch auf die Gründungsjahre, die ersten 15 Jahre der Republik zwischen nationaler Befreiung 1923 bis zum Tod Atatürks 1938. Für den konservativen Islamisten Mithat Baydur (ZAM) machten sich seit den Tanzimat-Reformen die Türken auf den Weg nach Europa, jedoch, wenn er diese ungleiche Behandlung sehe - bezogen auf den EU-Beschluss von Luxemburg 1997 - dann gebe er Sultan Abdulhamids II. (1876-1909) Feststellungen Recht:

12 Es ist eine Ähnlichkeit zwischen der polnischen (und russischen) und türkischen nationalen Identität bezüglich der ambivalenten Bedeutung Europas erkennbar. Törnquist-Plewa (2002) weist in ihrem Aufsatz »The Complex of an Unwanted Child « auf eine solche ambivalent-dualistische Bedeutung Europas in der polnischen nationalen Identität hin. In diesem nationalen Diskurs sähen sich die Polen einerseits als »Brücke« zwischen westlichem und östlichem Christentum sowie zwischen Christentum und Islam und nähmen »Europa« als Modell, andererseits fühlten sie sich von Europa bedroht. Aufgrund ihres Minderwertigkeitskomplexes fühlten sich die Polen auch nach 1989 als »das ungewollte Kind Europas«, das stets im Stich gelassen worden sei (vgl. Törnquist-Plewa 2002: 225ff). Auch die nationale Identität Russlands ist Malmborg und Stråth (2002) zufolge traumatisiert durch die Spannung zwischen West und Ost seit seinem Modernisierungsprozess ab dem 18. Jahrhundert (vgl. Malmborg/Stråth 2002: $16 \mathrm{ff})$. 
»Aber es sind die trügerischen Spiele der großen westlichen Mächte, die uns zum Verfall bringen. Diese Mächte provozieren meine Untertanen Schritt für Schritt zur Rebellion und bringen uns somit in Schwierigkeiten. Mit den Geldern, die wir auf diese Weise ausgeben, hätten wir unser Reich vorangebracht, wir finden jedoch keine Gelegenheit. Leider haben wir unser Zelt auf dem Transitionsgebiet der europäischen Wölfe aufgeschlagen.« (Sultan Abdulhamid, zit.n. Baydur, ZAM: 08.12.1997)

Die Europäer beschäftigen Baydur zufolge die Türkei zum einen mit EU-Erwartungen, die stets verschoben würden, und zum anderen kritisierten sie die geostrategische Politik und das unitäre Prinzip des türkischen Staates. Weiterhin unterstütze Europa einerseits diejenigen, die gegen die Einheit des Staates operierten, andererseits wolle es die »Türken« über die Menschenrechte unterrichten (Baydur, ZAM: 08.12.1997). Der nationalistische Diskurs, gerahmt von einer politischen Romantik nach der verlorengegangenen osmanischen Herrschaft, ist auch im Artikel von Mustafa Yazgan (ZAM) zu erkennen. Die »Tanzimat-Periode markiere den Anfang des Verfalls der osmanischen Zivilisation. 1839 sei jenes Datum, das das »osmanische Schicksal« bestimmt habe. »Seitdem haben unsere Feinde den Mut, den Zivilisationsstaat (der Osmanen) mittels offenen und geheimen Allianzen mit verräterischen Organisationen und Banden zu zerschlagen«. Wie Baydur bezieht sich auch Yazgan auf Sultan Abdulhamid II., der den osmanischen Staat und die Nation vor der »verräterischen Allianz zu retten« versuchte (Yazgan, ZAM: 21.12. 1997).

»Ich respektiere immer die europäische Zivilisation, aber niemals habe ich das Christentum dem Islam vorgezogen, es hat keine Überlegenheit gegenüber dem Islam. Ich mag nicht die Europäer willkürlich imitieren. Die Tugend besteht darin, diese Zivilisation unserem Körper anzupassen. Ich habe die guten Seiten dieser Zivilisation an meinen Hof gebracht. Im Yıldız Palast habe ich befohlen, westliche Theaterstücke und Konzerte zu organisieren. [...] Meine Absicht war, dass mein Hof ein Beispiel dafür wird wird, wie die westlichen Normen und Werte von oben nach unten in die osmanische Kultur diszipliniert und kontrolliert zu übernehmen seien. Aber unsere Feinde haben uns keine Gelegenheit gegeben, ihre Absicht war den Staat zu zerschlagen und nicht ihn zu retten.« (Sultan Abulhamid II, zit.n. Yazgan, ZAM: 21.12.1997)

Yazgan aktualisiert diese Aussage und fügt hinzu, dass die Beziehung zwischen EU und Türkei heute genau so sei wie damals, die Europäer inszenierten ein Schauspiel (Yazgan, ZAM: 21.12.1997). Hilmi Yavuz (ZAM), als einer der bekanntesten afrozentristischen Kulturalisten, der den kemalistischen Säkularismus stets kritisiert, weil der Kemalismus 
sich völlig vom Osten, den Osmanen und dem Islam abgewandt bzw. die Türkei »orientalisiert« habe, bedient sich derselben kemalistischen nationalen Mythen. Yavuz macht seine Leser bezüglich der Kopenhagener Kriterien auf ein Legende während der Lausanner Verhandlungen im Jahre 1923 aufmerksam: Nachdem der Außenminister Ismet Paşa als Vertreter der neuen türkischen Republik auf der Lausanner Konferenz die türkischen Forderungen auflistete, so Yavuz, habe der englische Verhandlungspartner Außenminister Lord Curzon ${ }^{13}$ nach dem Ende der Verhandlungen Ismet Paşa vorhergesagt: »Paşa, nun akzeptieren wir eure Bedingungen. Aber ihr seid ein armes Land. Sie werden ja irgendwann notwendigerweise zu uns kommen und um Hilfe bitten. Dann werden wir Ihre Forderungen, die wir heute hier akzeptiert haben, Schritt für Schritt zurückverlangen.«(Yavuz, ZAM: 22.12.2004)

Yavuz deutet die politischen Bedingungen der EU-Mitgliedschaft als Außerkraftsetzen des zum türkischen Gründungsmythos erhobenen »Lausanner Sieges«. Europa bedeute dabei »geheime Operationen«, »hinterhältige Allianzen« und »trügerische Spiele«, die seit der »Tanzimat-Periode« die Absicht hätten, das Osmanische Reich bzw. den türkischen Staat zu ruinieren. In seinem Artikel »Unehrlichkeit ist der Charakter des Westens« schreibt der konservative Islamist Ahmet Selim (ZAM), dass die Türkei vor einem halben Jahrhundert das Mehrparteiensystem etabliert habe, um ein Teil Europas zu werden: Sie sei NATO-Mitglied, im Europäischen Rat, praktiziere in ihren Schulen eine westliche Ausbildung und Millionen von Türken lebten auf dem europäischen Territorium. ") Jetzt sagen sie uns, ihr seid orientalisch, ihr seid anders.< Wenn wir es doch tatsächlich geschafft hätten, so anders zu sein, wie die Europäer es meinen, wären sie nicht in der Lage die muslimische Türkei seit Tanzimat so [ungleich] zu behandeln. Welch ein Schmerz ist das! (Selim, ZAM: 22.12.1997)

Die konservativen Islamisten beziehen sich auf den deutsch-europäischen konservativen Diskurs und stellen dessen exklusive orientalistische Äußerungen als europäischen Gesamtdiskurs dar. Sie phantasieren von den verlorengegangenen goldenen Zeiten, in denen die Osmanen den Europäern machtpolitisch überlegen gewesen seien. Diese Überlegenheit sei lediglich dadurch verlorengegangen, dass die TanzimatBürokraten, Jungtürken und Kemalisten sich maßlos verwestlicht hätten, ihrer Kultur verlustig wurden und die Modernisierung falsch begriffen und umgesetzt hätten. Sie identifizieren sich dabei weniger mit den mo-

13 George N. Curzon (1859-1925) vertrat Großbritannien als Außenminister während der Verhandlungen in Lausanne. Er thematisierte Minderheitenrechte von Nichtmuslimen, insbesondere forderte er ein autonomes Gebiet für die armenische Minderheit (vgl. Eryılmaz 1996: 210). 
dernen Mythen der türkischen Republik, sondern mit dem Mythos der "goldenen glücklichen Zeiten« eines Osmanischen Reiches, das als die EU seiner Zeiten gekennzeichnet wird.

»Heute haben wir Länder um uns herum, die damals ein Teil des Osmanischen Reiches waren, und in Frieden lebten und glücklich waren. Heute haben sie ihre Freiheit, sie finden jedoch keine Ruhe und sind damit unglücklich. Ist es doch offensichtlich, dass sie auf eine Dachorganisation angewiesen sind, die sie regiert [Gemeint ist ein Reich wie das Osmanische, mit einer türkischen Vorherrschaft. B. K.].« (Kamış, ZAM: 08.12.2004)

Wenn es die reformistischen »Jungtürken« - gemeint sind die »Gesellschaft von Einheit und Fortschritt (ITC) « ${ }^{14}$ sowie die Gründer der Republik - und die »hinterhältigen europäischen Spiele« nicht gegeben hätten, so Mehmet Kamış (ZAM), wäre das Osmanische Reich nicht zerfallen, es hätte keinen Krieg zwischen Israel und Palästinensern gegeben, Selbstmordattentate und Staatsterror wären nicht so weit gekommen. Wenn die Osmanen sich so entwickelt hätten wie die USA heute, dann hätte es keinen Genozid in Falludscha (im Irak) gegeben, die palästinensischen Kinder und Jugendlichen würden nicht getötet, der Genozid in Bosnien hätte nicht stattgefunden, Kaukasien und Kosovo hätten noch länger in Frieden gelebt.

»Dass die EU der Türkei immer wieder neue Begründungen abverlangt und Bedingungen stellt, zeigt eben, dass der Westen Angst vor all denen hat, die ihnen nicht ähnlich sind. Im Osmanischen Reich dagegen konnten unterschiedliche ethnische und religiöse Gruppen mit- und nebeneinander leben. Das Osmanische Reich hat die Differenzen akzeptiert, hat nie versucht diese Differenzen zu eliminieren oder sie zu assimilieren. Deswegen ist das Osmanische Reich demokratischer als die EU gewesen, da die EU alles ähnlich machen und assimilieren möchte und vor der Differenz Angst hat.« (Kamış, ZAM: 08.12.2004)

Wie Tanzimat, der »Verfall« und die »Zersplitterung« des Osmanischen Reiches für die konservativen Islamisten ein >Trauma ist und sie sich nach der verlorengegangenen Vormachtstellung zurücksehnen, so sind die »territorialen Verluste« auf dem Balkan und das Abkommen von Sèvres nach dem Ersten Weltkrieg das >Trauma der kemalistischen Nationalisten. Während der Modernisierungs- und Verwestlichungsprozess nach der Gründung der türkischen Republik für die kemalistischen Eliten einen neuen Anfang markiert, einen »richtigen Reformprozess zum

14 Siehe Fußnote 2 im Kapitel IV 
Erreichen des Zivilisationsstandes«, sind für die konservativen Islamisten die kemalistischen Reformen lediglich eine radikale Fortsetzung der falschen Verwestlichungspolitik der Jungtürken, die die osmanischislamische Tradition eliminiert hat. Während die konservativen Islamisten Europäer, Jungtürken und Tanzimat-Reformisten für den Zerfall des Osmanischen Reiches verantwortlich machen, unterscheiden die Nationalisten zwischen den Tanzimat-Reformen im 19. Jahrhundert und der »Atatürk-Revolution« nach der Gründung der Republik. Atatürk habe das Land modernisiert, nicht verwestlicht. Dies sei der Hauptunterschied zwischen Tanzimat und Republik. Die gegenwärtige Politik der Europäisierung sei nichts anderes als die Fortsetzung der »falschen gefährlichen Verwestlichungspolitik« der Tanzimat-Reformisten, da die Bedingungen der EU unter dem Zwang europäischer Patrone verwirklicht würden. Die Republik dagegen hätte die Bemühungen für »das Erreichen des Zivilisationsstandes« nicht mittels äußerer Gewalt, sondern selbstständig aus ihrem eigenen Willen heraus verwirklicht (vgl. Leitartikel, CUM: 13.12. 1999).

Wie im Teil IV erwähnt, bringt die Ambivalenz im türkischen Okzidentalismus widersprüchliche Bedeutungen und Repräsentationen von Europa hervor. Europa ist in der türkischen nationalen Identität ein Objekt der politischen Phantasie, dessen Nicht-Begehren unmöglich ist. Die Annäherung an dieses Objekt erzeugt jedoch eine traumatische Angst. Der Westen wird einerseits begehrt und zum Ziel erhoben, andererseits wird von einem »unehrlichen« und »gefährlichen« Europa gesprochen. Die osmanischen und türkischen Eliten wollten das Land verwestlichen, um dem »Verfall« des Reiches und der kolonialen Invasion nach dem Ersten Weltkrieg entgegen zu wirken. Die Bedeutung des Westens bestand in einem Paradox: Auf der einen Seite importierte man Technik und Güter aus dem Westen, seine Institutionen wurden imitiert, auf der anderen Seite wurde ab den 1850er Jahren zunehmend von der »Habgier« und »Doppelmoral« des Westens gesprochen. Der »Westen« wurde für den »Verfall« des Osmanischen Reiches verantwortlich gemacht (vgl. Mardin 2003a: 277f; 2003b: 239).

Der Diskurs formierte sich in einem Spannungsverhältnis zwischen westlichem »materiellen Außen« und östlichem »immateriellen Innen«. Die Reformen und Imitationen im Materiellen wurden als äußere Notwendigkeiten und Zwänge betrachtet, die das nationale »Wir« aufnehmen musste, doch die türkisch-osmanischen immateriellen Elemente, die als isolierte »authentische Kultur« betrachtet wurden, sollten davon unberührt bleiben. Zivilisation (die westlichen Technologien) wurde als Außen, Kultur als Innen, als nationale Kultur vorgestellt. Auf der einen Seite zeigte der Diskurs Resistenz gegenüber der europäischen »Kolo- 
nialmacht «, auf der anderen Seite akzeptierte er die zentralen Ausgangspositionen der modernen Epistemologie, auf der koloniale Macht sich gründete und rechtfertigte (vgl. Chatterjee 1993: 120). Der Westen bedeutete das »Geräusch von Maschinen«, »eine Kreatur mit lediglich einem verbliebenen Zahn«, eine materielle Zivilisation mit einer geistig verfallenen Kultur (vgl. Ahıska 2005). Als die Hegemonie des Westens sich auf das Osmanische Reich ausdehnte, hatten die Osmanen dem Historiker Taner Timur zufolge zwar Respekt für die Europäer und waren von ihren Technologien beeindruckt, doch hätten sie den Westen nie geliebt (vgl. Timur 1986: 16).

Diese Ambivalenz ist weder mit der Gründung der Republik noch in der Gegenwart verschwunden. Zwischen dem konservativen kulturalistischen Diskurs Anfang des 20. Jahrhunderts und dem heutigen nationalistischen Okzidentalismus kann diesbezüglich eine Kontinuität festgestellt werden. Dem Soziologen Cemil Meriç ${ }^{15}$ zufolge beschwerte sich der konservative osmanische Großwesir Said Halim Paşa in seinem Buch »Buhran-i Fikrimiz« (Die Krise unserer Ideen) 1919 über die ITCReformisten folgendermaßen:

»Das Bedürfnis unseres Landes nach Entwicklung und Fortschritt, [...] brachte bei uns eine denkende Klasse hervor. Diese Intellektuellen herrschen über das Schicksal der Nation (Millet), wie es ihnen beliebt. Sie haben weder Konkurrenten noch Kontrolleure [...]. Sie erzeugen imaginäre gesellschaftliche Krisen und schleppen das Land in eine ungewisse dunkle Zukunft. Sie machen die gesellschaftliche Umwelt schlecht, in der sie leben. Da sie nicht erklären und beweisen können, beschuldigen und verleumden sie [...]. Diese westsüchtigen Intellektuellen/Bürokraten schreiben der Gesellschaft, wie unerfahrene Medizin-Studenten, die Krankheiten zu, die sie aus dem Buch auswendig ge-

15 Cemil Meriç (1916-1987) ist im nationalistisch-kulturalistischen Milieu einer der prominentesten Soziologen. Sein Bekanntheitsgrad kann mit dem des Soziologen Ziya Gökalp Anfang des 20. Jahrhunderts verglichen, und er kann als eine der Hauptfiguren der türkischen afrozentristischen Okzidentalisten bezeichnet werden. Wie Gökalp unterscheidet auch Meriç zwischen westlicher Zivilisation und authentischer türkisch-islamischer Kultur, die durch den Verwestlichungsprozess seit der »Tanzimat-Periode« eliminiert wurde. Demzufolge wurde insbesondere im Zuge der kemalistischen Reformen (und hier insbesondere der Sprachreform) das Kollektivgedächtnis einer »großen Nation« gelöscht. Die westliche und östliche Kultur seien nicht miteinander vereinbar, beide hätten unterschiedliche Prägungen und Ursprünge. Als Antwort auf den eurozentristischen Orientalismus, der seinen Ursprung in der Antike erfindet, sucht Meriç einen romantischen Ursprung im Osten, wobei er Indien und das alte Ägypten glorifiziert. Seit Tanzimat könne die türkische islamische Gesellschaft keine Intellektuellen hervorbringen, sondern lediglich Übersetzer, die den Westen kopierten (Meriç 1995: 345ff; 1996: 9ff). 
lernt haben. Um diese Gesellschaft zu heilen, greifen sie zu Büchern und infizieren sie mit imaginären Krankheiten: Sie haben nur ein einziges vor: die Gesellschaftsstruktur einzureißen. [...].« (Said Halim Paşa 1919, zit.n. Meriç 1996: 61)

Der kontra-europäische Diskurs formiert sich jedoch weniger im kulturellen Rahmen, in dem die Entfremdung der »türkisch-islamischen authentischen Kultur« in den Vordergrund gestellt wird. Vielmehr formiert sich der türkische Diskurs in der EU-Türkei-Debatte in einem nationalistischen Deutungsrahmen. In der türkischen Öffentlichkeit dominiert die Dichotomie zwischen »Europäisierung als Demokratisierung« versus »Europäisierung als Gefährdung nationaler Einheit«. Es findet dabei eine Verschiebung bezüglich der diskursiven Positionierungen statt. Die ehemaligen Träger des Verwestlichugsprozesses bilden heute den kontra-europäischen Block, während seine ehemaligen Gegner den gegenwärtigen pro-europäischen Block bilden. Ersterer akzentuiert die Gefährdung der »Einheit des Staates und der türkischen Nation« durch den Beitrittsprozess, während Letzterer die »Demokratisierung des Landes durch den Beitritt« in den Vordergrund stellt. Nach der Demokratievorstellung der nationalistischen Okzidentalisten müsse die Türkei zwar noch demokratisiert werden, doch sie solle die »nationale Einheit und Sicherheit« und die »laizistischen Strukturen« nicht gefährden. Die Demokratisierung solle ohne »europäische Einmischung« und ohne »äußeren Zwang« vonstatten gehen. Die Türkei habe bestimmte politische »Sensibilitäten«, die nicht verhandelt werden dürften. Die Rolle des Militärs in der Innen- und Außenpolitik sei zwar unerwünscht, aber notwendig, da die Türkei intern und extern bedroht werde. Die Türkei ist insofern »neither caught between nor a successful synthesis of an >East< and a $>$ West $<$. It is, rather, a country in which many of the fundamental social divisions have been experienced, articulated, concealed, or displaced in a cultural/ideological vocabulary mobilizing the $>$ West $<$ in different power and justification strategies« (Irzık/Güzeldere 2003: 285).

Die türkisch-muslimischen Eliten distanzieren sich einerseits von ihrem »Volk«, um sich mit dem Westen identifizieren zu können, andererseits versuchten sie, es vor den westlichen Gefahren zu schützen und von unerwünschten Elementen fern zu halten. Diese Selbsttechnologien kennzeichnen genau an diesem ambivalenten Ort der Grenzziehung zwischen Westen und Osten die türkische Subjektivität, die in dieser spannungsgeladenen Schwankung einerseits westlich sein und andererseits östlich bleiben möchte. Der säkulare Charakter des türkischen Staates unterstützt, wie Irzık und Güzeldere (2003) feststellen, nicht das Klischee über die außerordentliche Rolle der Türkei als Brücke. »It appears, 
rather, as a specific appropriation of one ideal of Western modernity, only partially realized through the exclusion or adulteration of such other ideals as democracy and individual autonomy« (Irzık/Güzeldere 2003: 285).

»Brücke« und »Grenze« sind zwei Seiten derselben Medaille. Die Türkei als Brücke und Grenze, Distanzierung und Annäherung sind Versuche, die »Nation« vom orientalistischen Stigma zu entlasten bzw. es zu beantworten, wobei der imaginäre Westen je nachdem entweder als Freund oder Feind gedeutet wird. Dieses Hin- und Herrotieren zwischen westlich und östlich sein, die Ambivalenz und doppelte imaginäre Konstruktion charakterisieren vor allem die internen Machtstrategien und Grenzziehungstechniken, die sichtbar werden. Gerade die Frage der Minderheitenrechte kennzeichnet den türkischen symptomatischen Mangel, der als türkische »Sensibilität« bezeichnet wird. Dabei hat die politische Phantasie vom doppelgesichtigen Europa einen Funktion: Sie integriert die pro-europäischen Pragmatisten und die kontra-europäischen Nationalisten, indem beide die gleiche Position einnehmen, indem beide Stimmen den internen Subalternen zu maskieren und die Nation zu disziplinieren versuchen.

\section{Minderheiten als interner Okzident}

Im gegenwärtigen türkischen Diskurs um den EU-Beitritt wird sichtbar, dass eines der sensibelsten Themen die Frage nach den kulturellen Rechten von muslimischen (Kurden und Aleviten) und nicht-muslimischen Minderheiten (Armeniern, Griechen und Juden) ${ }^{16}$ ist. Das »unehrliche,

16 Inoffiziellen Schätzungen zufolge handelt es sich dabei um 60000 armenisch-orthodoxe Christen, 20000 Juden, 20000 römische Katholiken, 20 000 syrisch-orthodoxe Christen, 3000 griechisch-orthodoxe Christen, 2500 Protestanten, 2000 syrische Katholiken, 2000 armenische Katholiken, 500 armenische Protestanten und 300 chaldäische Katholiken. Nicht-muslimische Minderheiten in der Türkei stoßen nach wie vor auf Schwierigkeiten, obwohl die Glaubensfreiheit verfassungsrechtlich garantiert und die Religionsausübung weitgehend frei möglich ist. Sie verfügen über keine Rechtspersönlichkeit, müssen eingeschränkte Eigentumsrechte und Eingriffe in die Verwaltung ihrer Stiftungen hinnehmen und dürfen ihre Geistlichen nicht ausbilden. Die Generaldirektion für das Stiftungswesen greift weiterhin in religiöse Stiftungen ein und darf Stiftungen auflösen, ihr Eigentum beschlagnahmen, ihre Treuhänder ohne richterlichen Beschluss entlassen und in die Verwaltung ihrer Vermögenswerte und ihre Rechnungsführung eingreifen. Versuche, auf dem Rechtsweg beschlagnahmtes Eigentum wieder zu erlangen, stoßen auf zahlreiche Hürden (vgl. Oran 2004: 25ff). 
doppelgesichtige Europa« möchte in der Türkei »Minderheiten erzeugen«, so lautet der nationalistische Plot, die die »Einheit der Nation und des Staates« gefährden.

Im Kommissionsbericht von 2004, der die Aufnahme der Verhandlungen mit der Türkei empfahl, wurden die kulturellen Rechte von Minderheiten angesprochen. ${ }^{17}$ In denselben Tagen haben einige kurdische Intellektuelle und Politiker ihre diesbezüglichen Forderungen in einer britischen Zeitung veröffentlicht, die wiederum in mehreren türkischen Zeitungen zitiert wurde. In der Anzeige sprachen sie von den ungerecht behandelten Kurden, die mit dem EU-Beitritt der Türkei auf »eine bessere Zukunft hoffen«, da die Europäische Union sich als eine multikulturelle Gesellschaft verstehe, in der »Demokratie und Frieden« herrsche. Die Türkei müsse, wenn sie europäisches Mitglied werden wollte, ihre kulturelle Diversität respektieren und ihren kurdischen Staatsbürgern die gleichen Rechte garantieren, die Basken, Katalanen, Südtiroler und Wallonen genössen. Diese Rechte seien ja jene, welche die Türkei selbst für die türkische Minderheit in Zypern fordere (HÜR: 10.12.2004). Im Oktober 2004, etwa einen Monat vor dem Kopenhagener Gipfel, besuchte Borrell, der Vorsitzende des EU-Parlamentes, die Stadt Diyarbakır in Ostanatolien).

Bezogen auf diese Meldung sprach Tayyip Erdoğan von einem »Sturzversuch gegen das türkische Regime« und einer »politische Provokation gegen das Zusammenleben«. »Wie können sie diese ehrenvolle Nation, den Geist dieser Geographie, seine Beschaffenheit mit absolut Fremden vergleichen!« (Erdoğan, ZAM: 09.12.2002). Die Kurden seien »Leib und Seele« und ein »eigentlich-ursprünglicher Bestandteil der

171993 hat der Europäische Rat in Kopenhagen den Respekt vor und den Schutz von Minderheiten als eine politische Bedingung für die Mitgliedschaft erklärt, seitdem ist dies ein Aspekt der europäischen Außenpolitik geworden. Mit dem Amsterdamer Vertrag 1997 hat die EU diese Minderheitenrechte nicht in die interne Rechtsordnung eingeführt. Seitdem besteht ein Widerspruch zwischen europäischer Außenpolitik und interner Rechtsordnung. Zwischen neuen und alten Mitgliedern entstand somit ein widersprüchlicher Umstand. Im Jahre 1998 haben alle EU-Mitglieder (bis auf Frankreich, Griechenland und Belgien) den Schutz von nationalen Minderheiten akzeptiert. Der Europäische Rat von Kopenhagen stellte für die Bewerberländer folgende politische Beitrittskriterien auf: institutionelle Stabilität als Garantie für die demokratische und rechtsstaatliche Ordnung, Wahrung der Menschenrechte, Achtung und Schutz von Minderheiten. Im Europäischen Rat in Nizza im Dezember 2000 wurden diese Grundsätze als Grundrechte der EU hervorgehoben (vgl. Kurban 2005: 285ff). 
Republik ${ }^{18}{ }^{18}$ Die türkische Nation ist Erdoğan zufolge gegenüber Minderheiten tolerant, dies dürfe allerdings nicht missbraucht werden. $\mathrm{Er}$ empfehle stets seinen europäischen Freunden, dass sie auch eine der anderen 81 Städte der Türkei wie Erzurum, Konya, Kayseri oder Rize besuchen sollen, statt immer nur Diyarbakır (Erdoğan, HÜR: 24.12.2004). Borells Besuch in Diyarbakır kommentierte Erdoğan als einen Plan derjenigen, die gegen die »türkische Einheit und das Zusammenleben« agierten. Der MHP-Vorsitzende Devlet Bahçeli appellierte an die Bevölkerung von Diyarbakır, den EU-Repräsentanten nicht willkommen zu heißen und ihm eine solche Abfuhr zu erteilen, welche der Stadt Diyarbakır eine »Heldenauszeichnung für seine Tapferkeit von der türkischen Nation« einbringen würde, eine ebenbürtige Auszeichnung, die die Nachbarstädte während des Befreiungskrieges 1919-22 aufgrund ihres »tapferen Widerstandes« gegen die europäischen Besatzer erhalten hatten. ${ }^{19}$ Die Pläne der EU seien immer mit jenen Plänen identisch, die in der Vergangenheit den »türkischen Staat spalten und die Nation zu zerstückeln« beabsichtigten (Bahçeli, HÜR: 13.12. 2004). Mit ähnlichem Sarkasmus fragt auch Kamran İnan (ANAP) danach, warum europäische Politiker, Bürokraten und Kommissionen stets nach Diyarbakır gingen, nicht aber nach Trabzon oder Samsun (Städte am Schwarzen Meer) (İnan, CUM: 14.12.2004).

Die Nationalisten und die Pragmatisten erklären die Gesellschaft zu einem Ort der Gefahr. Die Nation bleibt im Diskurs imaginär, das $»$ Volk« selbst soll vor internen »Parasiten« und externen »Feinden« geschützt werden. Die »Nation« hat für İnan eine »Ehre« und eine »tapfere Geschichte«, doch die reale Gesellschaft selbst ist ein Ort, in dem am meisten »Verräter « aufwachsen. ${ }^{20}$ Die ausländischen Mächte hätten deswegen kaum »Schwierigkeiten«, die Türkei von innen her zu manipulieren (İnan, CUM: 14.12.2004). Er erzeugt ein Bild von einer (naiven) Gesellschaft, die leicht von »Fremden« zu verführen ist. Während man also die Gesellschaft von der staatlichen Macht real fernhalten möchte, propagiert man eine türkisch-muslimische nationale Identität und betont insbesondere ihre Verletzbarkeit.

Für Ali Bulaç, einen der prominentesten islamischen Intellektuellen und Kolumnisten der ZAM, kann die islamische pro-europäische Ein-

18 Paradoxerweise wurde die Aussage »die Kurden sind ein eigentlicher, konstitutiver Bestandteil der Republik« von PKK-Führer Abdullah Öcalan aus seiner Verteidigungsrede im Gerichtsaal zur Sprache gebracht.

19 Urfa wurde Şanlıurfa (Ruhm-Urfa) genannt, Antep Gaziantep (VeteranenAntep), Maraş Kahramanmaraş (Helden-Maraş).

20 In Europa befinden sich laut İnan 407 türkische Vereine, die gegen ihren eigenen Staat tätig seien. 205 Tausend Menschen aus der Türkei agierten gegen den türkischen Staat und seien Verräter (İnan, CUM: 14.12.2004). 
stellung seit dem 28. Februar 1997 nicht auf einen »pragmatischen Strategiewechsel« reduziert werden, der nur dazu diene, eine drohende Militärintervention abzuwenden. Es gehe vielmehr um einen »Mentalitätswechsel«, bei dem die islamischen Eliten sich eingestünden, dass gesellschaftlicher Wohlstand und Befreiung lediglich durch Erhöhung des wirtschaftlichen, politischen und rechtlichen Standards erreichbar seien. Der »28. Februar-Prozess« habe keine andere Möglichkeit für eine demokratische Ordnung außerhalb der türkischen Integration in die EU übrig gelassen. Insofern füge dieses Ereignis langfristig nicht den Islamisten Schaden zu, sondern denjenigen, die diesen Prozess in Gang setzten, also dem Militär und den Kemalisten. Der »28. Februar-Prozess« habe den Formierungsprozess einer neuen »demokratisch eingestellten islamischen Politik« in Gang gesetzt und sie von den bisherigen nationalistisch-zentralistischen Einstellungen abgerückt und somit für Europa und die Globalisierung geöffnet (vgl. Bulaç, ZAM: 10.12.2002).

Die Deutungsstrategien des pro-europäischen Diskurses auf dem Feld der Minderheitenrechte unterscheiden sich jedoch kaum von denen des kontra-europäischen. Auch Ersterer bestimmt die »guten« Seiten der europäischen Demokratie, die man sich zu Eigen macht, und definiert die »schlechten«, "gefährlichen« Seiten derselben, von denen er sich distanziert. Die türkische Nation dürfe, laut Erdoğan, mit »absolut fremden« europäischen Nationen und die Kurden mit absolut »Fremden« nicht gleichgesetzt werden. Erdoğan deutete kurdische Forderungen nach kulturellen Rechten als »Sturzversuch«, als »krebserregenden Stoff«, der die »körperliche Verfassung der türkischen Nation« angreife. Gleichzeitig werden Kurden als »unser Leib und Seele« bezeichnet, die nicht mit »fremden Basken« verglichen werden dürften. Die türkischen Reformbemühungen haben für Erdoğan in der »Weltöffentlichkeit« ein "positives Image« geschaffen, das durch solche »störenden« Forderungen nicht zunichte gemacht werden dürfe (Erdoğan, HÜR: 24.12.2004). Es zeigt sich eine imaginäre Dialogizität mit dem Blick des westlichen Anderen, wobei relevant wird, was der europäische Andere von der Türkei hält bzw. wie die Türkei im Westen erscheint. Er möchte so tun, als ob bereits alles für die Demokratisierung bzw. die Erfüllung politischer Kriterien getan sei. ${ }^{21}$ Mit Mardins Formulierung heißt das: $»$ man sollte

21 Von 2000 bis 2004 wurden sieben Reformpakete verabschiedet: Von der Abschaffung der Todesstrafe, Garantien der Meinungs- und Versammlungsfreiheit über die Aufhebung des Ausnahmezustandes im kurdisch bewohnten Ostanatolien bis zur Unterbindung von Folterpraktiken wurden gewisse Fortschritte gemacht. Die Kurdenfrage ist thematisierbar geworden und die Rolle des Militärs wurde im MGK (Nationalen Sicherheitsrat) teilweise eingeschränkt, erner wurde das Zivil- und Strafrecht grundlegend reformiert (vgl. Kramer 2004). Im Januar 2004 wurde eine neue Verord- 
so tun, als ob alles geworden ist« (zit.n. Ahıska 2005: 91). Mit diesem imaginären Blick des Anderen maskiert er die Differenz der kurdischen und sonstigen internen Anderen. Insofern erscheinen die Reformen weniger als eine Lösung aktueller politischer Probleme, sondern werden vielmehr entweder als Kodex einer gewünschten oder gefürchteten Verwestlichung angesehen. Die Reformen haben in erster Linie einen taktischen und pragmatischen Charakter in dem Spiel, dessen Regeln von Europa festgelegt und beaufsichtigt werden. Wie der Historiker Halil Berktay (1998) feststellt, hat sich in der Türkei eine Art von Formalismus entwickelt, in dem das »Zufriedenstellen der Europäer« in den Vordergrund gestellt wird. Eine Gewohnheit, »die Freiheit und Menschenrechte nicht als Selbstzweck und Tugenden zu behandeln, sondern als Instrumente; eine Überwertung des Scheins vor dem Sein« (Berktay 1998: 162). Es werden Reformen verabschiedet, oder wie im Falle der Minderheitenrechte blockiert, weil diese Forderungen von der EU gestellt werden.

Die politischen Bedingungen des EU-Beitritts werden insbesondere vom nationalistischen kontra-europäischen Block als »Auflagen« und die Erfüllung dieser Bedingungen als »Abstriche« bezeichnet. Für Gülerce (ZAM) wurden auf dem Gipfel in Luxemburg 1997 derartige »Auflagen für die Türkei aufgelistet«, als wäre sie ein »Kriegsverlierer« (Gülerce, ZAM: 15.12.1997). In einem Symposium über den Beitrittsprozess und die Prinzipien der Rechtsstaatlichkeit erzählt der rechtskonservative DYP-Vorsitzende Mehmet Ağar, dass seit Tanzimat alle Reformen unter Auflagen des Westens gemacht würden. Was passiert, wenn sie immer noch mit diesen von »Fremden ausgestellten Rezepten« Reformen durchsetzen, fragt auch der ehemalige Polizeichef und spätere türkische Innenminister Ağar: »Ich sage euch, wir nähern uns dem 17. Dezember 2004, jeder will etwas, sie verhalten sich, als ob die Türkei einen Krieg verloren hat [...].« (Ağar, CUM: 08.12.2004) Der Hochschullehrer und CUM-Kolumnist Erol Manisal1, der eine der bekanntesten kontra-europäischen Figuren ist, veränderte seine Argumentationsstrategie im Jahre 2004. Während er in den Jahren 1997, 1999 und 2002

nung erlassen, die es privaten Fernseh- und Radiosendern ermöglicht, neben der staatlichen Rundfunkgesellschaft TRT in anderen Sprachen als Türkisch auszustrahlen. Trotz dieser Verbesserungen wird die Verordnung weiterhin restriktiv umgesetzt. Den Ausstrahlungen in anderen Sprachen werden strenge zeitliche Grenzen gesetzt (im Fernsehen vier Stunden pro Woche und höchstens 45 Minuten täglich und im Rundfunk fünf Stunden pro Woche sowie höchstens 60 Minuten täglich). Voraussetzung für den Rundfunk auf lokaler und regionaler Ebene ist die Erstellung eines Hörer/Zuschauerprofils durch den RTÜK (vgl. Kommission der europäischen Gemeinschaften 2004: 40). 
stets von der »Aufnahmefähigkeit« der EU gesprochen hatte, und zwar, dass die EU ein Land wie die Türkei mit 70 Millionen Menschen, Armut und Arbeitslosigkeit nicht zu integrieren in der Lage wäre, spricht er von nun an von einem westlichen Imperialismus, der die Türkei okkupiere.

»Im Namen des Westens okkupieren diese Kollaborateure die Regierung. Nicht die Türkei tritt in die EU ein, sondern Europa penetriert die Türkei [...] Die >Besatzungsmedien` [gemeint sind pro-europäische Medien] feiern mit Chirac, Schröder und Berlusconi. Sie feiern zusammen die europäische Besatzung der Türkei. Es wird gegen die Türkische Republik gefeiert, die von Atatürk gegen den westlichen Imperialismus gegründet wurde. Das ist keine Feier von 70 Millionen, sondern von einheimischen Kollaborateuren und von Imperialisten. Diejenige Mentalität, die während der Besatzung (1920 Besetzung von Istanbul durch England) Fußballturniere mit den Besatzungsarmeen organisierte, stößt heute feierlich mit Schröder, Chirac und Berlusconi an.« (Manisalı, CUM: 08.11.2004)

Die Europäer teilen das, was als harmonisch gedacht wird, sie zerstückeln das, was als einheitlich vorgestellt wird. Die nationalistischkemalistischen Bedrohungserzählungen sind Versuche, den Riss in der türkischen Nation zu nähen, um ihren strukturellen Mangel abzudecken. Die Unvollständigkeit der Identität, das die türkische Nation nicht vollständig harmonisch, nicht ausschließlich muslimisch und nicht ganz türkisch ist, wird verdeckt. Das »doppelgesichtige unehrliche Europa« zeigt genau diese Abwehr des kontra-europäischen Blocks, es verdeckt sowohl die inneren Ambivalenzen und Antagonismen des türkischen Selbst als auch die Differenzen innerhalb des europäischen Anderen. Das negative Bild von Europa externalisiert die internen Konflikte und Antagonismen, die Verantwortung für diese Konflikte wird nach außen übertragen. Dabei bleiben Europa und die türkische Nation immer abstrakt und imaginär. Mustafa Balbay (Hauptkolumnist der CUM) schreibt in seinem Artikel »Europa, kranker Mann der Türkei!«:

»Die europäischen Freunde raten uns immer, wenn wir über unsere Sensibilitäten berichten, dass wir uns von dem 〉Sèvres-Syndrom〈 befreien sollen. Doch nicht wir, sondern die Europäer haben das `Sèvres-Syndrom`. Man sieht es heute noch auf in manchen europäischen Staaten verwendeten Landkarten, in denen viele unserer Regionen mit dieser Sèvres-Phantasie eingezeichnet sind. Ein Touristenführer hat mir eine von einer Kirche verteilte Landkarte für europäische Touristen gezeigt. Viele Orte in Anatolien waren gekennzeichnet und mit >Auf uns wartende Landschaften< kommentiert." (Balbay, CUM: 06.12.2002) 
Balbays Sorge bezüglich der angeblich von einer Kirche verteilten Landkarte ähnelt der von Jungtürken und türkisch-osmanischen Eliten. Anfang des 20. Jahrhunderts bis zum Ende des Ersten Weltkrieges artikulierten sie Angst vor territorialen Verlusten und der Spaltung des Reiches, als das Osmanische Reich einen großen Teil seines Territoriums auf dem Balkan verlor (Mazedonien, Bulgarien, Saloniki etc.). Dieselbe Sorge spiegelt sich in der Äußerung eines osmanischen Abgeordneten des ITC vor dem Parlament während des Balkankrieges 1912-13:

»Eine lebhafte Konspiration wird fortgeführt, Kreta ist verloren, Ägypten wird verloren, die Türkei wird verloren gehen, Islam wird verloren gehen [...] In dieser Woche habe ich die Landkarte angeschaut, vieles ist verloren gegangen, wenig ist übrig geblieben. Dieses Wenige wird auch verloren gehen.« (Hanioğlu 1985, zit.n. Akçam 1995: 90)

Der imperialistische Westen hätte sich - laut Jungtürken und kemalistischen Eliten - > unter dem Deckmantel der Menschen- und Minderheitenrechte (von christlichen Minderheiten) in die inneren Angelegenheiten des Reiches eingemischt und das Reich dadurch zersplittert. Wenn die Nase eines Christen blutete, hätte der Westen rebelliert, doch als Tausende von Muslimen und Türken auf dem Balkan ermordet wurden, hätten sie lediglich zugeschaut (Kocabaş, zit.n. Akçam 1995: 83). Die christlichen Minderheiten (auch die Armenier) hätten die Muslime (Türken) getötet und das Reich provoziert, und als die Muslime darauf reagierten, hätten sie sich in den westlichen Medien als Opfer eines Genozids dargestellt, um die Einmischung des Westens zu ermöglichen. »Was die in unserem Land lebenden christlichen Elemente erlebt haben [...] ist die Folge ihrer barbarischen separatistischen Politik durch den Missbrauch ihrer Privilegien« (Atatürk, zit.n. Akçam 1995: 85).

Anatolien war nicht nur ein imaginärer Ort für die Gründer der Republik, sondern es wurde durch Zwangsmigration und Deportation als türkisch konstruiert, wobei Christen durch Muslime ersetzt wurden. Im Vergleich zu anderen Gebieten des osmanischen Territoriums war Anatolien für ITC und die Gründer der Republik immer türkisch und immer authentisch. Die Gründer der Republik erfanden Anatolien als kulturelle Essenz der türkischen Nation. In Abgrenzung zur osmanischen Tradition und gegen den multikulturellen Charakter Istanbuls wurde die bisher unbekannte kleine Stadt Ankara in der »Wüste« Mittelanatoliens zur Hauptstadt der Republik und modernen Kapitale nach westlichem Vorbild aufgebaut. Die kurdischen Aufstände wurden entweder auf die »rückständigen feudalen Strukturen« zurückgeführt, als »Einmischung ausländischer Mächte« und »islamistischer Fundamentalismus« gekenn- 
zeichnet oder als Aufstand »krimineller Räuber« diskreditiert (vgl. Yeğen 2003) und mittels militärischer Maßnahmen eingedämmt. Der Staat hat gespalten, reguliert, abhängige Beziehungen hergestellt und kolonisiert. Einige Elemente der osmanischen staatlichen Mechanismen wurden transformiert, mit einigen (türkisch-muslimischen) Eliten des alten Regimes wurden Allianzen gebildet, andere wurden neutralisiert (vgl. Keyder 1998: 30f; Kaliber 2002: 109f). Der Diskurs vom nationalen »Fortschritt« stärkte den Staat, diesbezüglich war der Populismus das zentrale diskursive Repertoire, um zu regieren und $\mathrm{zu}$ regulieren (vgl. Keyder 1998: 32f). Dieser Diskurs konstruierte einen Gründungsmythos; der real erfahrene Genozid, die Deportationen und ethnisierten Konflikte wurden während des Krieges und auch danach maskiert. Die Erinnerung an das brutale »demographische Management« wurde aus dem kollektiven Gedächtnis gelöscht (vgl. Keyder 2003). Da nun die nationale Identität nicht mehr über die erfahrenen Praktiken konstruiert werden konnte, weil die Erfahrungen und Differenzen verdrängt wurden, musste eine mythisierte nationale Geschichte neu erfunden werden. Von heroischen Denkmälern bis zu ethnographischen Spezifitäten, von Volksmusik und Legenden bis zu Ritualen und Symbolen wurde die nationale Matrix aufgebaut (vgl. Keyder 1998: 37). Nur mit Hilfe von Mythen und politischen Phantasien konnten eine Geschichte rekonstruiert, die erfahrenen Realitäten stigmatisiert, gegen kritische Reflexion immunisiert und eine symbolische Schließung erreicht werden. Deshalb ist der türkische Nationalismus ein Mechanismus zur Kontrolle, zur sozialen Mobilisation für die Modernisierung, zum Verdecken von Deportationen und Völkermord sowie zur Grenzziehung gegenüber als »rückständig« dargestellten internen Anderen.Jeder Hinweis in der gegenwärtigen EUDebatte auf die Existenz von Minderheiten wirkt deswegen symptomatisch. Ilhan Selçuk (CUM) äußert, er habe die EU für eine demokratische Vereinigung in Wirtschaft und Justizwesen gehalten. »Doch die EU-Staaten verstehen die EU als eine historische und politische Abrechnung mit der Türkei. Wie viele Schmerzen, die sie unter osmanischer Herrschaft erlitten haben, möchten sie nun rächen? Mehr noch, sie wollen die Ethnizitäten in Anatolien aufhetzen« (Selçuk, CUM: 08.12. 2004).

Beide, pro-europäischer und kontra-europäischer Diskurs, unterscheiden zwischen »ursprünglich-originalem Bestandteil der türkischen Republik« und »sekundärem nicht-originalem Bestandteil« (Minderheiten). ${ }^{22}$ Somit imaginieren sie eine harmonische einheitliche »Nation«,

22 Mesut Yeğen (2004) stellt fest, dass alle türkischen Verfassungen (von 1921, 1924, 1961 und 1980) das Türkischsein beschreiben. In diesen Definitionen finden sich sowohl ethno-kulturelle als auch politisch-territo- 
die sich qualitativ und authentisch von (nicht-muslimischen) Minderheiten abhebt. ${ }^{23}$ Hier gibt es einen wesentlichen Aspekt, der in diesem Kontext bisher nur am Rande behandelt wurde: Der türkische Laizismus ist nicht etwa eine Trennung von Religion und Staat, vielmehr reguliert und kontrolliert er den Islam, und hebt gegenüber diversen christlichen Minderheiten einen nationalisierten Islam hervor. Wie Leyla Neyzi (2002) bezüglich der »Dönme « ${ }^{24}$ in der Türkei feststellt: $»[D o ̈ n m e]$ points up the Janus-faced character of Turkish national identity: while Kemalism [...] was based on modernist values predicated on a rejection of tradition, Turkishness continued to be defined vis-à-vis Sunni Muslim heritage identified with an imagined Turkish ethnicity« (Neyzi 2002: 138).

Während man die Gesellschaft von der staatlichen Macht real fernhalten möchte, propagiert man eine türkisch-muslimische nationale Identität. Der staatliche Nationalismus unterstreicht vor allem die Existenz der internen und externen Feinde, die die türkische Existenz bedrohen. In der politischen Kultur hat »Einheit» versus »Spaltung« eine symbolische Dimension und einen stark zynischen Charakter. Nicht die argumentative Debatte und die deliberativen Prozesse, sondern die semantischen und manipulativen Formen prägten die EU-Debatte in der türkischen Öffentlichkeit. Diese Techniken der Grenzziehung sind insti-

riale Elemente. Die höheren nationalen (Militär-)Behörden reden von einem »rassischen « Türkentum, die niederen Behörden dagegen von türkischer Staatsbürgerschaft. Die türkischstämmigen Migranten aus Bulgarien werden Volksgenossen genannt, während die nicht-muslimischen Minderheiten entweder als »Türkische Staatsbürger« oder als »Ausländer« bezeichnet werden (vgl. Yeğen 2004).

23 Paradoxerweise lehnen die Aleviten und Kurden die europäische Minderheitsbezeichnung für sich ab. Sie deuten sie als eine Art von Beleidigung, obwohl die politischen Kriterien bestimmte symbolische Gelegenheiten bzw. eine Legitimationsbasis gegen den nationalistisch-kulturalistischen Diskurs bieten. Die Aleviten bilden nach den Sunniten die zweitgrößte Religionsgemeinschaft (12-15 Mio.) und die Kurden sind größte ethnische Minderheit in der Türkei (10-15 Mio.) (vgl. Kommission der europäischen Gemeinschaften 2004: 44ff). Sie fordern in ihren Aussagen positive und kulturelle Rechte, die mit dem europäischen Minderheitendiskurs zum großen Teil übereinstimmen. Die Äußerung »wir sind auch ein eigentlicher Bestandteil der Nation« rekonstruiert einen »nicht-eigentlichen Bestandteil der Nation«. Die Sorge um sich selbst, »Warum sollen wir uns auf den Minderheitenstatus reduzieren, wenn wir >eigentlicher Bestandteil der Nation« sind?«, artikuliert, dass christliche und jüdische Minderheiten, die während des Osmanischen Reiches einen autonomen »Millet-Status« hatten und in der Türkei seit dem Lausanner Abkommen als Minderheiten anerkannt sind, dieser »nicht-eigentliche Bestandteil der Nation« sind, sozusagen ein »Fremdkörper« in der »muslimisch-türkischen eigentlichen Nation«.

24 Der Begriff bezeichnet die Konversion vom Judentum zum Islam. 
tutionalisierte Praktiken des zentralistischen Staates. In ihrer Untersuchung von Schullehrbüchern von 1908 bis zu den 1990er Jahren stellt Füsun Üstel fest, dass die »türkische Solidarität« vor allem entlang effektiver Bedrohungserzählungen (internen und externen Feinden) hergestellt wird. In den Bildungsinstitutionen ${ }^{25}$ wird der Typus eines Bürgers erzogen, der nicht zivil, sondern militant ist. Die Nation solle wach und, wenn nötig, aktiv sein (vgl. Üstel 2005: 295ff). Um die Nation vor diesen Gefahren zu schützen, müsse der Staat heroisch, mutig und stark sein. Es ist Teil der politischen Kultur, Oppositionen durch Vorwürfe wie »Heimatverrat« und »Nationsspalter« zu diskreditieren. Es ist dies eine Rationalität, die die Möglichkeiten der Einflussnahme von gesellschaftlichen Gruppen auf die politischen Prozesse blockiert (vgl. Mardin 2003a).

Wie im vierten Teil beschrieben wurde, geht Şerif Mardin davon aus, dass mit der »Jungtürken-Revolution« 1908, und insbesondere mit der Gründung der Republik ein Bruch zwischen Zentrum und Peripherie stattgefunden hat. Die modernistischen zentralistischen Eliten haben Mardin zufolge die religiösen intermediären Institutionen zwischen Staat (Zentrum) und Volk (Peripherie) abgeschafft, die Religion wurde aus dem öffentlichen Raum verbannt. Der dadurch entstandene Bruch konnte auch durch die neuen Institutionen nicht mehr gekittet werden. Doch ein anderer zentraler Aspekt ist außer Acht gelassen worden, und zwar die symbolische Integration des »türkischen muslimischen Volkes« gegen nicht-muslimische Minderheiten während des Ersten Weltkrieges und nach der Gründung der Republik. ${ }^{26}$ Die nicht-muslimischen Minderheiten werden als interne Werkzeuge der westlichen Mächte dargestellt, die gegen die muslimisch-türkische Identität mobilisiert wurden. Die Verbindung zwischen Zentrum und Peripherie wurde durch diese Technik der Beherrschung wiederhergestellt. Es ging nicht lediglich um einen gesellschaftspolitischen Ausschluss von nicht-muslimischen Min-

25 In dem Projekt, ein neues türkisches Individuum zu erziehen und dadurch eine neue Gesellschaft hervorzubringen, spielt neben den Schulen nach wie vor das Militär eine dominante Rolle. Das Militär übernahm insbesondere seit den 1930er Jahren die Mission das Volk zu erziehen. Nationalistische Erziehung und Indoktrination verlagerten sich sozusagen in die Kasernen und diese bekamen einen »Volksschulcharakter« (vgl. Gökmen 2002: 347). Diejenigen Männer, die der schulischen Erziehung entkommen, werden hier aufgefangen und (nach-)erzogen.

26 Der türkische Staat bestreitet nach wie vor den Genozid an den Armeniern und versucht, andere Staaten davon abzuhalten, ihn anzuerkennen. Bis heute weitgehend vergessen und unaufgearbeitet scheint der zeitgleich begangene Völkermord an den Aramäern zu sein, einer syrisch-orthodoxen Minderheit auf dem Staatsgebiet der Türkei. 
derheiten, sondern dieser Ausschluss fand unter der allgemeinen $\mathrm{Zu}$ stimmung der muslimischen Mehrheitsgesellschaft statt, was eine besondere Identität hervorgebracht hat: Die Nation konnte sich über dieses kollektive Verbrechen mit dem Staat identifizieren (vgl. Ahıska 2006; Keyder 2003; Akçam 1995).

Der nationalistische Okzidentalismus ist, so könnte zusammengefasst werden, primär nach innen gerichtet und dient dazu, mit Hilfe einer anti-kolonialen Rhetorik die bürokratischen Machtstrukturen zu konsolidieren. Er bestimmt, was vorzustellen ist und was nicht, was wahr und was falsch ist. Er markiert also die Grenzen der Vorstellung von der Modernisierung bzw. Demokratisierung. Er ist ein Modus der Repräsentation, der die Komplexität der türkischen und der europäischen Gesellschaften auf nationale Deutungsmuster reduziert. Die nationalistische Phantasie intendiert, die Schließung und Harmonie der türkischen Gesellschaft durch die stabilisierende Seite des »unehrlichen Europas« und der »spalterischen Minderheiten« zu ermöglichen. Der Diskurs gestattet die Symbolisierung und verdeckt innerhalb ihrer die Konflikte und Differenzen, schafft eine illusionäre Harmonie und Nation, indem »Europa« diskreditiert und die Minderheiten stigmatisiert werden. Es geht dabei nicht lediglich um kontra-europäische Okzidentalisten, die innertürkische Differenzen zu maskieren versuchen, sondern, wie im ersten Kapitel des empirischen Teils ausgeführt, auch der pro-europäische pragmatische Diskurs spricht mit demselben nationalistischen Repertoire. Die beiden dominanten kemalistischen und islamistischen Diskurse schließen die Vielstimmigkeit der Gesellschaft aus und stigmatisieren oder ignorieren die Stimme der Minderheiten, die den Begriff Europa als Metapher für Demokratisierung und Anerkennung kultureller Differenzen einsetzen. Diese Stimmen des Anderen sind ausgeschlossene Symptome der nationalistischen symbolischen Ordnung, die identifikatorisch und de-identifikatorisch zugleich wirken. Die Hinweise auf den Mangel an Schutz von kulturellen Differenzen der nicht-türkischen und nichtmuslimischen Minderheiten versetzen die türkische symbolische Ordnung. Beide Diskurse beantworten diese Versetzung mit unterschiedlichen diskursiven Praktiken, doch beide versuchen, die zerrissene Nation zusammenzuflicken und mittels bestimmter leerer Signifikanten die Hegemonie wiederherzustellen. Während der pro-europäische Diskurs auf die religiösen Gemeinsamkeiten hinweist (Kurden und Aleviten seien Muslime) und von der »tausendjährigen Bruderschaft« spricht, erzählen die kontra-europäischen Nationalisten Geschichten über den türkischen »nationalen Befreiungskrieg«, wobei »Kurden und Türken, Aleviten und Sunniten vereint gegen den gemeinsamen Feind« gekämpft hätten, nämlich gegen »Europa $\ll$. 


\section{Muslimische Migranten als interner Orient}

Die Integration von türkischen muslimischen Migranten ist jenes diskursive Nebenfeld, das im Zusammenhang mit einem zukünftigen EUBeitritt der Türkei von beiden deutsch-europäischen Diskursen thematisiert wird. Während der exklusive Diskurs dahin geht, dass ein türkischer Beitritt die Integration von türkisch-muslimischen Migranten »aussichtslos « machen würde, konstatiert der inklusive Diskurs, dass er den Integrationsprozess beschleunigen würde. Der exklusive Diskurs von 1997 artikuliert, dass muslimische Migranten in der BRD nicht diskriminiert würden, wobei er auf die Existenz »zahlreicher Moscheen und Vereine in der freiheitlichen deutschen Demokratie« hinweist. Der türkische Vorwurf, die EU sei ein »christlicher Club« und wolle der vom Islam geprägten Türkei die Tür vor der Nase zuschlagen, ist Horst Bacia (FAZ) zufolge bequem und entlastend für diejenigen, die ihn machen (Bacia, FAZ: 13.12.97). Dem außenpolitischen Sprecher der CDU/CSUBundestagsfraktion Karl Lamers zufolge suchte der damalige türkische Premierminister Mesut Yilmaz (ANAP) »[...] einen Schuldigen für eigene Versäumnisse [...] Der Islam ist kein Beitrittshindernis für die Europäische Union. Wäre Deutschland der Auffassung, dass Islam und westliche Welt nicht zu vereinbaren sind, wären auch Aufforderungen an Türken, die deutsche Staatsbürgerschaft anzunehmen, nicht zu rechtfertigen.« (Lamers, SZ: 20.12.1997)

Ab 1999 ist eine Verschiebung auf dem deutschen diskursiven Feld zu beobachten. Für den exklusiven Diskurs würde mit einem TürkeiBeitritt eine »Migrationswelle« ausgelöst werden, die zu einer »schleichenden Islamisierung« der deutschen bzw. europäischen Gesellschaft führe. Ähnlich wie die CDU-Politiker Wehler und Winkler argumentiert auch Helmut Schmidt, dass die Mitgliedschaft Freizügigkeit für alle türkischen Staatsbürger mit sich bringen und die Integration der hier lebenden Türken und Kurden »aussichtslos werden lassen« würde (Schmidt, FAZ: 11.12.2002). Für den inklusiven Diskurs hingegen würde dieses "Migrationsproblem« vermieden und die Integration muslimischer Migranten erleichtert. Der Beitritt würde eine positive Botschaft an die in Europa lebenden Muslime und grenzübergreifend an den Mittleren Osten senden. Eine Ablehnung würde die Migranten in Europa desintegrieren und ausdrücken, dass die Europäer die Muslime bzw. islamische Demokratien als Bürger und Demokratien zweiter Klasse betrachteten (Watson, ZAM: 10.12.2004).

Insbesondere seit 2002 erleben die exklusiven hegemonialen Äußerungen Hochkonjunktur. Es findet eine massive diskursive Orientalisierung des Integrationsdiskurses statt, indem die Alterität des Ostens in 
der Gestalt der muslimischen Migranten erscheint. Europa wird von der »islamischen« Türkei und die Europäer von »muslimischen« Migranten abgegrenzt, indem auf einen Unterschied zwischen »dem Abendländischen, durch Reformation geprägten Europa und der muslimischen Kultur« verwiesen wird. Der exklusive Diskurs orientalisiert die muslimischen Migranten, er verwandelt sie durch Bedrohungserzählungen in einen »internen Orient « und erzeugt somit eine harmonische deutsche bzw. europäische Gesellschaft, die vom »internen Orient« essentiell abweicht. Er unterscheidet nicht lediglich den Westen vom Osten in den geographischen Orten außerhalb Europas. Er zieht ebenso die Grenze zwischen Europa und einem internen subalternen Orient, der sich in den muslimisch-türkischen Migranten verkörpert.

»Überall in Europa erweisen sich muslimische Minderheiten als nicht assimilierbar und igeln sich in ihrer Subkultur ein. Auch die Bundesrepublik hat bekanntlich kein Ausländer-, sondern ausschließlich ein Türkenproblem. Man kann nur durch die strikte Verpflichtung zum Sprachunterricht, zum Sprachtest vor der Einschulung, zum regelmäßigen Schulbesuch, zur Bindung der Staatsbürgerrechte an ein Examen (wie etwa in Holland) die starre Minderheitenlage allmählich auflockern. Aber warum sollte man diese Diaspora millionenfach freiwillig vermehren und damit die bisher willige Bereitschaft zum Zusammenleben einer extremen Belastungsprobe aussetzen?«(Wehler, DIE ZEIT: 38/2002)

Für Wehler sind nicht Migranten an sich, sondern türkisch-muslimische Minderheiten diejenigen, die unassimilierbar bleiben. Er konstruiert eine Wahrheit und Ausgangszugehörigkeiten über die Migranten türkischer Herkunft, stellt sie als eine besondere, partikulare Erscheinung und als »Problem» dar und schlägt anschließend Disziplinierungsmaßnahmen vor. Die Türken verweigern sich demnach staatsbürgerlichen Verpflichtungen, schicken ihre Kinder nicht regelmäßig zur Schule und lernen die deutsche Sprache nicht. Die türkischen muslimischen Migranten sind also unfähig, »sich selbst zu verfeinern« und es fehlt ihnen der Wille, sich zu »integrieren«, sie ghettoisieren und kriminalisieren sich. Die logische Schlussfolgerung seiner Konstruktion lautet dann, die Mobilität dieser unassimilierbaren »Türken« durch einen Beitritt der Türkei nicht noch »millionenfach « zu vermehren.

Zeliha Etöz (2001) macht darauf aufmerksam, dass die griechischen, armenischen oder muslimischen Jungen, die in den Großstädten Westeuropas in der zweiten Hälfte des 19. Jahrhunderts studierten und fließend und ohne Scheu Englisch oder Französisch sprachen sowie sich nach westlicher Art kleideten, dennoch als »Unruhestifter« gekennzeichnet wurden. Diese jungen Stundenten seien »faul«, frech« und 
»respektlos«, sie besäßen zu wenig positive Eigenschaften wie Mut, Neugier, Fleiß, Handlungsfähigkeit und Streben nach Freiheit. Während die Migranten in ihrem Heimatland von Reisenden als ehrlich, gutherzig und gastfreundlich repräsentiert wurden, waren sie in Europa »kriminell«. Nur die Gastfreundlichkeit bleibt als einzige Tugend des Orientalen, da sie diese als »ein Gebot des Propheten « betrachteten (Belgiojoso 1858, zit.n. Etöz 2001: 69).

Basam Tibi meint, dass die jetzigen (religiösen) Praktiken von muslimischen Migranten dem »Europaverständnis« nicht entsprächen. Als Stimme des besseren Anderen verbindet er die Frage der »Integration « von muslimischen Migranten mit dem Türkei-Beitritt, wenn er sagt: »Ein islamischer Migrant kann durch die Annahme einer europäischen Bürgeridentität ein Euromuslim werden; diese Erkenntnis gilt auch für die Türkei.« (Tibi, TAZ: 13.12.02) Die Türkei müsse nicht nur ihre üblichen politischen und wirtschaftlichen Probleme lösen, sondern auch am Islam arbeiten und ihn reformieren, um »europatauglich « zu werden. Sowohl die Türkei als auch islamische Migranten müssten sich dieser Anstrengung unterziehen.

Wie bei den kemalistischen Okzidentalisten, die den Islam als Hindernis für westliche Mondernität betrachten, ist in Tibis Äußerungen ein statusbedingter Mangel erkennbar, der durch einen Assimilationsdruck im deutschen Kontext ausgelöst wird. ${ }^{27}$ Es handelt sich hierbei um den internalisierten Blick des Anderen, einen Selbstzweifel, der in einer niederen gesellschaftlichen Stellung und der migrantischen Bemühung begründet liegt, so sein zu wollen wie der Etablierte. Die Akzeptanz des eigenen Mangels lässt ihn in eine Phantasie flüchten, in der er die »Schande« der Anpassungsunfähigkeit den muslimischen Migranten und den Türken - als selbstverschuldet - zuschreibt. Denn, weniger die »Integrationsunwilligkeit« von Migranten, so Elias und Scotson, sondern gerade ihr erhöhter Integrationsgrad in die etablierte Gesellschaft bringt die stigmatisierenden Artikulationen hervor, weil durch die Integration das Machtgefälle zwischen dem europäischen Selbst und dem Anderem undeutlicher wird (vgl. Elias/Scotson 1993). Der türkischmuslimische Andere wird einerseits gezwungen, die Werte der dominanten Kultur zu imitieren. Gleichzeitig muss das subalterne Andere hinreichend von dieser dominanten Kultur different bleiben, so dass Letztere

27 Laut Nevim Çil wird das Schamgefühl für Bauman (1995) erst durch Assimilationsdruck ausgelöst. Es sei »die jüdischste der Emotionen« überhaupt. Die ambivalente Haltung zum Selbst - einerseits Selbstverachtung, andererseits die Mühe, durch Assimilation sich selbst, d.h. seiner Herkunft zu entrinnen - beschreibt Bauman als ein einschneidendes Moment im westjüdischen Assimilationsprozess (vgl. Çil 2007: 50ff). 
weiterhin diese Subjekte erkennen und kontrollieren kann (vgl. MooreGilbert 2001). »Solange die Neger Sklaven bleiben und die Juden Kleinhändler oder Hausierer, die als erkennbare Ghetto-Angehörige in fremdartiger Kleidung im Lande umherziehen, hat der Spannungsdruck zwischen Etablierten und Außenseitern, der natürlich immer vorhanden ist, ein vergleichsweise niedriges Niveau.«(Elias 1990, zit.n. Çil 2007: 37)

Nevim Çil (2007) weist diesbezüglich darauf hin, dass solange die Gastarbeiter (der Pioniergeneration) in der Bundesrepublik Deutschland in der ihnen zugeschriebenen Sphäre blieben und die vorgesehene niedere Arbeit verrichteten, sie zwar nicht unbedingt willkommen, so doch geduldet waren. Gerade weil die Generation der Nachkommen soziale, politische und wirtschaftliche Rechte um Gleichwertigkeit anstrebt, wird sie als bedrohliches Problem konstruiert (vgl. Çil 2007: 45ff). Werner Schiffauer (2006) spricht diesbezüglich von einer »moral panic« in Deutschland, verstanden als kollektive Hysterie, die sich im Integrationsdiskurs manifestiert. Ähnlich wie für Elias und Çil sind für Schiffauer die Gründe dieser »moral panic« nicht in der Integrationsunwilligkeit der muslimischen Migranten zu finden, sondern in der Wandlung der Machtbalance zwischen etablierter Mehrheitsgesellschaft und muslimischem Außenseiter, der »gestern gekommen ist und morgen bleiben wird«. Migranten wechseln ihren Status von »Ausländern« zu Staatsbürgern und fangen an, für ihr Recht auf Subjektivität mit demokratischen Mitteln zu kämpfen. Die Reaktion der Etablierten erzeugt die zunehmende Feindschaft gegenüber der politischen Subjektivität des Anderen. $^{28}$

28 Schiffauer demonstriert diese Hysterie anhand von drei Fallbeispielen, die in der deutschen Öffentlichkeit Grundsatzdebatten ausgelöst haben. Erstens: Mitgliedern von konservativen muslimischen Organisationen wird, Schiffauer zufolge, in bestimmten Bundesländern (Bayern und BadenWürttemberg) die Staatsbürgerschaft versagt, um den Einfluss von ungewollten Immigranten zu begrenzen. Zweitens: Die Forderung von muslimischen Migranten nach Anerkennung und nach politischen Rechten wird als »Missbrauch« des Rechtsstaates und als »falsche Toleranz« dargestellt. Diese öffentlichen Irritationen führten wiederum zu »Hexenjagden«, wie im Fall von Fereshta Ludin, die einen Teilerfolg bezüglich ihres Rechtes, als Lehrerin mit einem Kopftuch bekleidet an öffentlichen Schulen zu unterrichten, erreicht hatte. Jara Kehl (2004) macht darauf aufmerksam, dass in der Diskussion um die Anstellung einer Kopftuch tragenden Lehrerin Themen verhandelt werden, die über die Frage nach dem Mäßigungsgebot staatlicher Amtswalter hinausgehen: In der >Kopftuchdebatte< wird nämlich das muslimische Andere zur Negativfolie der abendländischchristlichen Identität (vgl. Kehl 2004). Drittens: Öffentliche Mittel für muslimische Jugendorganisationen (in Düsseldorf) wurden gestrichen, begründet mit Gerüchten, sie würden damit verfassungsfeindliche Organisationen finanzieren (vgl. Schiffauer 2006: 94ff). 
»In westlichen Kulturen wird Respekt dem Individuum für eine persönliche Leistung erwiesen; die Kinder und Enkel islamischer Einwanderer dagegen fordern »Respekt« für ihre Religion und ihre Gruppe, womit zum Ausdruck kommt, dass sie der traditionellen Schamkultur verhaftet sind. Wird die Ehre infrage gestellt - beispielsweise, wenn eine Frau der Gruppe die Regeln des sexuellen Anstands verletzt, - droht Statusverlust für die Männer, dazu der damit einhergehende gesellschaftliche Abstieg [...].« (de Winter, DIE ZEIT, 48/2004)

De Winter stellt hier die »westliche« Kultur der »östlichen« islamischen gegenüber. Die östliche Kultur befindet sich jedoch geographisch nicht im Osten, sondern im europäischen Innen, sie verkörpert sich in den Kindern und Enkeln islamischer Einwanderer. Dem Westen schreibt er Modernität, Rationalität und Individualität, dem Osten Primitivität und Sippenhaft zu. In der westlichen Kultur ist für de Winter Respekt etwas Individuelles, Persönliches und Leistungsorientiertes, in der östlichen dagegen etwas Kollektives, in »Ehre« und »Schamkultur« Traditionsverhaftetes. Für de Winter geht es gar nicht um die Frage, wie und unter welchen Bedingungen im Migrationsprozess bestimmte Außenseiterpositionen entwickelt und nach welchen Mechanismen und Praktiken diese Positionen verfestigt werden. Er spricht von einer vernatürlichten Ehre und Schamkultur, die Zeit und Ort transzendierend auf die Enkelkinder ohne Veränderung vererbt wird. Die sozialen und kulturellen Deutungs- und Umgangsmuster, die de Winter für typisch orientalischmuslimisch in der geographischen Ferne hält, haben für ihn auch für Migranten und ihre Nachkommengeneration in den Ghettos von europäischen Großstädten Gültigkeit. Somit verwandelt der Diskurs die Migranten zum internen orientalen Anderen. Der exklusive Diskurs bringt

»Turkishness and Islam into refined parameters of difference and identity and uses the Turk as the ultimate signifier of the migrant who sis tied to an unyielding past, the past of his home and culture, and a persistent present, the present of his host place, his bureaucratic shackles, and his otherness. (Soysal 2003, zit.n. Irzık/Güzeldere 2003: 289)

Im selben Deutungsmuster wie de Winter, aber mit einer noch bedrohlicheren Rhetorik erzählt »der Spiegel« über die muslimisch-türkischen Migranten. Auf dem »Spiegel«-Cover (13/2007) gehen Halbmond und Stern im Dunkeln über der Quadriga des Brandenburger Tores auf. Übertitelt mit »Mekka Deutschland, die stille Islamisierung«, wird dem Betrachter das ohnehin eindeutige Bild der »heimlichen Unterwanderung« der Republik aufgezeigt. Dabei nehmen die Autoren des »Spiegels «, Bartsch et al., die Entscheidung einer Frankfurter Familienrichte- 
rin im Rechtsstreit um häusliche Gewalt in einer muslimischen Familie zum Anlass als Warnung vor der drohenden Gefahr. Sie warnen die deutsche Gesellschaft vor einer »falschen Toleranz« bzw. einer »schleichenden Islamisierung «, um »[...] die - in Deutschland mühsam - gewonnene Liberalität [vor Missbrauch des Rechtsstaates] zu schützen, notfalls mit null Toleranz gegenüber Intoleranz« (Bartsch et al., Der Spiegel 13/2007: 24). Die Frage, wie Deutschland mit seinen Fremden umgehen soll, müsse - so der Tenor des Artikels - endlich enttabuisiert werden, es gehe schließlich um die Frage, »[...] wie viel Fremdheit die Deutschen noch $[\mathrm{zu}]$ ertragen $[. .$.$] in der Lage seien:$

»Akzeptieren die Deutschen die manchmal altertümlichen Vorstellungen anderer Kulturkreise? Gestatten sie also Gruppen, nicht nur neben der Bevölkerung in einer Parallelgesellschaft zu leben - sondern auch in einem anderen Zeitalter und mit einer ganz anderen Geschwindigkeit? Ist die Republik nicht verpflichtet, auch die Menschen, die der Gesellschaft fremd sind, mitzunehmen, wenigstens schon mal bis in die Gegenwart?« (Bartsch et al., Der Spiegel 13/2007: 24)

Die muslimischen Migranten sind rückständig, sie haben »altertümliche Vorstellungen«, sie leben in einem »anderen Zeitalter« und mit einer anderen »Geschwindigkeit«. Die Migranten mit muslimischer Herkunft werden somit in der Kategorie der »traditionellen Gesellschaften« eingesperrt. Sie werden zu einem kulturellen Objekt, das verwandelt werden muss. Es wird dabei nicht nur ein einheitlicher Orient entworfen, sondern es werden auch die Differenzen in den deutschen bzw. europäischen Gesellschaften eliminiert. Die deutsche Gesellschaft integriert sich, laut Bartsch et al. mit Hilfe eines »kleinsten gemeinsamen Nenners«, gegen die »islamische Gefahr« in deutschen Städten, »auf den sich linke Feministinnen, Neu- und Altkonservative immerhin einigen können«. Sie schaffen einen Konsens gegen die Unterdrückung der muslimischen Frauen durch ihre Männer, um die bedrohten westlichen Werte $\mathrm{zu}$ verteidigen und die »Liberalität des Rechtsstaates« vor dem »islamistischen Missbrauch« zu schützen.

»Die Bundesrepublik hat vor allem mit streng religiösen muslimischen $\mathrm{Mi}$ granten ein ähnliches Problem wie die modernen Israelis mit ihren orthodoxen Juden: Die Fundamentalisten zeugen Kinder, den Männern und Frauen der Vergangenheit könnte sehr wohl ein erheblicher Teil der Zukunft gehören auch den Muslimen in Deutschland. Deren Zahl wird sich [...] schon 2030 deutlich mehr als verdoppelt haben. «(Bartsch et al., Der Spiegel 13/2007: 24) 
Um sich von einem möglichen rassistischen Vorwurf im Voraus zu entlasten, geben die Autoren des »Spiegels« gezielt ein Beispiel aus dem " modernen« Israel, das ein ähnliches Problem mit ihren nicht-modernen »jüdischen Fundamentalisten« habe, die sich beständig vermehrten, wie die Deutschen mit ihren »mittelalterlichen« »strengreligiösen« muslimischen Migranten. Es ist nicht der Diskurs der Romantik, der aus kulturellen Deutungsmustern kulturelle Differenzen essentialisiert, sondern es handelt sich um eine aufgeklärte Diskursformation, die auf universalistisch-säkularistischen Deutungsmustern operierend sich als Verteidiger bzw. Besitzer der Werte des Rechtsstaates präsentiert. Der Diskurs transportiert politische und soziale Spannungen um die Dichotomie »Islam versus Säkularismus« herum (z.B. aus der Türkei) in die deutsche Öffentlichkeit hinein, wodurch die Problematik des Begriffes »Deutsch«, seine ambivalente, verdächtige Beziehung zur Nazi-Vergangenheit untermauert wird. Die sichtbare Figur des muslimischen Mannes bzw. der muslimischen Frau wird dabei der neue phantasmatische objektivierte Andere des Deutschseins, während die Figur des säkularistischen türkischstämmigen deutschen Staatsbürgers als Demonstration der deutschen Multikulturalität zelebriert wird (vgl. Irzık/Güzeldere 2003: 288). Bezogen vor allem auf Leon de Winter macht Michael Bodemann darauf aufmerksam, dass der heutige Diskurs über muslimische Migranten demjenigen ähnelt, der sich vor einhundert Jahren gegen Juden richtete. Bodemann zitiert den Soziologen Werner Sombart, dem zufolge sich die Juden

»in einer innerlichen Gegensätzlichkeit zu der sie umgebenden Bevölkerung, im Sinne einer fast kastenmäßigen Abgeschlossenheit gegen die >Wirtsvölkerく befinden. Die Juden wollten rabgeschlossen leben`, >zusammengeschlossen und darum abgesondert<. Die Juden treten aus der »Starre und der Leere der Wüste« hervor, als die >Macht kalter Rationalität, des nomadischen Wanderns und der Anpassbarkeit«.« (Bodemann, TAZ: 25.11.2004)

Turners Hinweis auf zwei Formen des Orientalismus scheint an dieser Stelle zuzutreffen, wenn er feststellt, dass der »Westen« sich zwischen zwei Polen, zwischen »[...] the lazy sensual Arab and the untrustworthy, greedy Jew « orientiert (vgl. Turner 2000a: 13). Der Orientalismus habe nach außen die Araber und nach innen die Juden als sein negatives, unterlegenes und bedrohliches Andere markiert: »Within Orientalism, there are two related discourses for Semites, namely the Islamic discourse of gaps, and Judaic discourse of contradictions« (Turner 2000a: 12). Der Diskurs des Orientalismus schließt Turner zufolge also zwangsläufig den Antisemitismus ein. Der Anti-Islamismus sei ein Teil der Feindschaft gegen die semitischen Gesellschaften. Es wird nicht nur auf dem 
deutschen diskursiven Feld von der »Unassimilierbarkeit« bzw. »Integrationsunwilligkeit« von Migranten gesprochen. Im politischen Establishment mehrerer westeuropäischer Länder, wie in Frankreich, Österreich, Holland oder England scheint ein Konsens bezüglich der »NichtAssimilierbarkeit« muslimischer Migranten zu herrschen (vgl. Malik 1996: 196; Triandafyllidou 2006: 119f; Brubaker 1992: 148ff; Kastaryano 2006: 62f; Parekh 2006: 180f). Die muslimischen Migranten leben zwar in Europa, werden jedoch nicht als Teil Europas angesehen (vgl. Asad 2003: 171).

$»[\ldots]$ real Europeans acquire their individual identities from the character of their civilization. Without that civilizational essence, individuals living within Europe are unstable and ambiguous. That is why not all inhabitants of European continent are >really< or >fully< European [...] Until just after World War II, European Jews were marginal too, but since that break the emerging discourse of a >Judeo-Christian tradition $<$ has signalled a new integration of their status into Europe.« (Asad 2003: 168)

Asad hebt hervor, dass nicht nur muslimische Migranten und ihre Nachkommen, sondern auch »einheimische« europäische Muslime, z.B. in Bosnien, sowohl vom liberalen inklusiven als auch vom konservativen exklusiven Diskurs als nicht dazugehörig angesehen werden. Die bosnischen Muslime seien zwar in Europa, doch nicht Teil Europas, auch wenn sie nicht aus Asien nach Europa migriert sind und säkulare politische Institutionen adaptiert haben. "It is precisely because Muslims are external to the essence of Europe that >coexistence $<$ can be envisaged between >us« and >them» «(Asad 2002: 213ff).

Auch in der europäischen Migrationspolitik wird ein Widerspruch zwischen postnationaler Zielsetzung und realpolitischer Regulation sichtbar. Die Unterscheidung zwischen »Einheimischen« und »NichtEinheimischen« verlagert sich auf die europäische institutionelle Ebene, wo zwischen europäischen Einheimischen und nicht-europäischen Ausländern unterschieden wird. Es werden Drittstaatler und illegale Migranten auf der nationalen Ebene institutionell und symbolisch ausgeschlossen. Dabei wird eine Identität idealisiert, die in erster Linie in Opposition zu südlichen Populationen konzipiert wird (vgl. Wallerstein/Balibar 1991: 105).

»By deciding to accord EU citizenship on the basis of member-state nationality rather than residence or some other form of permanent affiliation within Europe, member states enshrined the traditional sovereign prerogative over questions of citizenship, but failed to provide an inclusive basis for belonging in Europe.« (Bhahba 1999: 15) 
Dieser doppelte Ausschluss auf nationaler wie auf europäischer Ebene erzeugt und fördert die ethno-kulturellen Dimensionen »europäischer Bürgerschaft« und stellt die territoriale Postnationalität der europäischen Union in Frage, weil sie das Konzept und die Form des Nationalstaates nicht ganz transzendiert, sondern ihn auf eine erweiterte territoriale Ebene reproduziert. Auf der europäischen Ebene ist die Bildung einer »fragmentierten Bürgerschaft« zu beobachten, »[...] die nicht nur unterschiedliche Mobilitäts-, sondern auch unterschiedliche politische, soziale und ökonomische Rechtsstandards produziert« (vgl. Hess/Tsianos 2007: 27). Die EU bezieht nicht alle auf ihrem Territorium lebenden Personen ein, selbst die nicht, die hier hineingeboren sind. Insofern ist sie nicht prinzipiell offen und inklusiv. Die individuellen wie kollektiven politischen Rechte der Bürger werden auch auf EU-Ebene verwehrt (vgl. Balibar 2003).

Es ist jedoch nicht nur die Ambivalenz der auf dem europäischen Territorium ansässigen muslimischen »Fremden« im Baumanschen Sinne, die eine europäische symbolische Schließung verhindert, die als »Unassimilierbarkeit«, »falsche Toleranz« oder »Parallelgesellschaft« artikuliert wird. Auch die transräumliche »Autonomie der Migration«, macht eine territorial-räumliche Schließung unmöglich und stellt somit den Diskurs um das »Integrationsdefizit« des Anderen auf Dauer. Diese transnationale Migration führt wiederum zur Europäisierung der Migrationspolitik der Mitgliedsländer. Mit neuartigen europäischen Migranten-Lagern wird zwar versucht, die Geschwindigkeit der transnationalen Migration temporär zu bremsen. Da Migration ihrer Dynamik folgt, kann sie zwar kanalisiert und entschleunigt, jedoch nie völlig abgeschottet und unterbunden werden (vgl. Karakayal1/Tsianos 2007: 16). Diese Autonomie wirkt auf den exklusiven Diskurs belastend, wenn er sich zur Türkei äußert. Die sich einer vollständigen Symbolisierung, Kontrolle und Regulation entziehende dynamische Subjektivität der stetigen Ankunft der Migranten scheint für den exklusiven orientalistischen Diskurs symptomatisch zu wirken. In diesem Fall werden Migranten entweder als »Opfer« von Schleppern dargestellt oder treten in Gestalt der »Schlepper« selbst auf und werden somit kriminalisiert.

Die Orientalisierung und der institutionelle Ausschluss von muslimischen Migranten führen einerseits zu ihrer Ausgrenzung und andererseits zur Vereinheitlichung der europäischen Differenzen. Die muslimischen Migranten scheinen dabei als ausgeschlossene europäische Symptome zu fungieren. Sie weisen auf den Mangel der deutschen bzw. europäischen symbolischen Ordnung hin, sie zerreißen sie, entweder durch die Migrationsbewegungen oder durch die symptomatische Generation der Nachkommen. Sie rufen orientalistische Artikulationen hervor, die 
dem Zweck dienen sollen, den »Riss « zu nähen, den europäischen Mangel abzudecken. Die Aussagen über »Integrationsunwilligkeit«, »Missbrauch des Rechtsstaates« und »falsche Toleranz« der Migranten kennzeichnen eben diese Versuche ihre Subjektivität zu objektivieren. Es ist diese Unmöglichkeit der deutsch-europäischen kulturellen Identität, die die Politik und die Prozesse der Identifikation durch ein orientalistisches Repertoire bedeutsam macht. Der Diskurs richtet sich nach innen wie nach außen. Er bringt das Innen mit dem Außen in Verbindung. Insofern bildet der Orient sowohl das Innen als auch das Außen des orientalistischen Diskurses. 



\section{SCHLUSSBETRACHTUNG}

In dieser Arbeit habe ich anhand poststrukturalistischer und postkolonialer Theorien die Debatte über einen möglichen Beitritt der Türkei in die Europäische Union in der deutschen/europäischen und türkischen Öffentlichkeit analysiert. Ich wollte herausfinden, wie die deutschen, europäischen und türkischen Akteure im Hinblick auf den EU-Beitritt der Türkei miteinander kommunizieren, ob, und falls ja, wie sie sich aufeinander beziehen und welche diskursiven Interdependenzen in den Öffentlichkeiten sichtbar werden. Ich habe früh gemerkt, dass diese Debatte einen bedeutenden Überhang hat, nämlich dass von allen Seiten zunehmend das Europäischsein der Türkei problematisiert wird, indem die Dichotomien »Ost-West« und »Europa-versus-Islamische Welt« in der deutschen bzw. türkischen Öffentlichkeit kommuniziert und strukturiert werden: Hier werden die gesuchten identifikatorischen Motive eines vorgestellten Europas sichtbar. Aus diesen ersten Beobachtungen und Überlegungen heraus schien es mir sinnvoll, die Bedeutung des Ostens in Europa und des Westens in der Türkei in den Mittelpunkt meiner Analyse zu stellen.

Als theoretisch-analytischen Rahmen bot sich hierfür Edward Saids Theorie des Orientalismus an. Ich argumentierte, dass Saids von der strukturalistisch konzipierten Diskurstheorie Foucaults geprägter Orientalismusbegriff die Dynamiken und Veränderungen im Diskurs nicht hinreichend berücksichtigt. Von der Diskurstheorie Laclaus und Žižeks ausgehend habe ich daher die Heterogenität, Intertextualität und Offenheit des Diskurses betont. Diskurse sind nicht dauerhaft festgelegt und haben keine klaren Außengrenzen, sondern sind sich durch Artikulationen verändernde Formationen. Die symbolischen Strukturen sind somit aufgrund von Bedeutungsüberschüssen und Mehrdeutigkeit der Begriffe 
unvollständig, und es ist deswegen dem Subjekt möglich, sie zu verändern. Dies habe ich als Unvollständigkeit der diskursiven Struktur bzw. der Identität bezeichnet. Die Offenheit der diskursiven Struktur bzw. Unvollständigkeit der Identität dynamisiert das Verhältnis zwischen Subjekt und Struktur, bringt die politischen Subjektivitäten hervor und ermöglicht somit den Subjekten, sich in bestimmten historischen Hegemonieformationen zu integrieren bzw. zu desintegrieren. In diesem Sinne hat der Orient als Signifikant heterologische Bedeutungen und Interpretationen in den unfixierten heterologischen Kontexten. In dieser Hinsicht muss statt von einem Orientalismus von diversen Formen von Orientalismen gesprochen werden, die sich entlang bestimmter diskursiver Knotenpunkte verflechten oder sich voneinander abgrenzen können.

Ferner akzentuierte ich, dass Said im Prozess der Orientalisierung des Orients Foucaults Macht- und Subjektbegriff anwendet, und damit der Subjektivität des Anderen wenig autonome Handlungsräume zulässt. Ich habe dabei argumentiert, dass die nicht-westlichen Gesellschaften zwar von den westlichen Subjekten zum Anderen gemacht werden, jedoch diese Gesellschaften nicht allein als Opfer dieses Prozesses zu verstehen sind. Sie reagieren mit unterschiedlichen Strategien unter unterschiedlichen historischen Bedingungen auf das ihnen auferlegte Modell. Die orientalistischen Repräsentationen können dem Ausdruck von Kolonialismus und Eindringung dienen, sie können in einem dialogischen Verhältnis von den kolonisierten Anderen aber auch pervertiert werden. An dieser Stelle habe ich den Begriff Okzidentalismus eingeführt, der als der performative Diskurs des Anderen die Formierung der türkischen Subjektivität in Kontext der nicht-westlichen Gesellschaften artikuliert. Unter Okzidentalismus verstand ich jene diskursiven Praktiken, die sich in einem hegemonialen dialogischen Verhältnis zum Orientalismus formieren, wobei der imaginäre Blick des westlichen Anderen konstitutiv wirkt. Wie beim Orientalismus soll auch hier von diversen Formen von Okzidentalismen gesprochen werden, die sich im unterschiedlichen Maße mit dem Diskurs des Orientalismus verflechten und unterschiedliche Machteffekte nach innen zur Folge haben.

Die Debatte über die Türkeiintegration erinnert an die von Tzvetan Todorov (1985) in »Die Eroberung Amerikas. Das Problem des Anderen« beschriebenen Subjektpositionen während der spanischen Eroberung, die von dem Philosophen Sepúlveda und dem Bischos Las Casas repräsentiert werden. Während Sepúlveda die Indianer versklavt sehen will, da sie den Spaniern unterlegene Barbaren seien, vertritt Las Casas die Auffassung, dass sie nach dem christlichen Gleichheitsprinzip zu behandeln seien und jeder Indianer demnach die Möglichkeit habe, ein Christ zu werden. In beiden Fällen sind die Indianer der gemeinsame 
Andere für die Spanier: für den einen der barbarische für den andern der nicht-christliche Pagan. Das Thema des Streits ist also nicht, ob über Differenzen ein bestimmtes Andere markiert wird, sondern, nach welchen Kriterien das Selbst konstruiert wird. Es blieb Todorov zufolge abzuwarten, welcher Diskurs die Deutungsmacht gewinnen würde, weil eben die Spanier nicht darüber einig waren, was ihre gemeinsame Kollektivität ausmachte. Unterschiedliche konkurrierende Diskurse stritten deswegen mit unterschiedlichen Deutungsmustern, um zu bestimmen, was das Eigene ist bzw. was der Andere sei. Die Effekte dieses Streits hätten wiederum unmittelbare Konsequenzen für die Indianer: Im ersten Fall wären sie der absolute Andere, im zweiten Fall ergebe sich eine Option, die das Fremde zu konvergieren bzw. zu assimilieren vermag (vgl. Todorow 1985: 224ff). Es ist dies die Debatte zwischen zwei Typen der kollektiven Vorstellung von eigenen Identitäten bzw. der Differenzen zu Anderen: zwischen einer exklusiven und einer inklusiven Identität. Die erste basiert auf inhärenten Charakteristiken, die zweite auf erwerbbaren Eigenschaften, womit sie prinzipiell offen ist, falls bestimmte Kriterien erfüllt werden. Beide Diskurse markieren unterschiedliche Differenzen und definieren damit zwei verschiedene Selbst und zwei verschiedene Andere. ${ }^{1}$

Die hegemoniale Bedeutung des Europabegriffes auf dem deutschen bzw. europäischen diskursiven Feld wird im türkischen Fall durch eine gegen-hegemoniale kulturelle Bedeutung interveniert. Das bisherige europäische Selbstverständnis, das die Grenzziehung nach außen auf die politisch-rechtliche normative Basis beschränkt, wird durch eine exklusive kulturelle Identitätsvorstellung in Frage gestellt. Dabei wird entweder von einer geographisch-kulturellen Entität, oder von einer geostrategischen politischen Einheit gesprochen. In beiden Fällen geht es um den Kampf, den europäischen symbolischen Mangel, der durch die symptomatische Wirkung der Türkei verursacht wird aufzuheben bzw. die Bedeutung einer europäischen Identität zu fixieren. Während der pro-türkische inklusive Diskurs den ökonomischen, politisch-strategischen Interessen und die kulturelle »Brückenfunktion« der Türkei in den Vordergrund zu stellen versucht, beruft sich der exklusive Diskurs auf eine vorgestellte gemeinsame Tradition und auf ein Ideales Selbstbild Europas.

Der Begriff »Europa« erhält eine semiotische Leere, die mit identifikatorisch-phantasmatischen Szenarien gefüllt wird. Politische und kultu-

1 Wie das Andere auf die spanische Eindringung reagierte bzw. was die politische Subjektivität des Anderen gewesen war, wird von Todorow jedoch nicht beantwortet. Dem Anderen wird nur eine passive Rolle zugeteilt, sie besteht nur in der Imitation oder Nicht-Imitation. 
relle Elemente werden zum Repertoire dieses Deutungskampfes, in den türkische, deutsche und europäische kollektive Akteure in der Öffentlichkeit immer wieder eingreifen. Europa bewegt sich somit zwischen einer postmodernen Gesellschaft mit einer prinzipiell inklusiven Identität und einer kulturellen Gesellschaft mit exklusiver Identität, und somit zwischen politischer Offenheit und kultureller Schließung. Entlang welcher dieser politischen Phantasien sich eine bestimmte partikuläre Bedeutung durchsetzt und wie dadurch der strukturelle Mangel an Identität aufgehoben wird, bleibt noch abzuwarten. Um es mit Žižek zu sagen: Die europäische symbolische »Realität« trifft hier im türkischen Fall ihr externes Symptom, das der bisherigen Bedeutung Europas und seinem Selbstverständnis »Widerstand « leistet und die deutschen und europäischen Antagonismen sichtbar macht. Europa als Signifikant kann nicht sein Signifikat abdecken, es bleibt ein Rest. Da es nun symbolisch an Kollektivität mangelt, werden orientalistische Phantasien zur Aufhebung dieses Mangels zur Hilfe gerufen, das türkische Muslimische wird das europäische Unmögliche.

Dabei manifestierten sich zwei Diskursformationen, die unterschiedliche Repräsentationen über sich Selbst und das türkische Andere privilegieren: Das französische Modell bzw. den »Diskurs der Aufklärung« habe ich durch eine begriffliche Erweiterung differenziert und als inklusiven Orientalismus, und äquivalent das deutsche Modell bzw. den »Diskurs der Romantik» als exklusiven Orientalismus bezeichnet. Im Gegensatz zum Diskurs der Osterweiterung, in dem zwischen dem sogenannten »Diskurs der Aufklärung« und dem »Diskurs der Romantik« für eine »Wiedervereinigung Europas« Konsens herrschte - und zwar eine Logik der Differenz, nach dem Motto: Wir sind alle Europäer - werden im türkischen Fall politische Symptome sichtbar, wobei diese beiden Diskurse sich antagonistisch positionieren. Der Diskurs der Aufklärung manifestiert sich nach außen inklusiv orientalisch, während der Diskurs der Romantik sich nach außen exklusiv orientalistisch artikuliert. Der inklusive Diskurs verweist auf die »Brückenfunktion« der Türkei zwischen »Europa« und »Islamischer Welt" und hebt hervor, dass »das Land durch die Mitgliedschaft stärker an die westliche Demokratie zu binden« sei, um die »Stabilisierungsfunktion« der Türkei für die gesamte »unstabile« Region zu erhalten. Europa ist diesem Verständnis nach eine politisch-rechtliche Gemeinschaft, die sich prinzipiell über Demokratie, Rechtsstaatlichkeit, Menschen- bzw. Minderheitenrechte definiert. Der exklusive Diskurs plädiert dagegen für eine kultur- bzw. religionsbezogene europäische Identität, in der die türkische Differenz als »nicht europäisch«, »nicht-christlich«, »nicht aufgeklärt« und »nicht demokratisch« bezeichnet wird. Die europäischen symbolischen Gren- 
zen hören demnach da auf, wo das türkisch-islamische Terrain beginnt. Diese Markierung zu überschreiten würde das Ende des EU-Projektes einleiten. Die EU wird dabei als eine moderne Kollektivität verfasst, als eine Formation nationalstaatlichen Typus' auf einer höheren Ebene, wobei die kollektive Identität durch die exklusive kulturelle Bedeutung Europas gefördert wird. Der exklusive Diskurs geht davon aus, dass ein nationalstaatliches Ideal für die europäische kulturelle Integration mit Hilfe interner und externer muslimisch-türkischer Anderer adaptiert werden kann. Diese kulturelle Dimension, eingebettet in der orientalistischen Phantasie, soll nun nach ähnlicher Logik zur europäischen kulturellen Kohäsion führen. Europa wird dabei nicht als Produkt von ambivalenten dynamischen diskursiven Prozessen, sondern als dessen Subjekt verstanden, nicht als eine diskursive imaginäre Konstruktion, deren Grenzen und Bedeutung im Laufe der Geschichte sich verändert und verschoben haben, sondern als ein von der Antike bis zur Gegenwart kontinuierliches und kontexttranszendierendes europäisches Subjekt.

Dem exklusiven Diskurs zufolge ist die Türkei »zerrissen« zwischen westlicher Moderne und Islam, während sie für den inklusiven Diskurs eine »Brücke« bedeutet, die verspricht, diese beiden historischen Konstrukte zu verbinden. Der Begriff »Zerrissenheit« versucht zu beschreiben, dass die Türkei gespalten sei zwischen West und Ost, zwischen Moderne und Tradition, Europa und Islam, und dass diese inhärenten Gegensätzlichkeiten nicht miteinander kompatibel seien. Die Brückenmetapher markiert ebenfalls Differenzen zwischen West und Ost, Europa und Islam, sie verspricht jedoch, diese naturalisierte Spaltung imaginär zu verbinden, wobei die Türkei als »Modell« für die »Islamische Welt« konzipiert wird, das die Kompatibilität von Demokratie, Laizismus und Islam beweisen soll. Aus diesen beiden diskursiven Blöcken resultieren zwei europäische Identitätsvorstellungen, die machtpolitisch in konkurrierende Handlungsoptionen für die Türkei münden: In einem soll sie inkludiert, in dem anderen Fall exkludiert werden.

Der exklusive Diskurs ist geprägt vom deutschen (»frontier«-) Orientalismus des 19. Jahrhunderts, ist defensiv und primär an Europa gerichtet, um eine belastbare europäische Identität zu konstruieren, die ein handlungsfähiges Europas gewährleisten soll. Dabei zieht er die europäischen Grenzen abseits der Türkei. Er akzentuiert die »Unvereinbarkeit von westlichen und östlichen Zivilisationen«. Der inklusive orientalistische Diskurs geht dagegen von einer missionarischen, offensiven und disziplinierenden Position aus, die sich an dem Blick einer vorgestellten »Islamischen Welt« orientiert. Europäische Werte werden $\mathrm{zu}$ universalistischen erklärt und dadurch adaptierbar gemacht. In diesem Sinne sind sie auch als eine Disziplinierung des türkischen Anderen 
im foucaultschen Sinne zu verstehen. (Es gelingt Europa jedoch keine vollständige Disziplinierung.)

Die europäische Identität formiert sich also weder isoliert noch aus sich selbst heraus und sie leitet sich nicht von sich selbst ab, sondern artikuliert sich unmittelbar in der dialogisch-diskursiven Relation zum Anderen. Die Frage, wie Europa »drüben« erscheint, was die Anderen von Europa halten, scheint dabei konstitutiv zu sein. Diese dialogische Repräsentation und Erzählstrategie zur Konsensbildung zwischen deutsch-europäischen und türkischen Diskursen jenseits der türkischen und europäischen Öffentlichkeit, hebt die Grenzen zwischen imaginiertem Europa (West) und Islamischer Welt (Ost) nicht auf, sondern verschiebt sie jenseits der Türkei. In meiner Analyse zeige ich, dass in beiden Fällen diese imaginäre »Islamische Welt« als Superadressat das konstitutive Andere des europäischen Selbst darstellt. Der Dissens zwischen beiden verlagert sich lediglich auf die Frage, ob die Türkei zum europäischen Eigenen oder zum islamischen Anderen gehört.

Die deutschen und europäischen Diskurse richten sich dabei nicht nur an einen Orient im Außen, sondern auch an einen Orient im Inneren. Sie verknüpfen die Integration von Migranten mit einem türkischen EUBeitritt: Während der exklusive orientalistische Diskurs hierbei ein Bild von »integrationsunwilligen Migranten« konstruiert und verbreitet, dass mit dem türkischen Beitritt die Integration dieser Migranten in der BRD unmöglich würde, sieht der pro-türkische inklusive Diskurs die Möglichkeit, diese »integrationsunwilligen Migranten« gerade mit Hilfe eines EU-Beitritts leichter $\mathrm{zu} »$ integrieren«. Die EU würde sich somit vom kulturellen und religiösen »Verdacht« befreien und zeigen, dass sie keine exklusive christliche Gemeinschaft, sondern ein offenes kosmopolitisches Gebilde ist.

Der exklusive Diskurs zieht hierbei mit einer Bedrohungsrhetorik ins Feld und macht muslimische Migranten zu internen orientalen Anderen. Er erbringt eine doppelte Leistung: Zum einen maskiert er durch orientalistische Bedrohungserzählungen Differenzen in nicht-westlichen Gesellschaften. Zum anderen naturalisiert er die Differenzen zwischen imaginiertem »Europa« und imaginierter »Islamischer Welt«, neutralisiert gleichzeitig innere europäische Differenzen. Die Konstruktion der Bedrohung ist als phantasmatische Abwehrtechnik zur Mobilisierung eines exklusiven Euronationalismus zu verstehen, die dazu dient, Migranten auf Distanz zu halten und die Türkei auszuschließen. Wie Talal Asad feststellt, ist der Diskurs der europäischen Identität »a symptom of anxieties about non-Europeans« (Asad 2003: 161). Nur diese privilegierte konstitutive Hauptdifferenz kann den internen strukturellen Mangel 
der kollektiven europäischen Identität verschleiern und eine harmonische Kollektivität ermöglichen.

Insofern kann, solange Europa sich von dieser politischen Phantasie des Nationalstaates nicht distanziert, kaum von seiner postnationalen Identität und über europäische Staatsbürgerschaft gesprochen werden. Der kosmopolitische Traum von einem offenen Europa hat, so zeigen der europäische Integrations- und Türkeidiskurs, die Grenzen des Nationalismus, Rassismus und Orientalismus nicht überwunden. Die Grenzen Europas werden mit dem institutionalisierten Selbstverständnis »Einheit in Vielfalt«, das vom Multikulturalismus der Nationalstaaten inspiriert scheint, nicht aufgehoben, sondern lediglich nach Osten verschoben. Die anti-kosmopolitische Figur des weißen, christlichen Europas erlebt eine politische Renaissance durch die erneute Ausgrenzung seines »anderen Selbst« (vgl. Römhild 2007: 214). Es bildet sich im Zuge seiner »Erfolgsgeschichte $\ll$, wobei die Kolonialgeschichte im Außen ausgeblendet und die Verfolgung von Minderheiten im Inneren von einem PhantasieObjekt zum anderem verschoben wird.

Mit anderen Worten: Es geht nicht um falsche Repräsentationen, die die orientalen Realitäten missrepräsentieren, sondern um eine konstruierte Phantasie bzw. Wahrheit, die Machteffekte erzeugt. Die Bedrohungserzählungen über die Türkeiintegration und Integration von muslimischen Migranten sind als Abwehrstrategien des deutschen und europäischen exklusiven Diskurses zu verstehen. Sie verdecken die Mangelhaftigkeit des deutschen und europäischen Selbst und des türkischen Anderen und weisen den Wunsch des türkischen Anderen nach einem Beitritt in die EU und die Subjektivität von muslimischen Migranten zurück. An die Stelle des europäischen strukturellen Mangels wird ein türkisch-muslimisches Phantasie-Objekt gesetzt, das den Riss, der die Gesellschaft durchzieht, verdeckt. Der Mangel erlangt somit eine illusionäre Konsistenz und Kohärenz. Die exklusive orientalistische Phantasie begehrt, durch die stabilisierende Seite des Phantasmas eine europäische Gesellschaft zu regulieren, die soziale Antagonismen und innere Differenzen verleugnet, um dadurch ein handlungsfähiges europäisches Subjekt zu erzeugen.

Sonst könnte nicht erklärt werden, warum dieser exklusive Diskurs die Spielregeln in dem Moment verändern möchte, in dem die Türkei »fähig« wurde, gewisse politische Fortschritte für die »Selbstverfeinerung« in »Richtung Europa« zu erbringen und sich den europäischen politischen Normen anzupassen. Des Weiteren bliebe unklar, warum gerade die in der deutschen bzw. europäischen Gesellschaft geborenen nachkommenden Generationen als »nicht-assimilierbar« bzw. »integrationsunwillig« gekennzeichnet werden, nicht aber die Pioniergeneration. 
Der »Dolch« des exklusiven Orientalismus scheint sich nun hinter dem Motto der sog. »Integrationsfähigkeit Europas« und »Nicht-Integrationsbereitschaft« von Migranten zu verschanzen.

In diesem ambivalenten dialogischen Formierungsprozess soll das türkische Andere in der Identitätsformation seiner selbst nicht passiv betrachtet werden. Die Performanzen des Diskurses des türkischen Anderen sollen nicht lediglich auf Reaktionen bzw. Imitationen reduziert werden. Die Türkei ist weder zerrissen zwischen »West und Ost «, »Modernität und Mittelalter« noch eine erfolgreiche Synthese dieser beiden Konstrukte. Sie ist vielmehr ein Ort, an dem soziale Spaltungen und Antagonismen erfahren, artikuliert, maskiert oder versetzt werden, wobei westliche Repräsentationen für verschiedene interne Macht- und Rechtfertigungsstrategien mobilisiert werden. Das türkische Andere gestaltet dabei seine Identität performativ mit, konstruiert Repräsentationen über Europa und den Westen, wobei deren Bedeutungen im türkischen Diskurs ambivalent bleiben. Die Ambivalenz ermöglicht widersprüchliche Bedeutungen, Repräsentationen und Spaltungen. Die westliche Zivilisation ist sozusagen ein Phantasma mit einem Januskopf ${ }^{2}$ : Der Westen ist aggressiv und bedrohlich, steht aber auch für Fortschritt und Wohlstand. Man muss seine Geschwindigkeit erreichen und sich gleichzeitig von der Dekadenz befreien, um zu überleben, man muss aber auch ihm gegenüber immer wachsam bleiben.

Die türkische nationale Identität ist somit ein paradigmatisches Modell für »Dritte-Welt-Nationalismen«, bei denen die ambivalente Bedeutung des Westens eine zentrale Rolle spielt. Die türkischen Eliten hatten und haben eine zweifache Aufgabe: Sie müssen sich sowohl nach außen vor Europa als auch nach innen vor der »Nation« legitimieren. Diese Aufgabe wird durch eine mehrdeutige Diskursformation gemeistert. Eine Modernisierungs- und Demokratisierungsstrategie, die die als notwendig erachteten modernen Technologien und Normen der westlichen »Zivilisation« domestiziert und auf jene verzichtet, die für übermäßig gehalten werden. Die nach innen gerichteten Machtstrategien der türkischen modernistischen Eliten formieren sich in dieser Balance zwischen dem, was für gut und nützlich befunden, und dem, was als schlecht und schädlich angesehen wird (vgl. Ahıska 2005). Genau hier, in diesen inneren Grenzziehungstechniken, manifestiert sich die türkische Subjektivität. »Wir übernehmen die westliche Zivilisation nicht, um sie zu imitieren, sondern internalisieren jene Elemente, die unserem Körper ange-

2 Allein im Text der türkischen Nationalhymne wird die okzidentalistische Angst konstruiert. Sie fängt schon ermutigend mit den Worten an: »Fürchte dich nicht « (Korkma). 
messen sind, um das Stadium der westlichen Zivilisation zu erreichen.« (Afet İnan 1968, zit.n. Kahraman 2002: 162f)

Den türkischen Gesamtdiskurs habe ich als Okzidentalismus bezeichnet, der den türkischen Akteuren einen autonomen Handlungsspielraum in der Begegnungspraxis mit den europäischen Diskursen anbietet. Es geht hierbei um die Formation eines Gesamtdiskurses, der sich aus der Kombination einer westlichen Konstruktion der Türkei mit einer türkischen Konstruktion vom Westen zusammensetzt. Dabei blicke ich nicht nur auf die ambivalente türkische Identität, in der das Bild und der Blick vom Westen ein integraler Bestandteil dieser Identität wurde, sondern betrachte explizit die widersprüchlichen Praktiken des türkischen Anderen sowie die nach innen gerichteten Machteffekte des Okzidentalismus. Wie der Orientalismus ist auch der Okzidentalismus als diskursive Reaktion des Anderen widersprüchlich. Er unterscheidet sich vom Orientalismus, aber er formiert sich nicht isoliert, sondern befindet sich in einem hegemonialen dialogischen Formierungsprozess mit ihm. Sein Verhältnis zum Westen resultiert aus einem Gefühl des Mangels bzw. des Verspätetseins, das den Identifikationsprozess mit dem Westen auf Dauer stellt. Die Konstruktion der türkischen Nation findet, wie Meltem Ahıska beobachtet, im Kontext eines vorgestellten Westens statt, anhand dessen die türkischen Eliten die »Defizite« beim lokalen Volk identifizieren und sie dann nach diesem imaginierten westlichen Modell »zivilisieren« wollen (vgl. Ahıska 2005).

$» \mathrm{I}$ understand the Turkish Revolution as Westernization. All the works achieved until today are nothing other than this. I would like to express my opinions on the defect of the Revolution from this point of view [...] As we westernize we should transfer the Western worldview, the Western mentality [...] We do not even have an encyclopaedia. The developed countries already have their own. What we should do is to translate them with some additions. Moreover, we have to translate all classical and main works of the West. We should add the works of the ancient Greece and Rome to them.« (Esat, zit.n. Ertuğrul 2000: 81)

Der modernistische türkische Blick hat sich historisch immer am Westen orientiert, ihn beantwortet und adressiert und sich darüber selbst reguliert. Die Begründung der republikanischen Reformen während zu Beginn des türkischen Nationsbildungsprozesses (ca. 1923-1932) lautete: »it was necessary to show that the mentality of Turkish nation was not different from that of the civilized social life« (Atatürk, zit.n. Ertuğrul 
2000: 82). ${ }^{3}$ Der imaginierte Westen wird dabei zum Modell, an dem der türkische Diskurs selbst mit seinem politischen Diskurs konstruierend beteiligt ist. Es wird davon ausgegangen, dass der Westen die Türkei beobachtet, und unter der Vorstellung von diesem Blick betrachtet er sich selbst. Europa als »Superadressat" ist ein konstitutiver Aspekt der türkischen nationalen Identität, er strukturiert den türkischen Diskurs, konzipiert als imaginierter Zuhörer und Beobachter.

Die interne Teilungspraktik - zwischen Türkischsein und NichtTürkischsein -zwischen modern/fortschrittlich und feudal/rückschrittlich durch die dialogische Konstruktion von imaginärem Westlich- und Östlichsein im Außen und Innen, hatte in der frühen Phase der türkischen Republik das Ziel, eine harmonische türkische Gesellschaft nach einem vorgestellten westlichen Modell zu konstruieren. Alles, was mit dieser Imagination nicht vereinbar war, war »östlich« und »rückständig«, konstruierte interne Differenzen (islamisch-osmanische Tradition, ethnische und religiöse Differenzen etc.) und wurde verleugnet - nach dem Motto: Maskieren von Differenzen und Eliminierung der für rückständig gehaltenen Lokalitäten, um westlich und modern zu erscheinen. Die türkische nationale Identität wurde genau auf diesem Spannungsverhältnis zwischen imaginärem West und Ost konstruiert, das zwar nach wie vor präsent ist, jedoch bezüglich seiner Subjektpositionen im okzidentalistischen Diskurs eine Verschiebung erlebt. Paradoxerweise sind es gegenwärtig diese ausgeschlossenen internen »östlich-rückständigen « Subjekte, die nun zu Trägern des Europäisierungsprozesses, also zu Befürwortern der Türkei-Integration in die EU geworden sind. Die ehemaligen Träger des Modernisierungsprozesses (kemalistische Säkularisten) hingegen, die zum Ziel hatten, das Land auf einen »zeitgemäßen (westlichen) Zivilisationsstand« zu bringen, wirken nun der Integration entgegen.

Es formieren sich somit auch innerhalb des türkischen symbolischen Feldes zwei hegemoniale Blöcke. Wenn ich auf der deutschen bzw. europäischen Ebene zwischen einem pro-türkischen inklusiven und einem kontra-türkischen exklusiven Orientalismus unterschieden habe, so habe ich im Kontext des türkischen diskursiven Feldes zwischen einem kontra-europäischen nationalistischen und einem pro-europäischen pragmatischen Okzidentalismus unterschieden. Der kontra-europäische nationalistische Okzidentalismus versucht, über eine negative Zuschreibung Europas sich national zu konsolidieren. Europa sei demnach »unehrlich« und »doppelgesichtig«, behandle die Türkei nicht

3 Atatürk beantwortete eine Frage im Hinblick auf das Verbot des Fez während der sog. Hutreform. 
gleich, »erzeuge« Minderheiten und stelle Bedingungen, die die Integrität des Staates bedrohen.

Der nationalistische Okzidentalismus verschiebt die Gegenwart und fokussiert sich auf eine vorgestellte Zukunft, die wiederum von der Vergangenheit überschattet ist. Auch in der Gegenwart spielt dieser Diskurs als ein historisches Konstrukt eine zentrale Rolle. Dieses ambivalente nationale Imaginäre ist mehr als eine Begeisterung oder ein Hassgefühl, es kennzeichnet die nach innen gerichteten zentralistischen Machtstrategien. Es ist jenes Dispositiv ${ }^{4}$, das die türkischen Machtstrukturen konsolidiert, indem es stetig Differenzen und Konflikte maskiert oder sie durch Bedrohungserzählungen als interne und externe Andere identifiziert und damit versucht, den gesellschaftlichen Dissens außer Kraft zu setzen. Es begrenzt, was vorzustellen ist und was nicht, was wahr und was falsch ist. Es ist eine mythische Vorstellung von Modernität, die unter mangelnder Historizität leidet. Es ist ein Modus der Repräsentation, der die Komplexität und Heterogenität der türkischen sowie der europäischen Gesellschaft auf ein nationales Deutungsmuster reduziert. Dies geschieht entweder durch die Unterdrückung oder durch die Aufhebung von Differenzen, indem die Vorstellung einer zeitlosen Polarisierung zwischen West und Ost in den Vordergrund gestellt wird.

Der nationalistische Diskurs unterscheidet nicht nur zwischen dem externen »West « und »Ost«, sondern konstruiert diese ebenfalls in der türkischen Gesellschaft. Mittels dieser Spaltung teilt er die türkische Gesellschaft in Freunde und Feinde, Patrioten und Verräter, Laizisten und islamische Fundamentalisten. Obwohl er sich nach außen richtet und Europa herauszufordern scheint, hat er unmittelbare innenpolitische Folgen. Mit Hilfe einer anti-imperialistischen Rhetorik versucht der Diskurs vor allem, jene innenpolitischen Dissense aufzulösen und Minderheiten zu disziplinieren, die sich während des fortschreitenden EUIntegrationsprozesses der Türkei öffentlich immer stärker artikulieren. Er okzidentalisiert die Minderheiten, die Ansprüche auf politische Rechte und auf Gleichstellung stellen. Der Diskurs bemüht sich, diesen

4 Foucaults Begriff des Dispositivs geht über den Diskurs hinaus, es stellt ein heterogenes Ensemble dar, das Diskurse, Institutionen, reglementierende Entscheidungen, Gesetze, kollektive Symbole, symbolische und/ oder psychische Gewalt, wissenschaftliche Aussagen, kurzum, Gesagtes wie Ungesagtes einschließt. Das Dispositiv zeigt ein Netz zwischen verschiedenen sagbaren und sichtbaren Praktiken an (vgl. Foucault 1978: 119). Verbinden die Diskurse einzelne Aussagen nach bestimmten Formationsregeln, so stellen die Dispositive Anschlüsse von Diskursen, Praktiken und Macht dar (vgl. Seier 1999: 80), als ein komplexes Netzwerk von Macht und Herrschaftsbeziehungen (vgl. Lorey 1999: 94; Torfing 1999: 91). 
»Riss« zu nähen, indem er Europa bzw. die EU als hinterhältig und unehrlich stigmatisiert und unterstellt, Europa wolle unter dem Deckmantel der Menschenrechte die Türkei spalten.

Der nationalistische Okzidentalismus bringt also zwei zentrale Performanzen hervor. Die erste ist: Mittels Bedrohungserzählungen stellt er die europäischen Institutionen unter Verdacht und die Legitimität der politischen Kriterien in Frage. Er neutralisiert innereuropäische Differenzen. Durch die Konstruktion einer solchen »unehrlichen« Europa-Repräsentation schafft er zweitens ein imaginär homogenes Türkischsein, indem innertürkische Differenzen und Identitäten maskiert werden. Er konstruiert anhand der Erzeugung einer geschichtslosen Familien-Simulation eine transhistorische ästhetische Nation. Diese Familie hat »ältere Brüder« und einen »Vater«, die die Mission übernommen haben, die Einheit der im öffentlichen Raum symbolisch konstruierten Familie vor internen »Nestbeschmutzern « und externen Feinden zu schützen. Die Familie setzt einen autoritären Vater voraus, der für Gehorsam, Disziplin und Geschlossenheit zuständig ist (vgl. Sarıbay 1995: 160ff). Der väterliche Staat muss daher geliebt werden, er hat viele Feinde und kaum Freunde. Alle diese symbolischen Figuren und Elemente bestimmen die Grenzen der Ordnung des okzidentalistischen Gesamtdiskurses, die stets durch interne (Minderheiten) und externe (Europa) Symptome versetzt werden. Der Staat wird dabei nicht als Institution, sondern vielmehr als eine ästhetische moralische Gemeinschaft konzipiert, die eine Ausdifferenzierung der Gesellschaft als Bedrohung wahrnimmt. Er wird nicht als eine gemeinsame öffentliche Institution, sondern als ein Gut, das bestimmte Besitzer hat, wahrgenommen.

Der (pro-europäische) pragmatische Diskurs hingegen akzentuiert die »Brückenfunktion«. Er orientiert sich am inklusiven orientalistischen Diskurs. Die Brücke wird somit das Medium der diskursiven Verknüpfung. An dieser Schnittstelle offenbart sich die dialogische Identifikation des Türkischen mit dem inklusiven Diskurs des europäischen Anderen. Hier wird die orientalistische Repräsentation angeeignet und der Blick des europäischen Anderen wirkt konstitutiv. Es formiert sich eine prekäre hegemoniale Übereinstimmung zwischen den deutschen und europäischen inklusiven Orientalisten und den türkischen pragmatischen Okzidentalisten, entlang der »Brückenfunktion« der Türkei und ihrer geostrategischen Relevanz sowie ihrer Demokratisierung und Stabilisierung durch den EU-Beitritt. Die Hegemonie des europäischen Diskurses scheint in dieser Hinsicht heute nunmehr weniger über ehemalige etatistische (nationalistische) Eliten im Zentrum hergestellt zu sein - was zu Beginn des vergangenen Jahrhunderts sicherlich der Fall war - sondern vielmehr über die subalternen internen Anderen, die während des türki- 
schen Nationsbildungsprozesses marginalisiert und maskiert wurden. Ein EU-Beitritt der Türkei bietet diesen internen Anderen diskursive und institutionelle Gelegenheiten und eine Legitimationsbasis an, ihre politische Subjektivität $\mathrm{zu}$ artikulieren. Es wird als eine Metapher für den politisch-rechtlichen Kampf gegenüber dem etablierten nationalistischen säkularistischen Dispositiv verstanden. Es ist genau diese »heimliche Allianz«, diese diskursive Verschränkung zwischen europäischem inklusivem Diskurs und ausgeschlossenen symptomatischen Stimmen, die die nationalistisch-säkularistische symbolische Ordnung versetzt und nationalistische Bedrohungserzählungen hervorruft. Die Effekte dieser symptomatischen Wirkung führen zu einer massiven Zunahme des Nationalismus in der Türkei, der sich in den hysterischen Massenmobilisierungen in den Großstädten der Türkei manifestiert.

Der politische Islam taucht als Symptom des säkularistischen Diskurses bzw. Dispositivs auf. Es gilt zu unterstreichen, dass der pragmatische islamistische Diskurs sich kaum vom türkischen Nationalismus distanziert, er formiert sich mit eigener »versöhnlich-toleranter« nationalistischer Rhetorik, wobei die Bedeutung Europas auch für ihn ambivalent bleibt, insbesondere wenn Minderheitenrechte thematisiert werden. Genau hier hört sein dialogischer »Kommunikationszusammenhang« mit dem inklusiven orientalistischen Diskurs auf. Es entsteht eine symbolische Lücke, sein okzidentalistischer Diskurs stößt an seine externen Grenzen. Auf diesem thematischen Feld integriert das »unehrliche Europa « den nationalistischen und pragmatischen Diskurs entsprechend der Devise: Wir sind alle »orientale«/muslimische Brüder und Schwestern, die mit europäischen Fremden nicht verglichen werden dürfen. Beide Positionen, eingebettet im okzidentalistischen Imaginären, lassen sich also verschränken, indem sie nicht nur ein ideales Bild von einer harmonischen »östlichen« Türkei konstruieren, sondern gleichzeitig eine einheitliche negative Europa-Repräsentation entgegenstellen. Während die Aussagen über »türkische Sensibilitäten«, »europäische Doppelgesichtigkeit« und »Erzeugung von Minderheiten« die nationalistische Positionierung des okzidentalistischen Diskurses zeigen, signalisieren die Aussagen »die türkische Brückenfunktion« bzw. »das türkische Modell« eine pragmatische Positionierung des okzidentalitischen Diskurses. Für beide werden die politischen gesellschaftlichen Reformen weniger als eine Lösung aktueller politischer und sozialer Probleme, sondern vielmehr entweder als Kodex und Symbol einer gewünschten oder als Bedrohung einer gefürchteten Verwestlichung angesehen, wobei der imaginäre Blick des europäischen Anderen konstitutiv wirkt. 



\section{LITERATUR}

Untersuchte Zeitungen (jeweils Dezemberausgaben von 1997, 1999, 2002, 2004)

Cumhuriyet (CUM)

Frankfurter Allgemeine Zeitung (FAZ)

Hürriyet (HÜR)

Süddeutsche Zeitung (SZ)

Tageszeitung (TAZ)

Zaman (ZAM)

\section{Sekundärliteratur}

Abélès, Marc (2000): Virtual Europe, in: Bellier, Irene/Wilson, Thomas M. (Hg.), An Anthropology of The European Union. Building, imaging and experiencing the new Europe, Oxford/New York: Berg, S. $31-53$

Abromeit, Heidrun (1998): Ein Vorschlag zur Demokratisierung des europäischen Entscheidungssystems, in: Politische Vierteljahresschrift, 1, S. 81-90

Adanır, Fikret (2001): Das Osmanische Reich als orientalistische Despotie in der Wahrnehmung des Westens, in: Kürşat-Ahlers, Elçin (Hg.), Türkei und Europa. Facetten einer Beziehung in Vergangenheit und Gegenwart, Frankfurt: IKO Verlag, S. 83-122

Adler, Emanuel (1997): Seizing the Middle Ground: Constructivism in World Politics, in: European Journal of International Relations, 3, S. 319-363 
Adler, Emanuel/Barnett, Michael (Hg.) (1998): Security communities, Cambridge: Cambridge University Press

Ahıska, Meltem (2000): Occidentalist Fantasy: Turkish Radio and National Identity, Ph.D. Diss., Goldsmiths College, University of London

- (2003): Occidentalism: The Historical Fantasy of the Modern, in: The South Atlantic Quarterly, 102 (2/3), Duke University Press, S. 351379

- (2005): Radyonun Sihirli Kapısı. Garbiyatçılık ve Politik Öznellik, Istanbul: Metis

- (2006): Hayal edilemeyen toplum: Türkiye'de »çevresiz merkez« ve Garbiyatçılık, in: Toplum ve Bilim, 105, İstanbul, S. 11-29

Ahmad, Aijaz (2000): Between Orientalism and Historicism, in: Macfie, Alexander L. (Hg.) Orientalism. A Reader, New York: New York University Press, S. 285-298

Akça, Ismet (2003): Peripheral Type of Military - Industrial Complex: Military Capital in Turkey, Paper presented at the Fourth Mediterranean Social and Political Research Meeting, Florence/Montecatini Terme, 19.-23. March

Akçam, Taner (1995): Türk Ulusal Kimliği ve Ermeni Sorunu, İstanbul: Iletişim

Alcorn, Marshall W. (1994): The Subject of Discourse: Reading Lacan through (and beyond) Poststructuralist Contexts, in: Bracher, Marc et al. (Hg.), Lacanian Theory of Discourse. Subject, Structure and Society, New York/London: New York University Press, S. 19-45

Alkan, M. Nail (1994): Die Perzeption der Türkei im Spiegel der westdeutschen Presse von 1960 bis 1971, Diss. Phil., Bonn

Altan, Mehmet (2002): Batılılaşmanın Sosyo-politik Temelleri, Düşünsel ve Toplumsal Yapısı, in: Modern Türkiye'de Siyasi Düşünce, Modernleşme ve Batıcılık, Band 3, İstanbul: İletişim, S. 141-147

Althusser, Luis (2000); Ideology and Ideological State Apparatuses (Notes towards an Investigation), in: Žižek, Slovaj (Hg.), Mapping Ideology, London/New York: Verso, S. 100-140

Amin, Samir (2001): The Construction of Eurocentric Culture, in: Brydon, Diana (Hg.), Postcolonialism. Critical concepts in literary and cultural studies, Band 4, S. 1674-1691

Angelova, Penka (2007): Der Balkan - »Eine Landschaft als Schicksal«? Die Landschaft und das Schicksal, in: www.inst.at/berge/ perspektiven/angelova.htm (zuletzt aufgerufen: 24.03.2007)

Angermüller, Johannes (2005): Diskurs als Aussage und Äußerung. Die enunziative Dimension in den Diskurstheorien Michel Foucaults und 
Jacques Lacans, in: www.johannes-angermueller.de (zuletzt aufgerufen: 20.05.2005)

Arai, Masami (2001): Jön Türk Dönemi Türk Milliyetçiliği, in: Modern Türkiye'de Siyasi Düşünce, Tanzimat ve Meşrutiyet'in Birikimi, Band 1, İstanbul: İletişim, S. 180-196

Asad, Talal (2002): Muslims and European Identity: Can Europe Represent Islam?, in: Pagden, Aanthony (Hg.), The Idea of Europe. From Antiquity to the European Union, Washington: Woodrow Wilson Press/Cambridge University Press, S. 209-227

- (2003): Formations of the Secular. Christianity, Islam, Modernity, Stanford: Stanford University Press

Ataç, İlker/Şener, Ulaş. (2005): Aufeinanderprallende Diskurse: Der türkische EU-Beitritt und die besondere europäische Frage, in: Kurswechsel, 1, S. 84-92

Ataç, İlker (2001): Der politische Islam in der Türkei: eine geographische und historische Analyse der Hegemoniebildung, nicht veröffentlichte Diplomarbeit, eingereicht am Institut für Politikwissenschaft der Universität Wien

- (2007): Überlegungen über das Verhältnis von Staat und Ökonomie in der Semiperipherie. Vortrag im Rahmen der Tagung »Staatstheorie vor neuen Herausforderungen« der Assoziation für kritische Gesellschaftsforschung, 13.-15. April 2007, Frankfurt a.M.

Atatürk, M. Kemal (1999): Medeniyet ne Demektir, in: Atatürk Kültür, Dil ve Tarih Yüksek Kurumu (Hg.), Atatürk'ün Kültür ve Medeniyet Konusundaki Sözleri, Ankara: AKM, S. 3

Aydın, Suavi (2001): İki İttihat-Terraki: İki Ayrı Zihniyet, İki ayrı Siyaset, in: Modern Türkiye'de Siyasi Düşünce, Tanzimat ve Meşrutiyet'in Birikimi, Band 1, İstanbul: İletişim, S. 117-128

Bakhtin, Mikhail (2001): Romanda Söylem, in: Irzık, Sibel (Hg.), Karnavaldan Romana. Mikhail Bakhtin. Edebiyat Teorisinden Dil Felsefesine Seçme Yazılar, İstanbul: Ayrıntı, S. 33-79

- (2001): Dostoyevski'nin yapıtlarında tür ve olay örgüsü oluşumunun karakteristikleri, in: Irzık, Sibel (Hg.), Karnavaldan Romana. Mikhail Bakhtin. Edebiyat Teorisinden Dil Felsefesine Seçme Yazılar, İstanbul: Ayrınt1, S. 209-314

Balibar, Ètienne (2003): Sind wir Bürger Europas? Politische Integration, soziale Ausgrenzung und die Zukunft des Nationalen, Hamburg: Hamburger Edition

- (2002/2003): Europe: Vanishing Mediator?, Mosse-Lectures, Humboldt Universität zu Berlin

Banchoff, Thomas (1999): German Identity and European Union, in: European Journal of International Relations, 5 (3), S. 259-289 
Barrett, Michele (2004): Marx'tan Foucault'ya İdeoloji, Ankara: Doruk - (2000): Ideology, Politics, Hegemony: From Gramsci to Laclau and Mouffe, in: Žižek, Slovaj (Hg.), Mapping Ideology, London/New York: Verso, S. 235-264

Bartlett, Robert (1993): The Making of Europe, London: Penguin

Bauman, Zigmund (1996): Moderne und Ambivalenz. Das Ende der Eindeutigkeit, Frankfurt: Fischer

Belge, Murat (2002): Batılılaşma: Türkiye ve Rusya, in: Modern Türkiye'de Siyasi Düşünce, Modernleşme ve Batıcılık, Band 3, İstanbul: İletişim, S. 43-56

Bellier, Irène (2000): The European Union, Identity politics and the Logic of Interests' Representation, in: Ders./Wilson, Thomas M., An Anthropology of The European Union. Building, imaging and experiencing the new Europe, Oxford/New York: Berg, S. 53-75

Bellier, Irène/Wilson, Thomas M. (2000): Introduction, in: Dies. (Hg.), An Anthropology of The European Union. Building, imaging and experiencing the new Europe, Oxford/New York: Berg, S. 1-31

Berkes, Niyazi (2006): Türkiye'de Çağdaşlaşma, İstanbul: YKY

Berktay, Halil (1998): Geschichte, gesellschaftliches Gedächtnis und die aktuelle Neurose, in: Grenzfall Europa. Deutch-Türkisches Symposium 1998, Hamburg: Körber-Stiftung, S. 153-168

Bhahba, Homi K. (2001): DissemiNation: time, narrative, and the margins of the modern nation, in: Brydon, Diana (Hg.), Postcolonialism. Critical concepts in literary and cultural studies, Band 2, S. 610-645

Bhahba, Jacqueline (1999): Belonging in Europe: citizenship and postnational rights, in: International Social Science Journal, 51, S. 11-23

Bieler, Andreas/Morton, A. David (2004): A Critical Theory Route to Hegemony, World Order and Historical Change: Neo-Gramcian Perspectives, in: Capital and Class, 82, S. 85-113

Biersteker, Thomas J. (1989): Critical reflections on Post-Positivism in International Relations, in: International Relations Quarterly, 33 (3), S. 263-267

Bilmez, Bilmez Can (2000): Demiryolu'ndan Petrole: Chester Projesi (1908-1923), İstanbul: Tarih Vakfi

Bodemann, Michael (2004): Das Phantom der Wüstengesellschaft, in: www.taz.de/index.php?id=archivseite $\&$ dig=2004/11/25/a0176 (zuletzt aufgerufen: 20.05.2007)

Bora, Tanıl (2002): Milliyetçi - Muhafazakar ve İslami Düşünüşte Negatif Batı İmgesi, in: Modern Türkiye'de Siyasi Düşünce, Modernleşme ve Batıcılık, Band 3, İstanbul: İletişim, S. 251-269

Bracher, Marc et al. (Hg.) (1994): Lacanian Theory of Discourse. Subject, Structure and Society, New York/London 
Brague, Remi (1993): Europa. Eine exzentrische Identität, Frankfurt/ New York: Campus

Brubaker, R. (1992): Citizenship and Nationhood in France and Germany, Cambridge: Harvard University Press

Bublitz, Hannelore (1999): Diskursanalyse als Gesellschaftstheorie, in: Dies. et al. (Hg.), Das Wuchern der Diskurse. Perspektiven der Diskursanalyse Foucaults, Frankfurt/New York: Campus, S. 22-48

Bublitz, Hannelore. et al. (1999): Diskursanalyse - (k)eine Methode. Eine Einleitung, in: Dies. et al. (Hg.), Das Wuchern der Diskurse. Perspektiven der Diskursanalyse Foucaults, Frankfurt/New York: Campus Verlag, S. 10-22

Bührmann, A. Dorothea (1999): Der Diskurs als Diskursgegenstand im Horizont der kritischen Ontologie der Gegenwart, in: Bublitz, Hannelore et al. (Hg.), Das Wuchern der Diskurse. Perspektiven der Diskursanalyse Foucaults, Frankfurt/New York: Campus, S. 49-63

Campbell, David (1992): Writing Security, Minneapolis: University of Minnesota Press

- (1998): National Deconstruction: Violence, Identity, and Justice in Bosnia. Minneapolis: University of Minnesota Press

Chatterjee, Partha (1993): The Nation and its Fragments, Princeton: Princeton University Press

- (2006): Mağdurların Siyaseti, İstanbul: İletişim [Original: The Politics of the Governed]

Checkel, Jeffrey T. (1999): Social Construction and Integration, in: Journal of European Public Policy, 6 (4), S. 545-560

Chen, Xiaomei (2001): Introduction to Occidentalism, in: Brydon, Diana (Hg.), Postcolonialism. Critical concepts in literary and cultural studies, Band 3, S. 934-960

Christiansen, Thomas et al. (Hg.) (1999): The Social Construction of Europe, in: Journal of European Public Policy, 6 (4), S. 528-544

Cizre, Ümit (2004): Problems of democratic governance of civil-military relations in Turkey and the European Union enlargement zone, in: European Journal of Political Research, 43, S. 107-125

Clausen, S. Erik (1998): Applied Correspondence Analysis. An Introduction, London/New Delhi: Sage Publication

Connolly, William E. (1995): Kimlik ve Farklılık, Siyasetin Açmazlarina Dair Demokratik Çözüm Önerileri, İstanbul: Ayrıntı [Original: Identity \& Difference. Democratic Negotiations of Political Paradoks]

Conrad, Sebastian/Randeria, Shalini (Hg.) (2002): Einleitung. Geteilte Geschichten - Europa in der postkolonialen Welt, in: Dies. (Hg.), Jenseits des Eurozentrismus. Postkoloniale Perspektiven in den Ge- 
schichts- und Kulturwissenschaften, Frankfurt/New York: Campus, S. 9-49

Coronil, Fernando (2002): Jenseits des Okzidentalismus. Unterwegs zu nichtimperialen geohistorischen Kategorien, in: Conrad, Sebastian/Randeria, Shalini (Hg.), Jenseits des Eurozentrismus. Postkoloniale Perspektiven in den Geschichts- und Kulturwissenschaften, Frankfurt/New York: Campus, S. 177-218

Çaha, Ömer (2000): Aşkın Devletten Sivil Topluma, İstanbul: Gendaş

Çetinsaya, Gökhan (2001a): Kalemiye'den Mülkiye'ye Tanzimat Zihniyeti, in: Modern Türkiye'de Siyasi Düşünce, Modernleşme ve Bat1cılık, Tanzimat ve Meşrutiyet'in Birikimi, Band 1, İstanbul: İletişim, S. 54-72

- (2001b): Islami Vatanseverlikten Islam Siyasetine, in: Modern Türkiye'de Siyasi Düşünce, Modernleşme ve Batıcılık, Tanzimat ve Meşrutiyet'in Birikimi, Band 1, İstanbul: İletişim, S. 265-273

Çil, Nevim (2007): Topographie des Außenseiters. Türkische Generationen und der deutsch-deutsche Wiedervereinigungsprozess, Berlin: Schiler

Davies, Norman (1996): Europe. A History, Oxford/New York: Oxford University Press

Delanty, Gerard (1995): Inventing Europe. Idea, Identity, Reality, London: Macmillan

Demirel, Tanel (2003): Civil-Military Relations in Turkey: Two Patterns of Civilian Behavior towards Military, in: Turkish Studies, 4 (3), London: Frank Cass, S. 1-25

Bartsch, Matthias et al. (2007): Haben wir schon die Scharia?, in: Der Spiegel, Mekka Deutschland. Die stille Islamisierung, 13, S. 22-25

Derrida, Jacques (1992): Reflections on Today's Europe. Indianapolis: Indiana University Press

Diaz-Bone, Rainer (1999): Probleme und Strategien der Operationalisierung des Diskursmodells im Anschluss an Michel Foucault, in: Bublitz, Hannelore et al. (Hg.), Das Wuchern der Diskurse. Perspektiven der Diskursanalyse Foucaults, Frankfurt/New York: Campus, S. 119-136

Diez, Thomas (1999): Speaking Europe: The Politics of Integration Discourse, in: Journal of European Public Policy, 6 (4), S. 598-613

- (2001): Europe as a Discoursive Battleground. Discourse Analysis and European Integration Studies, in: cooperation and conflict, 36 (1), S. 5-38

Donati, Paolo R. (2001): Die Rahmenanalyse politischer Diskurse, in: Keller, Rainer et al. (Hg.), Handbuch Sozialwissenschaftliche Dis- 
kursanalyse, Band 1: Theorien und Methoden, Opladen: Leske \& Budrich, S. 145-177

Doty, Roxanne (1996): Imperial Encounters, Minneapolis: University of Minnesota Press

Dreyfus, Hubert L./Rabinow, Paul (1994): Michel Foucault. Jenseits von Strukturalismus und Hermeneutik, Weinheim: Beltz-Athenäum

- (2000): Ideology and its Vicissitudes in Western Marxism, in: Žižek, Slovaj, Mapping Ideology, London/New York: Verso, S. 179-226

Eder, Klaus (1999): Integration durch die Kultur. Das Paradox der Suche nach einer europäischen Identität, in: Segers, Rien T./Viehoff, Reinhold (Hg.), Kultur, Identität, Europa: über die Schwierigkeiten und Möglichkeiten einer Konstruktion, Frankfurt: Suhrkamp, S. 147-179

- (2000): Zur Transformation nationalstaatlicher Öffentlichkeit in Europa, in: Berliner Journal für Soziologie, 2, S. 167-184

- (2004): Europäische Öffentlichkeit und multiple Identitäten - das Ende des Volksbegriffs?, in: Franzius, Claudio/Preuß, Ulrich K. (Hg.), Europäische Öffentlichkeit Baden-Baden: Nomos, S. 59-78

- (2005): Remembering together, in: Ders./Willfried, Sphon. (Hg.), Collective Memory and European Identity. The Effects of Integration and Enlargement, Aldershot: Ashgate, S. 197-220

- (2006a): Transnationale Kommunikationsräume und die Entstehung einer europäischen Gesellschaft, in: Hettlage, Robert/Müller, H. Peter. (Hg.), Die europäische Gesellschaft, Konstanz: UVK, S. 155173

- (2006b): Europe's borders. The narrative construction of the boundaries of Europe, in: European Journal of Social Theory, 9, S. 255-271

Eder, Klaus et al. (1998): Regieren in Europa jenseits öffentlicher Legitimation? Eine Untersuchung zur Rolle von politischer Öffentlichkeit in Europa, in: Kohler-Koch, Beate (Hg.), Regieren in entgrenzten Räumen, Opladen/Wiesbaden: Westdeutscher Verlag, S. 321-344

Elias, Norbert/Scotson, John L. (1993): Etablierte und Außenseiter, Baden-Baden: Suhrkamp

Ertuğrul, Kürşat (2000): Contemporary Image of European Identity and Turkish Experience of Westernisation, nicht veröffentlichte Dissertation, Middle East Technical University, Ankara

Eralp, Atilla (1997): Türkiye ve Avrupa: Batılılaşma Kalkınma Demokrasi, Ankara: Imge

Eryılmaz, Bilal (1996): Osmanlı Devletinde Gayrimüslim Tebaanın Yönetimi, İstanbul: Risale

Europäischer Rat Kopenhagen, 21.-22. Juni 1993, in: www.consilium. europa.eu (zuletzt aufgerufen: 29.06.2007) 
Etöz, Zeliha (2001): Das Osmanische Reich in Reisebeschreibungen und Konsulberichten, in: Kürşat-Ahlers, Elçin et al. (Hg.), Türkei und Europa. Facetten einer Beziehung in Vergangenheit und Gegenwart, Frankfurt: IKO Verlag, S. 63-82

Fanon, Frantz (1967): Black Skin. White Masks, New York: Grove Press

Fink, Bruce (1997): The Lacanian Subject. Between Language and Jouissance, Princeton/New Jersey: Princeton University Press

Foucault, Michel (1973): Archäologie des Wissens, Frankfurt: Suhrkamp

- (1977): Überwachen und Strafen. Die Geburt des Gefängnisses, Frankfurt: Suhrkamp

- (1978): Dispositive der Macht, Berlin: Merve

— (1983): Der Wille zum Wissen. Sexualität und Wahrheit I, Frankfurt: Suhrkamp

- (1987): Nachwort von Michel Foucault. Das Subjekt und die Macht, in: Dreyfus, Hubert L./Rabinow, Paul (1994): Michel Foucault. Jenseits von Strukturalismus und Hermeneutik, Weinheim: BeltzAthenäum, S. 243-260

- (1991): Die Ordnung des Diskurses, Frankfurt: Fischer

- (1999): In Verteidigung der Gesellschaft, Vorlesungen am College de France (1975-1976), Frankfurt: Suhrkamp

Frank, Robert (2002): The Meaning of Europe in French National Discourse: A French Europe or Europeanized France?, in: Malmborg, Mikael/Stråth, Bo (Hg.), The Meaning of Europe, Oxford/New York: Berg, S. 311-326

Franzosi, Roberto (1987): The Press as a source of socio-historical data: Issues in the methodology of data collection from newspapers, in: Historical Methods, 20, S. 5-15

Fröhlich, Anne S. et al. (2000): Das Mittelmeer. Festungsgraben oder Brücke? Wie ein anderes Europa Menschen im und aus dem Mittelmeerraum begegnen könnte, in: Kutz, Martin/Weyland, Petra (Hg.), Europäische Identität. Versuch kulturelle Aspekte eines Phantoms zu beschreiben, Bremen: Edition Temmen, S. 271-298

Geier, Manfred/Woetzel, Harald (1983): Das Subjekt des Diskurses, Berlin: Argument

Gerhards, Jürgen (2003): Diskursanalyse als systematische Inhaltsanalyse. Die öffentliche Debatte über Abtreibungen in den USA und in der BRD im Vergleich, in: Keller, Rainer et al. (Hg.), Handbuch Sozialwissenschaftliche Diskursanalyse, Band 2: Forschungspraxis, Opladen: Leske \& Budrich, S. 299324 
Gingrich, Andre (1999): Österreichische Identitäten und Orientbilder. Eine ethnologische Kritik, in: Dostal, Walter et al. (Hg.), Wir und die Anderen, Wien: WUV Universitätsverlag, S. 29-34

Göçek, F. Müge (1996): Rise of the Bourgeoisie, Demise of Empire. Ottoman Westernization and Social Change, New York/Oxford: Oxford University Press

Gökmen, Özgür (2002): 28 Şubat: Bir »Batılılaşma Restorasyonu mu?«, in: Modern Türkiye'de Siyasi Düşünce, Modernleşme ve Batıcılık, Band 3, İstanbul: İletişim, S. 347-351

Göle, Nilüfer (1998): Modernleşme Bağlamında Islami Kimlik Anlayışı, in: Bozdoğan, Sibel/Kasaba, Reşat (Hg.), Türkiye'de Modernleşme ve Ulusal Kimlik, İstanbul: Tarih Vakfi, S. 70-82

Gülalp, Haldun (1998): Türkiye'de Modernleşme Politikaları ve İslamcı Siyaset, in: Bozdoğan, Sibel/Kasaba, Reşat (Hg.), Türkiye'de Moderleşme ve Ulusal Kimlik, İstanbul: Tarih Vakfi, S. 43-54

Gür, Gürsel (1998): Das Türkeibild in der deutschen Presse unter besonderer Berücksichtigung der EU-Türkei-Beziehungen: eine Inhaltsanalyse für den Zeitraum 1987-1995, Frankfurt a.M. et al.: Peter Lang

Habermas, Jürgen (2003): Making Sense of the EU. Toward a Cosmopolitan Europe, in: Journal of Democracy, Band 14, S. 86-100

Hajer, Marten A. (2003): Argumentative Diskursanalyse. Auf der Suche nach Koalitionen, Praktiken und Bedeutung, in: Keller, Rainer et al. (Hg.), Handbuch Sozialwissenschaftliche Diskursanalyse, Band 2: Forschungspraxis, Opladen: Leske \& Budrich, S. 271-298

Hall, Stuart (1994): Rassismus und kulturelle Identität, Ausgewählte Schriften 2, Hamburg: Argument

— (2004): Ideologie, Identität, Repräsentation. Ausgewählte Schriften 4, Hamburg: Argument

Hanioğlu, M. Şükrü (1995): The Young Turks in Opposition, New York/Oxford: Oxford University Press

Hanke, Christine (1999): Kohärenz versus Ereignishaftigkeit? Ein Experiment im Spannungsfeld der foucaultschen Konzepte ,Diskurs' und ,Aussage', in: Bublitz, Hannelore et al. (Hg.), Das Wuchern der Diskurse. Perspektiven der Diskursanalyse Foucaults, Frankfurt/New York: Campus, S. 119-136

Hansen, Lene/Williams, Michael C. (1999): The Myths of Europe: Legitimacy, Community and the >Crisis` of the EU, in: Journal of Common Market Studies, 37, S. 233-249

Heil, Reinhard (2003): Subjekt und Ideologie: Althusser, Lacan, Žižek, nicht veröffentlichte Magisterarbeit am Institut für Philosophie der Technischen Universität Darmstadt 
Heine, Peter (2000): Islam in Europa als Problem einer europäischen Identität, in: Kutz, Martin/Weyland, Petra (Hg.): Europäische Identität. Versuch kulturelle Aspekte eines Phantoms zu beschreiben, Bremen: Edition Temmen, S. 259-270

Hentsch, Thierry (1996): Hayali Doğu. Batı' nın Akdenizli Doğu’ya Politik Bakışı, İstanbul: Metis

Heper, Metin (1993): Political Culture as a Dimension of Compatibility, in: Ders. et al. (Hg.), Turkey and West. Changing Political and Cultural Identities, London/New York: I.B. Tauris, S. 35-68

Hess, Sabine/Tsianos, Vassillis (2007): Europeanizing Transnationalism! Provincializing Europe Konturen eines neuen Migrationsregimes im Südosten Europas, in: Transit Migration Forschungsgruppe (Hg.), Turbulente Ränder - Neue Perspektiven auf Migration an den Grenzen Europas, Bielefeld: transcript, S. 23- 40

Hoffman, Michael (1996): The European Mentality and Islam, in: Islamic Studies, 35, S. 87-97

Holmes, Douglas R. (2000): Surrogate Discourse of Power. The European Union and the problem of society, in: Bellier, Irene/Wilson, Thomas M. (Hg.), An Anthropology of The European Union. Building, imaging and experiencing the new Europe, Oxford/New York: Berg, S. 93-119

Holquist, Michael (2002): Dialogism. Bakhtin and his World, London/New York: Routledge

Howarth, David/Stavrakakis, Yannis (2000): »Introducing discourse theory and political analysis«, in: Howarth, David et al. (Hg.), Discourse theory and political analysis. Identities, hegemonies and social change, Manchester u.a.: Manchester University Press, S. 1-24

Huber, Wolfgang (2002): Europa als Wertegemeinschaft. Seine christliche Grundlagen gestern, heute, morgen, in: Münkler, Herfried (Hg.), Der demokratische Nationalstaat in den Zeiten der Globalisierung, Berlin: Akademie

Irzık, Sibel (2001): Önsöz, in: Dies. (Hg.), Mikhail Bakhtin, Karnavaldan Romana. Edebiyat Teorisinden dil felsefesine seçme yazılar, İstanbul: Ayrıntı, S. 7-33

Irzık Sibel/Güzeldere, Güven (2003): Introduction, in: The South Atlantic Quarterly, 102: 2/3 Spring/Sommer: Duke University Press, S. 283-292

İslamoğlu-İnan, Huri (1990): Introduction. Orientals despotism in world-system perspective, in: Ders. (Hg.), The Ottoman Empire and the World-Economy, Cambridge: Cambridge University Press, S. $1-27$ 
İslamoğlu-İnan, Huri/Keyder, Çağlar (1990): Agenda for Ottoman History, in: İslamoğlu-İnan, Huri (Hg.), The Ottoman Empire and the World-Economy, Cambridge: Cambridge University Press, S. 42-62

Jachtenfuchs, Markus et al. (1998): Which Europe? Conflicting Models of a Legitimate European Order, in: European Journal of International Relations, 4 (4), S. 409-445

Jachtenfuchs, Markus (2000): Verfassung, Parlamentarismus, Deliberation. Legitimation und politischer Konflikt in der Europäischen Union, in: Landfried, Christine (Hg.), Politik in einer entgrenzten Welt, Frankfurt: Suhrkamp, S. 71-90

- (2001): Die Konstruktion Europas: Verfassungsideen und institutionelle Entwicklung, Baden-Baden: Nomos

Jacobs, Dirk/Maier, Robert (1998): European Identity: construct, fact and fiction, in: Gastelaars, Marja/Rujiter, Arie D. (Hg.), A United Europe. The Quest for a Multifaceted Identity, Maastricht: Shaker, S. 13-34

Jäger, Siegfried (2001): Kritische Diskursanalyse. Eine Einführung, Duisburg: Diss

Jäger, Margret (2003): Die Kritik am Patriarchat im Einwanderungsdiskurs. Analyse einer Diskursverschränkung, in: Keller, R. et al. (Hg.), Handbuch Sozialwissenschaftliche Diskursanalyse, Band 2: Forschungspraxis, Opladen: Leske \& Budrich, S. 421-438

Jalal al-Azm, Sadık (2000): Orientalism and Orientalism in Reverse, in: Macfie, A.L. (Hg.), Orientalism Reader, New York: New York University Press, S. 217-238

Kadıoglu, Ayşe (1996): The Paradox of Turkish Nationalism and Construction of Official Identity, in: Middle Eastern Studies, 32/2, S. 177-194

- (1999): Cumhuriyet Iradesi, Demokrasi Muhakemesi: Türkiye'de Demokratik Açılım Arayışları, İstanbul: Metis

Kaelble, Hartmut (2002): European Self-Understanding in the 20th Century, in: Sachsenmaier, Dominik et al. (Hg.), Multiple modernities. European, Chinese and other interpretations, Leiden: Brill, S. 167192

Kahraman, H. Bülent (2002): Içselleştirilmiş açık ve gizli Oryantalizm ve Kemalizm, in: Doğu Bat1, 20, Oryantalizm I, S. 159-185

Kahraman, H. Bülent/Keyman, E. Fuat (1998): Kemalizm, Oryantalizm ve modernite, in: Doğu Batı, 2, S. 64-77

Kaiser, Wolfram (2001): Institutionelle Ordnung und strategische Interessen: Die Christdemokraten und Europa nach 1945, in: Loth, Wilfried (Hg.), Das europäische Projekt zu Beginn des 21. Jahrhunderts, Opladen: Leske \& Budrich, S. 81-98 
Kaliber, Alper (2002): Türk Modernleşmesini Sorunsallaştıran Üç Ana Paradigma, in: Modern Türkiye'de Siyasi Düşünce, in: Modern Türkiye'de Siyasi Düşünce, Modernleşme ve Batıcılık, Band 3, İstanbul: İletişim, S. 107-125

Kara, İsmail (2001): İslam Düşüncesinde Paradigma Değişimi, in: Modern Türkiye'de Siyasi Düşünce, Modernleşme ve Batıcılık, Tanzimat ve Meşrutiyet'in Birikimi, Band 1, İstanbul: İletişim, S. 234264

Karaosmanoğlu, Ali L. (1993): Officers: Westernization and Democracy, in: Heper, Metin et al. (Hg.), Turkey and West. Changing Political and Cultural Identities, London/New York: I.B. Tauris, S. 2035

Karakayalı, Serhat/Tsianos Vasilli (2007): Movements that matter. Eine Einleitung, in: Transit Migration Forschungsgruppe (Hg.), Turbulente Ränder - Neue Perspektiven auf Migration an den Grenzen Europas, Bielefeld: transcript, S. 7-22

Karakayalı, Serhat (2006): There ain't no Halbmond in the Deutschlandfahne, in: www.migration-boell.de/web/integration/47_760.asp (zuletzt aufgerufen: 24.04.2006)

Kasaba, Reşat (1998): Eski ile Yeni Arasında Kemalizm ve Modernizm, in: Bozdoğan, Sibel/Kasaba, Reşat (Hg.), Türkiye de Moderleşme ve Ulusal Kimlik, İstanbul: Tarih Vakfi, S. 12-29

Kastaryano, Riva (2006): French secularism and Islam: France's headscarf affair, in: Modood, Tariq et al. (Hg.), Multiculturalism, Muslims and Citizenship. A European Approach, London/New York: Routledge, S. 57-69

Kehl, Jara (2004): Der Fall Fereshta Ludin. Leitlinien der Kontroversen Debatte um das Kopftuch, nicht veröffentlichte Diplomarbeit, eingereicht am Otto-Suhr-Institut für Politikwissenschaften der Freien Universität Berlin

Keller, Rainer (2004): Diskursforschung. Eine Einführung für SozialwissenschaftlerInnen, Qualitative Sozialforschung 14, Opladen: Leske \& Budrich

Keyder, Çağlar (1998): 1990'larda Türkiye'de Modernleşme Doğrultusu, in: Bozdoğan, Sibel/Kasaba, Reşat (Hg.), R. (Hg.), Türkiye'de Moderleşme ve Ulusal Kimlik, İstanbul: Tarih Vakfi, S. 29-43

- (2003): Memalik-i Osmanıye'den Avrupa Birliği'ne, İstanbul: İletişim

Keyman, Fuat (1996): Farklılığa Direnmek: Uluslararası İlişkiler Kavramında >Öteki`sorunu, in: Keyman, Fuat et al. (Hg.), Oryantalizm, Hegemonya ve Kültürel Fark, İstanbul: İletişim, S. 71-107 
Kielmansegg, Peter Graf (1996): Integration und Demokratie, in: Jachtenfuchs, Martin/Kohler-Koch, Beate (Hg.), Europäische Integration, Frankfurt: Leske \& Budrich, S. 47-73

Knoblauch, Hubert (2001): Diskurs, Kommunikation und Wissenssoziologie, in: Keller, Rainer et al. (Hg.), Handbuch Sozialwissenschaftliche Diskursanalyse, Band 1: Theorien und Methoden, Opladen: Leske \& Budrich, S. 207-223

Koçak, Cemil (2001): Yeni Osmanlılar ve Birinci Meşrutiyet, in: Modern Türkiye'de Siyasi Düşünce, Modernleşme ve Batıcılık, Tanzimat ve Meşrutiyet' in Birikimi, Band 1, İstanbul: İletişim, S. 72-83

Kommission der europäischen Gemeinschaften (2004): Regelmäßiger Bericht über die Fortschritte der Türkei auf dem Weg zum Beitritt, Brüssel, SEK (2004) 1201

Kovác, Melinda/Kabachnik, Peter (2001): The Shedding Light on the Quantitative Other: The EU's Discourse in the Commission Opinions of 1987, in: Böröcz, Jozsef/Kovác, Melinda. (Hg.), Empires new Clothes: Unveiling EU enlargement, Central Europe Review: www.ce-review.org, S. 147-195

Kögler, Hans-Herbert (1994): Michel Foucault, Frankfurt: J.B. Metzler

Kramer, Heinz (2002): Ein wichtiger Schritt in Richtung Europa, Berlin: SWP

— (2004): Demokratieverständnis und Demokratisierungsprozess in der Türkei, Berlin: SWP

Kurban, Dilek (2005): Avrupa Birliği'nin Anayasal Düzeninde Azınlık Hakları. Açılımlar, Fırsatlar ve Olasılıklar, in: Kaya, Ayhan/ Tarhanlı, Turgut (Hg.), Türkiye'de Çoğunluk ve Azınlık Politikaları. AB sürecinde Yurttaşlık Tartışmaları, İstanbul: TESEV, S. 285-304

Küçük, Bülent (2006): Kurdische Mobilisierung in der BRD: Zwischen Sichtbarkeit und positiver Resonanz, in: IFADE (Hg.), Insider Outsider. Bilder, ethnisierte Räume und Partizipation im Migrationprozess, Bielefeld: transcript, S. 138-160

Küçük, Bülent/Grojean, Olivier (2005): Re-formierung der Macht. Die ambivalente Transformation der kurdischen Teilbewegung PKK, in: Kurdische Studien, 4/5, Berlin, S. 41-60

Lacan, Jacques (2000): The Mirror-phase as formative of the Function of the I, in: Žižek, Slovaj (Hg.), Mapping Ideology, London/ New York: Verso, S. 93-100

- (1981): The Four Fundamental Concepts of Psycho-Analysis, New York/London: W.W. Norton and Company

Laclau, Ernesto/Mouffe, Chantal (1985): Hegemony und Socialist Strategy, London: Verso

— (1992): Hegemonya ve Sosyalist Strateji, Istanbul: Birikim 
Lemke, Thomas (1999): Antwort auf eine Frage: Ist Foucaults »Geschichte der Wahrheit« eine wahre Geschichte?, in: Bublitz, Hannelore et al. (Hg.), Das Wuchern der Diskurse. Perspektiven der Diskursanalyse Foucaults, Frankfurt/New York: Campus, S. 177-194

Lewis, Bernhard (1993): Modern Türkiye'nin Doğuşu, Ankara: TTK [Original: Emergence of Modern Turkey, 1968]

- (1997): The Future of the Middle East, London: Phoenix

Lewis, Reina (1996): Gendering Orientalism. Race, Femininity and Representation, London/New York: Routledge

Link, Jürgen (1999): Diskursive Ereignisse, Diskurse, Interdiskurse. Sieben Thesen zur Operativität der Diskursanalyse, am Beispiel des Normalismus, in: Bublitz, Hannelore et al. (Hg.), Das Wuchern der Diskurse. Perspektiven der Diskursanalyse Foucaults, Frankfurt/New York: Campus, S. 148-162

Lorey, Isabell (1999): Macht und Diskurs bei Foucault, in: Bublitz, Hannelore et al. (Hg.), Das Wuchern der Diskurse. Perspektiven der Diskursanalyse Foucaults, Frankfurt/New York: Campus, S. 87-97

Lowe, Lisa (1991): Critical Terrains. French and British Orientalisms, Ithaca and London: Cornell University Press

Maksudyan, Nazan (2005): Türklüğü Ölçmek. Bilimkurgusal Antropoloji ve Türk Milliyetçiliğinin Irkçı Çehresi 1925-1939, İstanbul: Metis

Malik, Kenan (1996): The Meaning of Race: Race, History and Culture in Western Society, London: Macmillan

Malmborg, Mikael/Stråth, Bo (2002): Introduction. The National Meanings of Europe, in: Dies. (Hg.), The Meaning of Europe, Oxford/New York: Berg, S. 1-27

Marcussen, Martin et al. (1999): Constructing Europe? The Evolution of French, British and German Nation State Identities, in: Journal of European Public Policy, 6 (4): S. 614-633

Marchart, Oliver (2007): Eine demokratische Gegenhegemonie. Zur neo-gramscianischen Demokratietheorie bei Laclau und Mouffe in: Buckel, Sonja/Fischer-Lescano, Andreas (Hg.): Hegemonie gepanzert mit Zwang. Zivilgesellschaft und Politik im Staatsverständnis Antonio Gramscis. Baden-Baden, S.105-119

Mardin, Şerif (1998): Modern Türk Sosyal Bilimleri üzerine bazı Düşünceler, in: Bozdoğan, Sibel/Kasaba, Reşat (Hg.), Türkiye’de Moderleşme ve Ulusal Kimlik, İstanbul: Tarih Vakfı, S. 54-70

- (2001): Yeni Osmanli Düşüncesi, in: Modern Türkiye'de Siyasi Düşünce, Tanzimat ve Meşrutiyet'in Birikimi, Band 1, İstanbul: İletişim, S. 42-53

— (2003a): Türk Modernleşmesi, Makaleler 4, Istanbul: İletişim 
— (2003b): Jön Türklerin Siyasi Fikirleri 1895-1908, İstanbul: İletişim Megill, Allan (1998): Aşırılığın Peygamberleri Nietzsche, Heidegger, Foucault, Derrida, Ankara: Bilim ve Sanat [Original: Prophets of Extremity]

Meier, Heinrich (1994): Die Lehre Carl Schmidts: Vier Kapitel zur Unterscheidung Politischer Theologie und Politischer Philosophie, Stuttgart: J.B. Metzler

Menon, Nivedita (1993): Orientalism and After, in: Public Culture, 6, S. $65-76$

Meriç, Cemil (1995): Sosyoloji Notları ve Konferanslar, İstanbul: İletişim

- (1996): Umrandan Uygarlığa, İstanbul: İletişim

Mignolo, Walter (2000): Local Histories \& Global Designs: Coloniality, Subaltern Knowledge and Border thinking, Princeton/Oxford: Princeton University Press

Milliken, Jennifer (1999): The Study of Discourse in International Relations: A Critique of Research and Methods, in: European Journal of International Relations, 5 (2), S. 225-254

Mills, Sara (1997): Discourse, London/New York: Routledge

Mitchell, Timothy (2002): Die Welt als Ausstellung, in: Conrad, Sebastian/Randeria, Shalini (Hg.), Jenseits des Eurozentrismus. Postkoloniale Perspektiven in den Geschichts- und Kulturwissenschaften, Frankfurt/New York: Campus, S. 148-176

Moore-Gilbert, Bart (2001): Spivak and Bhabha, in: Schwarz, Henry/Ray, Sangeeta (Hg.), A Companion to Postcolonial Studies, London/New York: Blackwell, S. 451-466

Mutman, Mahmut (1996): Oryantalizm gölgesi altında batıya karşı İslam, in: Keyman, Fuat et al. (Hg.), Oryantalizm, Hegemonya ve Kültürel Fark, İstanbul: İletişim, S. 25-71

Münkler, Herfried (1988): Politische Mythen - Mythen in der Politik, in: Ders./Wolfgang, Storch (Hg.), Siegfrieden. Politik mit einem deutschen Mythos, Berlin: Rotbuch Verlag

- (1994): Politische Mythen und nationale Identität, in: Frindte, Wolfgang/Pätzolt, Harald (Hg.), Mythen der Deutschen, Opladen: Leske \& Budrich, S. 21-27

- (1995): Die politische Idee Europa, in: Delgado, Mariano/LutzBachmann, Matthias (Hg.), Herausforderung Europa: Wege zu einer europäischen Identität, München: Beck, S. 9-28

- (1996): Reich - Nation - Europa. Modelle politischer Ordnung, Weinheim: Beltz-Athenäum

Navaro-Yashin, Yael (2002): Faces of the State. Secularism and public life in Turkey, Princeton/Oxford: Princeton University Press 
Nehring, Andreas (2003): Orientalismus und Mission. Die Repräsentation der tamilischen Gesellschaft und Religion durch Leipziger Missionare 1840-1940, Wiesbaden: Harrassowitz Verlag

Neumann, Iver B. (1999): Use of the other. The East in European Identity formation, Manchester: Manchester University Press

Neumann, Iver B./Welsh, Jennifer M. (1991): The Other in European Self-Definition: An Addendum to the Literature on International Society, in: Review of International Studies, 17, S. 327-348

Neyzi, Leyla (2002): Remembering to Forget: Sabbateanism, National Identity and Subjectivity in Turkey, in: Society for Comparative Study of Society and History, 2, S. 137-158

Özyürek, Esra (2006): Nostalgia for the Modern. State Secularism and Everyday Politics in Turkey, Durham/London: Duke University Press

Pagden, Anthony. (2002): Europe: Conceptualizing a Continent, in: Ders. (Hg.), The Idea of Europe. From Antiquity to the European Union, Washington: Woodrow Wilson Press/Cambridge University Press, S. 33-55

Panagiotidis, Efthimia/Tsianos, Vassillis (2007): Denaturalizing »Camps«: Überwachen und Entschleunigen in der Schengener Ägäis Zone, in: Transit Migration Forschungsgruppe (Hg.), Turbulente Ränder - Neue Perspektiven auf Migration an den Grenzen Europas, Bielefeld: transcript, S. 59-88

Parekh, Bhiku (2006): Europe, Liberalism and the >Muslim question<, in: Modood, Tariq et al. (Hg.), Multiculturalism, Muslims and Citizenship. A European Approach, London/New York: Routledge, S. 179-203

Passerini, Luisa (2002): From the Ironies of Identity to the Identity of Irony, in: Pagden, Anthony (Hg.), The Idea of Europe. From Antiquity to the European Union, Washington: Woodrow Wilson Press/Cambridge University Press, S. 191-208

Pocock, John G.A. (2002): Some Europes in Their History, in: Pagden, Anthony (Hg.), The Idea of Europe. From Antiquity to the European Union, Washington: Woodrow Wilson Press/Cambridge University Press, S. 55-71

Podraza, Antoni (1998): Das eine und geteilte Europa in der Neuzeit, in: Timmermann, H. (Hg.), Die Idee Europa in Geschichte, Politik und Wirtschaft, Berlin: Duncker \& Humboldt, S. 49-57

Polaschegg, Andrea (2005): Der Andere Orientalismus. Regeln deutschmorgenländlicher Imagination im 19. Jahrhundert, Berlin/New York: de Gruyter 
Pollock, Sheldon (2000): Indology, Power, and the Case of Germany, in: Macfie, Alexander L. (Hg.), Orientalism Reader, New York: New York University Press, S. 302-323

Porter, Denis (1983): Orientalism and its Problems, in: Francis Barker et al. (Hg.), The Politics of Theory, Colchester: University of Essex Press, S. 179-193

Potter, Jonathan (1996): Representing Reality: Discourse, Rhetoric and Social Construction, London: Sage

Oran, Baskın (2004): Türkiye'de Azınlıklar: Kavramlar, Lozan, İç Mevzuat, İçtihat, Uygulama, in: www.tesev.org.tr (zuletzt aufgerufen: 27.11.2005)

Oğuzlu, Tarik (2003): Turkey and the European Union: The Security Dimension, in: Contemporary Security Policy, 23 (3), London: Frank Cass, S. 61-82

Risse, Thomas (2001): A European identity? Europeanization and the Evolution of Nation-State Identities, in: Cowles, Maria G. et al. (Hg.), Transforming Europe, Ithaca, New York: Cornell University Press, S. 198-216

- (2003): An Emerging European Identity? What We Know and How To Make Sense Of It, Lecture delivered at the University of Helsinki April 25

Risse, Thomas/Engelmann-Martin, Daniela (2002): Identity Politics and European Integration: The Case of Germany, in: Pagden, Anthony (Hg.), The Idea of Europe. From Antiquity to the European Union, Washington: Woodrow Wilson Press/Cambridge University Press, S. 287-316

Robins, Kevin (1996): Interrupting Identities. Turkey \& Europe, in: Hall, Stuart/du Gay, Paul (Hg.), Questions of Cultural Identity, London: Sage, S. 61-86

Römhild, Regina (2007): Alte Träume, neue Praktiken: Migration und Kosmopolitismus an den Grenzen Europas, in: Transit Migration Forschungsgruppe (Hg.), Turbulente Ränder - Neue Perspektiven auf Migration an den Grenzen Europas, Bielefeld: transcript, S. 211228

Ruggie, John G. (1993): Territoriality and Beyond: Problematizing Modernity in International Relations, in: International Organization, 47:1, S. 139-174

Rumelili, Bahar (2002): Producing Collective Identity and Interacting with Difference: The Security Implications of Community-Building in Europe and Southeast Asia, Diss. Thesis, University of Minnesota 
- (2004): Constructing identity and relating to difference: understanding the EU's mode of differentiation, in: Review of International Studies, 30, S. 27-47

Said, Edward (1981): Orientalismus, Frankfurt: Ullstein

- (1994): Culture and Imperialism, New York: Vintage

- (2003): Orientalism Reconsidered, in: Ders., Reflection on Exile and Other Essays, Cambridge, Massachusetts: Harvard University Press, S. $198-216$

Salecl, Renata (1994): Deference to the Great Other: The Discourse of Education, in: Bracher, Marc et al. (Hg.), Lacanian Theory of Discourse. Subject, Structure and Society, New York/London: New York University Press, S. 163-185

Sarıbay, Ali Y. (1995): Postmodernite, Sivil Toplum ve İslam, İstanbul: İletişim

Sayyid, Bobby S. (1997): A Fundamental Fear. Eurocentrism and Emergence of Islamism, London/New York: Zed Books

Schaar, Stuart (2000): Orientalism at the Service of Imperialism, in: Macfie, Alexander L. Orientalism Reader, New York: New York University Press, S. 181-193

Scharpf, Fritz W. (1999): Regieren in Europa. Effektiv und demokratisch?, Frankfurt/New York: Campus

Schiffauer, Werner (2006): Enemies within the Gates. The debate about the citizenship of Muslims in Germany, in: Modood, Tariq et al. (Hg.): Multiculturalism, Muslims and Citizenship. A European Approach, London/New York: Routledge, S. 94-116

Schluchter, Wolfgang (Hg.) (1987): Max Webers Sicht des Islams. Interpretation und Kritik, Frankfurt: Suhrkamp

Schmalz-Bruns, Rainer (1999): Deliberativer Supranationalismus. Demokratisches Regieren jenseits des Nationalstaates, in: Zeitschrift für internationale Beziehungen, 6, S. 183-244

Schmidt, Carl (1932): Der Begriff des Politischen. Text von 1932 mit einem Vorwort und drei Corollarien, Berlin: Duncker \& Humboldt

Schwab-Trapp, Michael (2001): Diskurs als soziologisches Konzept. Bausteine für eine soziologisch orientierte Diskursanalyse, in: Keller, Rainer et al. (Hg.), Handbuch Sozialwissenschaftliche Diskursanalyse, Band 1: Theorien und Methoden, Opladen: Leske \& Budrich, S. 261-284

- (2003): Methodische Aspekte der Diskursanalyse. Probleme der Analyse diskursiver Auseinandersetzungen am Beispiel der deutschen Diskussion über den Kosovokrieg, in: Keller, Rainer et al. (Hg.), Handbuch Sozialwissenschaftliche Diskursanalyse, Band 2: Forschungspraxis, Opladen: Leske \& Budrich, S. 169-196 
Segers, Rien T./Viehoff, Reinhold (1999): Die Konstruktion Europas. Überlegungen zum Problem der Kultur in Europa, in: Dies. (Hg.), Kultur, Identität, Europa: über die Schwierigkeiten einer Konstruktion, Frankfurt: Suhrkamp, S. 9-50

Seier, Andrea (1999): Kategorien der Entzifferung: Macht und Diskurs als Analyseraster, in: Bublitz, Hannelore et al. (Hg.), Das Wuchern der Diskurse. Perspektiven der Diskursanalyse Foucaults, Frankfurt/New York: Campus, S. 75-87

Shayegan, Daryush (2002): Yaralı Bilinç. Geleneksel Tolumlarda Kültürel Şizofreni, İstanbul: Metis

Sher, Anna (2001): A Di-Vision of Europe: the enlargement Union enlarged, in: Böröcz, József/Kovác, Melinda (Hg.), Empires new Clothes: Unveiling EU enlargement, Central Europe Review: www. ce-review.org, S.235-275

Smith, Steve (1999): Social constructivism and European studies: a reflectivist Critique, in: Journal of European Public Policy, S. 682-691

Somel, Akşin (2001): Osmanlı Reform Çağında Osmanlıcılık Düşüncesi (1839-1913), in: Modern Türkiye'de Siyasi Düşünce, Tanzimat ve Meşrutiyet'in Birikimi, Band 1, İstanbul: İletişim, S. 88-116

Somers, Margaret R./Gibson, Gloria D. (1994): Reclaiming the Epistemological »Other«: Narrative and the Social Construction of Identity, in: Calhoun, Craig (Hg.), Social Theory and the Politics of Identity, Oxford: Blackwell, S. 36-99

Spivak, Gayatri C. (2001): Can Subaltern Speak, in: Brydon, Diana (Hg.): Postcolonialism. Critical concepts in literary and cultural studies, Band 4, S. 1427-1477

Spohn, Willfried (2002): Continuities and Changes of Europe in German national Identity, in: Malmborg, Mikael/Stråth, Bo (Hg.), The Meaning of Europe, Oxford/New York: Berg, S. 285-311

Stauth, Georg (2000): Islamische Kultur und moderne Gesellschaft. Gesammelte Aufsätze zur Soziologie des Islams, Bielefeld: transcript

Stavrakakis, Yannis (1999): Lacan and the Political, London: Routledge

Stäheli, Urs (2001): Die politische Theorie der Hegemonie: Ernesto Laclau und Chantal Mouffe, in: Brodocz, André/Schaal, Gary S. (Hg.), Politische Theorien der Gegenwart II, Opladen: Leske \& Budrich, S. 193-224

Stråth, Bo (2000): Introduction. Europe as Discourse, in: Europe and the Other and Europe as Other, in: Ders. (Hg.), Myth and Memory in the Construction of Community: Historical Patterns in Europe and Beyond, Series Multiple Europes, 10, Bruxelles: Peter Lang, S. 13-44

Şeker, Nesim (2005): Türklük ve Osmanlı Arasında: Birinci Dünya Savaşı Sonrası Türkiye'de >Milliyet` Arayışları ya da >Anasır Mese- 
lesi<, in: Zürcher, Erik J. (Hg.), Imparatorluktan Cumhuriyete Türkiye'de Etnik Çatışma, Istanbul: Iletişim, S. 157-175

Toker, Nilgün/Tekin, Serdar (2002): Batıcı Siyasi Düşüncenin Karakteristikleri ve Evreleri, in: Modern Türkiye'de Siyasi Düşünce, Modernleşme ve Batıcılık, Band 3, İstanbul: İletişim, S. 82-107

Tekelli, İlhan (2002): Türkiye'de Siyasal Düşüncenin Gelişimi Konusunda Bir Üst Anlat1, in: Modern Türkiye'de Siyasi Düşünce, Modernleşme ve Batıcılık, Band 3, İstanbul: İletişim, S. 19-43

Timur, Taner (1986): Osmanlı Kimliği, İstanbul: hil

Teubert, Wolfgang (2003): Provinz eines föderalen Superstaates - regiert von einer nicht gewählten Bürokratie?,, in: Keller, Rainer et al. (Hg.), Handbuch Sozialwissenschaftliche Diskursanalyse, Band 2: Forschungspraxis, Opladen: Leske \& Budrich, S. 353-388

Todorova, Maria (2007): Historical Legacies Between Europe and Near East. Vortrag im Rahmen von Carl Heinrich Becker Lecture of the Fritz Thyssen Stiftung an der Akademie der Wissenschaften, Berlin, 21. Mai

Todorow, Tzvetan (1985): Die Eroberung Amerikas. Das Problem des Anderen, Frankfurt a.M.: Suhrkamp

Torfing, Jacob (1999): New Theories of Discourse: Laclau, Mouffe and Žižek, Oxford: Blackwell

Törnquist-Plewa, Barbara (2002): The Complex of an Unwanted Child. The Meaning of Europe in Polish Discourse, in: Malmborg, Mikael/Stråth, Bo (Hg.), The Meaning of Europe, Oxford/New York: Berg, S. 215-243

Triandafyllidou, Anna (2006): Religious diversity and multiculturalism in Southern Europe: the Italian masque debate, in: Modood, Tariq. et al. (Hg.), Multiculturalism, Muslims and Citizenship. A European Approach, London/New York: Routledge, S. 117-142

Trunk, Achim (2001): Eine europäische Identität zu Beginn der 50er Jahre? Die Debatten in den europäischen Versammlungen, in: Loth, Wilfried (Hg.), Das europäische Projekt zu Beginn des 21. Jahrhunderts, Opladen: Leske \& Budrich, S. 49-80

Turner, Bryan S. (2000a): Outline of a Theory of Orientalism, in: Ders. (Hg.), Orientalism: Early Sources. Readings in Orientalism, Band 1, London/New York: Routledge, S. 1-31

- (2000b): From Orientalism to Global Sociology, in: Macfie, Alexander L. (Hg.), Orientalism Reader, New York: New York University Press, S. 369-375

Universitäts-Rechenzentrum Trier (1997): Korrespondenzanalyse mit SPSS 
Ünüvar, Kerem (2001): İttihatç1liktan Kemalizme, İhya'dan İnşa'ya, in: Modern Türkiye'de Siyasi Düşünce, Tanzimat ve Meşrutiyet'in Birikimi, Band 1, İstanbul: İletişim, S. 180-196

Üstel, Füsun (2005): Makbul Vatandaş'ın Peşinde. Ikinci Meşrutiyet'ten Bugüne Vatandaşlık Eğitimi, İstanbul: İletişim

Viehöver, Willy (2001): Diskurse als Narrationen, in: Keller, Rainer et al. (Hg.), Handbuch Sozialwissenschaftliche Diskursanalyse, Band 1: Theorien und Methoden, Opladen: Leske \& Budrich, S. 177-207

- (2003): Die Wissenschaft und die Wiederverzauberung des sublunaren Raumes. Der Klimadiskurs im Licht der narrativen Diskursanalyse, in: Keller, Rainer et al. (Hg.), Handbuch Sozialwissenschaftliche Diskursanalyse, Band 2: Forschungspraxis, Opladen: Leske \& Budrich, S. 233-270

Wallerstein, Immanuel/Balibar, Ètienne (1991): Race, Nation, Class. Ambiguous Identities, London/New York: Verso

Wallerstein, Immanuel. et al. (1990): The incorporation of the Ottoman Empire into the world economy, in: İslamoğlu-İnan, Huri (Hg.), The Ottoman Empire and the World-Economy, Cambridge: Cambridge University Press, S. 88-100

Wehler, Hans U. (2002): Das Türkenproblem in: www.zeit.de/2002/38/ Das_Tuerkenproblem (zuletzt aufgerufen: 20.06.2006)

Wendt, Alexander (1992): Anarchy is What States Make of It: The Social Construction of Power Politics, in: International Organization, 46 (2), S. 391-426

- (1994): Collective Identity Formation and International State, in: The American Political Science Review, 88 (2), S. 384-396

- (1999): Social Theory of International Politics, Cambridge: Cambridge University Press

Wæver, Ole (1998): Explaining Europe by Decoding Discourses, in: Anders, Wievel (Hg.) Explaining European Integration, Copenhagen: Copenhagen Political Studies Press, S. 100-146

Wilson III., Ernest J. (2000): Orientalism: A Black Perspective, in: Macfie, Alexander L. (Hg.), Orientalism Reader, New York: New York University Press, S. 239-248

Williken, Jennifer (1999): The Study of Discourse in international Relations; in: European Journal of International Relations, 5/2, S. 225254

De Winter, Leon (2004): Vor den Trümmern des großen Traums, in: www.zeit.de/2004/48/Leon_de_Winter (zuletzt aufgerufen: 20.06. 2007) 
Wintle, Michael J. (Hg.) (1996): Culture and Identity in Europe: perceptions of divergence and unity in past and present, Aldershot: Avebury Press

Wittfeld, Katharina (2001): Die Geometrie der Korrespondenzanalyse, nicht veröffentlichte Diplomarbeit, eingereicht am Institut für Mathematik und Informatik der Universität Greifswald

Yavuz, Hilmi (2002): Modernleşme: Parça mı bütün mü? Batılılaşma Simge mi, Kavram mı? in: Modern Türkiye'de Siyasi Düşünce, Modernleşme ve Batıcılık, Band 3, İstanbul: İletişim, S. 212-218

Yeğen, Mesut (2003): Devlet Söyleminde Kürt sorunu, İstanbul: İletişim

- (2004): Citizenship and ethnicity in Turkey, in: Middle Eastern Studies, 40 (6), S. 51-55

Yeğenoğlu, Meyda (1996): Peçeli Fantaziler: Oryantalist Söylemde Kütürel ve Cinsel Fark, in: Keyman, Fuat. et al. (Hg.), Oryantalizm, Hegemonya ve Kültürel Fark, İstanbul: İletişim, S. 107-161

Yıldız, Ahmet (2004): »Ne Mutlu Türküm Diyebilene«. Türk Ulusal Kimliğinin Etno-Seküler Sınırları (1919-1938), İstanbul: İletişim

Young, Robert (1990): White Mythologies, Writing, History and the West. London: Routledge

Zaretsky, Eli (1994): Identity Theory, Identity Politics: Psychoanalysis, Marxism, Post-Structuralism, in: Calhoun, Craig (Hg.), Social Theory and the Politics of Identity, Oxford/Cambridge: Blackwell, S. 198-215

Zima, Peter V. (2000): Theorie des Subjekts: Subjektivität und Identität zwischen Moderne und Postmoderne, Tübingen/Basel: Leske \& Budrich

Žižek, Slovaj (1989): The Sublime of Ideology, London: Verso

- (2003): Gıdıklanan Özne. Politik ontolojinin yok merkezi, Ankara: Epos [dt.: Die Tücke des Subjekts] 


\section{Global Studies}

Remus Gabriel Anghel,

Eva Gerharz,

Gilberto Rescher,

Monika Salzbrunn (eds.)

The Making of

World Society

Perspectives from

Transnational Research

November 2008, ca. 250 Seiten, kart., ca. $27,80 €$,

ISBN: 978-3-89942-835-3

Ines Braune

Aneignungen

des Globalen

Internet-Alltag in

der arabischen Welt.

Eine Fallstudie

in Marokko

Oktober 2008, ca. 200 Seiten,

kart., ca. $25,80 €$,

ISBN: 978-3-89942-971-8

Bülent Küçük

Die Türkei und

das andere Europa

Phantasmen der Identität

im Beitrittsdiskurs

September 2008, 236 Seiten,

kart., zahlr. Abb., 25,80 €,

ISBN: 978-3-8376-1012-3

Wiebke Keim

Vermessene Disziplin

Zum konterhegemonialen

Potential afrikanischer

und lateinamerikanischer

Soziologien

September 2008, 556 Seiten,

kart., $35,80 €$,

ISBN: $978-3-89942-838-4$
Peter Lindner

Der Kolchoz-Archipel im

Privatisierungsprozess

Wege und Umwege der

russischen Landwirtschaft in die globale Marktgesellschaft

März 2008, 282 Seiten,

kart., $27,80 €$,

ISBN: 978-3-89942-784-4

Friedrich Arndt,

Carmen Dege,

Christian Ellermann,

Maximilian Mayer,

David Teller,

Lisbeth Zimmermann (Hg.)

Ordnungen im Wandel

Globale und lokale

Wirklichkeiten im Spiegel

transdisziplinärer Analysen

Januar 2008, 386 Seiten,

kart., $30,80 €$,

ISBN: 978-3-89942-783-7

Moritz Csáky,

Johannes Feichtinger (Hg.)

Europa - geeint durch Werte?

Die europäische Werte-

debatte auf dem Prüf-

stand der Geschichte

2007, 218 Seiten,

kart., $24,80 €$,

ISBN: 978-3-89942-785-1

\section{Sérgio Costa}

Vom Nordatlantik zum

"Black Atlantic"

Postkoloniale Konfigu-

rationen und Paradoxien

transnationaler Politik

2007, 292 Seiten,

kart., $28,80 €$,

ISBN: 978-3-89942-702-8

Leseproben und weitere Informationen finden Sie unter: www.transcript-verlag.de 


\section{Global Studies}

Florian Feuser Der hybride Raum

Chinesisch-deutsche Zusammenarbeit in der VR China 2006, 344 Seiten, kart., $29,80 €$, ISBN: 978-3-89942-581-9

\section{Heiner Depner}

Transnationale Direktinvestitionen und kulturelle Unterschiede Lieferanten und Joint Ventures deutscher Automobilzulieferer in China 2006, 240 Seiten, kart., $25,80 €$, ISBN: $978-3-89942-567-3$

Christoph Wulf

Anthropologie kultureller Vielfalt Interkulturelle Bildung in Zeiten der Globalisierung 2006, 164 Seiten, kart., $17,80 €$, ISBN: 978-3-89942-574-1

\section{Helen Schwenken}

Rechtlos, aber nicht ohne Stimme

Politische Mobilisierungen um irreguläre Migration in die Europäische Union 2006, 374 Seiten, kart., $29,80 €$, ISBN: 978-3-89942-516-1
Lutz Leisering, Petra Buhr, Ute Traiser-Diop

Soziale Grundsicherung in der Weltgesellschaft Monetäre Mindestsicherungssysteme in den Ländern des Südens und des Nordens. Weltweiter Survey und theoretische Verortung 2006, 342 Seiten, kart., $29,80 €$, ISBN: $978-3-89942-460-7$

Christian Berndt, Johannes Glückler (Hg.) Denkanstöße zu einer anderen Geographie der Ökonomie

2006, 172 Seiten, kart., $17,80 €$,

ISBN: $978-3-89942-454-6$

Ulrich Heinze

Hautkontakt der

Schriftsysteme

Japan im Zeichen

der Globalisierung:

Geldflüsse und Werbetexte

2006, 208 Seiten,

kart., $25,80 €$,

ISBN: $978-3-89942-513-0$

Christian Kellermann

Die Organisation des

Washington Consensus

Der Internationale

Währungsfonds und seine

Rolle in der internationalen Finanzarchitektur 2006, 326 Seiten, kart., $28,80 €$, ISBN: $978-3-89942-553-6$

Leseproben und weitere Informationen finden Sie unter: www.transcript-verlag.de 


\section{Global Studies}

Ivo Mossig

Netzwerke der

Kulturökonomie

Lokale Knoten und globale

Verflechtungen der Film-

und Fernsehindustrie in

Deutschland und den USA

2006, 228 Seiten,

kart., $26,80 €$,

ISBN: 978-3-89942-523-9

Shingo Shimada,

Christian Tagsold

Alternde Gesellschaften

im Vergleich

Solidarität und Pflege in

Deutschland und Japan

2006, 178 Seiten,

kart., $18,80 €$,

ISBN: $978-3-89942-476-8$

\section{Matthias Otten}

Interkulturelles Handeln

in der globalisierten

Hochschulbildung

Eine kultursoziologische Studie

2006, 318 Seiten,

kart., $28,80 €$,

ISBN: $978-3-89942-434-8$

Leseproben und weitere Informationen finden Sie unter: www.transcript-verlag.de 
